\author{
Universidade de São Paulo \\ Instituto de Astronomia, Geofísica e Ciências Atmosféricas \\ Departamento de Geofísica
}

Letícia Rangel Dantas

RESSONÂNCIA MAGNÉTICA NUCLEAR E ANISOTROPIA MAGNÉTICA APLICADAS AO ESTUDO DA PERMOPOROSIDADE EM ARENITOS COM BANDAS DE DEFORMAÇÃO 
Letícia Rangel Dantas

\section{RESSONÂNCIA MAGNÉTICA NUCLEAR E ANISOTROPIA MAGNÉTICA APLICADAS AO ESTUDO DA PERMOPOROSIDADE EM ARENITOS COM BANDAS DE DEFORMAÇÃO}

"Versão Corrigida. O original se encontra disponível na Unidade."

Dissertação apresentada ao Departamento de Geofísica do Instituto de Astronomia, Geofísica e Ciências Atmosféricas da Universidade de São Paulo como requisito parcial para obtenção do título de Mestra em Ciências.

Área de Concentração: Geofísica Aplicada

Orientador(a): Prof. Dr. Ricardo Ivan Ferreira da Trindade

São Paulo 


\section{AGRADECIMENTOS}

Em primeiro lugar agradeço a Deus por me dar forças nos momentos mais difíceis e colocar no meu caminho pessoas especiais que me ajudaram nesta jornada.

À minha família, por todo o apoio na minha formação profissional.

A Henrique, pelo carinho e compreensão durante a realização deste trabalho.

Ao meu orientador Ricardo Trindade, pela paciência e dedicação na transferência de conhecimento.

Ao pessoal do LEAR (Everton, Arthur, Tito e Mari) pelo apoio técnico e estrutura laboratorial compartilhados, além das discussões extremamente enriquecedoras.

Ao professor Carlson que me acompanha desde a graduação, sempre contribuindo com críticas construtivas.

À Marta Jácomo pelo compartilhamento de conhecimento e experiências referentes ao conteúdo deste trabalho.

Aos meus amigos July, Carol, Uiara, Érica (Kinha), Welton (Tom), Shaila e Vitória que mesmo longe, fisicamente, estiveram comigo mandando muita energia positiva.

A Jany, Vitória, Rayza e Pamela, por terem tornado os momentos fora da universidade e longe da família muito mais agradáveis.

Aos meus colegas do IAG com quem mais convivi durante o curso e que tornaram esta jornada muito mais enriquecedora e divertida, em especial ao Caio que contribuiu diretamente com este trabalho.

Ao IAG e ao USPMag pela infraestrutura laboratorial e suporte técnico.

À FAPESP pelo custeio de parte das medidas laboratoriais durante a realização deste trabalho.

À CAPES pelo fornecimento da bolsa de mestrado. 


\section{RESUMO}

A distribuição de tamanho e conectividade dos poros em rochas reservatório permitem a estimativa de reserva, produtividade e planejamento de produção de petróleo, através de modelos petrofísicos confiáveis. Bandas de deformação, principalmente as cataclásticas, são estruturas marcadas por reorganização e fragmentação dos grãos. No entanto, há ainda poucos estudos que tratam das variações em microescala da porosidade nessas estruturas. Usualmente, somente dados de porosidade ou de permeabilidade em rocha total são reportados na literatura. O principal objetivo deste trabalho é caracterizar a distribuição e orientação dos macro e microporos, considerando os processos diagenéticos e deformacionais que influenciam na porosidade e na permeabilidade da rocha. Para tal foram comparadas as propriedades petrofísicas de arenitos com diferentes quantidades de bandas de deformação, desenvolvidas em afloramentos de duas unidades geológicas distintas: o Grupo Ilhas (depósitos fluviodeltaicos) e o Grupo Massacará (depósitos fluvio-eólicos) da Bacia do Tucano, nordeste do estado da Bahia. Como principais métodos foram utilizadas a ressonância magnética nuclear (RMN) e a anisotropia de susceptibilidade magnética em amostras impregnadas com ferrofluido (ASMff). Adicionalmente, microscopia óptica e eletrônica, microtomografia computadorizada de raios $\mathrm{X}(\mu \mathrm{CT})$ e ensaios de petrofísica básica (porosidade e permeabilidade a gás; densidade), auxiliaram nas interpretações. Do ponto de vista petrográfico, foram observados poros primários, poros em fraturas e originados por dissolução. As bandas de deformação foram identificadas nos picos intermediários de tempos de relaxação transversal $\left(\mathrm{T}_{2}\right)$, entre 3 e $50 \mathrm{~ms}$, podendo também ter influência em picos menores. A intensidade desses picos está relacionada principalmente ao volume das bandas, enquanto a largura ou proporção relativa depende da geometria e orientação. Estruturas mais homogêneas apresentaram apenas um pico mais estreito, enquanto estruturas com geometria anastomosada, contendo pods de rocha menos deformada em seu interior, foram associadas a dois picos ou a um pico mais largo. Nesse caso, a intensidade dos picos pode refletir até mesmo diferentes graus de fragmentação granular. Devido à baixa susceptibilidade magnética das amostras e ao fato da distribuição de $\mathrm{T}_{2}$ ter sido medida em baixo campo magnético, não houve indícios de subestimação significativa dos valores de porosidade, em relação a outras técnicas. Também ficou claro que efeitos em $\mathrm{T}_{2}$ decorrentes dos aspectos texturais primários podem ser obliterados pela modificação da estrutura porosa por processos deformacionais. Com isso, a ressonância magnética nuclear se mostrou uma ferramenta eficiente para auxiliar na identificação de bandas de deformação cataclásticas nos arenitos estudados neste trabalho. Contudo, a técnica permitiu apenas uma 
análise qualitativa do conteúdo de bandas nas amostras. Quanto a orientação dos poros a anisotropia de suscetibilidade magnética por ferrofluido mostrou uma compatibilidade satisfatória, entretanto mais estudos são necessários.

Palavras-chave: Bacia do Tucano, Bandas de Deformação, Ressonância Magnética Nuclear, Ferrofluido. 


\begin{abstract}
The distribution and connectivity of the pore size in reservoir rocks allow estimating the reserve, productivity and oil production planning, through reliable petrophysical models. Deformation bands, especially cataclastic ones, are structures marked by reorganization and grains fragmentation. However, there are still few studies that address the microscale variations in porosity in these structures. Usually, only porosity or permeability data in total rock are reported in the literature. The main objective of this work is to characterize the distribution and orientation of macro and micropores, considering the diagenetic and deformational processes that influence the porosity and permeability of the rock. For this purpose, the petrophysical properties of sandstones with different amounts of deformation bands were compared, developed in outcrops of two distinct geological units: the Ilhas Group (fluvio-deltaic deposits) and the Massacará Group (fluvio-eolic deposits) in the Tucano Basin, northeast of the state of Bahia. The main methods used were nuclear magnetic resonance (NMR) and magnetic susceptibility anisotropy in samples impregnated with ferrofluid (ASMff). Additionally, optical and electronic microscopy, X-ray computed microtomography $(\mu \mathrm{CT})$ and basic petrophysics tests (porosity and gas permeability; density), helped with the interpretations. From the petrographic point of view, primary pores, pores in fractures and originated by dissolution were observed. The deformation bands were identified in the intermediate peaks of transverse relaxation times $\left(\mathrm{T}_{2}\right)$, between 3 and $50 \mathrm{~ms}$, and may also have an influence on smaller peaks. The intensity of these peaks is mainly related to the volume of the bands, while the relative width or proportion depends on the geometry and orientation. More homogeneous structures showed only a narrower peak, while structures with anastomosed geometry, containing pods of less deformed rock inside, were associated with two peaks or with a wider peak. In this case, the intensity of the peaks can reflect even different degrees of granular fragmentation. Due to the low magnetic susceptibility of the samples and the fact that the T2 distribution was measured in a low magnetic field, there was no evidence of significant underestimation of the porosity values, in relation to the other techniques. It was also clear that effects in $\mathrm{T}_{2}$ resulting from the primary textural aspects can be obliterated by the modification of the porous structure by deformational processes. With that, nuclear magnetic resonance proved to be an efficient tool to assist in the identification of cataclastic deformation bands in the sandstones studied in this work. However, the technique allowed only a qualitative analysis of the band content in the samples. As for the orientation of the pores, the anisotropy of magnetic susceptibility by ferrofluid showed a satisfactory compatibility, however more studies are needed.
\end{abstract}


Keywords: Tucano Basin, Deformation Bands, Nuclear Magnetic Resonance, Ferrofluid. 


\section{LISTA DE ILUSTRAÇÕES}

Figura 1.1 - Mapa de localização geográfica das áreas de estudo. Base cartográfica IBGE, datum SIRGAS 2000.

Figura 2.1 - Mapa geológico simplificado com destaque para a localização das áreas de estudo. $\mathrm{AP}=$ Alto de Aporá, FI = Falha de Inhambupe, FRI = Falha Rio Itapecuru, FA = Falha de Adustina, FST = Falha de São Saité. A Bacia de Tucano (BT) compreende as Sub-bacias Tucano Sul (BTS), Central (BTC) e Norte (BTN).

Figura 2.2 - Carta estratigráfica das sub-bacias de Tucano Sul e Central. 21

Figura 2.3 - Mapa geológico simplificado da região do afloramento da Falha do Macaco. ... 22

Figura 2.4 - Mapa geológico simplificado da região do afloramento da Falha de Caritá........ 23

Figura 3.1 - Principais macroestruturas que controlam a distribuição de bandas de deformação em arenitos. 25

Figura 3.2 - Classificação cinemática das bandas de deformação. 26

Figura 3.3 - Classificação geométrica das bandas de deformação. a) Tipo olho; b) Tipo rampa; c) Par S-C; d) Disposição similar às fraturas do tipo Riedel; e) Losenges; f) Poligonais e g) Tipo Chevron. $\mathrm{Bd}=\mathrm{Banda}$ dilatacional; $\mathrm{Bcs}=\mathrm{Banda}$ cisalhante e $\mathrm{Bcp}=$ Banda compactacional. ...... 27 Figura 3.4 - Variação da porosidade e permeabilidade nas bandas de deformação, conforme a intensidade de cataclase. SECB = banda de compactação reforçada por cisalhamento.

Figura 4.1 - Quadro com as regras para determinação do tipo de spin. 31

Figura 4.2 - Quadro com as propriedades de RMN para espécies nucleares. 31

Figura 4.3 - Representação vetorial do movimento de precessão do spin em torno do campo B0. $\omega 0=$ velocidade angular; $\theta=$ ângulo de deslocamento.

Figura 4.4 - Magnetização resultante da orientação dos spins, paralelos à direção do campo externo $\mathrm{B}_{0}(\mathrm{a})$ e perpendicular (b), após a aplicação do pulso de radiofrequência. 32

Figura 4.5 - Exemplo de um FID no domínio do tempo (a) e da frequência (b), observado para núcleos de hidrogênio na água.

Figura 4.6 - Sequência de pulsos CPMG com os respectivos comportamentos do vetor de magnetização resultante. 36

Figura 4.7 - Gráfico da distribuição de $\mathrm{T}_{2}$ gerado a partir da curva de decaimento exponencial da intensidade de magnetização, obtida pela sequência CPMG.

Figura 5.1 - (a) Representação tridimensional do elipsoide magnético e (b) seus respectivos eixos de susceptibilidade magnética plotados em estereograma. 38 
Figura 5.2 - Representação tridimensional do elipsoide magnético para os diferentes parâmetros de forma e grau de anisotropia, com os seus respectivos eixos principais de susceptibilidade magnética.

Figura 5.3 - a) Elipsoide de anisotropia magnética resultante apenas da influência dos grãos magnéticos alinhados de acordo com o plano de deposição. b) Elipsoide cuja orientação dos eixos máximo e mínimo correspondem à direção das microfissuras, transversais ao plano de deposição, devido ao preenchimento com ferrofluido.

Figura 5.4 - Distribuição de tamanho das partículas de magnetita esféricas, sintetizada por decomposição térmica.

Figura 6.1 - Comportamento da curva de histerese com base no alinhamento dos spins das partículas magnéticas. 46

Figura 6.2 - Curvas de histerese para partícula com comportamento diamagnético (a), paramagnético (b), ferromagnético (c) e superparamagnético (d). 47

Figura 6.3 - Curva de aquisição da magnetização remanente isotérmica. 48

Figura 6.4 - Ilustração simplificada do processo de aquisição por microtomografia de raios-X.

Figura 7. 1 - A) Plano de acamadamento dos arenitos flúvio-deltaicos do Grupo Ilhas, com mergulho para leste; B) Parte preservada do rollover anticlinal; C). Zona de bandas de deformação associada à Falha do Macaco. Escala indicando o norte.

Figura 7. 2 - Scanlines delimitadas ao longo do afloramento da Falha do Macaco (A), mostrando variação na densidade de bandas ao longo de cada linha (B-I).

Figura 7. 3 - Vista do afloramento em planta (A) e perfil (B), além de diagrama de rosetas (C) e estereograma (D) evidenciando o padrão estrutural no afloramento da Falha do Macaco....55 Figura 7. 4 - Imagens tridimensionais dos plugues com diferentes volumes de bandas (BDs) do afloramento do Grupo Ilhas.

Figura 7.5 - Vista parcial do afloramento, em planta (A) e perfil (B), mostrando as bandas em destaque no relevo.

Figura 7. 6 - Localização das scanlines no afloramento da Falha Caritá (A), juntamente com fotos representativas mostrando a variação na densidade de bandas ao longo de cada linha (BF).

Figura 7. 7 - Vista do afloramento em planta (A), assim como diagrama de rosetas (B) e estereograma (C) evidenciando o padrão estrutural no afloramento da Falha de Caritá. 58 Figura 7. 8 - Fotomicrografia e imagem tridimensional das amostras do Grupo Massacará cujo volume de bandas (BDs) foi determinado. 
Figura 7. 9 - Diagrama de classificação dos arenitos do Grupo Ilhas (Folk, 1974) 60

Figura 7. 10 - Principais feições diagenéticas (crescimento secundário de quartzo e feldspato, alteração de minerais primários para argilomineral ou mineral opaco) observadas por MEV e microscopia óptica. Bt=Biotita; $\mathrm{Chl}=$ Clorita; Kfs=Kfeldspato; Fsp=Feldspato; Opq=Minerais opacos; Qz=Quartz.

Figura 7. 11 - Fotomicrografias mostrando fratura transgranular em grãos de quartzo (a); banda de deformação caracterizada pela redução localizada de porosidade, em comparação com a rocha hospedeira (b). RH=Rocha hospedeira; $\mathrm{BD}=\mathrm{Banda}$ de deformação.

Figura 7. 12 - Mapa de distribuição dos elementos químicos em amostra com banda de deformação da scanline 6. a) Diferença de proporção entre os elementos químicos na banda de deformação e na rocha hospedeira; b) Maior concentração de Ca na porção menos deformada; c) Conteúdo de Fe indicando provável alinhamento de mineral.

Figura 7. 13 - Fotomicrografias apresentando os tipos de poros presentes nas amostras: a) Primário parcialmente preservado, aumentado por dissolução; b) Em feldspato fraturado; c) Por dissolução, em banda de deformação.

Figura 7. 14 - Diagrama de classificação dos arenitos constituintes do afloramento da Falha de Caritá (Grupo Massacará) (Folk, 1974).

Figura 7. 15 - Principais feições diagenéticas (crescimento secundário de quartzo, alteração de minerais primários para argilomineral ou mineral opaco, deformação de grão dúctil, dissolução) observadas por MEV e microscopia óptica. $\mathrm{Bt}=$ Biotita; $\mathrm{Fl}=$ Fragmento lítico; Fsp=Feldspato; Ms=Moscovita; Opq=Minerais opacos; Qz=Quartz; Sme=Esmectita.

Figura 7. 16 - Principais feições microestruturais presentes nas amostras: a) Fraturas intra- e transgranular; b) Zoneamento presente em banda de deformação. RH=Rocha hospedeira; $\mathrm{ZD}=$ Zona de dano; $\mathrm{NC}=$ Núcleo da banda.

Figura 7. 17 - Mapa de distribuição dos elementos químicos em amostra, da scanlinescanline 3, totalmente constituída por banda. a) Conteúdo de Si condizente com o arcabouço da rocha, evidenciando os poros, em preto; b) Maior concentração de Ca associada aos poros; c) Concentração de Fe paralela à direção do fluxo cataclástico.

Figura 7. 18 - Fotomicrografias mostrando os tipos de poros: a) Primário parcialmente preservado, aumentado por dissolução; b) Em fraturas; c) Por dissolução.

Figura 7. 19 - Exemplos de curvas de histerese medidas (em cinza) e com a correção do efeito paramagnético (em preto).

Figura 7. 20 - Curvas de aquisição MRI para as amostras dos grupos Ilhas e Massacará. 
Figura 7. 21 - Gráfico com as curvas de ajuste mostrando a contribuição de cada fase com diferentes coercividades em amostras representativas dos grupos Ilhas (A-B) e Massacará (CD).

Figura 7. 22 - Graficos de correlação entre os dados de porosidade obtidos por diferentes métodos e a porcentagem de volume de bandas dos plugues analisados. .70

Figura 7. 23 - Comparação entre os valores de porosidade e permeabilidade a gás, para ambos os afloramentos. Em preto, correlação entre todas as amostras de ambos os afloramentos, exceto às referentes à scanline ILH2C e amostra ILH6C (em azul).

Figura 7. 24 - Comparação entre os valores de porosidade obtidos por saturação de fluido e por RMN.

Figura 7. 25 - Distribuição dos tempos de relaxação transversal para as amostras cujo volume de bandas foi quantificado, nas scanlines ILH1 (A), ILH6 (B) e MAS3 (C). 72 Figura 7. 26 - Correlação entre o volume percentual de bandas de deformação nos plugues e a área percentual das componentes de tempo de relaxação transversal. .74 Figura 7. 27 - Comparação entre os eixos principais de anisotropia de susceptibilidade magnética e o padrão estrutural nas scanlines, nos afloramentos dos Grupo Ilhas (A) e Massacará (B), ao longo das quais as amostras foram coletadas. As linhas em preto, azul e vermelho em $(\mathrm{B})$, correspondem às estruturas tipo Riedel $\mathrm{Y}, \mathrm{R}$ e R', respectivamente. ......... 75 Figura 7. 28 - Gráficos mostrando a relação entre a) parâmetro de forma (T) e grau de anisotropia (P) e b) Variação do grau de anisotropia em função da susceptibilidade magnética $(\mathrm{Km})$, na amostras dos grupos Ilhas e Massacará. .76 Figura 7. 29 - Gráfico de correlação entre as medidas de porosidade em amostras saturadas com água e amostras impregnadas com ferrofluido, mostrando uma eficiente impregnação das amostras.

Figura 7. 30 - Estereogramas com a representação dos principais eixos de susceptibilidade magnética e suas elipses de confiança, para as amostras antes (a) e após (b) a impregnação com ferrofluido. 78

Figura 7. 31 - Gráficos mostrando a relação entre o parâmetro de forma e o grau de anisotropia e deste último com a susceptibilidade magnética média, para as amostras antes (a) e depois (b) da impregnação com ferrofluido. 


\section{LISTA DE TABELAS}

Tabela 7.1 - Fases minerais magnéticas obtidas a partir do espectro de coercividade. 68 Tabela 7.2 - Parâmetros petrofísicos para as amostras dos grupos Ilhas (Falha do Macaco) e Massacará (Falha de Caritá). BDs = Quantidade de bandas de deformação obtida por microtomografia de computadorizada de raios-X e microscopia óptica; $\phi=$ dados de porosidade $\mathrm{k}=$ permeabilidade $; \mathrm{x}=$ suscetibilidade magnética $;<$ res. $=$ abaixo do limite de detecção do equipamento; 1 Plugue paralelo à direção de mergulho da banda; ${ }^{2}$ Plugue perpendicular à direção de mergulho da banda.

Tabela 7.3 - Contribuição dos picos de intensidade do tempo de relaxação transversal. 73

Tabela 7.4 - Parâmetros de anisotropia de susceptibilidade magnética para as amostras antes e após a impregnação com ferrofluido. L=lineação magnética; $F=$ foliação magnética; $\mathrm{P}=$ grau de anisotropia; T=parâmetro de forma; D,I=declinação e inclinação dos eixos de susceptibilidade magnética principais 77 


\section{SUMÁRIO}

1 INTRODUÇÃO ......................................................................................................................... 14

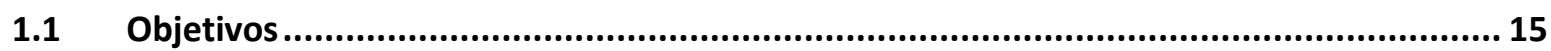

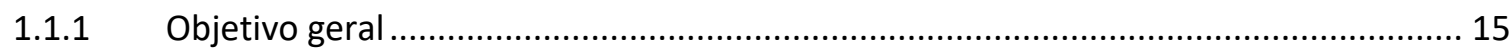

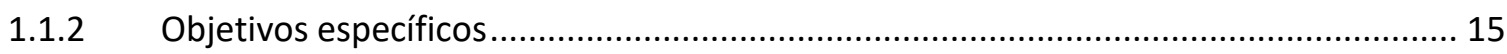

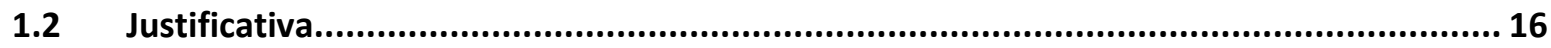

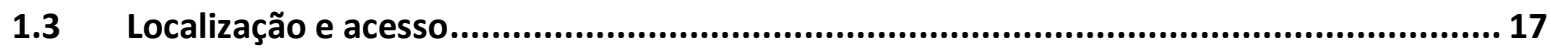

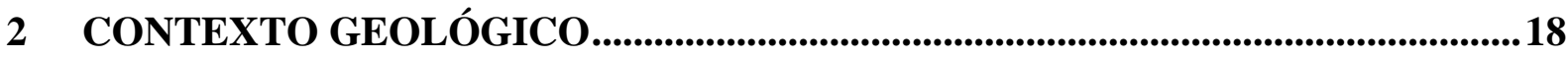

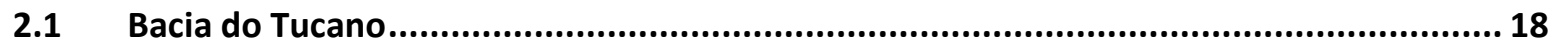

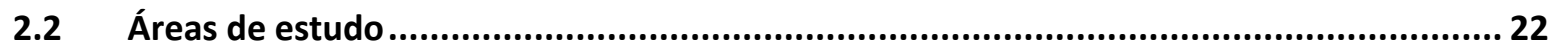

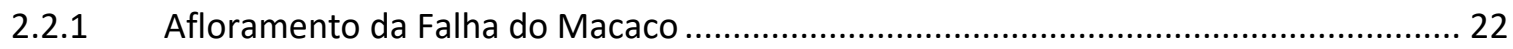

2.2.2 Afloramento da Falha de Caritá ................................................................................... 23

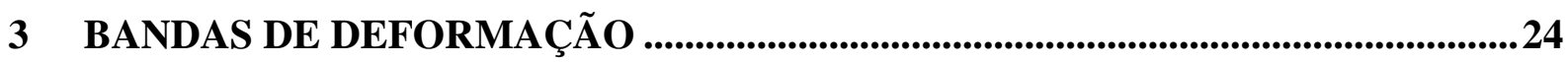

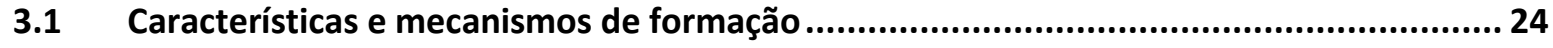

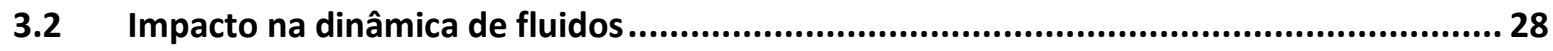

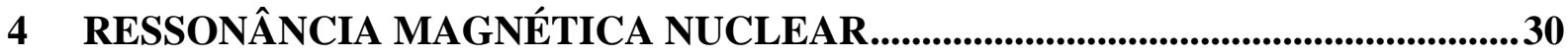

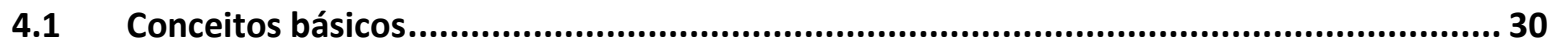

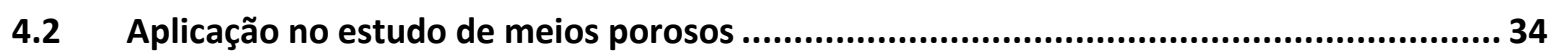

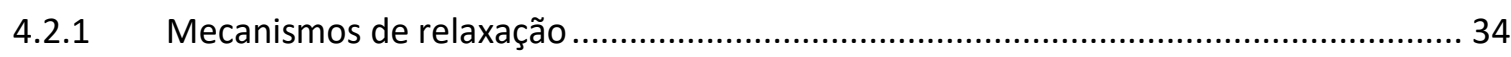

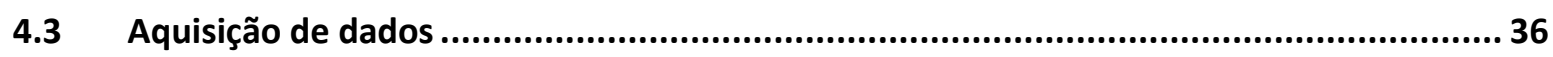

4.3.1 Tempo de relaxação transversal por Sequência CPMG .............................................. 36

5 ANISOTROPIA DE SUSCEPTIBILIDADE MAGNÉTICA POR FERROFLUIDO

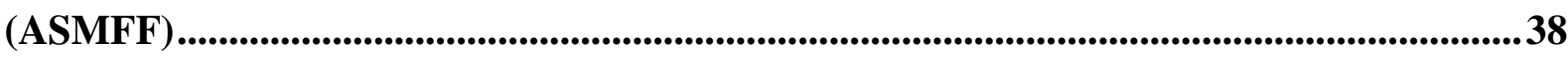

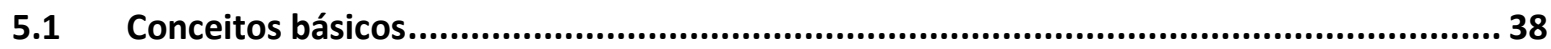

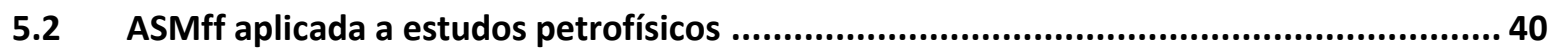

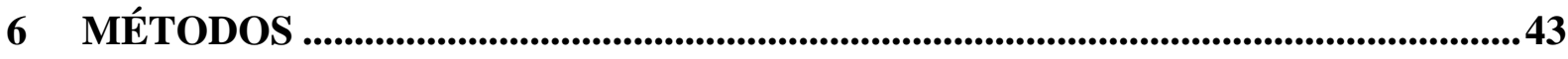

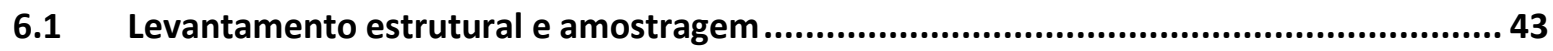

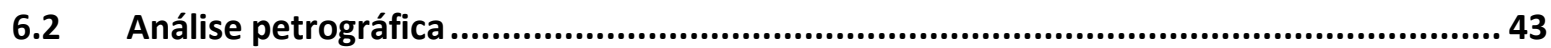

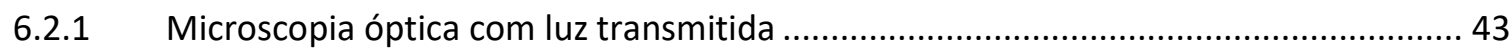

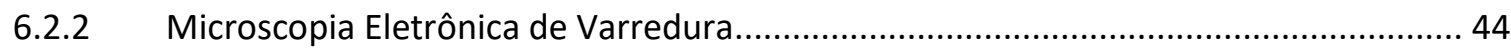

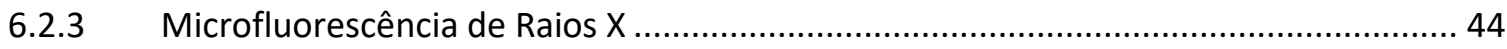

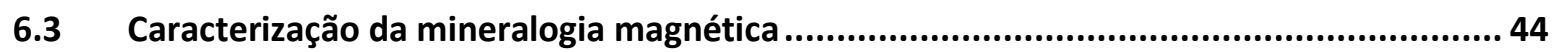


6.3.1 Susceptibilidade magnética (SM) e Anisotropia de Susceptibilidade Magnética (ASM) 45

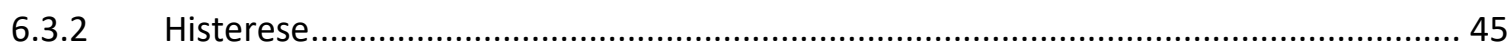

6.3.3 Magnetização Remanente Isotérmica (IRM, em inglês) …......................................... 47

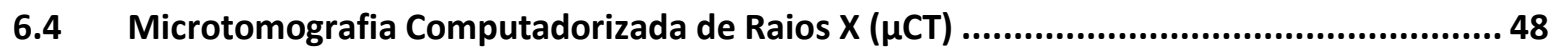

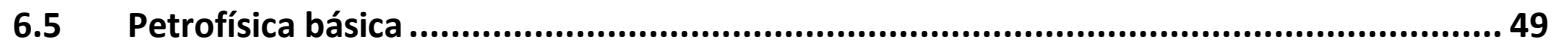

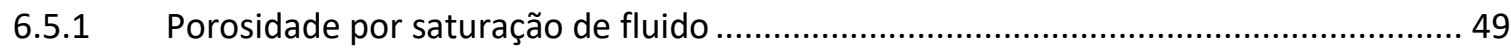

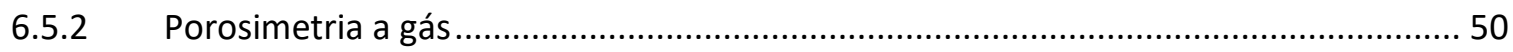

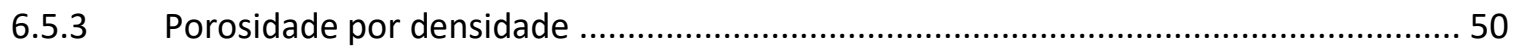

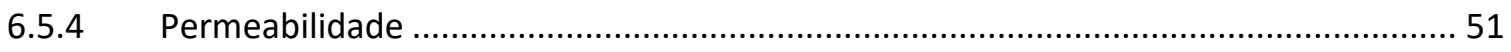

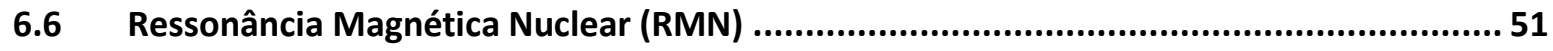

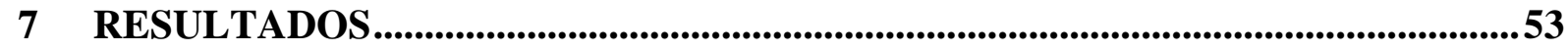

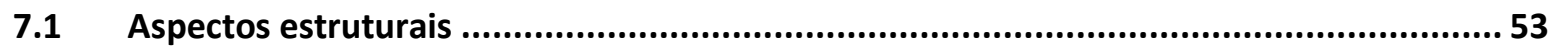

7.1.1 Afloramento da Falha do Macaco (Grupo Ilhas) ............................................................ 53

7.1.2 Afloramento da Falha de Caritá (Grupo Massacará) ......................................................... 56

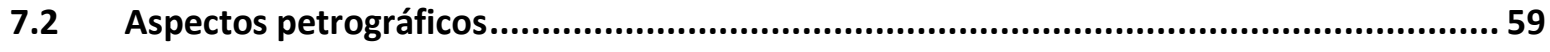

7.2.1 Afloramento da Falha do Macaco (Grupo Ilhas) ............................................................ 59

7.2.2 Afloramento da Falha de Caritá (Grupo Massacará) ..................................................... 63

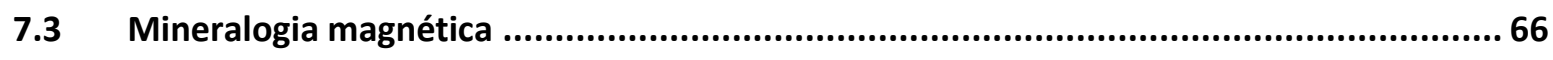

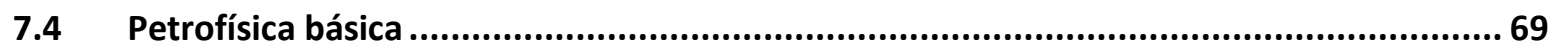

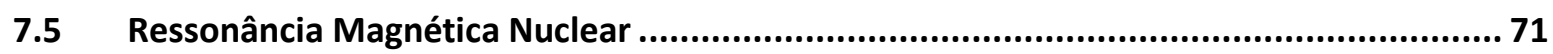

7.6 Anisotropia de Susceptibilidade Magnética ............................................................ 74

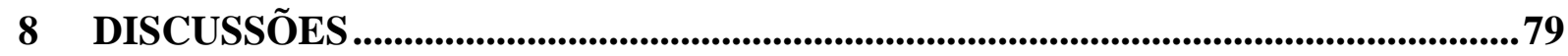

8.1 Efeito das bandas de deformação na distribuição de tempos de relaxação transversal por Ressonância Magnética Nuclear ....................................................................................... 79

8.2 Influência do desenvolvimento das bandas de deformação no alinhamento de minerais

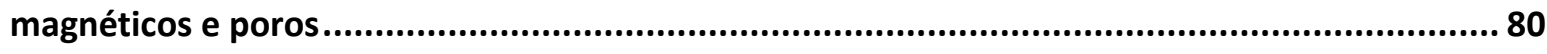

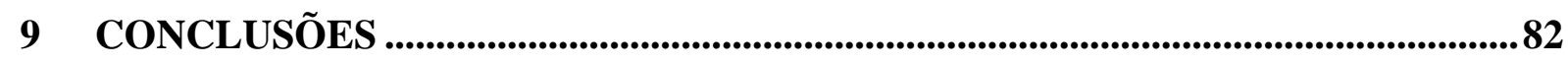

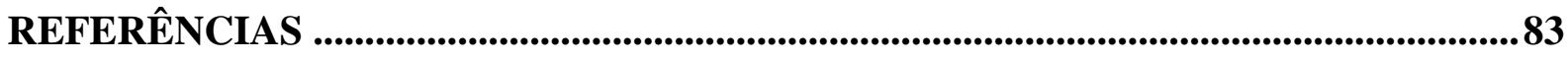

APÊNDICE A - DADOS ESTRUTURAIS DAS SCANLINES DO AFLORAMENTO

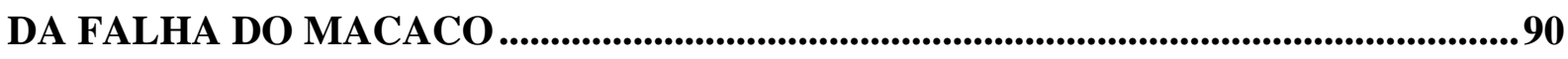

APÊNDICE B - DADOS ESTRUTURAIS DAS SCANLINES DO AFLORAMENTO DA

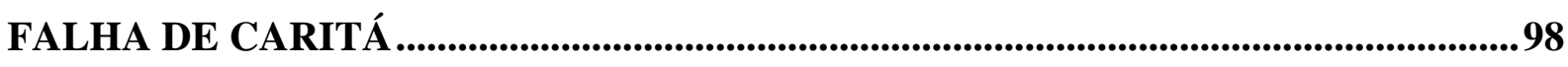

APÊNDICE C - DADOS DE AMOSTRAGEM .....................................................109 


\section{INTRODUÇÃO}

Devido ao seu potencial para compartimentalizar reservatórios de hidrocarbonetos e água subterrânea (TINDALL, 2014), bandas de deformação (BDs) têm sido muito estudadas desde a década de 90. A presença dessas estruturas pode causar significativa redução de porosidade e permeabilidade, influenciando na dinâmica dos fluidos de formação (ANTONELLINI \& AYDIN, 1995). Contudo, a depender da espessura, espaçamento e mecanismo de deformação predominante, as bandas podem não representar, expressivamente, barreiras ao fluxo de fluidos (FOSSEN et al., 2007).

A porosidade, distribuição de tamanho e conectividade dos poros são de grande importância para a estimativa de reserva, produtividade e planejamento de produção de hidrocarbonetos, exigindo modelos petrofísicos confiáveis (SAIDIAN \& PRASAD, 2015). No Brasil, estudos petrofísicos em arenitos com bandas de deformação foram realizados na Bacia do Paraná, utilizando microtomografia de Raios X (RODRIGUES et al., 2015); na Bacia do Rio do Peixe, com a determinação das propriedades geomecânicas e petrofísicas básicas (PONTES et al., 2019); e na Bacia do Tucano, por meio de ensaios de bombeamento para determinar a condutividade hidráulica ao longo dessas estruturas (MEDEIROS et al., 2010) e petrofísica básica (FIGUEIREDO, 2017).

$\mathrm{Na}$ Bacia do Tucano, os principais estudos sobre bandas de deformação estão concentrados na região centro-norte, no contexto geológico do Arco do Vaza-Barris (COSTA et al., 2005; MEDEIROS et al., 2010; FERREIRA \& ALVES DA SILVA, 2010; RODRIGUES \& ALVES DA SILVA, 2018; GOMES et al., 2018). Contudo, nenhum desses trabalhos apresenta uma análise detalhada da variação macro e microporosa das estruturas. Um dos aspectos pouco explorados nesse tipo de estudo é a variação na distribuição de porosidade em microescala entre a rocha sã e as bandas de deformação e sua relação com as propriedades geométricas destas estruturas. Usualmente, somente dados de porosidade ou de permeabilidade em rocha total são reportados na literatura (e.g. FOSSEN \& BALE, 2007).

A ressonância magnética nuclear $(\mathrm{RMN})$ permite explorar a distribuição de porosidade nas rochas e ainda fornece informações sobre as propriedades de superfície dos poros. $\mathrm{O}$ desenvolvimento considerável dessa técnica é devido, principalmente, à demanda no setor petrolífero. Contudo, também pode ser aplicada no gerenciamento de águas subterrâneas rasas e estudos ambientais, uma vez que é sensível à saturação por fluidos contendo núcleos hidrogênio, sendo também uma importante ferramenta geofísica para prospecção e monitoramento de aquíferos (SONG, 2010). 
Outra técnica cuja aplicação teve como precursor o trabalho de Pfleiderer \& Halls (1990) e tem apresentado crescente número de estudos nas últimas três décadas é a anisotropia de susceptibilidade magnética em amostras impregnadas com ferrofluido (ASMff). A praticidade, rapidez e baixo custo fazem dela uma alternativa promissora não apenas para a determinação de porosidade, mas também para identificar a orientação da estrutura porosa em rochas sedimentares (BIEDERMANN, 2019).

Neste trabalho foi desenvolvido um estudo petrofísico em arenitos com bandas de deformação da Bacia do Tucano, utilizando ressonância magnética nuclear associada a outras técnicas de petrofísica básica. Adicionalmente, foram realizadas medidas de anisotropia de susceptibilidade magnética com ferro fluido para verificar a orientação dos poros associados às bandas de deformação. O principal intuito foi caracterizar de maneira mais precisa a distribuição dos diferentes tamanhos de poros, considerando os processos diagenéticos e deformacionais que influenciam na porosidade e na permeabilidade da rocha. O trabalho está estruturado nas seguintes seções: Bandas de deformação, Ressonância Magnética Nuclear, Anisotropia de Susceptibilidade Magnética com Ferrofluido, Métodos, Resultados, Discussões e Conclusão.

\subsection{Objetivos}

\subsubsection{Objetivo geral}

O objetivo principal deste trabalho é verificar a distribuição de tamanho de poros em arenitos com diferentes características texturais e quantidade variável de bandas de deformação (BDs), assim como a orientação dos poros no interior dessas estruturas. Para isso foram estudadas amostras de duas unidades geológicas distintas, sendo elas os grupos Ilhas (arenitos fluvio-deltaicos bem selecionados) e Massacará (arenitos fluvio-eolicos com selecionamento ruim), integrantes da Supersequência Sin-rifte da Bacia do Tucano.

\subsubsection{Objetivos específicos}

- Determinar a geometria (forma e espessura), cinemática e disposição espacial das bandas de deformação em diferentes escalas.

- Identificar os mecanismos responsáveis pela variação da forma e tamanho dos grãos e poros, assim como as feições diagenéticas associadas aos processos deformacionais, resultantes na modificação das propriedades petrofísicas em arenitos com conteúdo de bandas variável; 
- Verificar a influência de componentes magnéticos (grãos detríticos, cimento e revestimento) na caracterização da porosidade por RMN e na anisotropia de susceptibilidade magnética dos litotipos com bandas de deformação.

\subsection{Justificativa}

As bandas de deformação, pela forte anisotropia que impõem às rochas nas quais se desenvolvem, podem condicionar direções preferenciais de escoamento de fluidos a depender da forma, orientação e conectividade dos poros. A porosidade resultante da sobreposição de processos deposicionais, diagenéticos e deformacionais pode apresentar uma componente direcional associada à estrutura porosa. Várias técnicas podem ser utilizadas para mapear o espaço poroso em duas (microscopia) ou três $(\mu \mathrm{CT})$ dimensões. Porém, limitações quanto à resolução podem dificultar a visualização de meso e microporos, além de que, dependendo dos cortes, as seções delgadas podem não ser representativas, por alterar a forma dos poros (BIEDERMANN, 2019). A técnica de medição de anisotropia de susceptibilidade magnética (ASM) em rochas impregnadas com ferrofluido, solução com Nanopartículas de Magnetita Superparamagnéticas (NPMag), permite estimar a porosidade da rocha e identificar a orientação da fábrica porosa associada ao plano de sedimentação (e.g. ARONCHI, 2017) ou a estruturas deformacionais (e.g. PARÉS et al., 2016). Isso porque as NPMag podem preencher poros de tamanhos nanométricos, além da facilidade, rapidez e baixo custo de aquisição e análise dos dados de ASM.

A determinação da porosidade e permeabilidade tem grande importância para a explotação de petróleo e água, uma vez que essas propriedades possuem íntima relação com o escoamento de fluidos (e.g. SOUZA, 2012). No entanto, há ainda poucos estudos que tratam das variações em microescala da estrutura dos poros em arenitos com bandas de deformação. A ressonância magnética nuclear é uma ferramenta bastante adaptada para a caracterização de meios porosos, fluidos e propriedades de superfície das paredes dos poros, além de possibilitar a identificação de microporosidade (e.g. JÁCOMO et al., 2019). Trata-se de uma técnica não destrutiva, que pode ser utilizada em laboratório ou a partir de medidas in situ em ambiente de poço (SOUZA, 2012, SILVA, 2014). Os resultados obtidos neste trabalho podem ser aplicados na melhoria da produtividade de poços e/ou na escolha de estratégias de produção em bacias petrolíferas. 


\subsection{Localização e acesso}

As áreas de estudo consistem em dois afloramentos localizados nas sub-bacias de Tucano Sul e Central, estado da Bahia (figura 1.1). O primeiro está associado à Falha do Macaco, porção oeste da Sub-bacia do Tucano Sul, 1,0 km a norte do distrito de Tracupá, município de Tucano. O segundo, englobando parte da Falha de Caritá, está localizado na Fazenda Olho D’Água, a 6,0 km da sede do município de Jeremoabo, porção nordeste da Sub-bacia do Tucano Central. O acesso é feito a partir de Salvador pela BR-324, seguindo a BR-116, e pela BR-110, respectivamente.

Figura 1.1 - Mapa de localização geográfica das áreas de estudo. Base cartográfica IBGE, datum SIRGAS 2000.

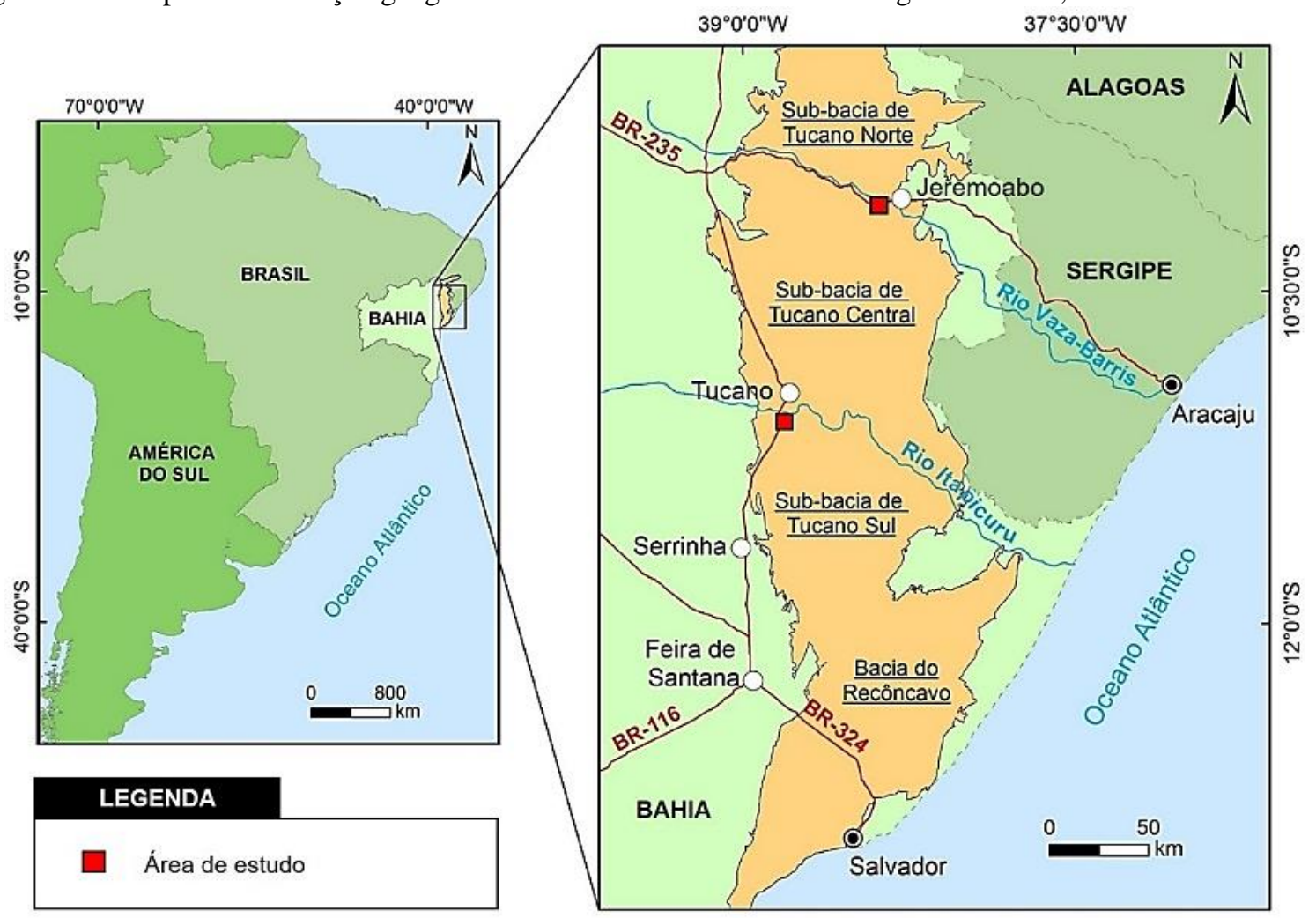




\section{CONTEXTO GEOLÓGICO}

\subsection{Bacia do Tucano}

Localizada no nordeste brasileiro, a Bacia do Tucano compõe o Sistema de Riftes abortados do Recôncavo-Tucano-Jatobá (SRRTJ), estruturado durante a fragmentação do Supercontinente Gondwana que culminou na formação do Oceano Atlântico Sul, no Eocretáceo (COSTA et al., 2007).

A Bacia do Tucano possui extensão territorial de $30.500 \mathrm{~km}^{2}$, sendo limitada pelo Alto de Aporá, a sul; pela Falha do Rio São Francisco, a norte; e por contato discordante com o embasamento a leste e oeste (MAGNAVITA et al., 2003; COSTA et al., 2007). É dividida em três sub-bacias denominadas Tucano Sul, Central e Norte, com área de 7.000 km², 14.700 km² e $8.800 \mathrm{~km}^{2}$, respectivamente. Apresenta geometria em forma de semi-gráben, cuja posição do depocentro e da margem flexural depende da orientação da falha de borda de cada sub-bacia. Duas feições principais, com orientação NW-SE, separam as sub-bacias, sendo elas a Zona de Acomodação do Rio Itapicuru, entre Tucano Sul e Central, e o Arco do Vaza Barris, entre Tucano Central e Norte.

As falhas de borda das sub-bacias de Tucano Sul, Central e Norte são denominadas Falha de Inhambupe, Adustina e São Saité, respectivamente. A primeira possui orientação $\mathrm{N} 25^{\circ} \mathrm{E}$ com mergulho para oeste e apresenta associada à ela falhas normais planares e antitéticas que acomodam as camadas em padrão dominó com mergulho para sudeste, configurando o depocentro. As demais, apesar de possuírem orientação N-S, apresentam mergulho para oeste (Adustina) e leste (São Saité) devido a inversão de polaridade da bacia, gerada pela zona de transferência associada ao Arco do Vaza Barris. Na sub-bacia de Tucano Central, as falhas antitéticas em padrão dominó com orientação N-S, definem o depocentro associado ao Baixo de Cícero Dantas, a leste. Enquanto na sub-bacia de Tucano Norte, as falha com mergulho para oeste, estabeleceram o depocentro na região do Baixo de Salgado do Melão.

O embasamento é composto por dois compartimentos tectônicos (COSTA et al., 2007; KOSIN, 2009), o Cratón do São Francisco e a Província Borborema. O primeiro engloba o Bloco Serrinha (mesoarqueano a paleoproterozoico), a oeste e sudeste da bacia; e a Cobertura Cratônica Estância (neoproterozoica), a noroeste e leste. O segundo é composto pela Faixa Sergipana e Terreno Canindé-Marancó (meso a neoproterozoicos), a noroeste e nordeste, além da bacia Palmares (cambrianas a ordovicianas), a leste. O Bloco Serrinha é constituído pelos ortognaisses migmatíticos, metamorfizados em fácies anfibolito alto, do Complexo Santa Luz; metavulcânicas e metassedimentos epiclásticos, vulcanoclásticos e siliciclásticos, associados ao Greenstone Belt do Rio Itapicuru; e granitoides sintectônicos. O Grupo Estância consiste em 
rochas metassedimentares carbonáticas e siliciclásticas de baixo grau metamórfico. O Terreno Canindé-Marancó é caracterizado por sequências metavulcanossedimentares, intercaladas com ortognaisses migmatíticos, enquanto a Faixa Sergipana apresenta rochas metassedimentares carbonáticas e siliciclásticas, depositadas em ambiente de margem passiva. A Bacia Palmares foi preenchida por sedimentos siliciclásticos em ambiente tectonicamente ativo, associado à uma bacia de antepaís, durante a orogênese brasiliana. Do ponto de vista estrutural são observados dois domínios principais, refletidos na orientação das estruturas da bacia (figura 2.1), um com feições quase N-S, associado às unidades do Cratón do São Francisco e outro com predomínio de zonas de cisalhamento com orientação NW-SE, na Província Borborema.

Figura 2.1 - Mapa geológico simplificado com destaque para a localização das áreas de estudo. AP = Alto de Aporá, FI = Falha de Inhambupe, FRI = Falha Rio Itapecuru, FA = Falha de Adustina, FST = Falha de São Saité.

A Bacia de Tucano (BT) compreende as Sub-bacias Tucano Sul (BTS), Central (BTC) e Norte (BTN).
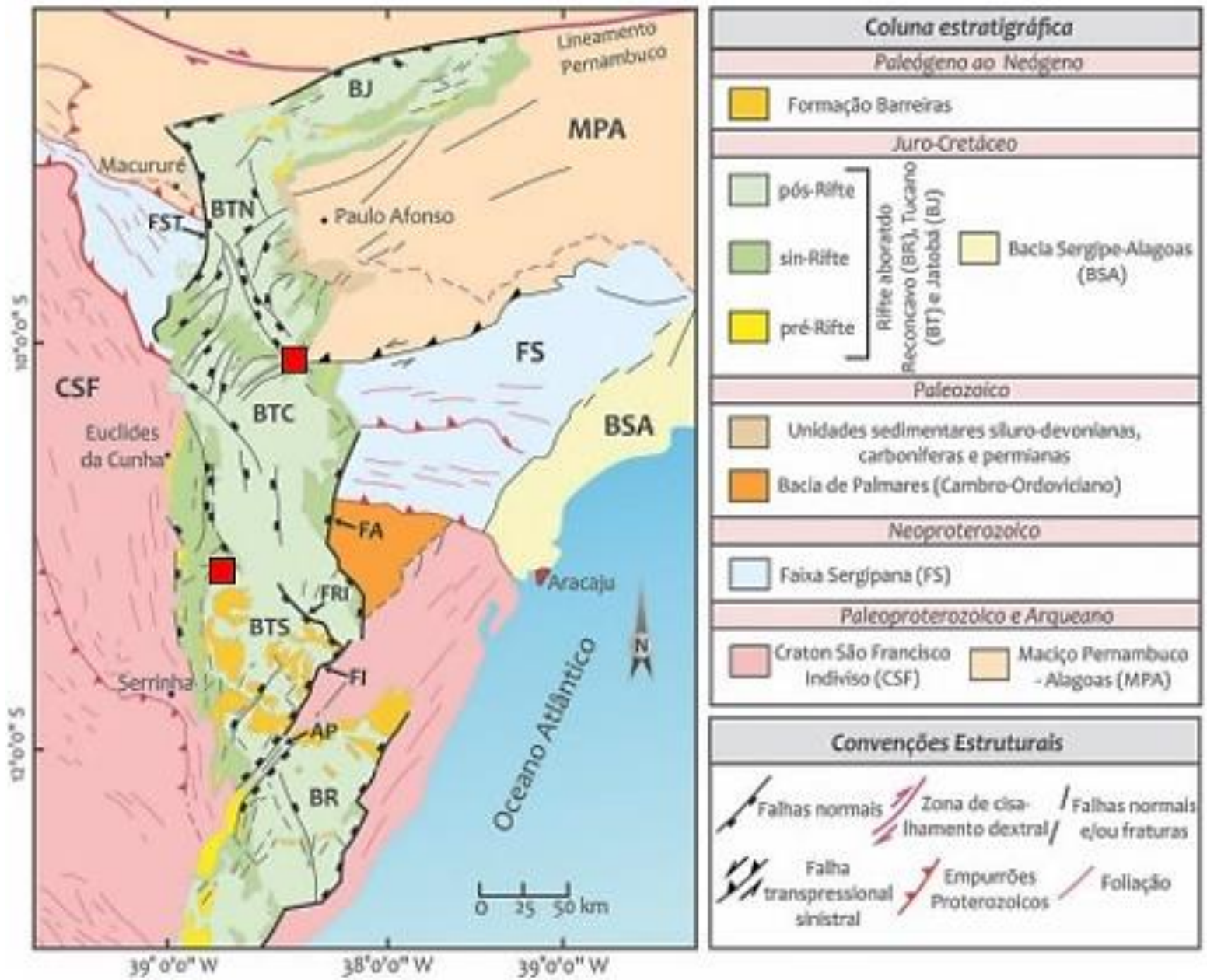

Fonte: Adaptado de Rodrigues (2018).

O preenchimento sedimentar do SRRTJ, revisado primeiramente por Viana et al. (1971), posteriormente por Caixeta et al. (1994) e Costa et al. (2007), pode ser dividido em quatro 
supersequências, depositadas durante o Paleozoico ao Juro-cretáceo, denominadas Sinéclise, Pré-, Sin- e Pós-rifte. Devido às similaridades da tectonossedimentação, as sub-bacias de Tucano Sul e Central partilham do mesmo empilhamento estratigráfico (figura 2.2). Além disso, pelo fato das unidades estudadas neste trabalho pertencerem a essas sub-bacias, apenas o seu registro sedimentar será detalhado.

A Supersequência Sinéclise é representada pelos depósitos de idade permiana da Formação Afligidos, constituída por fácies diagnósticas de ambiente marinho raso com tendência regressiva como laminitos algais e evaporitos. Isso é evidenciado por meio de sedimentos clásticos, laminitos microbiais e evaporitos, no membro Pedrão; e pelitos lacustres, no membro Cazumba. A Supersequência Pré-rifte é composta de sedimentos, depositados no final do neojurássico, por transgressões lacustres e ciclos flúvio-eólicos durante o Jurássico Superior. Os depósitos lacustres correspondem ao membro Capianga da Formação Aliança, enquanto os flúvio-eólicos são representados pelo Membro Boipeba da Formação Aliança e pela Formação Sergi. Também são encontrados folhelhos lacustres da Formação Itaparica e arenitos flúvio-eólicos da Formação Água Grande, no topo desta supersequência.

A deposição inicial da Supersequência Sin-rifte, durante o Berriasiano, é marcada por conglomerados sin-tectônicos da Formação Salvador, devido à implantação das falhas de borda de Inhambupe (sub-bacia de Tucano Sul) e Adustina (sub-bacia de Tucano Central) que configuram o depocentro de cada sub-bacia. Concomitantemente, foram depositados os folhelhos da Formação Candeias, correspondentes a uma fase lacustre com elevada taxa de subsidência, cujos estratos basais constituem o Membro Tauá. Com a diminuição da taxa de subsidência, indicada pela presença de calcários oncolíticos no topo da Formação Candeias, houve a instalação dos ciclos fluvio-deltaicos. Esses sistemas progradacionais de idade neoberriasiana, representados pelas Formações Marfim, Pojuca e Taquipe do Grupo Ilhas, apresentam-se intercalados aos depósitos lacustres na margem flexural. Os sedimentos deltaicos são sucedidos por ciclos flúvio-eólicos e lacustres do Grupo Massacará, de idade eoaptiana. Esses depósitos correspondem aos arenitos médios a grossos, da Formações São Sebastião, folhelhos e calcários, da Formação Poço Verde, respectivamente. A Supersequência Pós-rifte é composta pelos conglomerados e arenitos da Formação Marizal, depositados por sistemas aluviais em regime de subsidência térmica, no Neoaptiano. 
Figura 2.2 - Carta estratigráfica das sub-bacias de Tucano Sul e Central.

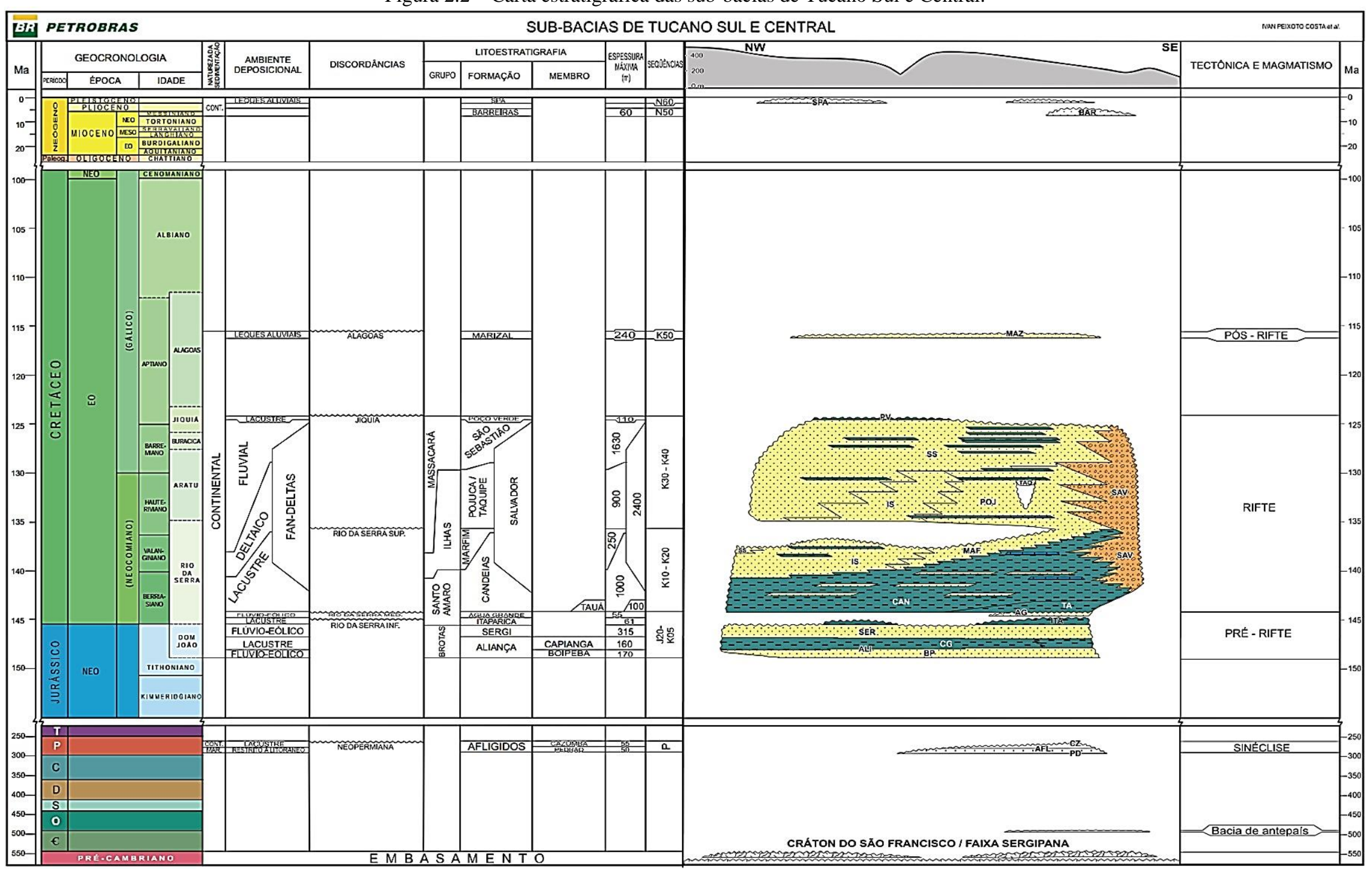

Fonte: Costa et al. (2007) 


\section{2 Áreas de estudo}

\subsubsection{Afloramento da Falha do Macaco}

A Falha do Macaco é uma estrutura normal oblíqua com tendência N-S, mergulhando para leste, localizada na sub-bacia do Tucano Sul (figura 2.3). As camadas de arenitos e siltitos do sistema flúvio-deltaico configuram um rollover anticlinal e dobra de arrasto sinclinal próximo à linha de falha, com eixo inclinado para o norte (MAGNAVITA, 1992).

Ao estudar afloramentos do Grupo Ilhas na região do Arco Vaza-Barris, Rodrigues \& Alves da Silva (2018) estimaram uma porosidade de 22 a $25 \%$ através da descrição de seções delgadas. Porosidade secundária móldica e poros sobredimensionados também foram observados, devido à dissolução parcial ou total dos grãos da estrutura.

Apesar das bandas de deformação, especificamente as cataclásticas, não compartimentalizarem totalmente o análogo do reservatório estudado, Miranda (2004) e Medeiros (2010) identificaram uma redução significativa na permeabilidade da rocha hospedeira para a zona das bandas de deformação. Usando testes de bombeamento e medição de permeabilidade in situ, eles obtiveram valores médios de permeabilidade de aproximadamente $2000 \mathrm{mD}$, para a rocha não deformada, e $5 \mathrm{mD}$, nas zonas de bandas de deformação. Os estudos desta unidade na sub-bacia do Tucano Sul são escassos, do ponto de vista estrutural e petrofísico, devido à má preservação dos afloramentos.

Figura 2.3 - Mapa geológico simplificado da região do afloramento da Falha do Macaco.
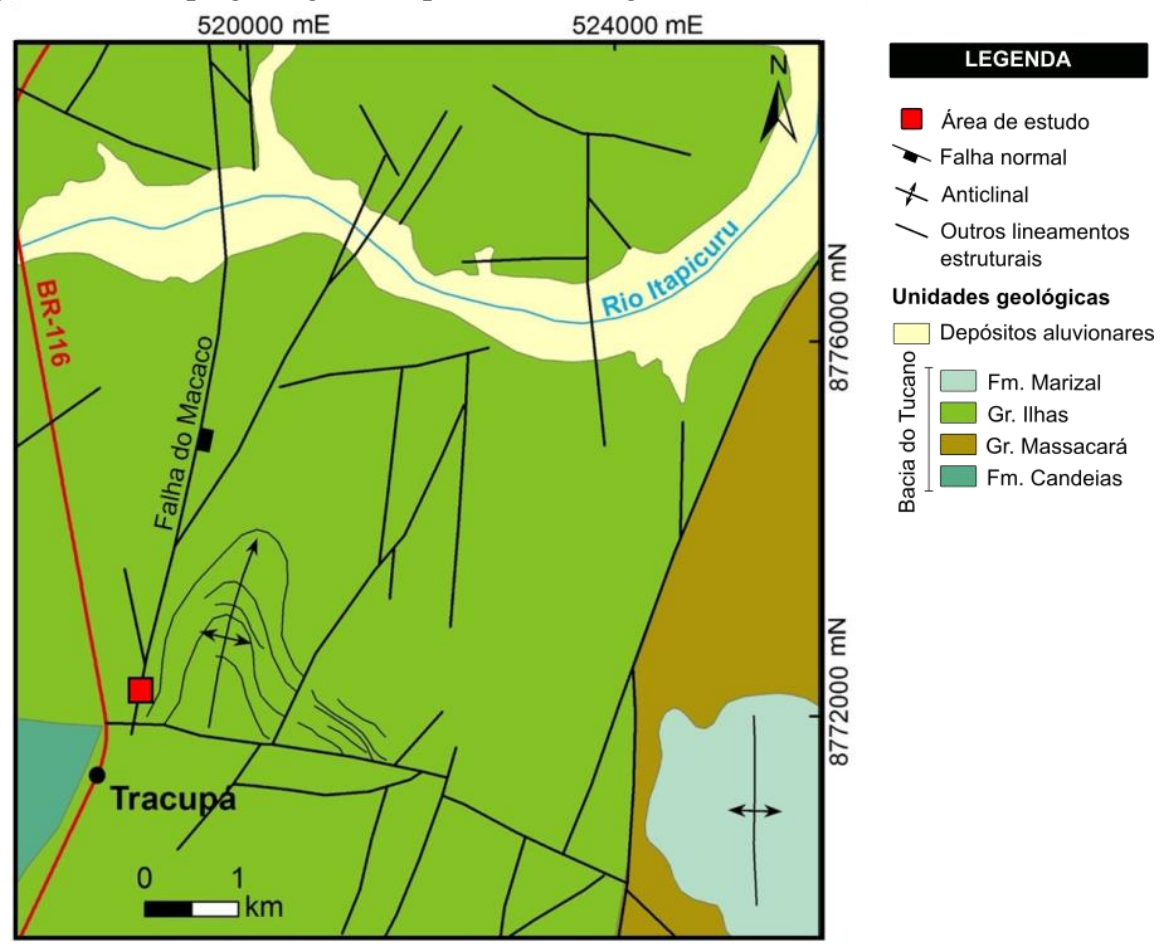

Fonte: Magnavita et al. (2006). 


\subsubsection{Afloramento da Falha de Caritá}

A Falha de Caritá é uma estrutura de transferência com tendência NW-SE e cinemática normal-dextral oblíqua que limita as sub-bacias do Tucano Central e do Tucano Norte (figura 2.4). Sua zona de falha apresenta um expressivo sistema conjugado de fraturas Riedel e antiRiedel com orientação N-S e NE-SW, respectivamente (VASCONCELOS, 2003). Na área de estudo, esse sistema está associado aos arenitos de granulometria fina a grossa, com níveis conglomeráticos, do grupo Massacará. A porosidade dos arenitos desta unidade foi determinada por porosimetria a gás (FIGUEIREDO, 2017) e saturação com fluido magnético para posterior identificação de anisotropia de porosidade (ARONCHI, 2017). Valores entre 21,4 a 31,7\% foram obtidos pela primeira técnica e 21,5 a $32,1 \%$ pela segunda.

Figura 2.4 - Mapa geológico simplificado da região do afloramento da Falha de Caritá.

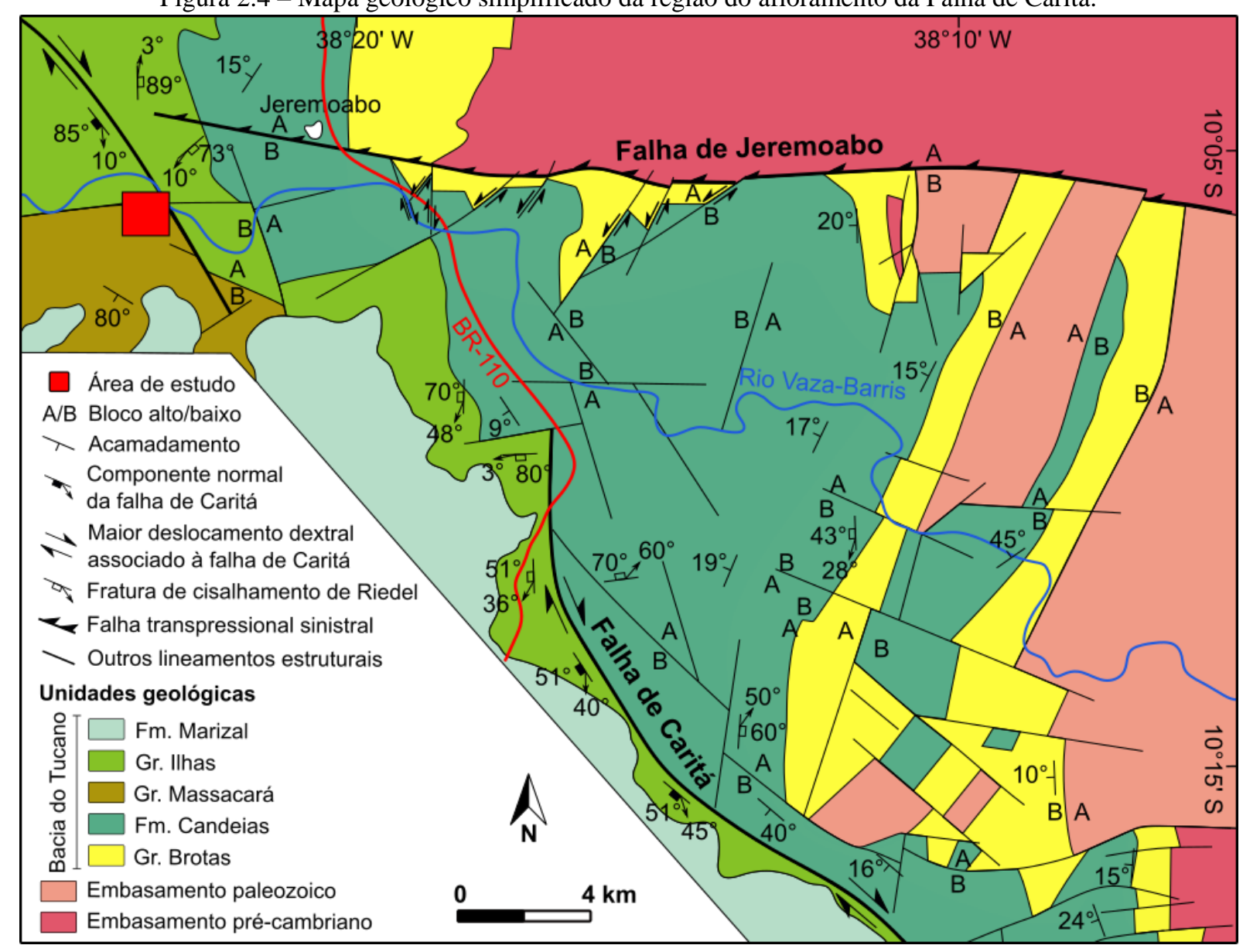

Fonte: Modificado de Destro et al. (2003); Magnavita \& Cupertino (1987). 


\section{BANDAS DE DEFORMAÇÃO}

\subsection{Características e mecanismos de formação}

Bandas de deformação (AYDIN, 1978) são estruturas subsísmicas de espessura milimétrica a métrica, resultantes de deformação rúptil localizada, marcada pela reorganização e/ou moagem de grãos (FOSSEN et al., 2007; FOSSEN et al., 2017). Desenvolvem-se em meios granulares com porosidade superior a 15\% (FOSSEN \& BALE, 2007; FOSSEN et al., 2017). Ocorrem notadamente em arenitos (ANTONELLINI \& AYDIN, 1995; BALLAS et al., 2014; PHILIT et al., 2018; SOLIVA et al., 2016), porém, também podem ser encontradas em sedimentos inconsolidados (BRANDES \& TANNER, 2012; BRANDES et al., 2018), rochas carbonáticas (ANTONELLINI et al., 2014; ROTEVATN et al., 2016), chalk (WENNBERG et al., 2013; KNUTSEN, 2016), ignimbritos (WILSON et al., 2003; LIN \& HUANG, 2014) e rochas vulcanoclásticas (TEWSBURRY et al., 2009; CAVAILHES \& ROTEVATN 2018).

De acordo com FOSSEN et al. (2017), a formação dessas estruturas geralmente envolve diferentes mecanismos de deformação em microescala, como: deslizamento e rotação friccional de grãos, fragmentação e catáclase. Bandas desenvolvidas por cisalhamento simples envolvem deslizamento e rotação sem fragmentação dos grãos, não havendo mudanças significativas de porosidade. A catáclase granular geralmente é promovida por minerais com maior granulometria, bom selecionamento, alta porosidade e profundidade de soterramento, a depender do contexto tectônico.

As bandas podem ser identificadas como estruturas individuais (singles) ou agrupadas (clusters), podendo desenvolver superfícies de deslizamento com a evolução progressiva da deformação (ANTONELLINI \& AYDIN, 1995), sendo a precursora de falhas (FOSSEN et al., 2017). Geralmente ocorrem associadas a macroestruturas em ambientes envolvendo soerguimento vertical, rifteamento, halocinese, lutocinese, colapso gravitacional ou processos glaciotectônicos (FOSSEN et al., 2007; FOSSEN et al., 2017). Essas macroestruturas podem controlar a distribuição e os tipos de bandas a depender da sua cinemática e dinâmica de desenvolvimento (RODRIGUES, 2018). Como exemplo dessas feições, podem ser citadas as dobras originadas por mecanismos de flexura ortogonal (buckling), fluxo flexural (bending) e propagação de falhas reversas, além de falhas normais, rampas de revezamento, nappes e rollover associado à falha lístrica (FOSSEN et al., 2017) (figura 3.1). Em regimes extensionais, bandas de deformação geralmente encontram-se associadas a zonas de falha formando pares conjugados, enquanto no regime contracional se desenvolvem de forma bem distribuída associadas a falhas reversas e dobramentos (FOSSEN et al., 2017). 
Figura 3.1 - Principais macroestruturas que controlam a distribuição de bandas de deformação em arenitos.
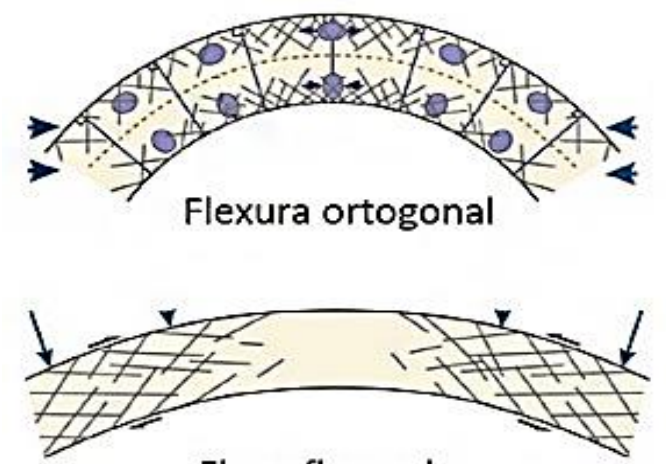

Fluxo flexural
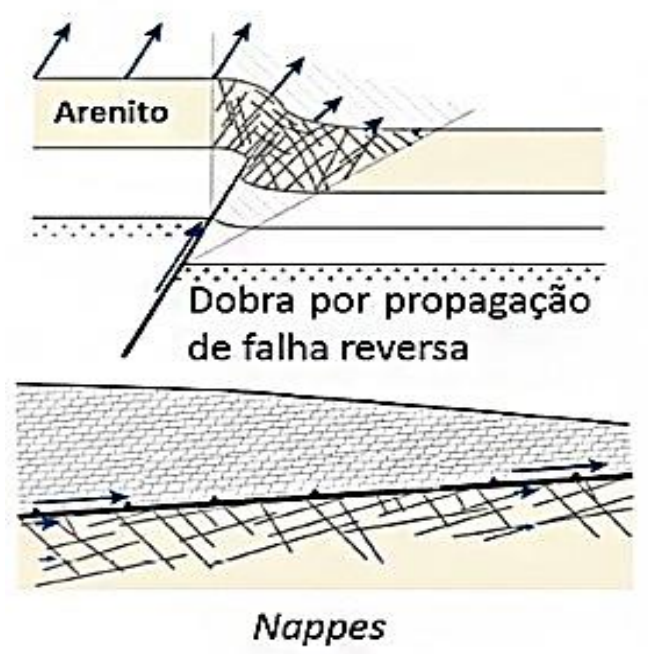
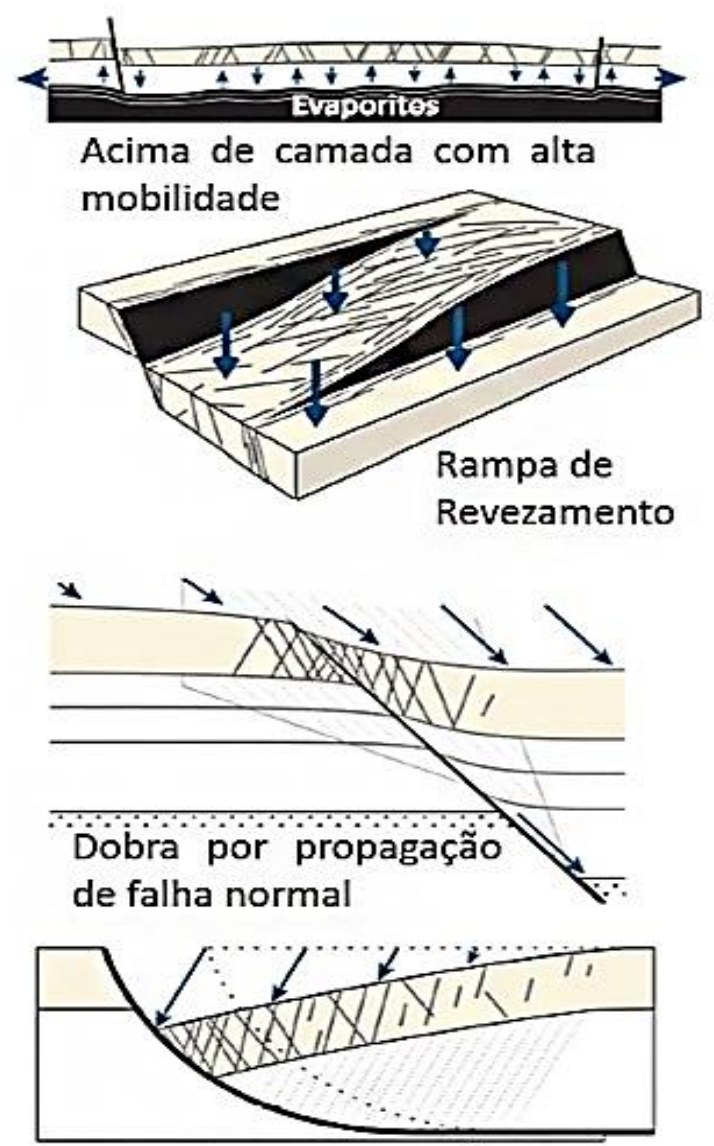

Rollover associado à falha lístrica

Fonte: Modificado de Fossen et al. (2017).

Conforme Fossen et al. (2007), bandas de deformação podem ser classificadas de acordo com a cinemática ou mecanismos de deformação. No primeiro caso, apresentam três membros extremos onde predominam a deformação por cisalhamento e por variação volumétrica positiva ou negativa (figura 3.2). A maioria das estruturas descritas na literatura geológica consiste em bandas de cisalhamento compactacionais (FOSSEN et al., 2007; FOSSEN et al., 2017). Isso pode ser explicado pela maior possibilidade de preservação das estruturas, uma vez que o seu processo formador resulta no endurecimento da mesma em relação à rocha parental.

No segundo caso, o mecanismo de deformação depende das propriedades da rocha original, como composição mineralógica, forma e tamanho dos grãos, cimentação, porosidade, mas também do estado de tensão (ANTONELLINI \& AYDIN, 1995; FOSSEN et al., 2007). Dessa forma, as estruturas podem ser classificadas em: bandas de desagregação (FOSSEN, 2010), nas quais o fluxo granular promove a rotação de grãos e deslizamento em torno dos seus limites gerando estruturas sutis e de difícil visualização em um material homogêneo. Bandas 
filossilicáticas, formadas a partir de arenitos com mais de 10 a $15 \%$ de minerais laminares e facilmente visualizadas devido aos filossilicatos alinhados. Bandas cataclásticas, que se originam por significativa fragmentação mecânica, gerando um núcleo central de cominuição intensa, envolto por grãos compactados e fraturados. Conforme a matriz tectônica (FERREIRA \& ALVES DA SILVA, 2010) é gerada, ocorre o intertravamento dos grãos maiores próximos ao núcleo, resultando no enrijecimento das bandas e tornando-as mais visíveis e resistentes ao intemperismo, em comparação com a rocha hospedeira. Bandas onde predominam a dissolução são compactas com grãos menores compondo uma matriz e pouca evidência de catáclase. As bandas com predominância da cimentação possuem intensa redução da porosidade em decorrência do crescimento mineral em superfícies altamente reativas formadas pelo fraturamento dos grãos.

Figura 3.2 - Classificação cinemática das bandas de deformação.

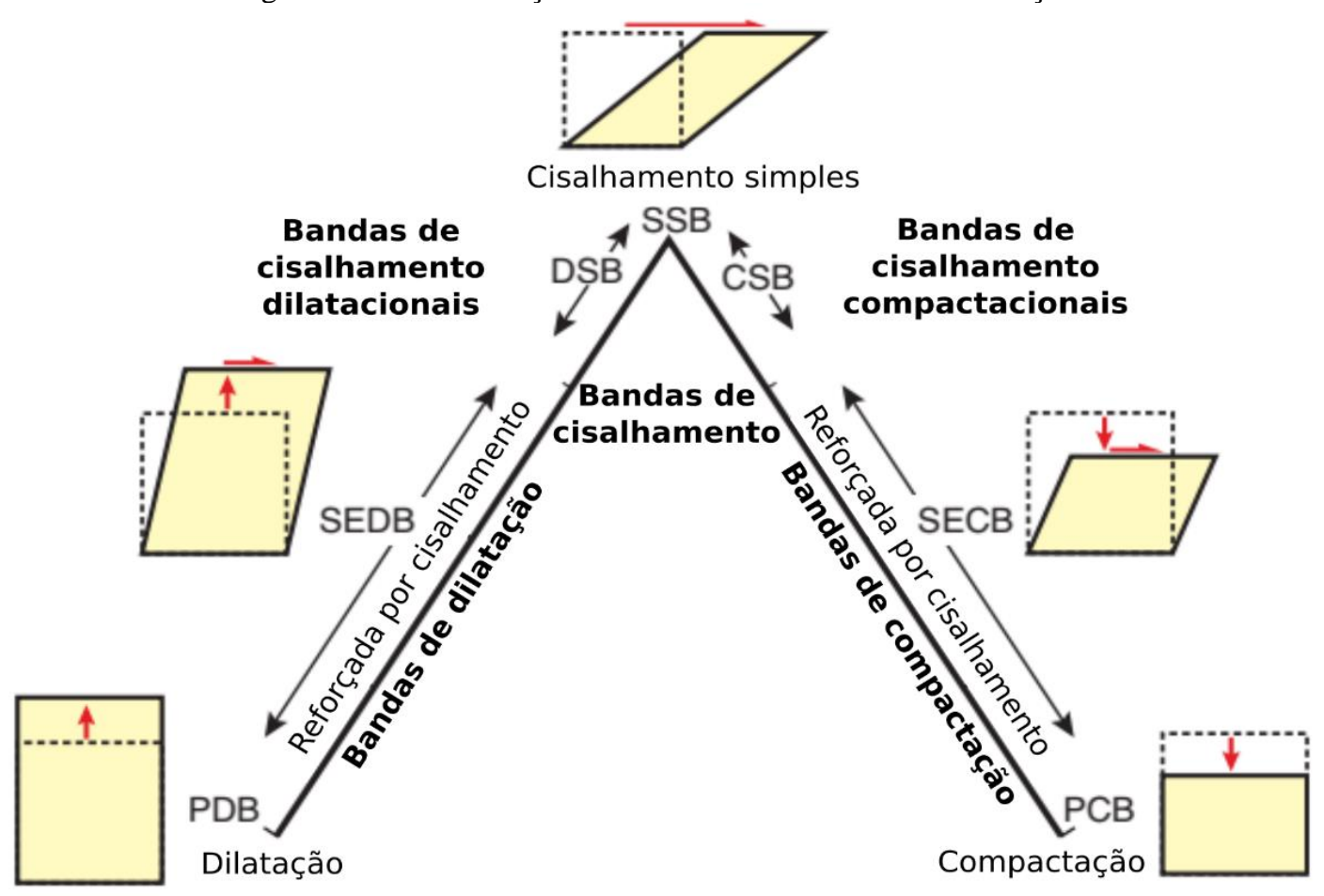

Fonte: Modificado de Fossen et al. (2017).

Outra forma de classificação, utilizada por RODRIGUES (2018), baseia-se na geometria das bandas de deformação, representada pelo arranjo externo e interno dos seus minerais componentes (figura 3.3). A exemplo, podem ser identificados arranjos em olho e rampa, nos quais há preservação de uma porção indeformada ou pouco deformada de rocha parental, cercada pelo material cominuído. O arranjo do tipo S-C (ARAÚJO NETTO et al., 2012), consiste em um plano de cisalhamento $\mathrm{C}$ definido por grãos cominuídos e orientados, associado 
a um plano S com geometria sigmoidal. Também podem ser encontradas bandas com arranjo similar às fraturas do tipo Riedel e em forma de lentes paralelas ao fluxo da deformação, sendo este tipo denominado losenges (AWDAL et al., 2014). ANTONELLINI \& MOLLEMA (2015) também identificaram bandas de deformação com geometria poligonal em contexto tectônico distensional, enquanto FOSSEN et al., (2015), caracterizaram bandas com arranjo em chevron em ambiente contracional.

Figura 3.3 - Classificação geométrica das bandas de deformação. a) Tipo olho; b) Tipo rampa; c) Par S-C; d) Disposição similar às fraturas do tipo Riedel; e) Losenges; f) Poligonais e g) Tipo Chevron. Bd=Banda dilatacional; $\mathrm{Bcs}=\mathrm{B}$ anda cisalhante e $\mathrm{Bcp}=\mathrm{B}$ anda compactacional.

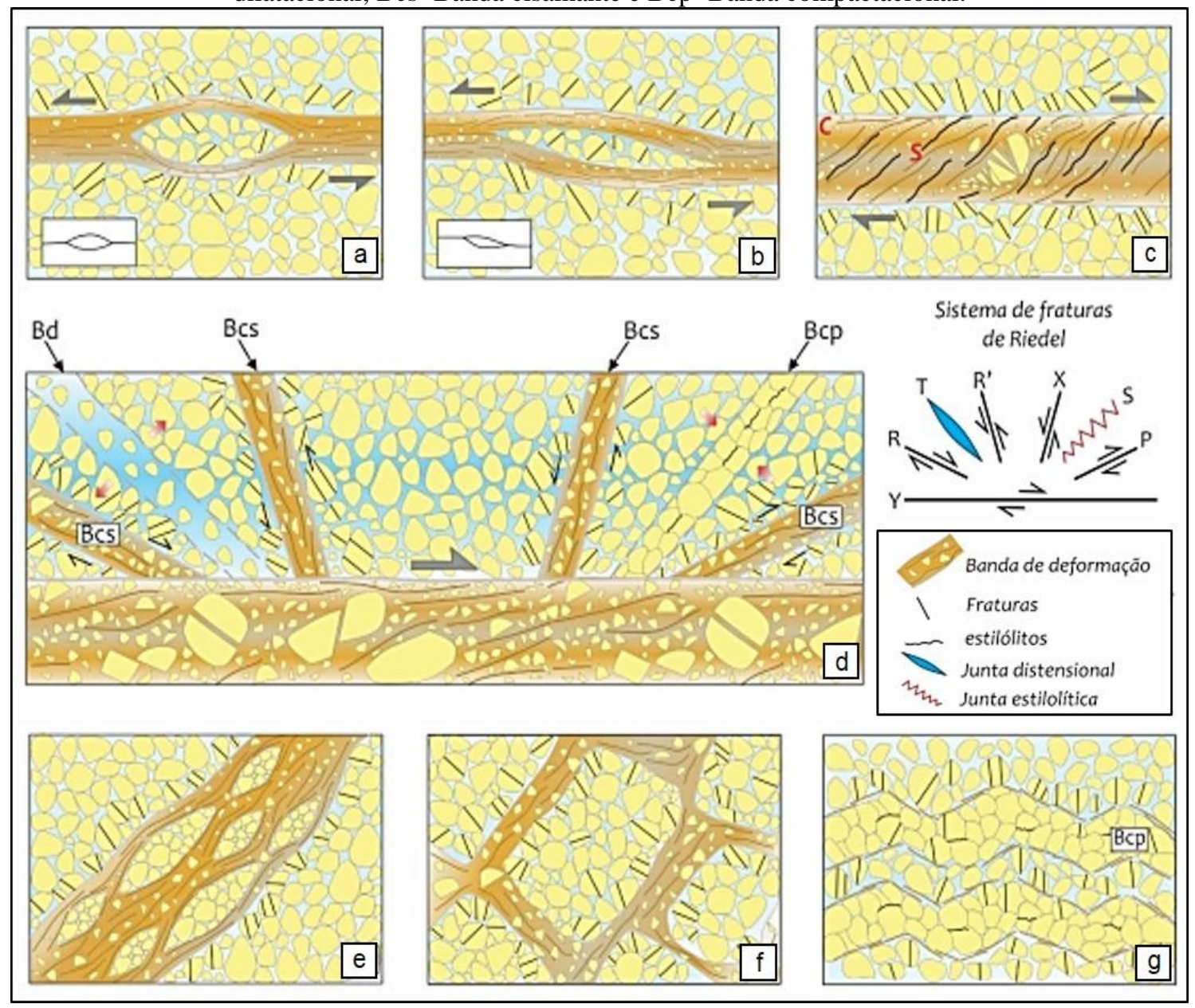

Fonte: Modificado de Rodrigues (2018).

A compreensão das interações entre a diagênese e a evolução estrutural também tem grande importância (BUSCH et al., 2017), principalmente no que se refere à migração e injeção de fluidos em subsuperfície para a explotação de hidrocarbonetos em reservatórios nãoconvencionais (LAUBACH et al., 2010). Isso porque, variações nos fatores termodinâmicos em condições diagenéticas $\left(<200^{\circ} \mathrm{C} \mathrm{e}<5 \mathrm{~km}\right)$ produzem reações químicas que interferem nos 
processos mecânicos de compactação, deslizamento, fricção e fraturamento de grãos. Estas interações podem produzir cimento durante a nucleação e evolução das bandas de deformação, impactando assim nas suas condições permoporosas.

Dentro desse contexto, a diagênese estrutural trata do estudo das modificações químicas em sedimentos ou rochas sedimentares associadas à deformação e às estruturas deformacionais (LAUBACH et al., 2010). O estudo das bandas de deformação se insere nesse campo, visto que elas ocorrem em condições crustais rasas. Estão associados a esse tipo de estrutura, reações químicas como dissolução e cimentação de minerais. Mesmo nas bandas cataclásticas/ cisalhantes ou filossilicáticas é possível haver algum tipo de dissolução e precipitação.

O processo de transformação e/ou neoformação mineralógica pode condicionar modificações geomecânicas na rocha, controlando o desenvolvimento de falhas e influenciando nas suas propriedades petrofísicas. Embora alguns trabalhos tenham analisado as variações dessas propriedades nas bandas de deformação (PONTES et al., 2019; KAMINSKAITE et al., 2019), não há estudos sistemáticos sobre a variação na estrutura de porosidade, incluindo macro e microporos formados nessas feições.

\subsection{Impacto na dinâmica de fluidos}

Quanto à influência das bandas de deformação no fluxo de fluidos, discute-se muito na literatura o seu potencial de trapeamento (ANTONELLINI \& AYDIN, 1995; FOSSEN \& BALE, 2007; TORABI \& ALIKARAMI, 2012; TINDALL, 2014; LOMMATZSCH et al., 2015; BALLAS et al., 2015), principalmente relacionado às bandas de cisalhamento com ou sem um componente compactacional. Esse impacto depende, em geral, da quantidade de catáclase envolvida que gera uma rocha mais rígida, compacta e com redução de porosidade e permeabilidade de várias ordens de magnitude (BALLAS et al., 2015) (figura 3.4).

Dentre os fatores que podem favorecer o comportamento das bandas como barreira à migração de fluidos, estão: continuidade lateral, espessura, orientação, tipo e conectividade (FOSSEN et al., 2007; FOSSEN et al., 2017; RODRIGUES, 2018). Contudo, apesar das variações dos parâmetros supracitados, essas estruturas ainda podem apresentar pontos de vazamento, não tendo efeito significativo de vedação (FOSSEN et al., 2017). A redução da porosidade e permeabilidade ocorre devido à compactação perpendicular às paredes da banda e ao cisalhamento paralelo às mesmas. Inclusive, ainda pode ocorrer uma cimentação póstectônica de minerais devido às superfícies frescas criadas durante o fraturamento de grãos (PHILIT et al., 2015), resultando em modificações na resistência da rocha. 
Figura 3.4 - Variação da porosidade e permeabilidade nas bandas de deformação, conforme a intensidade de cataclase. SECB = banda de compactação reforçada por cisalhamento.

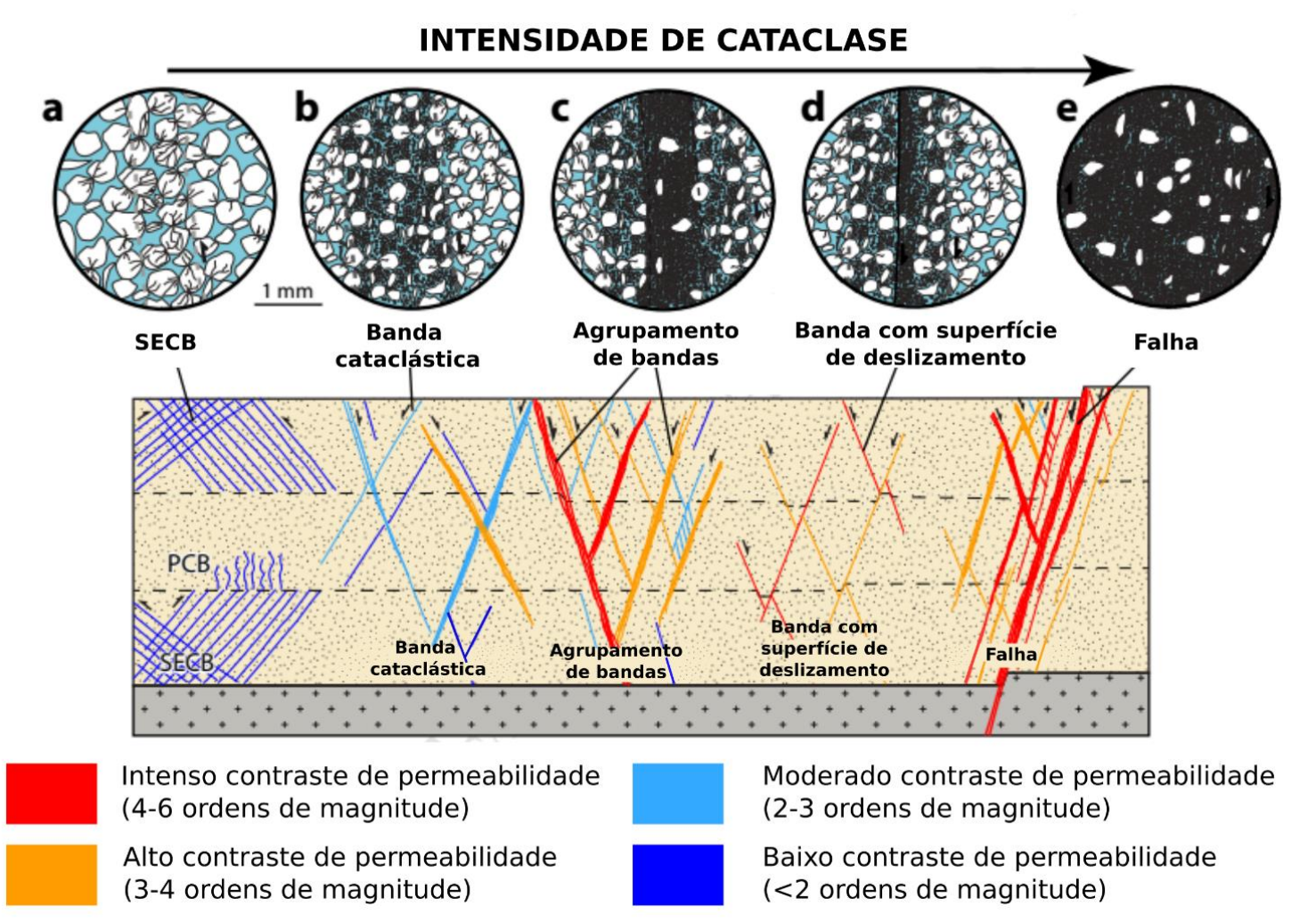

Fonte: Modificado de Ballas et al. (2015). 


\section{RESSONÂNCIA MAGNÉTICA NUCLEAR}

Em 1946, Edward Purcell e Felix Bloch publicaram os primeiros trabalhos sobre o fenômeno da ressonância magnética nuclear (RMN). Neles foram apresentados estudos sobre a indução nuclear e como determinados núcleos, sob a influência de um campo magnético, são capazes de absorver energia de radiofrequência e gerar um sinal proporcional que pode ser mensurado (PURCELL et al., 1946; BLOCH et al., 1946; BLOCH, 1946). Na década de 1950, essa técnica começou a ser empregada na exploração de petróleo em ferramentas de perfilagem, utilizando o campo magnético da Terra $\left(\sim 5 \times 10^{-5} \mathrm{~T}\right)$, ocorrendo na década 1990 a aplicação de ferramentas mais sofisticadas capazes de induzir campo maiores. Estudos de RMN aplicados à petrofísica, em geral, são realizados em meios saturados com um fluido que pode ser água doce, salobra ou hidrocarbonetos. A partir do sinal de RMN é possível obter informações não apenas sobre os fluidos saturantes nas rochas, mas também as distribuições de tamanho de poro (DUNN et al., 2002). Os conceitos abordados a seguir consistem em um compilado de informações obtidas a partir das publicações de Kleinberg et al. (1994), Kenyon (1997), Coates et al. (1999), Dunn et al. (2002), Song (2003), Kenyon (1997), Souza (2012), Schön (2015), Silva (2014), Oliveira (2015) e Jácomo (2018).

\subsection{Conceitos básicos}

Ressonância Magnética Nuclear consiste na resposta de núcleos atômicos a um campo magnético externo. Este fenômeno pode ser explorado para análises não destrutivas de fluidos que contém elementos cujo núcleo possui um número ímpar de prótons e/ou nêutrons. Sua aplicação depende do magnetismo nuclear expresso pelo momento magnético $(\mu)$, associado ao momento angular (L), constituindo um par de grandezas vetoriais coaxiais presentes em alguns núcleos atômicos. O momento angular é definido pelo spin nuclear (I) e a constante reduzida

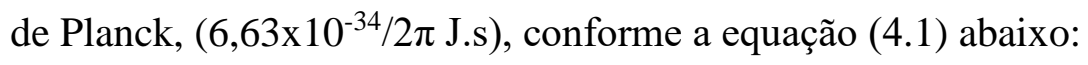

$$
\vec{\mu}=\gamma \vec{L}=\gamma \hbar \vec{I}
$$

Onde $\gamma$ é uma constante intrínseca do núcleo, denominada razão giromagnética, definida pela razão entre as magnitudes do momento magnético e do momento angular, correspondendo à medida da força do magnetismo nuclear.

O momento de spin possui autovalores que podem ser nulos, inteiros ou semi-inteiros a depender do número atômico (Z) e da massa (A) dos núcleos (figura 4.1): 
Figura 4.1 - Quadro com as regras para determinação do tipo de spin.

\begin{tabular}{|c|c|c|c|c|c|}
\hline $\begin{array}{c}\mathbf{N}^{\circ} \text { prótons } \\
(\mathrm{Z})\end{array}$ & $\mathbf{N}^{\circ}$ neutrôns & Massa (A) & \multicolumn{2}{|c|}{ Spin nuclear (I) } & Exemplos $\left({ }^{A} \mathbf{E}_{z}\right)$ \\
\hline \multirow{4}{*}{ Par } & Par & Par & Nulo & $\mathrm{I}=0$ & ${ }^{12} \mathrm{C}_{6},{ }^{16} \mathrm{O}_{8}$ \\
\hline & \multirow{3}{*}{ Ímpar } & \multirow{3}{*}{ Ímpar } & & $\mathrm{I}=1 / 2$ & ${ }^{1} \mathrm{H},{ }^{13} \mathrm{C}_{6}$ \\
\hline & & & & $I=3 / 2$ & ${ }^{33} \mathrm{~S}_{6}$ \\
\hline & & & $\begin{array}{l}\text { Semi- } \\
\text { inteiro }\end{array}$ & $I=5 / 2$ & ${ }^{17} \mathrm{O}_{8},{ }^{27} \mathrm{Al}_{2}$ \\
\hline \multirow{3}{*}{ Ímpar } & \multirow{2}{*}{ Par } & \multirow{2}{*}{ Ímpar } & & $\mathrm{I}=1 / 2$ & ${ }^{19} \mathrm{~F}_{9}$ \\
\hline & & & & $\mathrm{I}=3 / 2$ & ${ }^{11} \mathrm{~B}_{5},{ }^{23} \mathrm{Na}_{11}$ \\
\hline & Ímpar & Par & Inteiro & $\mathrm{I}=1$ & ${ }^{2} \mathrm{H}_{1},{ }^{14} \mathrm{~N}_{7}$ \\
\hline
\end{tabular}

Em rochas-reservatório, o núcleo de hidrogênio apresenta um sinal de RMN mais fácil de ser mensurado. Isso é possível devido à sua abundância, na água e nos hidrocarbonetos, além da elevada razão giromagnética $\left(0.2675 \times 10^{9} \mathrm{~s}^{-1} \mathrm{~T}^{-1}\right)$, (figura 4.2).

Figura 4.2 - Quadro com as propriedades de RMN para espécies nucleares.

$\begin{array}{cccc}\text { Núcleo } & \text { Spin } & \begin{array}{c}\gamma / 2 \pi \mathbf{e m} \\ \mathbf{M H z} / \mathbf{T}\end{array} & \begin{array}{c}\text { Abundância natural } \\ (\mathbf{\%})\end{array} \\ { }^{1} \mathrm{H} & 1 / 2 & 42,58 & 99,98 \\ { }^{23} \mathrm{Na} & 3 / 2 & 11,26 & 100,00 \\ { }^{13} \mathrm{C} & 1 / 2 & 10,70 & 1,11 \\ { }^{17} \mathrm{O} & 5 / 2 & 5,77 & 0,037\end{array}$

Fonte: SCHON (2015).

Naturalmente, os eixos de spin associados aos átomos de hidrogênio estão aleatoriamente distribuídos, apresentando magnetização resultante nula. Para realizar uma medida de RMN é necessário alinhar esses eixos a um campo magnético externo constante $\left(\mathrm{B}_{0}\right)$, ou seja, polarizalos. Isso ocorre devido ao torque exercido por $\mathrm{B}_{0}$ e que faz o spin realizar um movimento de precessão na mesma direção que o campo aplicado (figura 4.3). 
Figura 4.3 - Representação vetorial do movimento de precessão do spin em torno do campo B0. $\omega 0=$ velocidade angular; $\theta=$ ângulo de deslocamento.

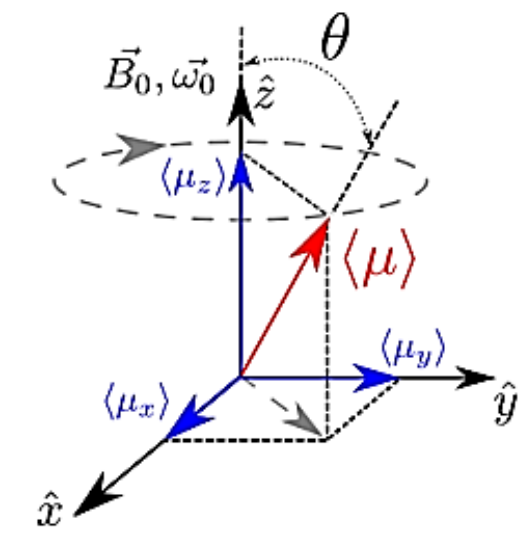

Fonte: OLIVEIRA (2015).

A frequência de precessão $\left(f_{L}\right)$, denominada frequência de Larmor, é definida pela equação (4.2):

$$
\mathrm{f}_{\mathrm{L}}=\gamma / 2 \pi * \mathrm{~B}_{0}
$$

Após a aplicação do campo $\mathrm{B}_{0}$, o alinhamento dos momentos magnéticos gera uma magnetização resultante paralela ao campo (figura 4.4a), denominada magnetização longitudinal ou magnetização de equilíbrio $\left(\mathrm{M}_{0}\right)$, e uma magnetização transversal $\left(\mathrm{M}_{\mathrm{x}, \mathrm{y}}\right)$ nula. Ao aplicar um campo secundário $\left(\mathrm{B}_{1}\right)$, oscilante na frequência de Larmor e perpendicular à direção de $\mathrm{B}_{0}$, os momentos magnéticos são deslocados para o plano transversal e passam a precessionar nesta direção. O deslocamento é induzido por um pulso de radiofrequência (RF) próximo à frequência de ressonância do próton (frequência de Larmor), cuja duração determina o quanto os prótons são inclinados em relação a $\mathrm{B}_{0}$ (figura $4.4 \mathrm{~b}$ ). Assim, a uma inclinação com ângulo de $90^{\circ}$ é identificado um sinal de ressonância magnética nuclear máximo.

Figura 4.4 - Magnetização resultante da orientação dos spins, paralelos à direção do campo externo $\mathrm{B}_{0}$ (a) e perpendicular (b), após a aplicação do pulso de radiofrequência.
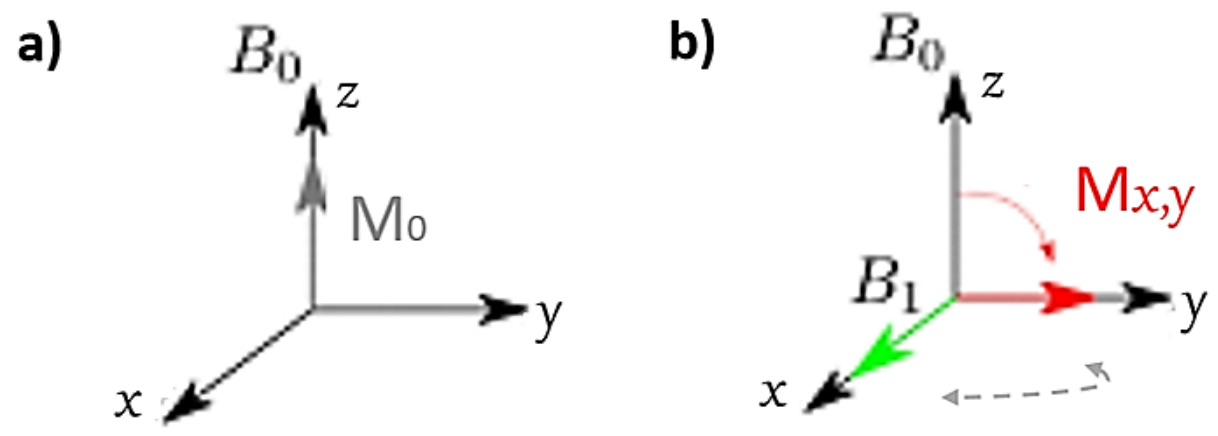

Fonte: Modificado de Silva (2014). 
Após a remoção do campo secundário $\left(\mathrm{B}_{1}\right)$, os núcleos começam a perder coerência de fase e a magnetização transversal tende a retornar a sua posição de equilíbrio anterior. Esse fenômeno é denominado relaxação e induz um fluxo magnético numa bobina posicionada perpendicularmente ao campo $\mathrm{B}_{0}$. Conforme a Lei de Faraday (lei de indução), a variação no fluxo magnético no interior da bobina, gera uma força eletromotriz possível de ser mensurada. Esse sinal consiste no decaimento exponencial denominado free induction decay (FID), cuja transformada de Fourier fornece o espectro de ressonância (figura 4.5), ou seja, a frequência na qual os núcleos precessionaram.

Figura 4.5 - Exemplo de um FID no domínio do tempo (a) e da frequência (b), observado para núcleos de

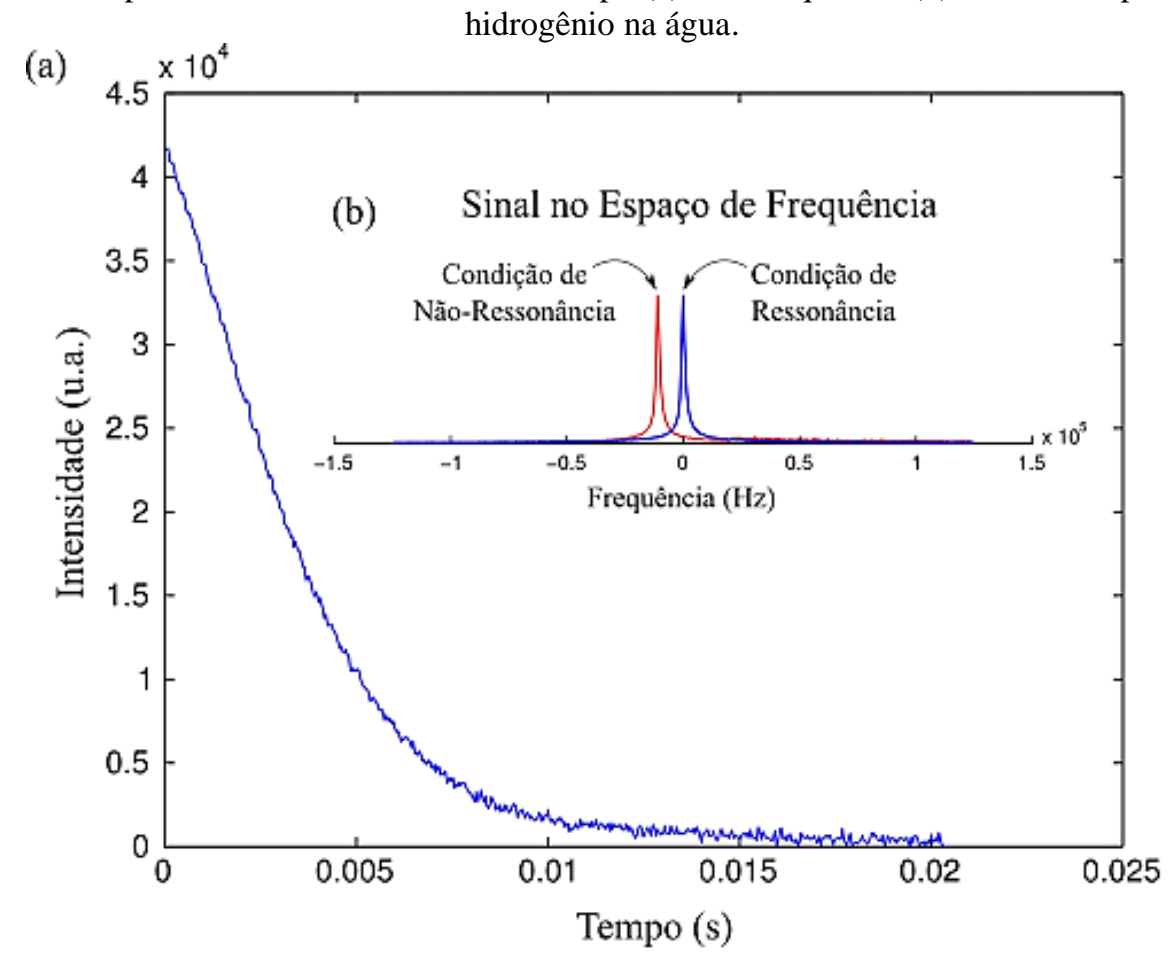

Fonte: Oliveira (2015).

O fenômeno de relaxação é descrito pelas equações (4.3 e 4.4), baseadas na evolução temporal da magnetização para o estado de equilíbrio após uma perturbação (pulso de RF). Essas equações descrevem as componentes da magnetização longitudinal e transversal, relacionadas ao campo externo $\left(B_{0}\right)$, cujo retorno à condição de equilíbrio depende exponencialmente dos tempos $\mathrm{T}_{1}$ (tempo de relaxação longitudinal) e $\mathrm{T}_{2}$ (tempo de relaxação transversal).

$$
\begin{aligned}
& M_{Z}(t)=M_{0}\left(1-e^{-t / T_{1}}\right) \\
& M_{X, Y}(t)=M 0_{X, Y}\left(e^{-t / T_{2}}\right)
\end{aligned}
$$


A relaxação longitudinal ocorre através da transferência de energia do conjunto de spins para o meio, devido à agitação térmica proveniente da dinâmica molecular, com o intuito de reestabelecer a condição de equilíbrio $\mathrm{M}_{\mathrm{z}}=\mathrm{M}_{0}$. Na relaxação transversal, a interação entre os spins resulta na mudança de velocidade angular e consequentemente de fase, gerando uma perda de coerência na orientação e fazendo com que a distribuição dos spins assuma orientações aleatórias, retornando ao estado de equilíbrio $M_{x}=M_{y}=0$. Uma vez que o sinal de RMN dos núcleos de hidrogênio é proporcional à população de átomos desse elemento na amostra, a taxa de relaxação do sinal também é proporcional à viscosidade do fluido.

\subsection{Aplicação no estudo de meios porosos}

A utilização da RMN é uma alternativa para estimar a porosidade em meios com estrutura porosa complexa. Essa técnica não necessita de modelagem geométrica dos poros, é aplicável a tamanhos de poros nanométricos a milimétricos, além de não ser influenciada pelos efeitos de percolação do fluido presente no meio. O sinal de RMN, de maneira geral, também independe da mineralogia da rochas, para os principais tipos analisados em formações produtoras, ao contrário das técnicas que se baseiam na emissão de raios gama e nêutrons, por exemplo. Porém, em rochas com quantidade significativa de minerais ferromagnéticos e/ou paramagnéticos, o sinal de RMN pode apresentar valores de $\mathrm{T}_{2}$ menores do que seria esperado na ausência desses minerais, resultando na subestimação da porosidade. Com isso, pode não haver mais correlação entre $\mathrm{T}_{2}$ e tamanho de poro. A seguir, alguns mecanismos que influenciam no sinal de RMN e devem ser considerados para a determinação da porosidade.

\subsubsection{Mecanismos de relaxação}

A relaxação da magnetização longitudinal e transversal é definida pelas equações (4.5 e 4.6), apresentando efeitos que influenciam no sinal e se superpõem na exponencial de decaimento.

$$
\begin{gathered}
1 / \mathrm{T}_{1}=1 / \mathrm{T}_{1} \text { Bulk }+1 / \mathrm{T}_{1} \text { Superficial } \\
1 / \mathrm{T}_{2}=1 / \mathrm{T}_{2} \text { Bulk }+1 / \mathrm{T}_{2} \text { Superficial }+1 / \mathrm{T}_{2} \text { Difusão }
\end{gathered}
$$

A relaxação bulk corresponde à relaxação intrínseca das moléculas que constituem o fluido, dependendo da viscosidade e temperatura. Para a água, esse termo é uma definição empírica dada pela equação (4.7):

$$
\mathrm{T}_{1 \text { Bulk }}=\mathrm{T}_{2 \text { Bulk }}=0,01007(\mathrm{~T} / \eta)
$$

onde $\mathrm{T}$ é a temperatura em Kelvin e $\eta$ é a viscosidade em Cp. 
A relaxação superficial é um efeito que ocorre na interface fluido-sólido e está relacionada à rapidez com a qual os núcleos perdem coerência de fase. Esse efeito é gerado pela presença de íons para- e/ou ferromagnéticos presentes na superfície dos poros, fazendo com que este mecanismo seja dominante no processo de relaxação. É definido pela equação (4.8):

$$
1 / \mathrm{T}_{2} \text { Superficial }=\rho_{2}(\mathrm{~S} / \mathrm{V})
$$

onde $\rho_{2}$ é a relaxatividade, capacidade da superfície de induzir a relaxação da magnetização associada ao núcleo, $\mathrm{S}$ é a superfície do poro e V o volume.

A relaxação associada à difusão resulta do movimento difusivo das moléculas do fluido na presença de um gradiente de campo magnético, provocando defasagem adicional na precessão dos spins, diminuindo os valores de $\mathrm{T}_{2}$. A fim de evitar esse efeito, utiliza-se campos magnéticos $\left(\mathrm{B}_{0}\right)$ mais baixos ou TEs mais curtos, uma vez que a intensidade dos gradientes, gerada pela diferença de susceptibilidade magnética entre a rocha e o fluido saturante, é diretamente proporcional ao campo. Esse mecanismo de relaxação é definido pela equação (4.9):

$$
1 / \mathrm{T}_{2 \text { Difusão }}=\mathrm{D} / 12(\gamma * \mathrm{G} * \mathrm{TE})^{2}
$$

onde $\mathrm{D}$ é o coeficiente de difusão do núcleo na água, $\gamma$ é a razão giromagnética, G é o gradiente de campo, TE é o tempo intereco da sequência CPMG. Para a água, o coeficiente de difusão é dado pela equação (4.10):

$$
\mathrm{D}_{\mathrm{w}}=1,2(\mathrm{~T} / 298 \eta) * 10^{-5}
$$

onde T é a temperatura em Kelvin e $\eta$ é a viscosidade em Cp.

Ao identificar o regime de difusão no qual a medida do sinal de relaxação é realizado, é possível correlacionar diretamente o valor de $\mathrm{T}_{2}$ apenas ao termo representado pela equação (4.7) e, consequentemente, ao tamanho dos poros. Isso é feito a partir da equação (4.11), de Brownstein \& Tarr (1979):

$$
\mathrm{k}=\rho_{2} \alpha / \mathrm{D}
$$

onde $\alpha$ é a distância que o próton pode se difundir em direção à superfície do grão, correspondendo à razão $\mathrm{S} / \mathrm{V}$. Ao considerar os poros esféricos, $\mathrm{S} / \mathrm{V}$ será equivalente a 3/R. Assim, para k $>10,1<\mathrm{k}<10$ e k $<<1$, o regime de difusão será lento, intermediário e rápido, respectivamente. Neste último, o núcleo pode percorrer uma maior distância no espaço poroso antes da relaxação, sendo possível correlacionar o $\mathrm{T}_{2}$ com a razão $\mathrm{S} / \mathrm{V}$. 


\subsection{Aquisição de dados}

\subsubsection{Tempo de relaxação transversal por Sequência CPMG}

$\mathrm{O}$ experimento mais comumente utilizado para a aquisição do tempo de relaxação transversal é a sequência CPMG (CARR \& PURCELL, 1954; MEIBOOM \& GILL, 1958) por meio da técnica de refocalização da magnetização, de maneira a minimizar o efeito da heterogeneidade do campo $\left(\mathrm{B}_{0}\right)$. Primeiramente é aplicado um pulso de $90^{\circ}$, aguardado um tempo intereco (TE), e então são realizadas sequências de pulsos de $180^{\circ}$ que invertem o efeito da perda de coerência dos spins devido à heterogeneidade de $\mathrm{B}_{0}$ (figura 4.6). Ou seja, a refocalização faz com que os núcleos que começaram a apresentar perda de fase (mais lentos) mudem a direção do momento magnético para uma posição à frente dos com precessão mais rápida e vice-versa. Isso resulta na recuperação da velocidade angular, revertendo a diminuição do sinal de magnetização. Com o tempo, há diminuição da amplitude do sinal obtido após cada um dos pulsos de $180^{\circ}$, denominado eco de spin ou eco de Hahn, gerando uma curva de decaimento exponencial. Isso ocorre porque, mesmo com a refocalização, há perda de coerência dos spins e diminuição da intensidade da magnetização devido às interações moleculares.

Figura 4.6 - Sequência de pulsos CPMG com os respectivos comportamentos do vetor de magnetização resultante.

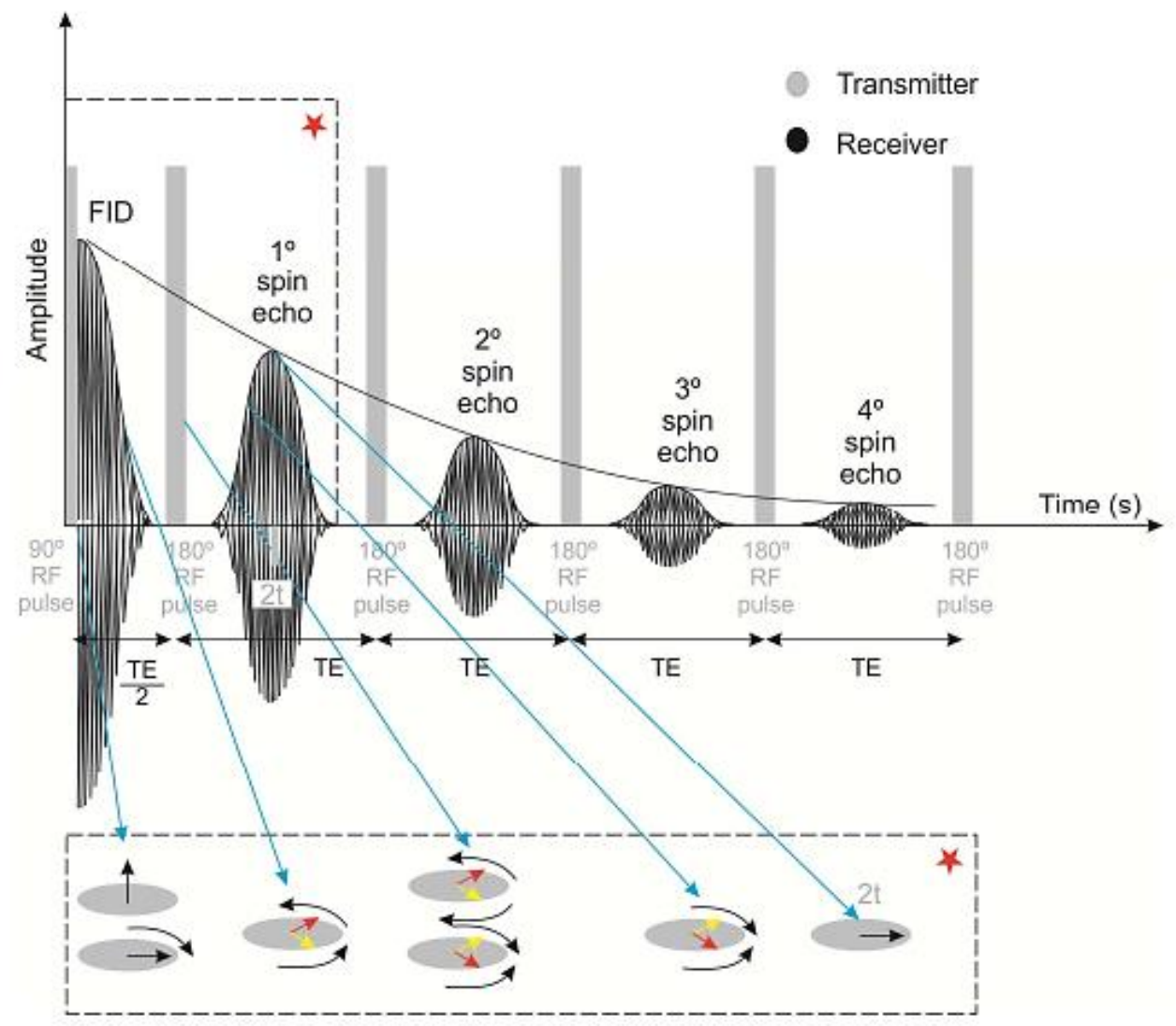

Fonte: Jácomo (2018). 
A partir da sequência CPMG, o sinal obtido pode ser visualizado em um gráfico exponencial de amplitude do sinal versus tempo. Ao aplicar a transformada inversa de Laplace é obtida uma distribuição de tempos de relaxação transversal, em que a posição do pico está relacionada ao tamanho do poro e a amplitude (área embaixo do pico) corresponde à quantidade de fluido naquele tamanho de poro (figura 4.7). O cálculo da área total, abaixo da curva de distribuição de $\mathrm{T}_{2}$, corresponde à porosidade da amostra, considerando o total preenchimento da amostra pelo fluido.

Figura 4.7 - Gráfico da distribuição de $\mathrm{T}_{2}$ gerado a partir da curva de decaimento exponencial da intensidade de magnetização, obtida pela sequência CPMG.

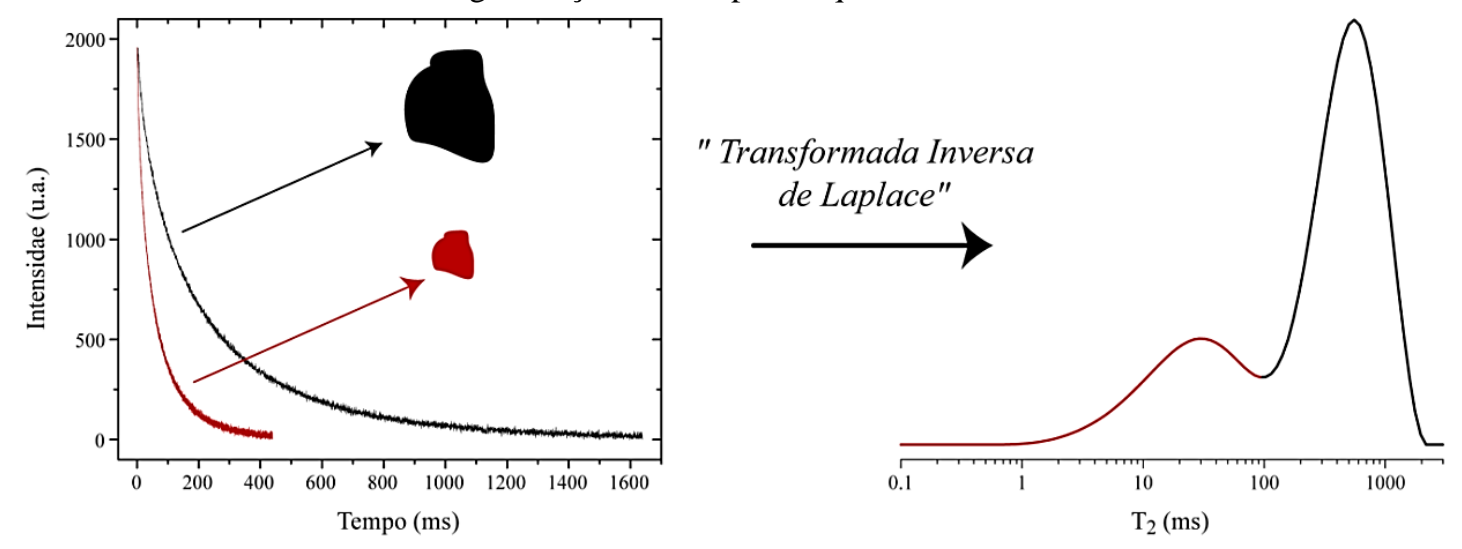

Fonte: Souza (2012).

Como esse tipo de experimento se baseia na magnetização dos núcleos de hidrogênio presentes no fluido saturante, também está sujeito aos efeitos de difusão decorrentes da presença de gradientes de campo magnético, e que podem resultar em um $\mathrm{T}_{2}$ mais curto. Além disso, impurezas magnéticas podem induzir gradientes internos nos poros e o sinal de relaxação nuclear e difusão nos meios porosos podem ser afetados significativamente, impedindo a correlação entre o tempo de relaxação transversal e o tamanho de poros. A aquisição de decaimentos por sequência CPMG com diferentes tempos entre ecos (TE) pode ser usada para determinar a magnitude da atenuação do sinal, pois quanto maior esse tempo, maior será o efeito da difusão molecular. 


\section{ANISOTROPIA DE SUSCEPTIBILIDADE MAGNÉTICA POR FERROFLUIDO (ASMFF)}

\subsection{Conceitos básicos}

Susceptibilidade magnética é a capacidade de um material ser magnetizado quando submetido a um campo magnético (DUNLOP \& OZDEMIR, 1997; BUTLER, 2004; TAUXE, 2008). Depende da composição química dos minerais magnéticos, concentração, tamanho de grão e características microestruturais. Considerando um material homogêneo e isotrópico, essa propriedade pode ser definida pela equação (5.1):

$$
\mathrm{M}=\chi \mathrm{H}
$$

Onde $\mathrm{M}$ é a magnetização induzida ou o momento magnético por unidade de volume $(\mathrm{A} / \mathrm{m}), \chi$ é susceptibilidade magnética (adimensional) e H é o campo magnético $(\mathrm{A} / \mathrm{m})$.

Em materiais anisotrópicos, como é o caso das amostras estudadas neste trabalho, a orientação e intensidade da magnetização varia de acordo com o campo indutor. Como a ASM é representada por uma matriz simétrica de segunda ordem, para uma determinada direção de $\mathrm{H}$, existirão três componentes ortogonais de $\mathrm{M}$, conforme as equações (5.2) abaixo:

$$
\begin{aligned}
& M_{1}=k_{11} H_{1}+k_{12} H_{2}+k_{13} H_{3} \\
& M_{2}=k_{21} H_{1}+k_{22} H_{2}+k_{23} H_{3} \quad \text { ou } \quad M_{i}=k_{i j} H_{j} \\
& M_{3}=k_{31} H_{1}+k_{32} H_{2}+k_{33} H_{3}
\end{aligned}
$$

$\mathrm{Na}$ diagonal principal temos os eixos $\mathrm{k}_{11} \geq \mathrm{k}_{22} \geq \mathrm{k}_{33}$ também escritos como $\mathrm{k}_{1} \geq \mathrm{k}_{2} \geq \mathrm{k}_{3}$ ou $k_{\max } \geq k_{\text {int }} \geq k_{\min }$, representando os eixos principais de susceptibilidade magnética do material, correspondendo ao valores máximo, intermediário e mínimo, respectivamente. A partir desses dados são determinados os seguintes parâmetros (JELINEK, 1981):

- Magnitude da lineação magnética $\left(\mathrm{k}_{1}\right)$ e da foliação magnética (plano perpendicular a $\mathrm{k}_{1}$ ) (figura 5.1);

Figura 5.1 - (a) Representação tridimensional do elipsoide magnético e (b) seus respectivos eixos de susceptibilidade magnética plotados em estereograma.
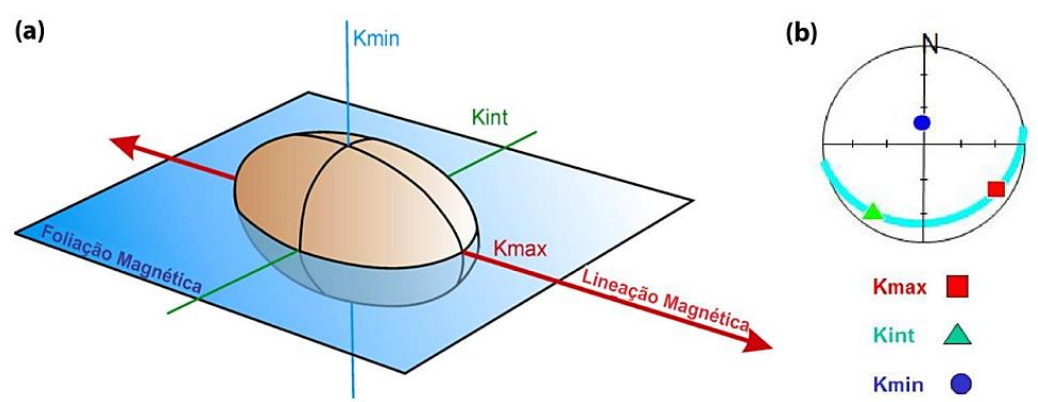

Fonte: Modificado de Hrouda (2014). 
- Susceptibilidade média $\left(\mathrm{K}_{\mathrm{m}}\right)$, definida por:

$$
\mathrm{K}_{\mathrm{m}}=\left(\mathrm{k}_{1}+\mathrm{k}_{2}+\mathrm{k}_{3}\right) / 3
$$

- Grau de anisotropia magnética (P) em que a excentricidade do elipsoide de susceptibilidade magnética gerado pelo três eixos é dada por:

$$
\mathrm{P}=\mathrm{k}_{1} / \mathrm{k}_{3}
$$

- Parâmetro de forma do elipsoide (T), dado por:

$$
T=\left[\left(2\left(\ln k_{2}-\ln k_{3}\right)\right) /\left(\ln k_{1}-\ln k_{3}\right)\right]-1
$$

Assim, para $0<\mathrm{T}<1$, a forma será oblata; para $-1<\mathrm{T}<0$, a forma será prolata; e para $\mathrm{T}=0$, o elipsóide será triaxial (figura 5.2).

Figura 5.2 - Representação tridimensional do elipsoide magnético para os diferentes parâmetros de forma e grau de anisotropia, com os seus respectivos eixos principais de susceptibilidade magnética.

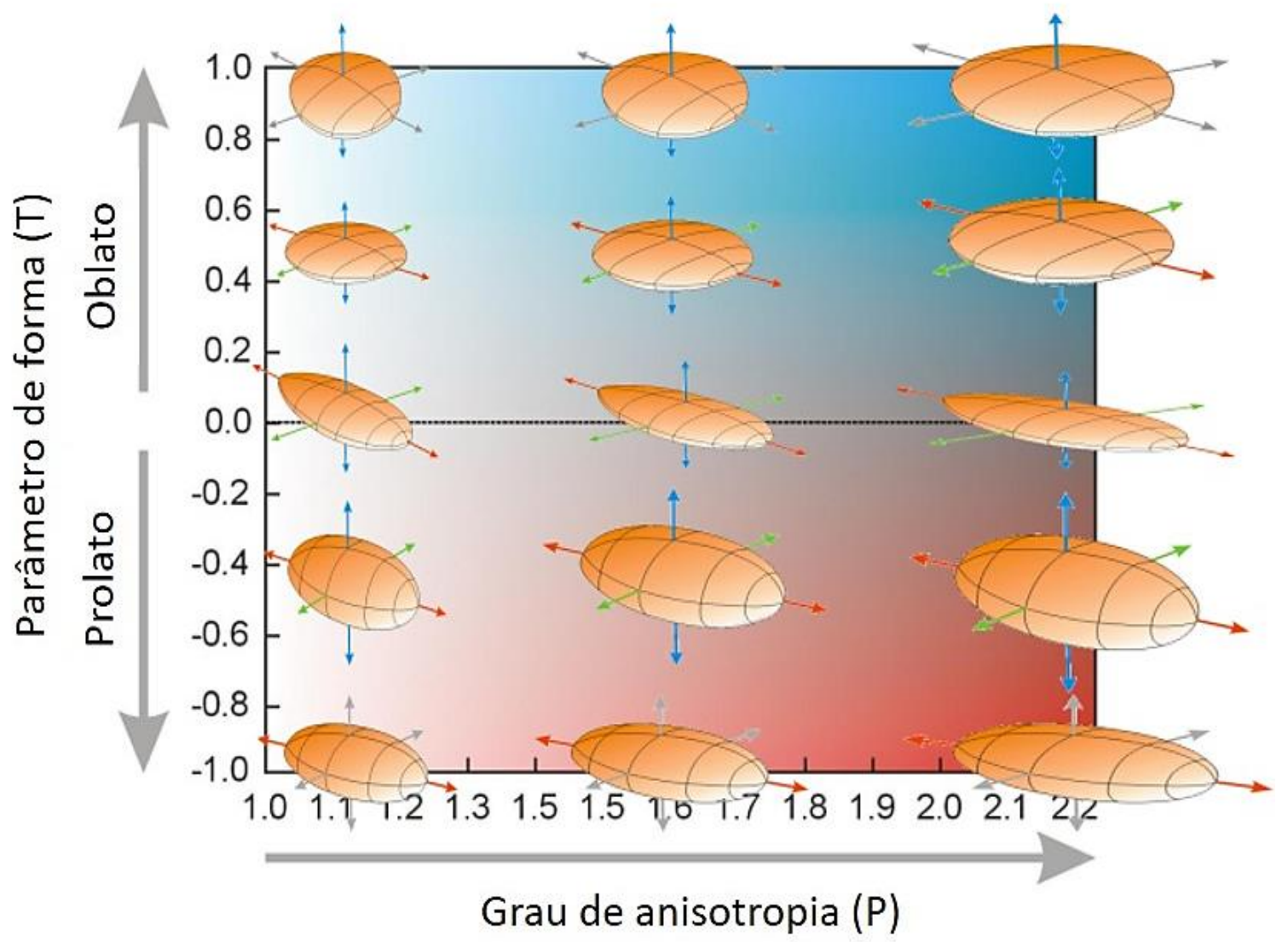

Fonte: Nédélec \& Bouchez (2015).

Dois tipos principais de anisotropia magnética nos minerais influenciam neste tipo de medição. A anisotropia magnetocristalina resulta da facilidade de magnetização ao longo de determinados eixos cristalográficos em decorrência da distribuição de íons ferromagnéticos (como $\mathrm{Fe}^{2+} \mathrm{e} \mathrm{Fe}^{3+}$ ) na rede cristalina do mineral, a exemplo da hematita e da biotita. A 
anisotropia magnetostática ou de forma, é gerada por eixos ao longo dos quais estão as direções de magnetização espontânea do cristal. A magnetita tem esse efeito sobreposto à anisotropia magnetocristalina devido à sua maior magnetização espontânea.

A partir da ASM é possível determinar a orientação de grãos ferromagnéticos e, consequentemente, a direção de paleocorrentes, fluxo de lavas, feições resultantes de eventos deformacionais, disposição de corpos intrusivos, dentre outras aplicações. Isso ocorre porque esse tipo de medição depende da anisotropia individual dos grãos e do seu alinhamento (BORRADAILE \& JACKSON, 2010).

\subsection{ASMff aplicada a estudos petrofísicos}

A determinação das propriedades direcionais é indispensável para a melhor compreensão da dinâmica de fluidos, pois a orientação preferencial dos eixos longos dos poros gera um forte controle na direção da permeabilidade máxima (PARÉS et al., 2016). Rochas sedimentares com preservação da estrutura porosa primária, tendem a condicionar o fluxo de fluidos na direção do plano de deposição. Contudo, devido à heterogeneidade intrínseca da rocha em diferentes escalas, variabilidade e complexidade de microestruturas, a orientação preferencial primária dos grãos pode não ser o único fator influenciador na direção de fluxo dessas rochas (ROBION et al., 2014). A medição de anisotropia magnética em amostras impregnadas com ferrofluido é uma maneira promissora e rápida de caracterizar o arranjo tridimensional da fábrica porosa. Além disso, também possibilita determinar a porosidade relacionada aos poros com tamanhos menores do que $10 \mathrm{~nm}$, sem a necessidade de conhecimento prévio sobre a orientação dos mesmos (BIEDERMANN, 2019).

Nas rochas siliciclásticas, em geral os argilominerais e óxidos de ferro dominam a anisotropia de susceptibilidade magnética e a fábrica porosa é delineada por processos deposicionais seguidos pela compactação. Quando há presença de microfissuras, a influência destas passa despercebida, pois é obliterada pela susceptibilidade dos minerais para- e ferromagnéticos presentes na rocha. Dessa maneira há a necessidade de preencher os poros com um material cuja susceptibilidade magnética se sobreponha à influência dos constituintes primários, fazendo com que os dados de ASM reproduzam a orientação do preenchimento (figura 5.3). 
Figura 5.3 - a) Elipsoide de anisotropia magnética resultante apenas da influência dos grãos magnéticos alinhados de acordo com o plano de deposição. b) Elipsoide cuja orientação dos eixos máximo e mínimo correspondem à direção das microfissuras, transversais ao plano de deposição, devido ao preenchimento com ferrofluido.
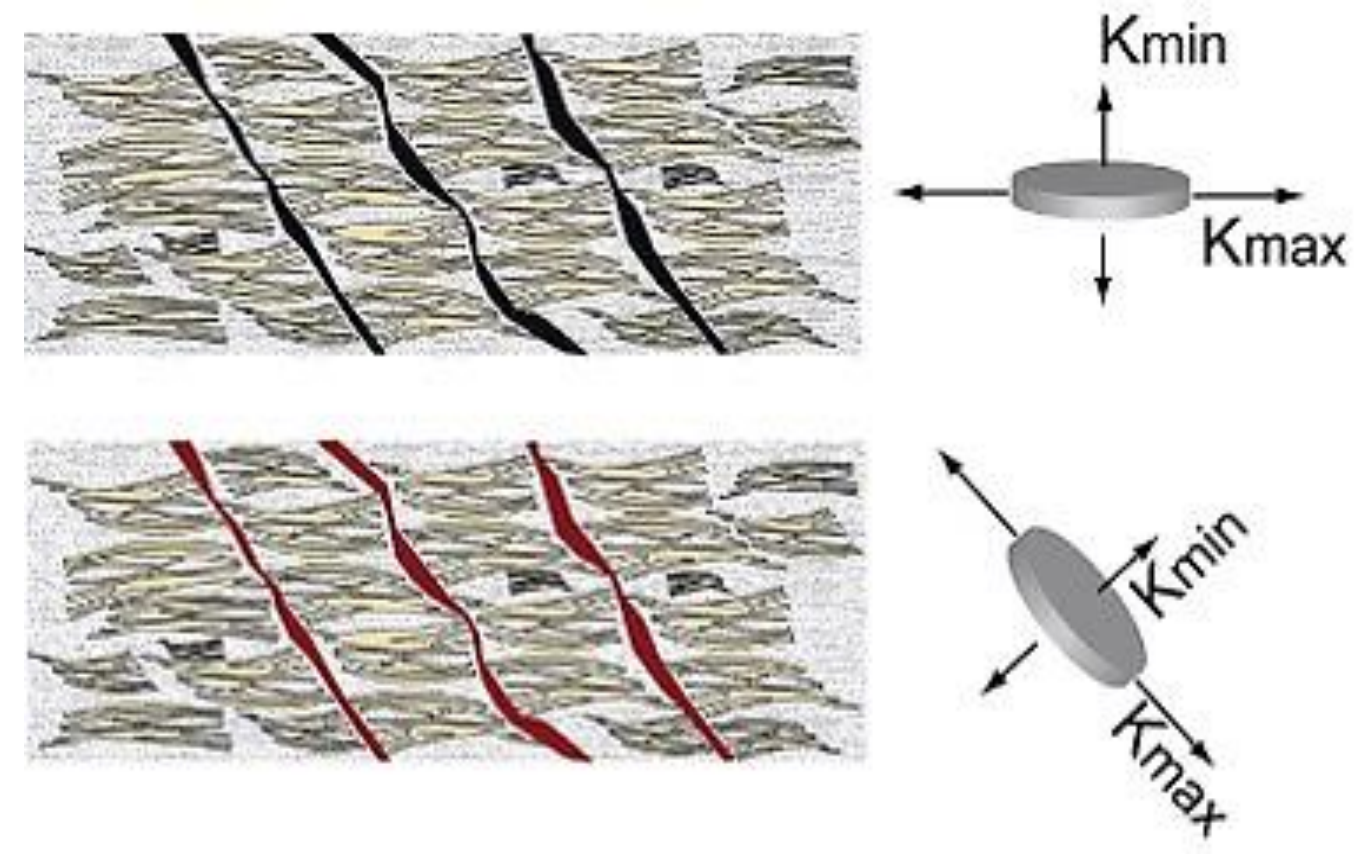

Fonte: Parés et al. (2016).

A aplicação da ASMff considera o total preenchimento dos poros interconectados, de maneira homogênea. Isso resulta em um grande contraste de susceptibilidade entre o ferrofluido e a rocha, de modo que o sinal referente aos poros preenchidos passa a ser algumas ordens de magnitude superior ao sinal dos minerais que constituem a matriz da rocha (PFLEIDERER \& HALLS, 1990; HROUDA et al., 2000).

O ferrofluido é uma suspensão constituída por nanopartículas coloidais de magnetita superparamagnéticas (NPMag)com diâmetro na escala de alguns nanometros (figura 5.4). Esse material é sintetizado pelo processo de decomposição térmica que garante um bom controle do tamanho e forma das partículas (EFFENBERGER et al., 2016). Ao final do processo as NPMag ficam dispersas em solventes orgânicos. Na literatura, diversos trabalhos indicam que os melhores resultados apresentados por amostras impregnadas com ferrofluido são obtidos com misturas à base de óleo, em comparação com as misturas à base de água (e.g. PFLEIDERER \& HALLS, 1990; HROUDA et al., 2000; BENSON et al., 2003; ROBION et al., 2014). 
Figura 5.4 - Distribuição de tamanho das partículas de magnetita esféricas, sintetizada por decomposição térmica.

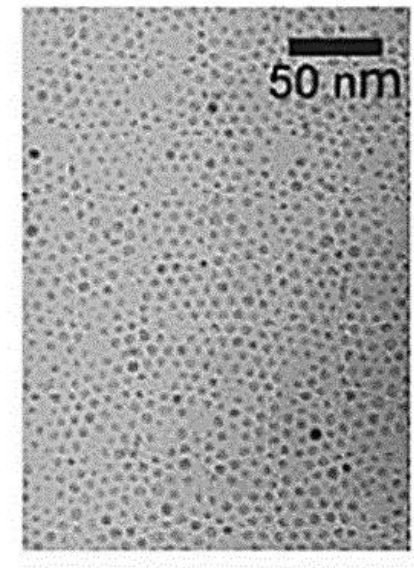

Fonte: Effenberger et al. (2016).

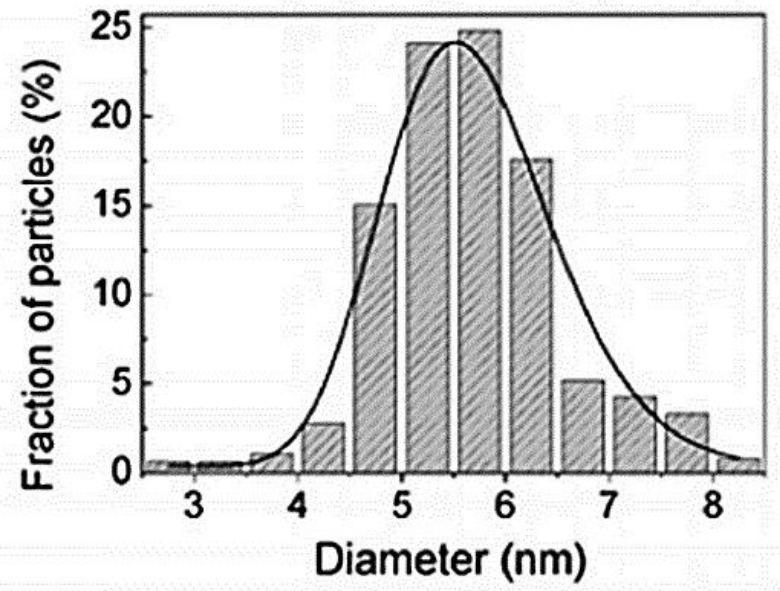

As duas principais limitações do método envolvem o tamanho das partículas NPMag e a quantidade de minerais magnéticos na amostra original. No primeiro caso, quanto maior o tamanho das NPMag, mais difícil será de acessarem os poros menores, resultando em descontinuidades que podem causar distorções na forma do espaço poroso e, consequentemente, nos eixos principais de anisotropia (ROBION et al., 2014). Além disso, é importante que a solução na qual as partículas ficam dispersas, apresente baixa viscosidade, principalmente se as amostras possuem baixa permeabilidade (ARONCHI, 2017). No segundo caso, grãos magnéticos presentes na matriz da rocha podem interagir com as partículas do ferrofluido e ocasionar a formação de concentrações de partículas magnéticas que não estão necessariamente associados à fábrica porosa, podendo dificultar a interpretação dos dados de ASMff. 


\section{MÉTODOS}

\subsection{Levantamento estrutural e amostragem}

O levantamento estrutural foi realizado por meio de observações e medidas de campo das estruturas deformacionais, em escala de afloramento, seguindo linhas de varredura (scanlines). Esta abordagem permitiu a investigação da disposição espacial das bandas de deformação, fornecendo, de maneira mais precisa, informações sobre a geometria (forma e espessura), cinemática, frequência e espaçamento destas estruturas (ORTEGA et al, 2006). As scanlines também serviram como guias para a coleta sistemática das amostras para petrofísica e microscopia. Foram amostrados blocos de rocha com variação na quantidade de bandas, da rocha indeformada ou pouco deformada até a banda, para que fosse possível verificar as modificações petrofísicas da rocha hospedeira para a estrutura em questão. No afloramento da Falha do Macaco (Grupo Ilhas), foram definidas oito scanlines, transversais à orientação da estrutura principal (N-S), e foram coletadas quinze amostras. No afloramento da Falha de Caritá (Grupo Massacará), foram delimitadas cinco scanlines, sendo uma com orientação paralela (NW-SE) e as outras transversais (NE-SW) à estrutura principal, e coletadas oito amostras. Os dados estruturais obtidos foram tratados no software de projeção esférica Orient versão 3.12.0.

\subsection{Análise petrográfica}

A microscopia óptica e microfluorescência de Raios X foram realizadas em lâminas petrográficas, correspondentes aos cilindros escolhidos para os estudos petrofísicos. As seções delgadas foram previamente impregnadas com resina Epoxy azul pelo processo de gotejamento em equipamento a vácuo. No microscópio eletrônico de varredura também foram analisados fragmentos das mesmas amostras, porém sem a resina. No caso das bandas, as lâminas foram confeccionadas a partir de cortes paralelos e transversais à estrutura.

\subsubsection{Microscopia óptica com luz transmitida}

Permitiu determinar os constituintes do arcabouço da rocha e minerais presentes na superfície dos grãos, como argilas e películas de óxido de ferro. A presença desses minerais influencia no efeito do gradiente de campo magnético interno (KEATING \& KNIGHT, 2007) utilizado para obter o tamanho dos poros e, consequentemente, na interpretação dos dados de ressonância magnética. A partir da descrição petrográfica foram interpretados os processos diagenéticos e deformacionais, possibilitando uma caracterização mais precisa dos fatores influenciadores da permoporosidade da rocha. A análise quantitativa foi realizada no Laboratório de Petrografia Sedimentar (LabPetro), no Instituto de Geociências - USP, por meio 
da contagem modal de 400 pontos em 18 seções delgadas das bandas de deformação e da rocha hospedeira. Foi escolhido esse número de pontos a fim de minimizar as heterogeneidades da lâmina petrográfica em decorrência da presença das bandas e eventual concentração de minerais. Os dados foram utilizados para a classificação da rocha de acordo com Folk (1974). O tamanho médio dos poros foi determinado em fotomicrografias das lâminas com o auxílio do software Pergeos (Thermo Fisher Scientific Logo), utilizando o método de segmentação de imagens denominado watershed.

\subsubsection{Microscopia Eletrônica de Varredura}

Possibilitou a verificação de características diagenéticas e microestruturais não visualizadas por meio da microscopia óptica. Foram geradas imagens da morfologia das amostras e observados tamanhos de grãos e poros, além das relações intergranulares que envolvem deformações em escala de grão individual, cimento e argila revestindo os poros. A Espectroscopia por Energia Dispersiva (EDS) foi utilizada para determinar a composição química pontual de crescimentos secundários de minerais e coberturas de grãos. O equipamento utilizado foi o microscópio eletrônico EVO® MA15 da ZEISS, no UNESPetro, vinculado ao Instituto de Geociências da UNESP.

\subsubsection{Microfluorescência de Raios X}

A microfluorescência de Raios $X(\mu \mathrm{FRX})$ viabilizou a investigação qualitativa e quantitativa da composição das amostras. Foi utilizada para verificar a variação da composição química da porção indeformada da rocha para a banda de deformação. As análises foram realizadas também no UNESPetro, utilizando um M4 TORNADO (BRUKER). Neste equipamento, as amostras são inseridas em uma câmara e bombardeadas com Raios X emitidos por um tubo de Ródio. Quando um feixe de Raios X atinge os átomos, ocorre a transição de elétrons entre os orbitais. Isso faz com que emitam energia correspondente à assinatura dos elementos químicos, sob a forma de Raios X que são detectados por um receptor.

\subsection{Caracterização da mineralogia magnética}

Minerais paramagnéticos e ferromagnéticos, principalmente quando ocupam a superfície do poro, podem causar variações nos tempos de relaxação, resultando em uma subestimação do tamanho do poro e valores de porosidade na análises de RMN (KEATING \& KNIGHT, 2007; SAIDIAN \& PRASAD, 2015; JÁCOMO et al., 2018). 


\subsubsection{Susceptibilidade magnética (SM) e Anisotropia de Susceptibilidade Magnética (ASM)}

Nesta etapa foram utilizados cilindros de amostras orientadas com 2,5 cm de diâmetro por 2,0 a 2,2 cm de altura. Todas as medidas foram realizadas no Laboratório de Paleomagnetismo da Universidade de São Paulo (USPmag) utilizando o Susceptômetro Kappabridge MFK1- FA (AGICO), operando a temperatura ambiente em campo AC de 200 $\mathrm{A} / \mathrm{m}$ e frequência de $976 \mathrm{~Hz}$

Os dados de ASMff foram obtidos por meio do seguinte procedimento, baseado em Pfleiderer \& Halls (1990), Robion et al. (2014) e Parés et al. (2016):

1. Secagem dos cilindros em estufa a $60^{\circ} \mathrm{C}$ por 12 horas;

2. Medição da massa das amostras secas;

3. Medição da ASM;

4. Saturação com água destilada;

5. Medição da massa da amostra saturada com água;

6. Secagem dos cilindros em estufa a $60^{\circ} \mathrm{C}$ por 12 horas;

7. Inserção das amostras em dessecador sob vácuo de $80 \mathrm{kPa}$ por 5 horas;

8. Introdução do ferrofluido nas amostras por embebição;

9. Medição da massa das amostras impregnadas com ferrofluido;

10. Medição da ASMff;

O ferrofluido foi disponibilizado pelo Laboratório de Nanomateriais e Catálise do Instituto de Química da USP. O material coloidal fornecido consiste em NPmag com tamanho médio de $5.6 \mathrm{~nm}$, dispersas em tolueno a uma concentração de $1 \%$.

O processo de aquisição dos dados de anisotropia de susceptibilidade magnética consistiu na leitura dos três eixos, ortogonais entre si, e na determinação da susceptibilidade média por meio da rotação automática da amostra inserida no holder do equipamento. As correções para a posição original das amostras em relação ao norte geográfico foram realizadas com base na orientação obtida em campo. Os dados foram normalizados de acordo com Jelinek (1977) e processados no software ANISOFT 5.1.03 (CHADIMA \& JELINEK, 2019), no qual foram gerados uma média para cada eixo principal e os parâmetros de anisotropia magnética.

\subsubsection{Histerese}

O comportamento dos minerais magnéticos pode ser identificado pela forma das curvas de histerese (figura 6.1), definidas pelos seguintes parâmetros: magnetização de saturação (Ms), magnetização remanente de saturação (Mrs), coercividade ou campo coercivo (Hc) e coercividade de remanência (Hcr). Estes parâmetros são obtidos com a aplicação de um campo 
magnético crescente que alinha os momentos magnéticos até atingir o valor máximo de magnetização (Ms). Com os momentos totalmente alinhados e a diminuição do campo a zero, a curva pode retornar à origem (materiais diamagnéticos e paramagnéticos) ou não (materiais ferromagnéticos). Caso isso não ocorra, os momentos ainda conservarão parte do alinhamento o que resulta em um valor de magnetização residual ou remanente (Mrs). Para a magnetização retornar a zero, é aplicado um campo em sentido oposto (Hc), sendo (Hcr) o campo em que a magnetização remanente da amostra será nula (DUNLOP \& OZDEMIR, 1997; BUTLER, 2004; TAUXE, 2008).

Figura 6.1 - Comportamento da curva de histerese com base no alinhamento dos spins das partículas magnéticas.

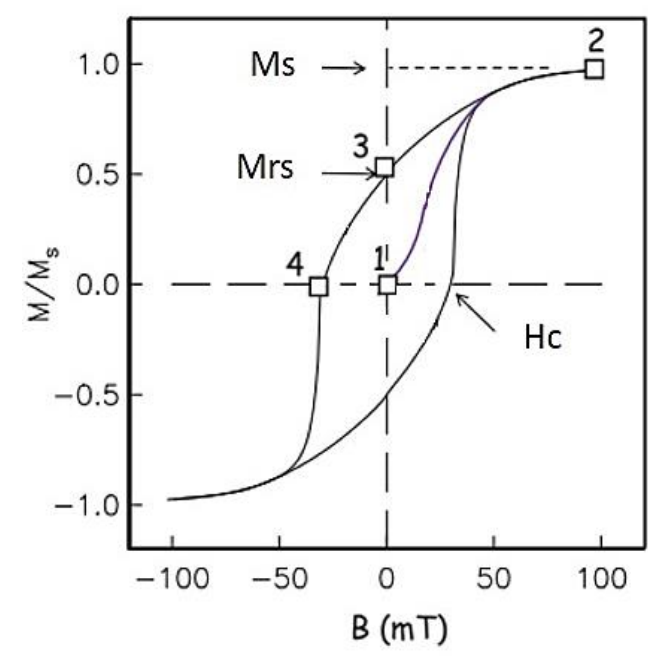

Fonte: Modificado de Tauxe (2008).

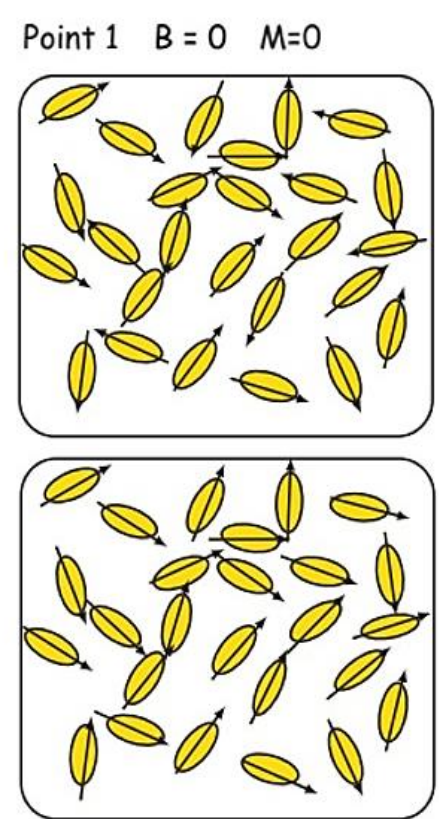

Point $3 \quad B=0 \quad M=M r$

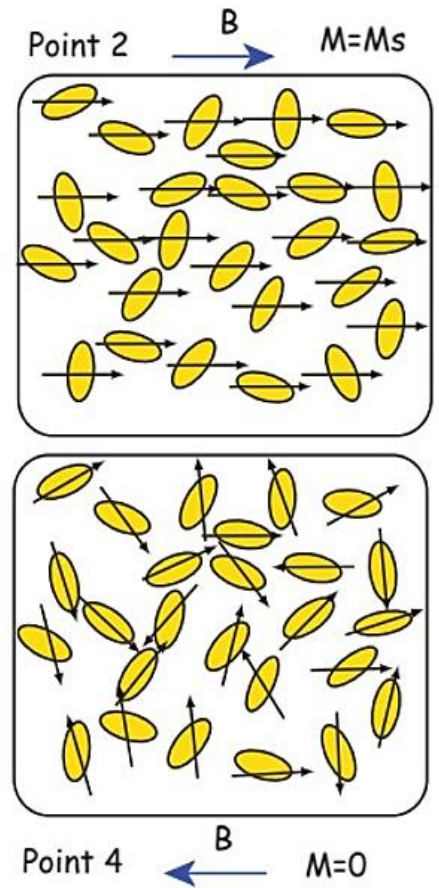

Materiais diamagnéticos (figura 6.2a) têm susceptibilidade magnética fraca e oposta (negativa) à direção do campo, não variando com a temperatura. Nos minerais com esse tipo de comportamento, a exemplo do quartzo e feldspato, o campo de magnetização se opõe ao campo aplicado e desaparece quando este é retirado. O paramagnetismo (figura 6.2b) consiste na tendência de alinhamento dos dipolos magnéticos atômicos com um campo magnético aplicado, resultando em uma susceptibilidade magnética positiva, porém fraca, variando com a temperatura. Esse comportamento ocorre devido à existência de spins desemparelhados nas camadas mais externas dos átomos, como em argilominerais, biotita e piroxênios. Contudo, quando o campo é removido ocorre o rompimento do alinhamento magnético. $\mathrm{O}$ 
ferromagnetismo (figura 6.2c), diferenciado em três tipos a seguir, determina a capacidade de certos minerais apresentarem magnetização espontânea e/ou reterem magnetização remanente. Contudo, quando os grãos magnéticos são muito pequenos, apresentam comportamento instável denominado superparamagnetismo (figura 6.2d).

Figura 6.2 - Curvas de histerese para partícula com comportamento diamagnético (a), paramagnético (b), ferromagnético (c) e superparamagnético (d).
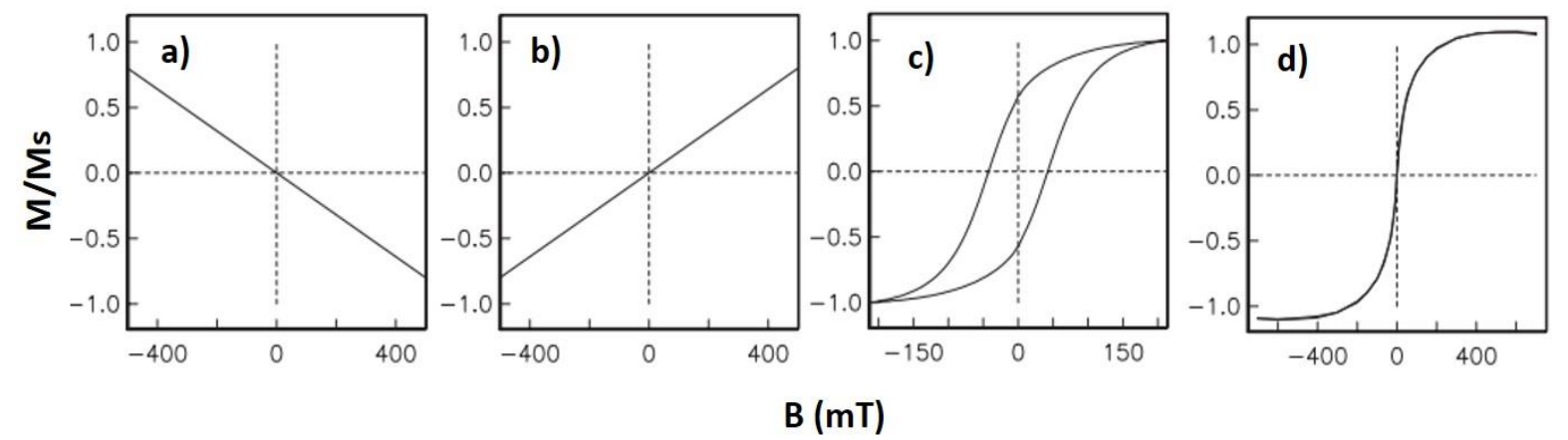

Fonte: Modificado de Tauxe (2008).

Cada mineral magnético apresenta valores característicos para cada um dos parâmetros de histerese apresentados anteriormente. Quando há misturas de minerais, ou seja, minerais com diferentes valores de Ms, Mrs, Hc e Hcr, as curvas de histerese se apresentam distorcidas (TAUXE, 2008; TAUXE et al., 1996).

As curvas de histerese também foram obtidas no Laboratório de Paleomagnetismo da Universidade de São Paulo (USPmag). O equipamento utilizado foi o Magnetômetro de Amostra Vibrante (VSM), da Princeton Measurements Corp., com campo máximo de 1,0 T. Após a aquisição dos dados foi realizada a correção do efeito paramagnético para o campo magnético máximo de 700 mT.

\subsubsection{Magnetização Remanente Isotérmica (IRM, em inglês)}

É a magnetização obtida com a aplicação instantânea de um campo magnético à temperatura ambiente. A amostra é magnetizada ao longo da direção do campo aplicado, que é aumentado progressivamente. Os valores de IRM permitem identificar fases minerais com diferentes coercividades de remanência, que depende da composição química, tamanho do grão e interações entre os grãos magnéticos (LOWRIE, 2007). A magnetização de saturação dos minerais ferrimagnéticos, como a magnetita, é alcançada com campos menores que $300 \mathrm{mT}$, enquanto nos minerais antiferromagnéticos, a exemplo da hematita e goethita, em campos maiores que $1000 \mathrm{mT}$ (figura 6.3). 
Figura 6.3 - Curva de aquisição da magnetização remanente isotérmica.

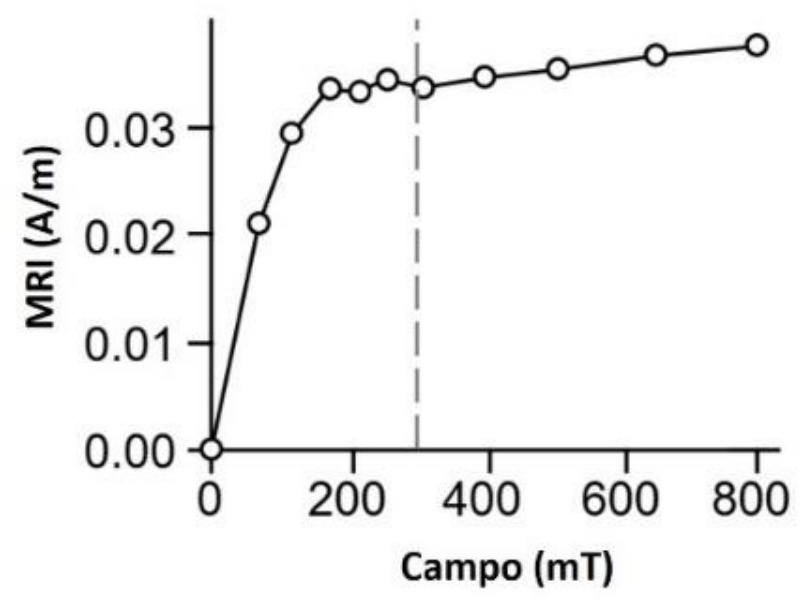

Fonte: Modificado de Butler (2004).

Esta etapa foi realizada no Laboratório de Paleomagnetismo da Universidade de São Paulo (USPmag) por meio de um magnetizador por pulso MMPM10 (Magnetic Measurements Ltd.) com campo indutor máximo de 1,0 T. Foram realizados 31 passos com a aplicação dos seguintes valores de campo magnético: 20, 25, 30, 35, 40, 45, 50, 60, 70 ,80, 90, 100, 120, 140, $160,180,200,220,240,260,280,300,350,400,450,500,600,700,800,900,1000$ mT. Os valores de MRI foram obtidos, em cada passo, em um magnetômetro 755 - 4K DC SQUID (2G Enterprises). Os dados foram analisados com o auxílio do software online MAX UnMix (MAXBAUER et al., 2016), disponível em http://shinyapps.its.carleton.edu/max-unmix/, que permitiu a quantificação da contribuição das fases magnéticas que compõem a curva de aquisição de $I R M$ de cada amostra. Para isso foi realizado o ajuste da curva por meio de funções log-gaussianas, separando componentes com diferentes espectros de coercividade (KRUIVER et al., 2001; ROBERTSON \& FRANCE, 1994).

\subsection{Microtomografia Computadorizada de Raios X $(\mu \mathrm{CT})$}

A $\mu \mathrm{CT}$ é uma técnica não destrutiva que permite a obtenção de seções transversais e imagens tridimensionais de uma amostra. $\mathrm{O}$ equipamento é constituído, basicamente, por uma fonte de raios $\mathrm{X}$, um detector e um suporte rotativo para amostras localizado entre ambos (figura 6.4). A diferença de intensidade medida no detector dependerá da atenuação dos raios $X$ decorrente da interação com a amostra, devido à variação da densidade e do número atômico dos seus constituintes (MEES et al., 2003). A partir desse princípio foi possível identificar fases com diferentes graus de atenuação dos raios $\mathrm{X}$, como poros, arcabouço da rocha (quartzo e feldspato) e minerais acessórios densos. 
Figura 6.4 - Ilustração simplificada do processo de aquisição por microtomografia de raios-X.

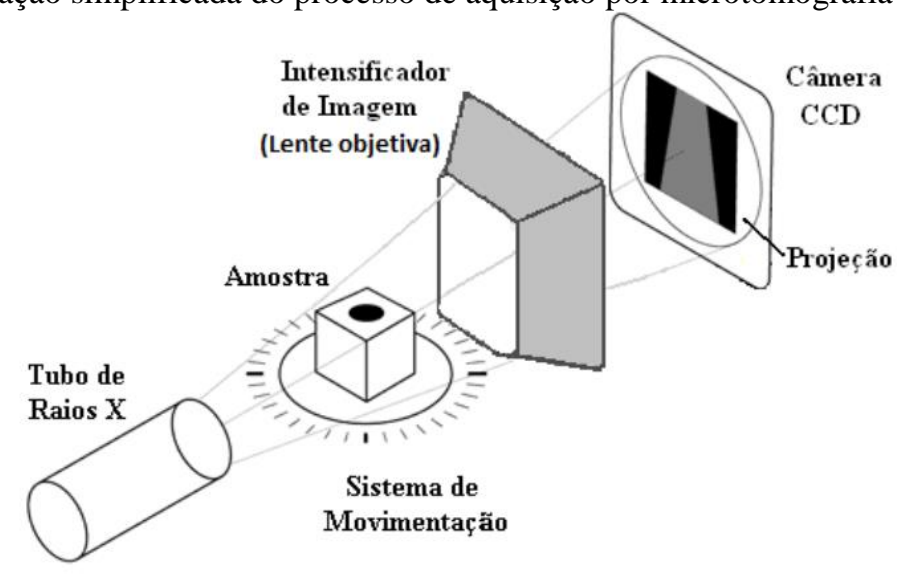

Fonte: Fernandes et al. (2009).

A aquisição ocorreu no Laboratório de Caracterização Tecnológica da Escola Politécnica - USP, com o intuito de quantificar a proporção das bandas de deformação em relação ao volume total das amostras. Foram utilizados cilindros com diâmetro de $2,5 \mathrm{~cm}$ e altura entre 2,5 e 3,8 cm. Os dados foram obtidos em um microtomógrafo ZEISS Xradia Versa XRM-510, com resolução de $45 \mu \mathrm{m}$.

\subsection{Petrofísica básica}

Esta etapa consistiu na determinação de propriedades petrofísicas como porosidade e permeabilidade das amostras. Os procedimentos foram realizados em 15 cilindros, obtidos a partir dos blocos de rocha coletados em campo, sendo dois paralelos e dois transversais às bandas de deformação. Com dimensões variáveis, as amostras apresentam diâmetro de 2,5 cm e altura entre 2,5 e $3,8 \mathrm{~cm}$.

\subsubsection{Porosidade por saturação de fluido}

O método consiste na determinação da porosidade a partir da saturação de amostras de rocha, com geometria regular, por um líquido molhante como água doce, salmoura, tolueno ou diclorometano, a depender da composição mineralógica. Não é aconselhável utilizar amostras de rochas que contenham argilas expansivas ou sejam pouco cimentadas (friáveis) devido ao risco de sua fragmentação durante a realização dos procedimentos.

Inicialmente, foi realizada a secagem das amostras em estufa a $60{ }^{\circ} \mathrm{C}$ durante 24 horas. As amostras secas foram pesadas e tiveram o seu diâmetro e comprimento determinados utilizando um paquímetro digital. Os valores utilizados na equação (6.1) foram obtidos pelo cálculo da média das cinco medidas realizadas para cada parâmetro (massa, comprimento e diâmetro). Então, as amostras foram saturadas por imersão em água deionizada e submetidas 
ao vácuo num dessecador. Após duas horas, quando estavam 100\% saturadas, cada amostra foi retirada do recipiente, teve o excesso de água removido da sua superfície e sua massa imediatamente medida.

$$
\phi=\mathrm{Vv} / \mathrm{Vt}=\mathrm{Vw} / \mathrm{Vt}=((\mathrm{Msat}-\mathrm{Msec}) / \rho \mathrm{w}) / \mathrm{Vt}
$$

Onde $\phi$ é a porosidade, Vv é o volume de vazios, Vt é o volume total, Vw é o volume de água que preenche os poros, Msat é a massa da amostra saturada de água, Msec é a massa seca da amostra e $\rho w$ é a densidade da água.

Os procedimentos foram realizados no Laboratório de Espectroscopia de Alta Resolução por Ressonância Magnética Nuclear (LEAR), Instituto de Física de São Carlos - USP.

\subsubsection{Porosimetria a gás}

O princípio de funcionamento do porosímetro se baseia na lei de Boyle-Mariotte, dada pela equação (6.2), na qual o produto da pressão e do volume entre duas partes de um sistema fechado é constante para uma certa quantidade de gás confinado a uma mesma temperatura, conforme a equação abaixo:

$$
\mathrm{P}_{1} \mathrm{~V}_{1}=\mathrm{P}_{2} \mathrm{~V}_{2}
$$

Onde $\mathrm{P}_{1}$ é a pressão inicial, $\mathrm{V}_{1}$ é o volume inicial, $\mathrm{P}_{2}$ é a pressão final e $\mathrm{V}_{2}$ é o volume final de um gás a temperatura constante.

Os dados foram obtidos no Laboratório de Petrofísica (LabPetrON) do Observatório Nacional, utilizando o porosímetro Ultrapore-300

\subsubsection{Porosidade por densidade}

A densidade é definida pela equação geral (6.3), abaixo:

$$
\rho=\mathrm{m} / \mathrm{v}
$$

onde $\rho$ é a densidade, $\mathrm{m}$ é a massa e $\mathrm{V}$ é o volume.

Esta propriedade pode ser diferenciada em quatro tipos (SCHÖN, 2015), sendo eles: densidade volumétrica, que é a densidade média da amostra incluindo os poros; densidade de um determinado componente mineral; densidade média dos sólidos (grãos); densidade média do fluido dos poros. Primeiramente, foi calculada a densidade média dos sólidos utilizando a equação:

$$
\rho_{\mathrm{s}}=\mathrm{m}_{\mathrm{s}} / \mathrm{V}_{\mathrm{s}}
$$

onde $\rho_{\mathrm{s}}$ é a densidade dos sólidos (grãos), $\mathrm{m}_{\mathrm{s}}$ é a massa dos sólidos e $\mathrm{V}_{\mathrm{s}}$ é o volume dos sólidos.

A partir dos valores obtidos na equação acima e da porosidade, a densidade volumétrica pode ser definida pela equação:

$$
\rho=(1-\phi) \rho_{\mathrm{s}}+\phi \rho_{\mathrm{fl}}
$$


onde $\phi$ é a porosidade e $\rho_{\mathrm{fl}}$ é a densidade do fluido que preenche os poros, no caso o ar.

A porosidade por densidade foi obtida a partir da equação (6.6):

$$
\phi \text { densidade }=1-\left(\rho / \rho_{\mathrm{s}}\right) * 100
$$

O volume de grãos foi determinado em procedimento prévio durante o ensaio de porosidade. Também foi utilizado o porosímetro Ultrapore-300 ${ }^{\mathrm{TM}}$ (Core Laboratories), no Laboratório de Petrofísica (LabPetrON) do Observatório Nacional.

\subsubsection{Permeabilidade}

Permeabilidade é uma propriedade direcional que determina a capacidade de um meio poroso transmitir um fluido, sendo definida pela lei de Darcy, equação (6.7). Pode ser diferenciada em três tipos, sendo eles: absoluta, quando há um único fluido saturando a amostra; efetiva, em que o fluxo de fluido medido ocorre na presença de outro fluido imiscível; relativa, definida pela razão entre permeabilidade efetiva e absoluta (SCHÖN, 2015). O permeâmetro consiste em uma célula do tipo Hassler, com invólucro de borracha, na qual foram inseridas as amostras. Posteriormente, foi aplicada uma pressão confinante de 500 PSI com água, entre a parede da célula e o invólucro de borracha. $\mathrm{O}$ gás foi inserido na extremidade inferior da célula de maneira que, ao atravessar a amostra, fosse possível a determinação da permeabilidade com base na variação de pressão e vazão.

$$
\mathrm{K}=\mathrm{Q} \mu \mathrm{L} / \mathrm{A}\left(\mathrm{P}_{1}-\mathrm{P}_{2}\right)
$$

Onde K é a permeabilidade da rocha (darcy), Q é a vazão $(\mathrm{cm} / \mathrm{s})$, L é o comprimento da amostra $(\mathrm{cm}), \mu$ é a viscosidade do fluido (cP), A é a área da seção transversal $\left(\mathrm{cm}^{2}\right)$ e $\mathrm{P}_{1}-\mathrm{P}_{2}$ é a diferença de pressão na direção do fluxo.

As medidas de permeabilidade absoluta foram obtidas após a aplicação da correção do efeito Klinkenberg nos valores adquiridos com o permeâmetro Ultraperm-500 ${ }^{\mathrm{TM}}$ (Core Laboratories), no Laboratório de Petrofísica (LabPetrON) do Observatório Nacional.

\subsection{Ressonância Magnética Nuclear (RMN)}

A técnica de RMN é particularmente adequada para o estudo de microporosidade e suas propriedades superficiais, podendo assim estabelecer a relação entre micro e macroporos (JÁCOMO et al., 2018; 2019). Além disso, também pode fornecer informações sobre a estrutura porosa, porosidade média, distribuição de tamanho dos poros e conectividade.

Neste trabalho, foram realizadas medidas de FID, $T_{2}$ nos quinze cilindros. Para todos os procedimentos as amostras se encontravam saturadas com água deionizada. A distribuição de $\mathrm{T}_{2}$ foi determinada com a utilização da sequência Carr-Purcell-Meiboom-Gill (CPMG) para o 
tempo de eco de $200 \mu$ s. Para minimizar o ruído do sinal, foram feitas 64 médias para cada amostra considerando um tempo de espera entre as médias de cinco vezes o maior valor de T2, obtido durante a sequência CPMG.

As medidas foram realizadas em baixo campo magnético com um espectrômetro LapNMRTM (Tecmag) operando a $2 \mathrm{MHz}$, usando um magneto permanente de 0,047 T, no Laboratório de Espectroscopia de Alta Resolução por Ressonância Magnética Nuclear (LEAR), Instituto de Física de São Carlos - USP. Os dados de distribuição de $\mathrm{T}_{2}$ foram tratados por meio da transformada inversa de Laplace, com base no método de regularização de Tikhonov (L2). 


\section{RESULTADOS}

\subsection{Aspectos estruturais}

A aquisição dos dados estruturais englobou os seguintes parâmetros: tipo e geometria da estrutura, orientação, mergulho (quando possível), cinemática (quando observável), espessura e frequência de bandas por metro, para cada scanline. A atitude das estruturas deformacionais e sedimentares, assim como da superfície dos blocos coletados para análises em laboratório, foi obtida utilizando a regra da mão direita, na qual a direção do plano (strike) está sempre a $90^{\circ}$ no sentido anti-horário do mergulho (dip).

\subsubsection{Afloramento da Falha do Macaco (Grupo Ilhas)}

O afloramento consiste na zona de dano da Falha do Macaco e apresenta extensão de 70 metros com exposição das estruturas deformacionais, predominantemente, em planta. A falha principal possui orientação N-S, evidenciada apenas pela presença de um vale resultante da erosão ao longo da sua superfície de deslizamento (figura 7.1). A estrutura apresenta mergulho para leste, associado a um rollover anticlinal, indicado pela orientação do mergulho das camadas deposicionais (355/42; 005/40; 000/44). Do lado oeste da falha foram observadas bandas de deformação distribuídas heterogeneamente ao longo do afloramento. As bandas apresentam cor mais clara do que a rocha hospedeira e são mais resistentes (menos friáveis), o que permite que se destaquem no relevo, em alguns casos, possibilitando a sua visualização em três dimensões.

Figura 7. 1 - A) Plano de acamadamento dos arenitos flúvio-deltaicos do Grupo Ilhas, com mergulho para leste; B) Parte preservada do rollover anticlinal; C). Zona de bandas de deformação associada à Falha do Macaco.

Escala indicando o norte.

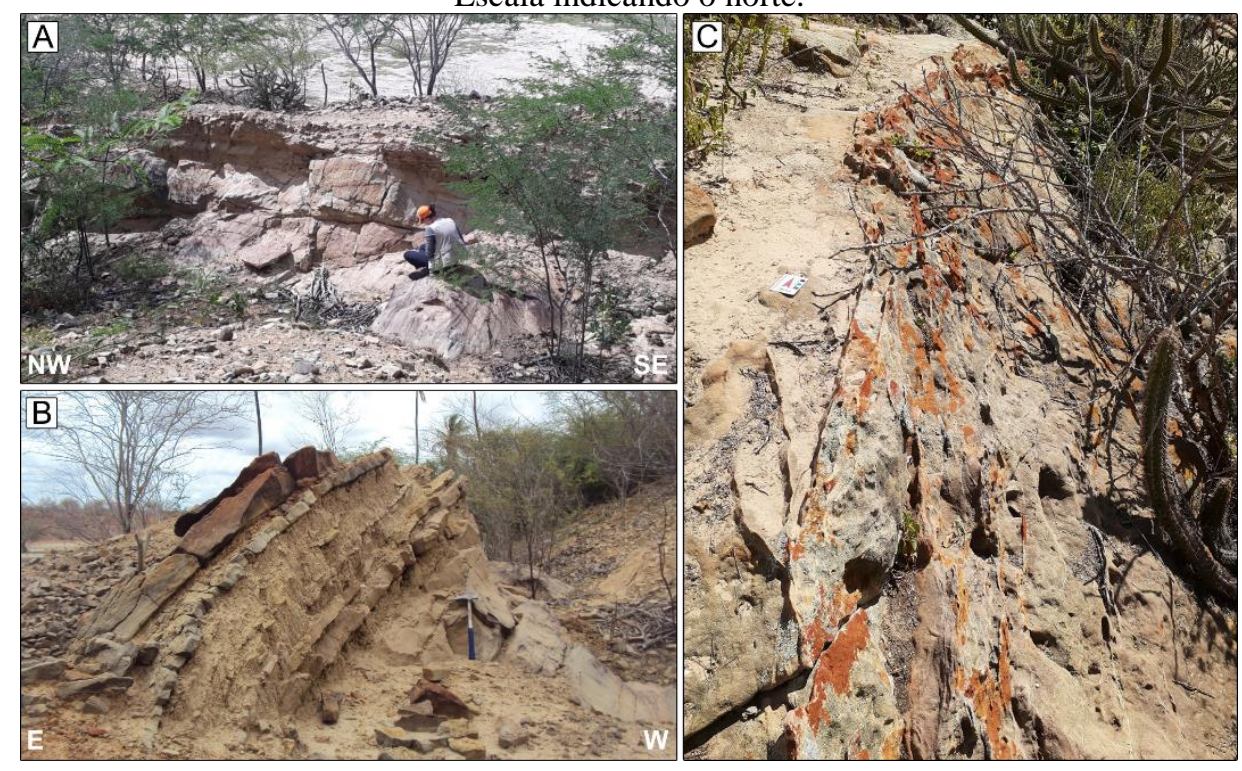


Foram delimitadas oito scanlines (figura 7.2) ao longo das quais também foram selecionadas amostras representativas para o estudo das propriedades petrofísicas, de acordo com a quantidade de bandas. Dessas linhas-guia, metade foi marcada em porções de afloramentos com bandas de deformação mais ao sul do local conhecidamente associado à Falha do Macaco. A localização das scanlines foi definida de forma a proporcionar uma visualização mais representativa da distribuição espacial das bandas no afloramento ao longo do strike da falha principal.

Figura 7. 2 - Scanlines delimitadas ao longo do afloramento da Falha do Macaco (A), mostrando variação na densidade de bandas ao longo de cada linha (B-I).
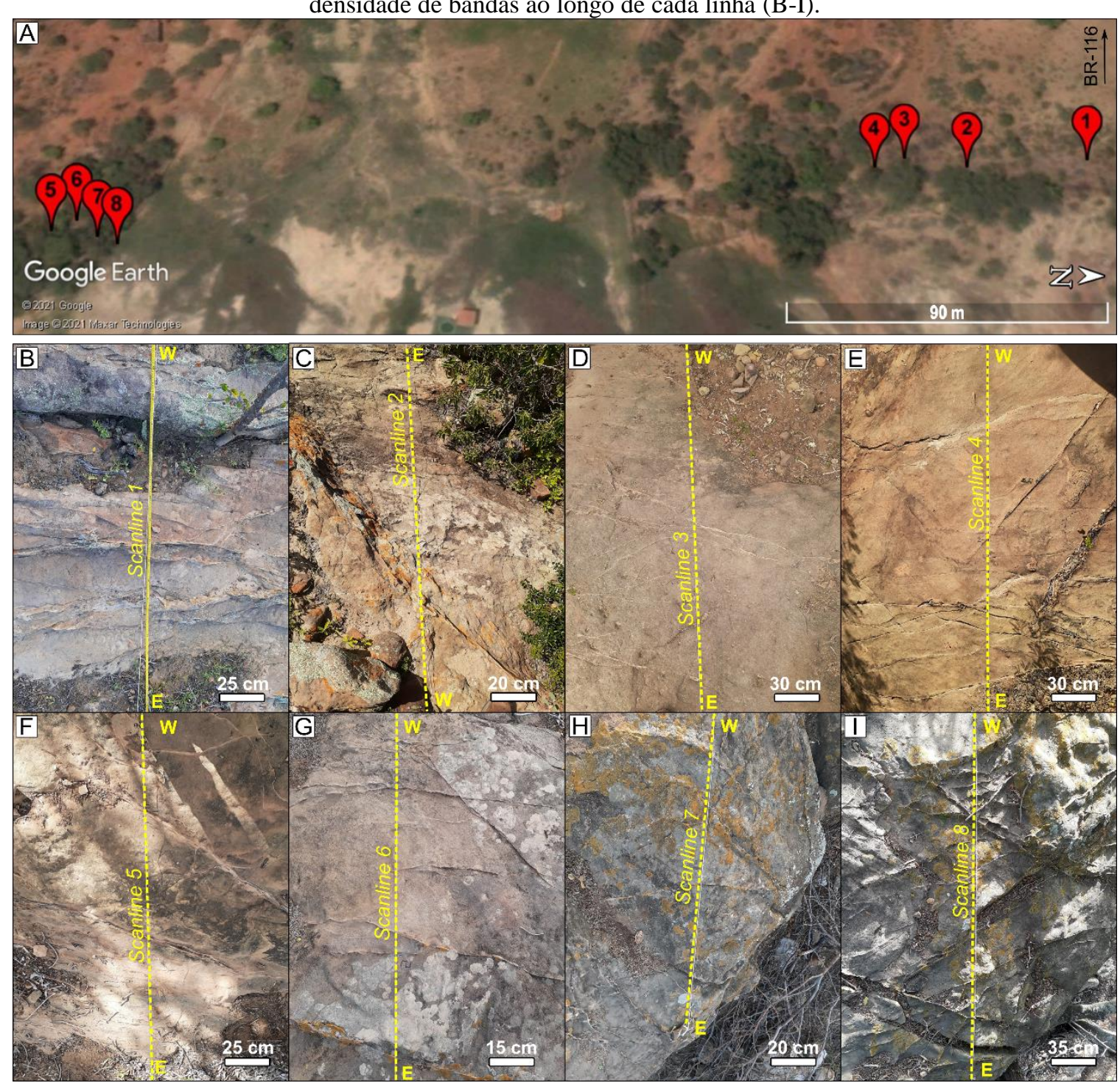

As bandas de deformação são predominantemente pares conjugados de orientação próximo a N-S com mergulho para leste e oeste, variando de $46^{\circ}$ a $84^{\circ}$ (figura 7.3 ). Também foram medidas estruturas de orientação NE-SW com mergulho subvertical, e NW-SE com 
mergulho de $40^{\circ}$ a $86^{\circ}$ para sudoeste. Os indicadores cinemáticos, com o movimento relativo entre partes de uma mesma estrutura, evidenciaram uma cinemática aparente normal e dextral nas bandas com orientação próximas a N-S. A variação da direção de mergulho em estruturas com alto ângulo pode ser explicada pelo padrão anastomosado das bandas de deformação, apresentando ângulo e direção de mergulho variáveis. Foram observadas bandas individuais e agrupamentos, retilíneos a anastomosados com espessura inferior a $0,10 \mathrm{~cm}$ a $0,50 \mathrm{~cm}$, nas bandas individuais, até $10,0 \mathrm{~cm}$, nos agrupamentos. A distribuição espacial heterogênea das bandas é evidenciada pelo aumento da densidade de sul para norte (figura 7.2). Na primeira porção, predominam bandas individuais e agrupamentos pouco espessos (scanlines 3 e 4), enquanto a norte são mais frequentes os agrupamentos de bandas com maior espessura (scanlines 1 e 2). No primeiro caso, a densidade de bandas não ultrapassa 12 bandas por metro, enquanto no segundo, pode chegar a 34 bandas por metro. As scanlines 5, 6, 7 e 8 foram delimitadas em outra porção de afloramento, tendo uma distribuição mais homogênea em termos de densidade e espessura de bandas, com densidade máxima variando de 12 a 17.

Figura 7. 3 - Vista do afloramento em planta (A) e perfil (B), além de diagrama de rosetas (C) e estereograma (D) evidenciando o padrão estrutural no afloramento da Falha do Macaco.
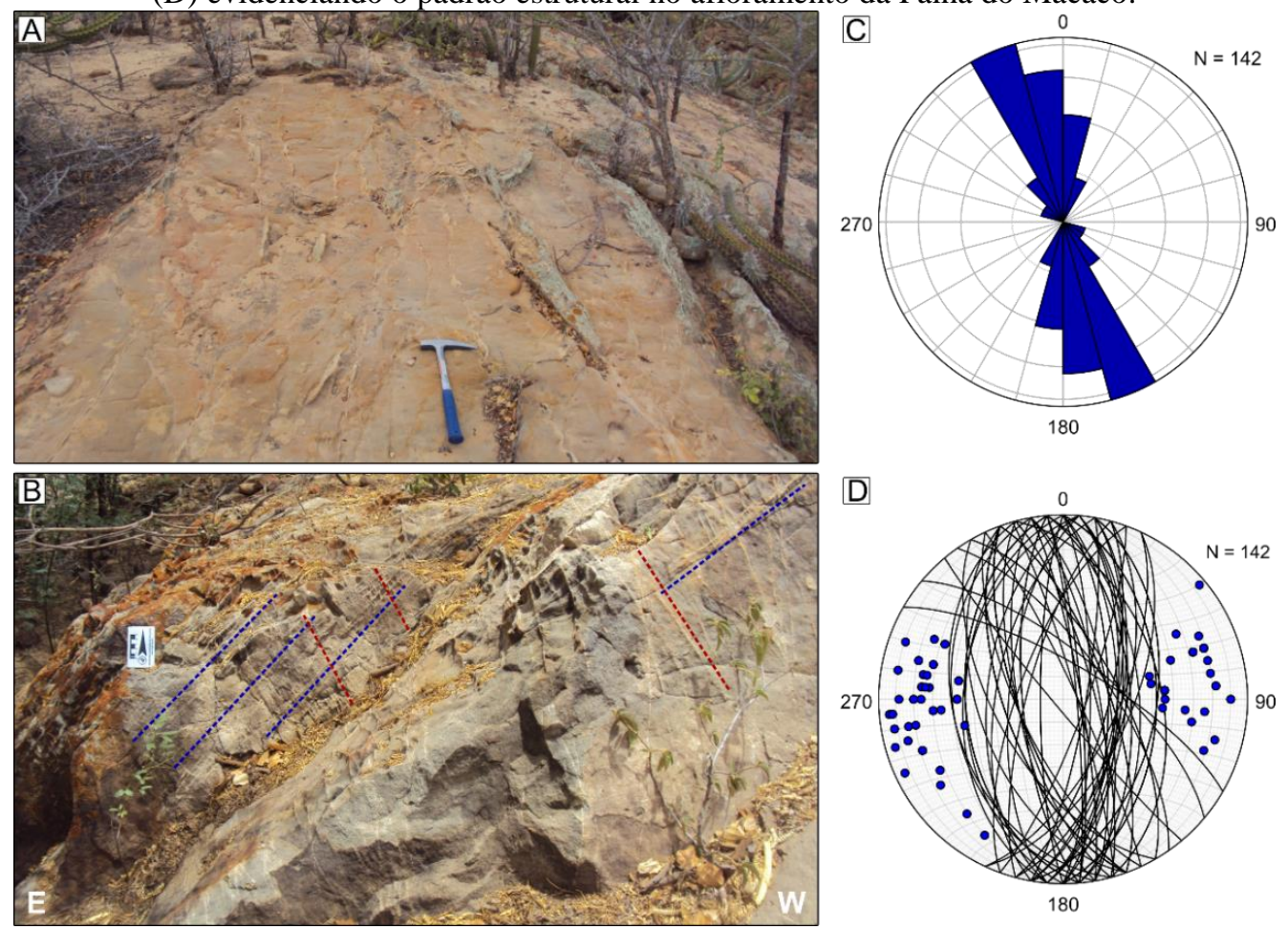

Como as mudanças na proporção das bandas em relação à rocha hospedeira podem variar dependendo da escala de observação, nas amostras coletadas ao longo de duas scanlines (ILH1 e ILH6) foi determinado o percentual do volume de bandas por microtomografia de raios-X 
(figura 7.4). As bandas de deformação foram consideradas como um volume uniforme, independente da variação de porosidade no seu interior. Foi utilizada uma resolução de $45 \mu \mathrm{m}$ para a aquisição dos dados, devido ao tamanho das amostras. As amostras selecionadas correspondem ao membros extremos das scanlines, em termos de quantidade de bandas definida em campo, e o volume de bandas em relação ao plugue foi de 100,0\% (ILH1A ${ }^{1}$ e ILH1A ${ }^{2}$ ), $11.1 \%$ (ILH1D), 2.6\% (ILH6B) e 47.1\% (ILH6C). A amostra ILH1A ${ }^{1}$ (plugue de orientação paralela à direção do mergulho da banda) é composta por uma única banda com espessura de 19,4 mm. A geometria da estrutura é retilínea com regiões de matriz tectônica intercaladas com pods de rocha menos deformada, paralelos ao comprimento do plugue. É importante ressaltar que a amostra ILH1A $^{1}$ foi imageada com a finalidade de quantificar também a porção da banda intensamente cominuida, sem influência dos pods. Com isso, foi obtido o valor de $88,9 \%$ a ser utilizado na comparação com os dados de ressonância magnética nuclear. Apesar de não ter sido imageada, a amostra ILH1A² apresenta a mesma geometria, porém suas intercalações de matriz tectônica e pods de rocha menos deformada são perpendiculares ao comprimento do plugue. Em ILH1D, identificamos duas bandas retilíneas com espessura de $0,9 \mathrm{~mm}$ e 1,2 a 2,1 mm, transversais ao comprimento do plugue. A amostra ILH6B contém uma banda retilínea com espessura de 0,8 mm, enquanto em ILH6C a banda é anastomosada com espessura média de $10,8 \mathrm{~mm}$, ambas transversais ao comprimento do plugue.

Figura 7. 4 - Imagens tridimensionais dos plugues com diferentes volumes de bandas (BDs) do afloramento do Grupo Ilhas. Linhas vermelhas tracejadas indicam o volume de bandas calculado.

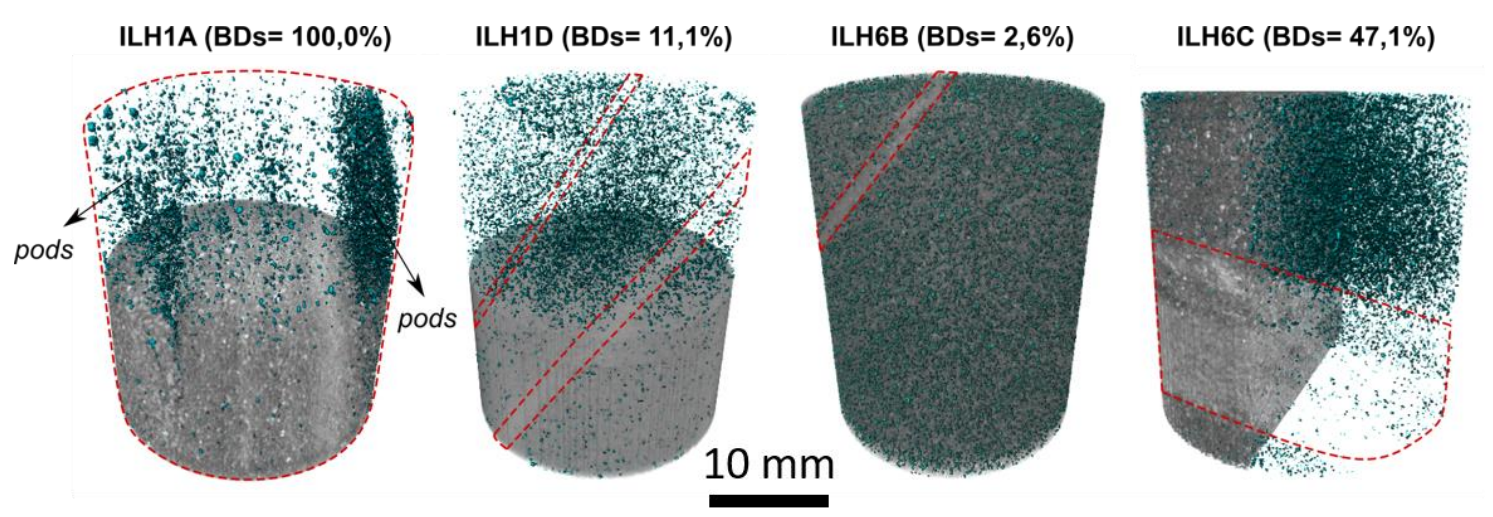

\subsubsection{Afloramento da Falha de Caritá (Grupo Massacará)}

A área engloba cinco porções de afloramento, em planta e perfil, associadas à Falha de Caritá. Essa estrutura possui orientação NW-SE, com cinemática normal-dextral. Assim como 
no afloramento da Falha do Macaco, as bandas de deformação apresentam cor diferente da rocha hospedeira e se destacam no relevo (figura 7.5) devido ao enrijecimento causado por cominuição e intertravamento de grãos associados às bandas de deformação.

Figura 7. 5 - Vista parcial do afloramento, em planta (A) e perfil (B), mostrando as bandas em destaque no

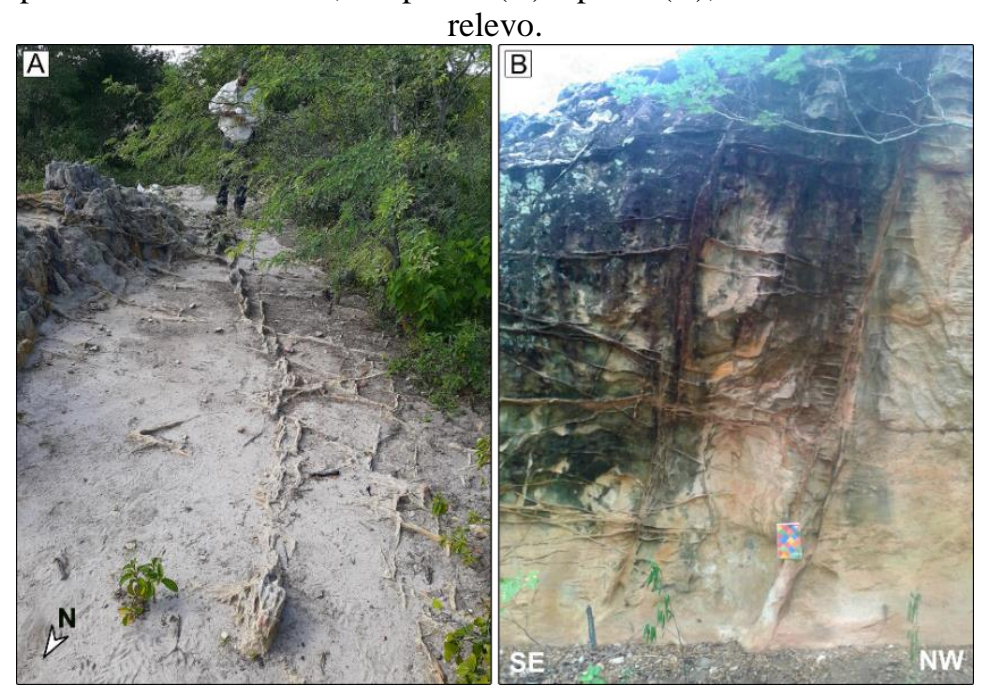

Foram delimitadas cinco scanlines (figura 7.6), uma em cada porção de afloramento, das quais também foram selecionadas amostras representativas para o estudo das propriedades petrofísicas. A localização das scanlines foi definida com o intuito de verificar a distribuição de bandas, conforme o aumento da distância a partir da falha principal (Falha de Caritá).

Figura 7. 6 - Localização das scanlines no afloramento da Falha Caritá (A), juntamente com fotos representativas mostrando a variação na densidade de bandas ao longo de cada linha (B-F).

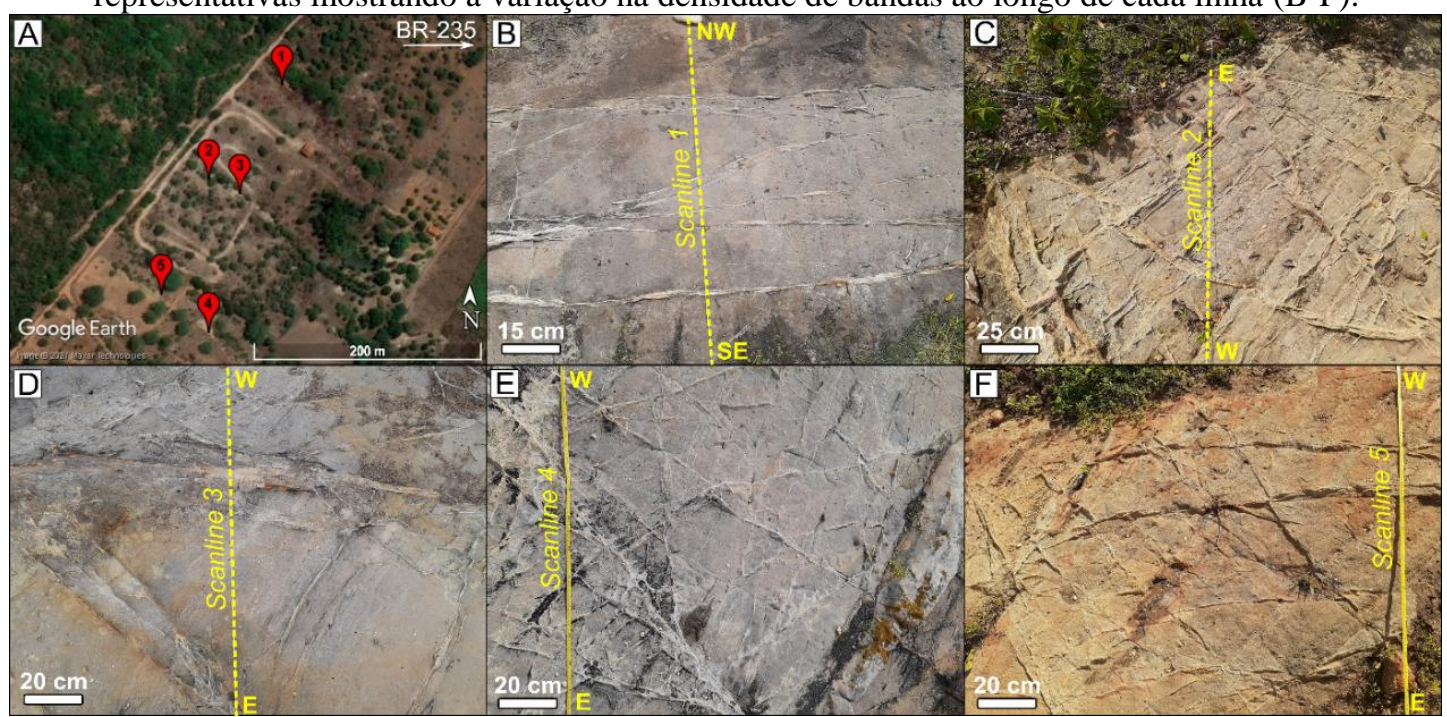


Três orientações principais de bandas de deformação foram observadas, sendo elas: NNW-SSE com mergulho de $43^{\circ}$ e $61^{\circ}$ a nordeste, NW-SE com mergulho de $46^{\circ}$ e $64^{\circ}$ para nordeste e NE-SW com mergulho de $46^{\circ}$ e $79^{\circ}$ a noroeste. Os indicadores cinemáticos apresentam deslocamento dextral, nas bandas com orientação NW-SE e NNW-SSE, e sinistral nas bandas com orientação NE-SW. Esse padrão de orientação e cinemática é compatível com as estruturas do tipo Riedel, previamente estudadas por Vasconcelos (2003) em outros afloramentos associados à Falha de Caritá. Neste arranjo, a orientação NW-SE da falha principal, as estruturas com orientação NNW-SSE, NE-SW e NW-SE correspondem a fraturas do tipo R, R 'e Y, respectivamente (figura 7.7). As bandas são predominantemente retas, com geometria anastomosada subordinada e ocorrem tanto como agrupamentos quanto estruturas individuais. A espessura das faixas individuais varia de menos de $0,10 \mathrm{~cm}$, principalmente nas individuais, a 22,0 cm, no caso dos agrupamentos, tendo uma distribuição relativamente homogênea ao longo do afloramento.

Figura 7. 7 - Vista do afloramento em planta (A), assim como diagrama de rosetas (B) e estereograma (C) evidenciando o padrão estrutural no afloramento da Falha de Caritá.
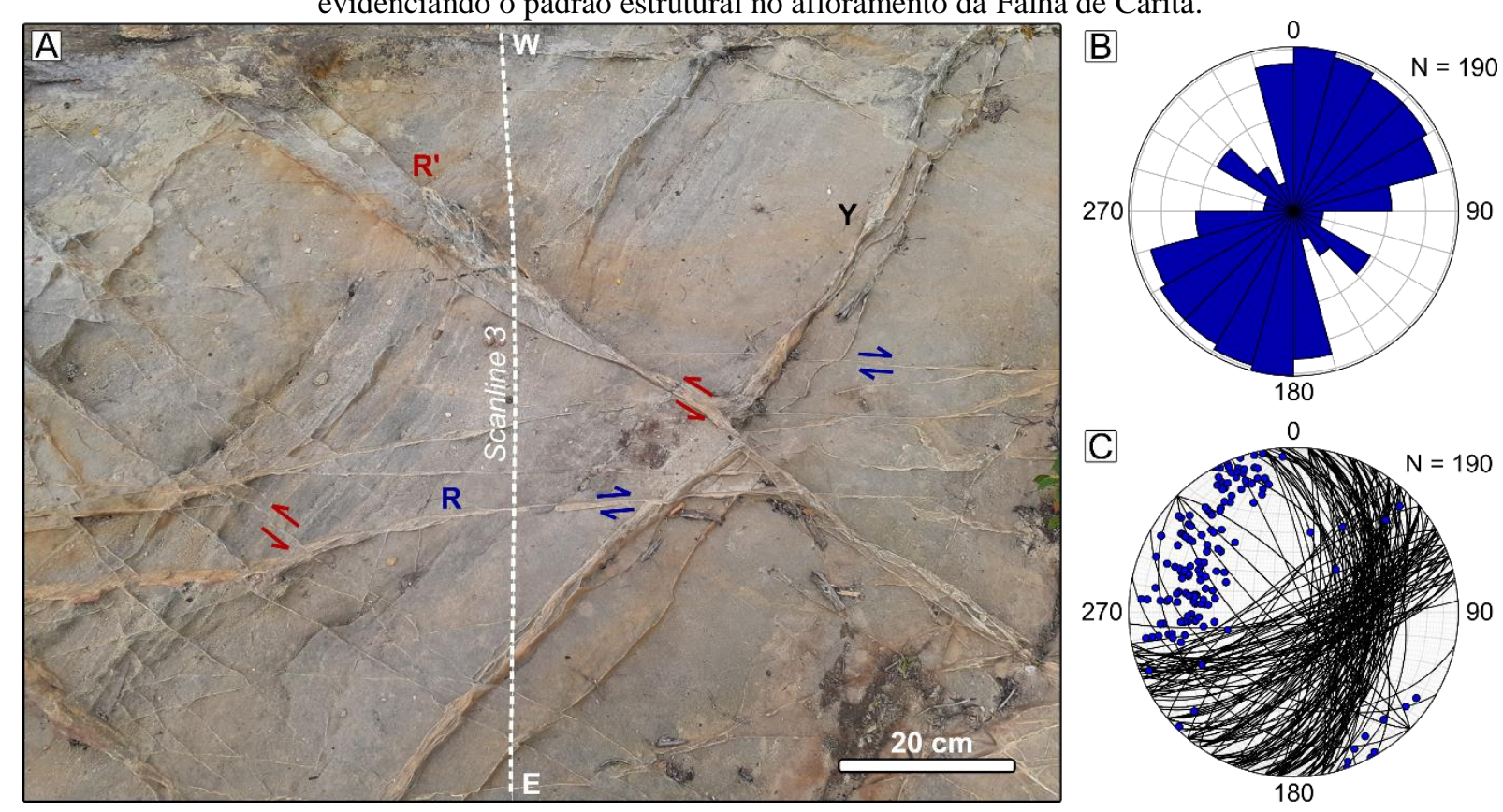

Dos plugues coletados ao longo da linha de varredura (MAS3), apenas a porcentagem de banda na amostra MAS3D foi calculada por imagens de micro-CT, apresentando o valor de $74,5 \%$ (figura 7.8). Como os plugues das amostras MAS3 $\mathrm{A}^{1}$ (paralelo ao strike) e MAS3A ${ }^{2}$ (perpendicular ao strike) são inteiramente constituídos pela banda de deformação, foi considerado um volume de banda de $100 \%$. Embora os plugues tenham sido feitos em orientações diferentes, em relação à banda de deformação da amostra MAS3A, em geral, a 
estrutura é homogênea em ambos. Em MAS3D, foi identificada uma banda anastomosada com espessura total de $23,8 \mathrm{~mm}$, transversal ao comprimento do plugue. Esta banda compreende quatro bandas menores $(2,2$ a $5,7 \mathrm{~mm})$ intercaladas com pods de rocha menos deformada.

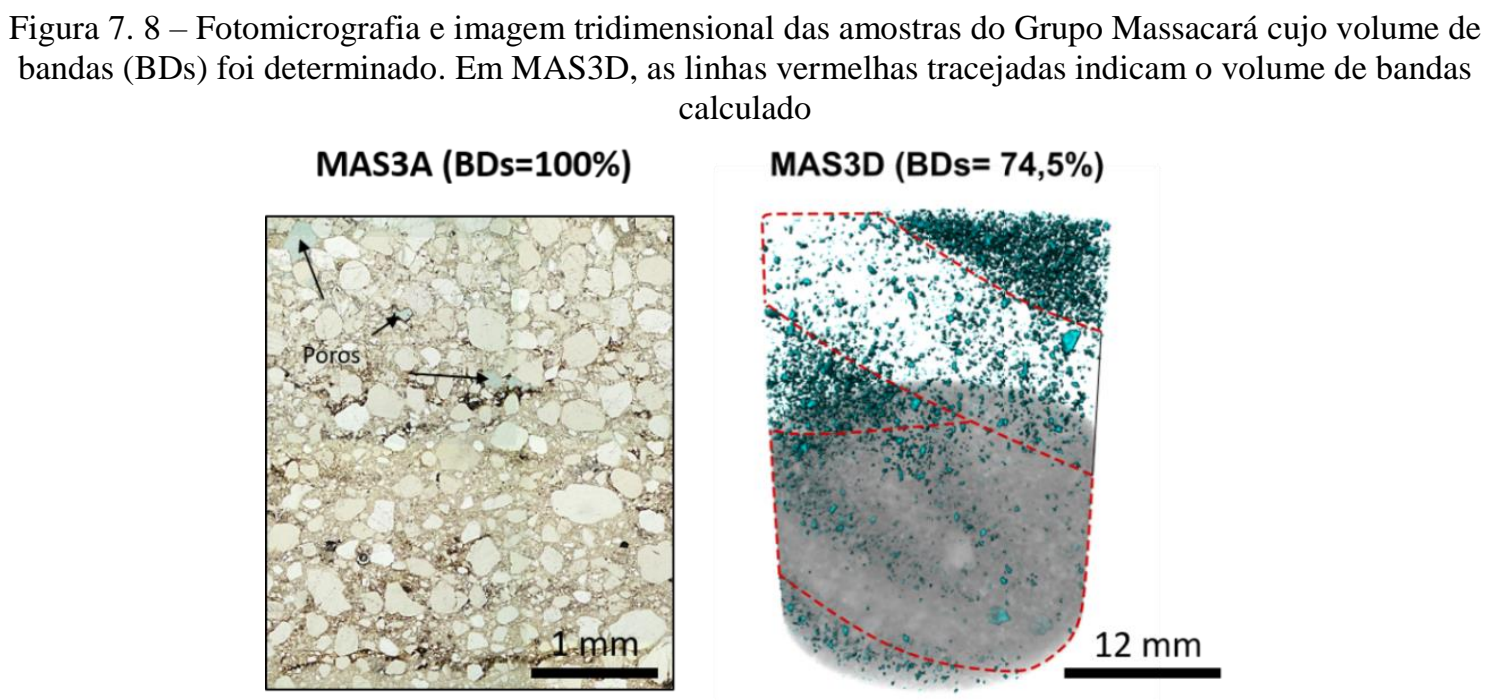

\subsection{Aspectos petrográficos}

A caracterização petrográfica das amostras envolveu a identificação da composição mineralógica, aspectos texturais e deformacionais da rocha hospedeira (porções com pouca ou nenhuma deformação rúptil dos grãos) e das bandas de deformação. Como composição mineralógica foram considerados os constituintes primários (grãos detríticos), incluindo minerais acessórios, diagenéticos (cimento e crescimentos secundários) e matriz tectônica. Também foi realizada a estimativa de porosidade em lâmina delgada para todas as amostras. Os aspectos texturais englobam selecionamento, esfericidade, arredondamento e empacotamento. Os aspectos deformacionais se referem a feições resultantes de microfraturamentos, cominuição granular com geração de matriz cataclástica, deslocamentos relativos aparentes e orientação dos grãos. Além disso, também foram identificados os tipos, tamanhos e orientação dos poros. Esse tamanhos foram obtidos através do processamento das fotomicrografias das amostras, convertidas para tons de cinza. A partir da intensidade de cor em cada região (grãos e poros) foi segmentada a estrutura porosa e determinado o raio médio da esfera equivalente ao tamanho dos poros.

\subsubsection{Afloramento da Falha do Macaco (Grupo Ilhas)}

A rocha hospedeira foi classificada, de acordo com Folk (1974), como um arcósio a subarcósio (figura 7.9) com predominância de granulometria areia fina $(0,136 \mathrm{~mm}$ a 0,224 mm), 
bem selecionado, de média a alta esfericidade e grãos subarredondados a arredondados. Apresenta empacotamento frouxo a normal, predominando os contatos entre grãos do tipo pontual e grão/não-grão. Contatos longos, côncavo-convexos e suturados, em geral, foram contabilizados como traço a raros, indicando pouca influência do soterramento na redução de porosidade primária das amostras.

Como principais constituintes primários foram identificados o quartzo (22,3 a 39,0\%) e o feldspato (5,8 a 21,5\%), com a maioria correspondendo a grãos parcialmente dissolvidos ou alterados, além de fragmentos líticos $(<1,0 \%)$. Biotita (exceto em ILH1A) e epidoto também foram observados como minerais acessórios $(0,3$ a 1,5\%).

Figura 7. 9 - Diagrama de classificação dos arenitos do Grupo Ilhas (Folk, 1974).

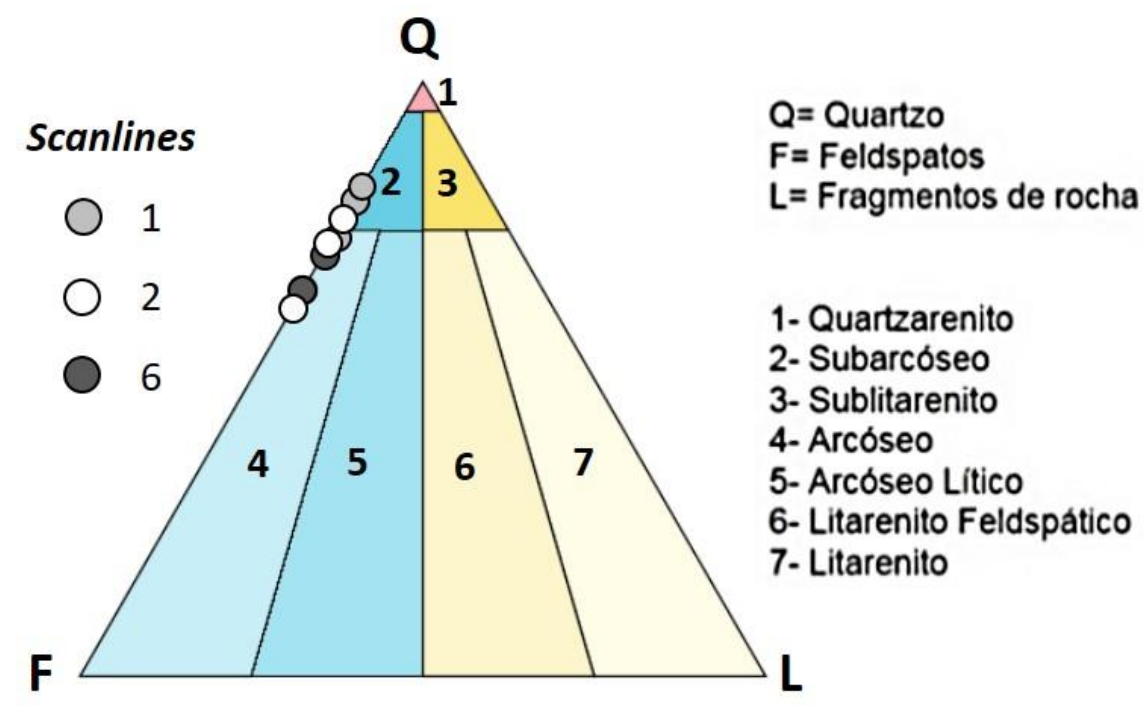

Os principais constituintes diagenéticos são o crescimento secundário de quartzo $(1,8$ a $4,3 \%)$ e feldspato $(0,8$ a $6,7 \%)$, minerais de argila (2,3 a 8,0\%), óxidos de ferro $(5,5$ a 7,8\%) e titânio (<1,0\%). O quartzo ocorre como projeção prismática sintaxial micro (figura 7.10a) e macrocristalina (figura 7.10b), frequentemente diferenciada do grão primário por meio de filmes de argila ou óxido de ferro entre eles. A variedade de potássio (K-feldspato) foi identificada por SEM-EDS como o principal constituinte das projeções prismáticas secundárias em grãos de feldspato alcalino e plagioclásio (figura 7.10b e d). Associado a este mineral, também ocorre o processo de dissolução, mais evidente nos grãos de plagioclásio. A corrensita, uma clorita-esmectita de camada mista interestratificada, foi identificada por meio de EDX nas amostras (figura 7.10b). Os minerais opacos, assim como a corrensita são encontrados preenchendo os poros intergranulares e aqueles gerados por fratura, e principalmente revestindo 
grãos. Eles também foram observados frequentemente associados a minerais de argila gerados pela alteração do feldspato e substituindo minerais como a biotita (figura 7.10c).

Figura 7. 10 - Principais feições diagenéticas (crescimento secundário de quartzo e feldspato, alteração de minerais primários para argilomineral ou mineral opaco) observadas por $\mathrm{MEV}$ e microscopia óptica. $\mathrm{Bt}=\mathrm{Biotita}$; $\mathrm{Chl=Clorita;} \mathrm{Kfs=Kfeldspato;} \mathrm{Fsp=Feldspato;} \mathrm{Opq=Minerais} \mathrm{opacos;} \mathrm{Qz=Quartz}$
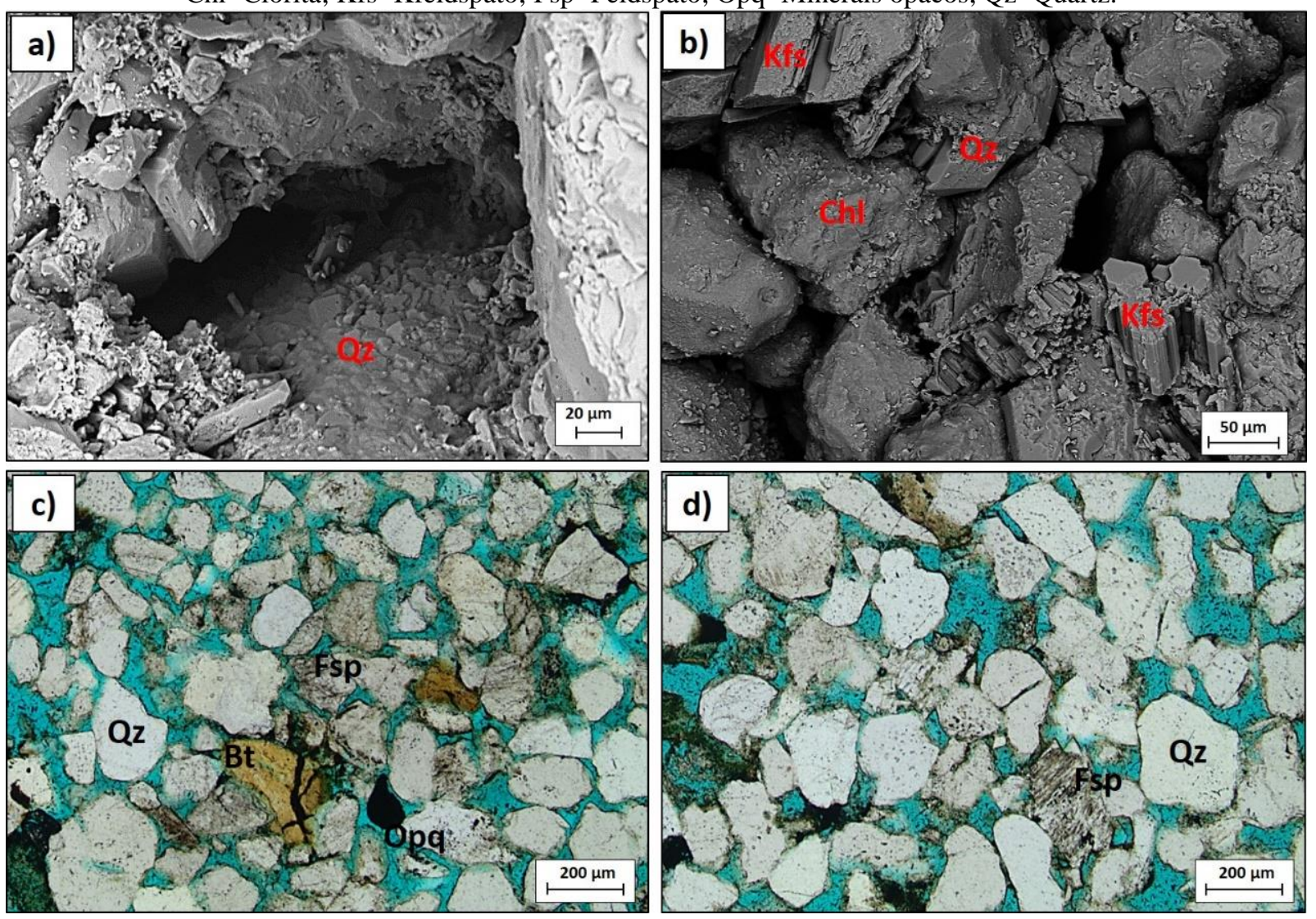

Do ponto de vista microestrutural, foram observadas predominantemente fraturas transgranulares em grãos de feldspato e quartzo (figura 7.11a). As bandas de deformação são cisalhantes com uma componente compactacional, conforme a classificação de FOSSEN et al. (2007; 2017). O principal mecanismo de deformação foi o fluxo cataclástico, resultando em grãos inequidimensionais de forma subangular a angular devido ao fraturamento (figura 7.11b). Nas amostras desse afloramento, as bandas não apresentam distinção significativa entre zona de dano (zona de transição) e núcleo, sendo a região como um todo mais homogênea com grãos ainda preservados, intercalados com a matriz tectônica. Além disso, há pouca variação de granulometria dos grãos da rocha hospedeira (areia fina) para os grãos preservados nas bandas (areia muito fina), predominando frações granulométricas menores que silte $(0,032$ a $0,036 \mathrm{~mm})$ compondo a matriz. 
Figura 7. 11 - Fotomicrografias mostrando fratura transgranular em grãos de quartzo (a); banda de deformação caracterizada pela redução localizada de porosidade, em comparação com a rocha hospedeira (b). RH=Rocha

hospedeira; $\mathrm{BD}=$ Banda de deformação.
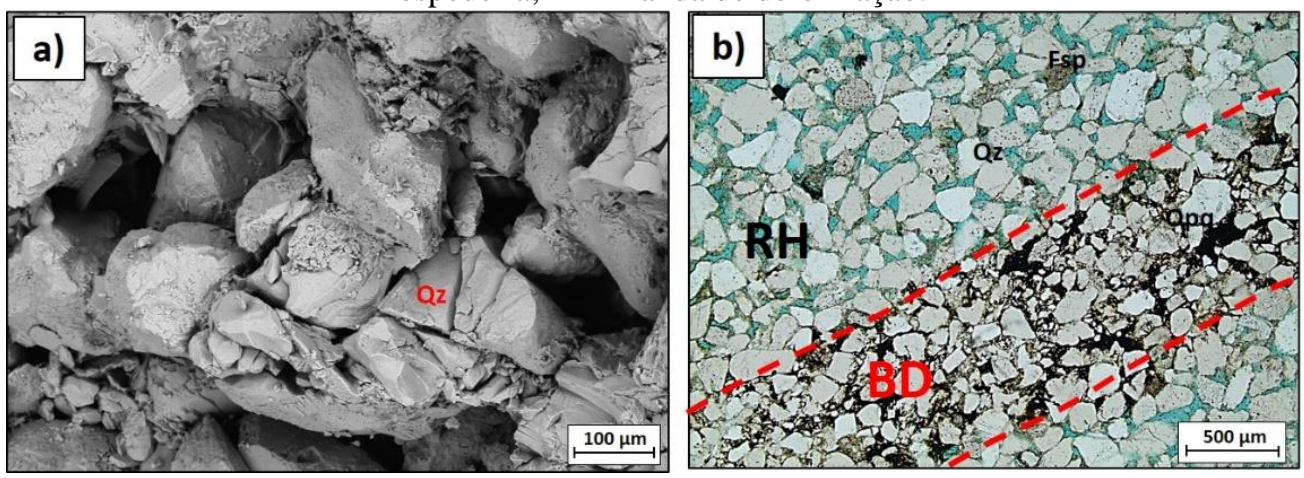

A partir da $\mu \mathrm{FRX}$ foi possível identificar a distribuição de elementos químicos nas lâminas e associar com a distribuição de minerais. Além disso, foi realizada a comparação de composição química entre a banda e a rocha hospedeira, da amostra ILH6C (figura 7.12a). No geral, a banda concentra mais ferro do que cálcio (figura 7.12b), o que pode ser explicado pelo fato deste último estar presente em minerais que podem ser facilmente alterados e dissolvidos. No caso do ferro, podem ser observadas duas orientações principais, uma associada à concentração desse elemento, por meio do fluxo cataclástico, e outra, provavelmente decorrente dos processos deposicionais (figura 7.12c).

Figura 7. 12 - Mapa de distribuição dos elementos químicos em amostra com banda de deformação da scanline 6. a) Diferença de proporção entre os elementos químicos na banda de deformação e na rocha hospedeira; b) Maior concentração de Ca na porção menos deformada; c) Conteúdo de Fe indicando provável alinhamento de mineral.
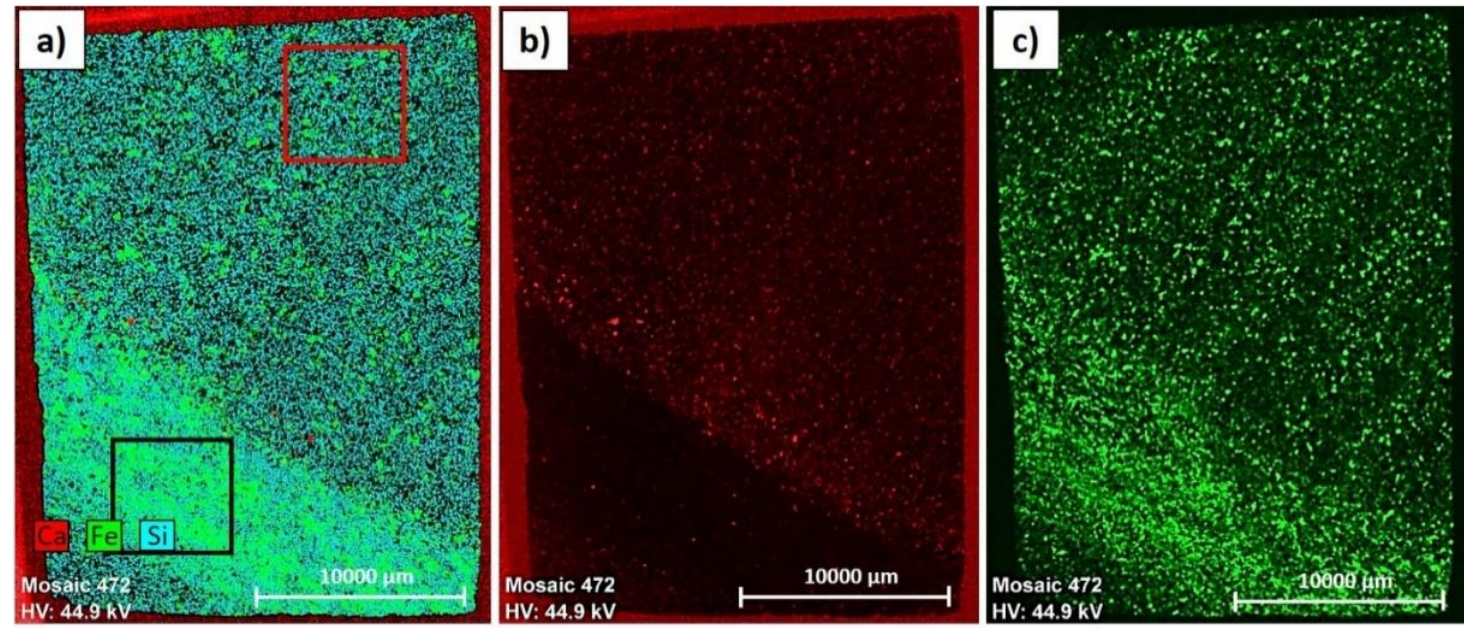

\begin{tabular}{|l|c|c|c|}
\cline { 2 - 4 } \multicolumn{1}{c|}{} & \multicolumn{3}{c|}{ Elemento (wt.\%) } \\
\cline { 2 - 4 } \multicolumn{1}{c|}{} & Si & Ca & Fe \\
\hline Rocha hospedeira & 42,50 & 1,23 & 0,20 \\
\hline Banda & 42,59 & 0,47 & 0,35 \\
\hline
\end{tabular}


Foram identificados três tipos de poros em lâminas delgadas (figura 7.13). Os poros intergranulares primários estão parcialmente aumentados pela dissolução e/ou fraturamento de grãos na estrutura, ou reduzidos por matriz tectônica e precipitação de minerais de argila ou óxidos de ferro. Poros intragranulares também foram observados, gerados pelo fraturamento de grãos de quartzo e feldspato, ou pela dissolução parcial ou total dos feldspatos. Este último é mais evidente nas amostras em que predominam as bandas, como ILH1A, devido à porosidade primária totalmente reduzida pela matriz cataclástica. $\mathrm{O}$ raio médio dos poros na rocha hospedeira desse afloramento estão em torno de 58,8 $\mu \mathrm{m}$ (ILH1A), 40,1 $\mu \mathrm{m}$ (ILH1D), 30,3 $\mu \mathrm{m}$ (ILH6B) e 27,0 $\mu \mathrm{m}$ (ILH6C), Em ILH1A e ILHA6C que apresentam tanto porções de rocha hospedeira quanto de bandas, também foi calculado o tamanho médio de poros nas bandas e obtivemos valores de $6,0 \mu \mathrm{m}$ e $2,4 \mu \mathrm{m}$, respectivamente.

Figura 7. 13 - Fotomicrografias apresentando os tipos de poros presentes nas amostras: a) Primário parcialmente preservado, aumentado por dissolução; b) Em feldspato fraturado; c) Por dissolução, em banda de deformação.
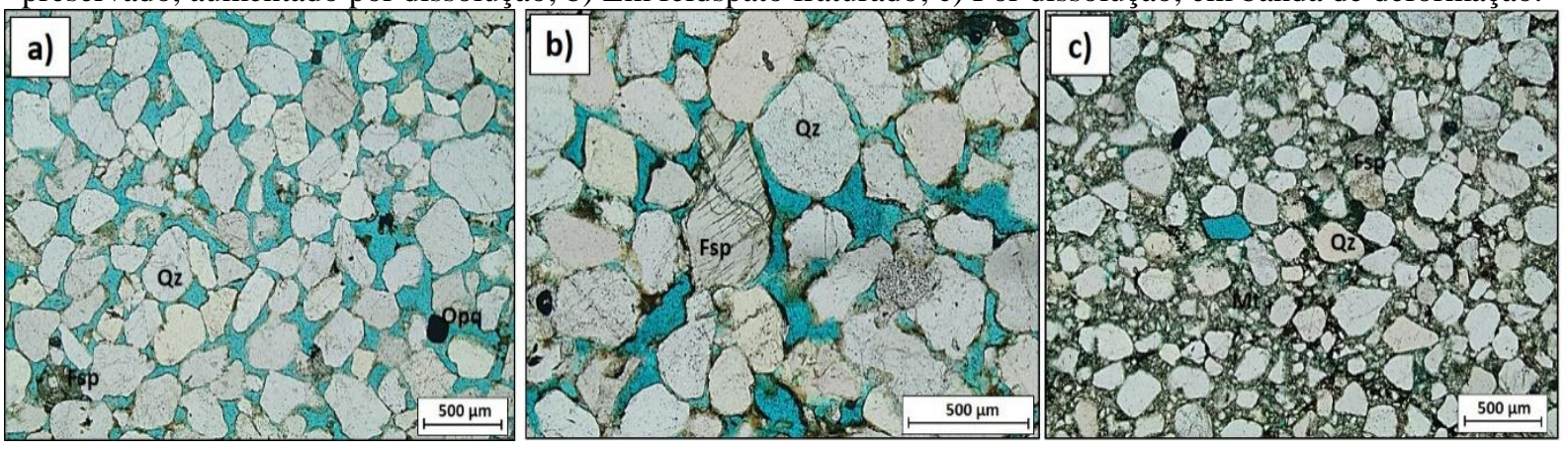

\subsubsection{Afloramento da Falha de Caritá (Grupo Massacará)}

A rocha hospedeira no afloramento da Falha de Caritá também foi classificada como arcósio a subarcósio (figura 7.14), com esfericidade média a alta, porém mal selecionado com tamanhos de grãos variando de areia fina $(0,08 \mathrm{~mm})$ a muito grossa $(1,65 \mathrm{~mm})$, predominando a fração areia média $(0,337 \mathrm{~mm})$. O empacotamento nessas amostras também é frouxo a normal, predominando os contatos entre grãos do tipo pontual e grão/ não-grão. Assim como no afloramento anterior, contatos longos, côncavo-convexos e suturados foram considerados traço a raros.

Os constituintes primários predominantes são o quartzo $(25,3$ a 40,3\%) e o feldspato $(7,5$ a 19,5\%), este último como grãos parcialmente dissolvidos ou alterados. Essas amostras também apresentam maior quantidade de fragmentos líticos $(0,3$ a 1,8\%). Poucos minerais acessórios foram identificados, como moscovita e epidoto $(0,3 \%)$. 
Figura 7. 14 - Diagrama de classificação dos arenitos constituintes do afloramento da Falha de Caritá (Grupo Massacará) (Folk, 1974).

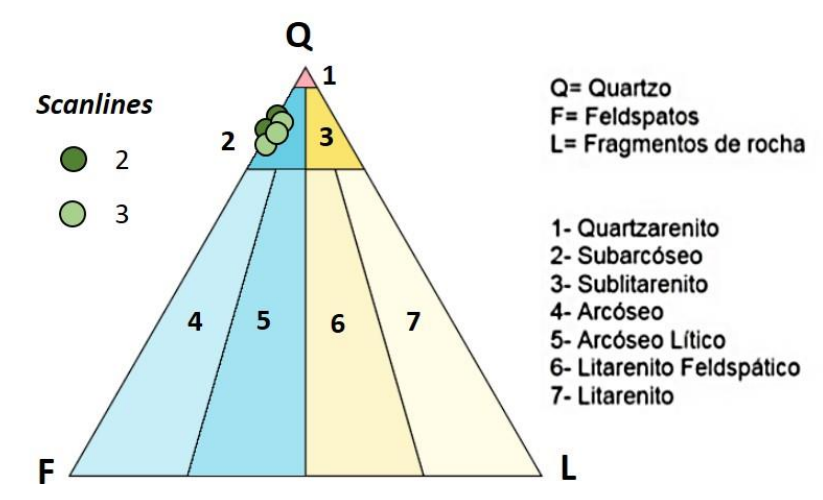

Os constituintes diagenéticos observados foram: projeções prismáticas de quartzo $(0,5$ a $2,0 \%)$ e feldspato (0,3 a 2,0\%), argilominerais (2,8 a 11,3\%) e óxidos/hidróxidos de ferro (2,5 a 5,8\%). A dissolução do feldspato também foi comumente observada (figura 7.15d). Minerais opacos (figura 7.15a) e nontronita (figura 7.15c), um membro rico em ferro do grupo da esmectita foi identificado por SEM-EDS em poros intergranulares e gerados por fratura, predominando como revestimento de grão. A deformação incipiente de grãos dúcteis como a muscovita (figura 7.15b) também indica a pouca influência da compactação na redução da porosidade das amostras.

Figura 7. 15 - Principais feições diagenéticas (crescimento secundário de quartzo, alteração de minerais primários para argilomineral ou mineral opaco, deformação de grão dúctil, dissolução) observadas por MEV e microscopia óptica. $\mathrm{Bt}=$ Biotita; $\mathrm{Fl}=$ Fragmento lítico; Fsp=Feldspato; Ms=Moscovita; Opq=Minerais opacos;

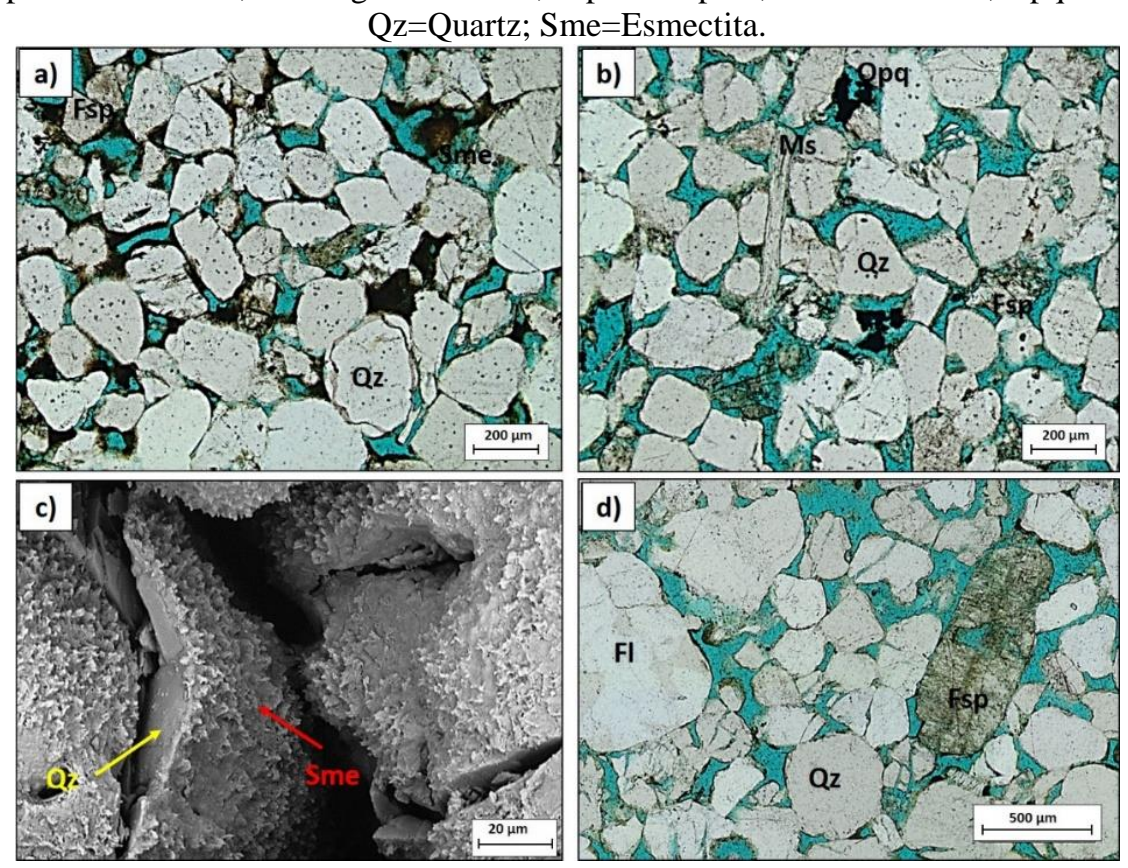

Fraturas intra e transgranulares em grãos de quartzo e feldspato são mais comuns nas amostras deste afloramento (figura 7.16a). Embora estejam associadas a uma configuração 
estrutural diferente, as bandas também são cisalhantes com uma componente compactacional, nas quais predomina o fluxo cataclástico. Em seção delgada, apresentam limites difusos, não sendo possível distinguir a zona de dano do núcleo. Porém, em um fragmento analisado em $\mathrm{MEV}$, foi possível observar a transição da rocha hospedeira para o núcleo da banda, onde predomina a matriz tectônica (figura 7.16b).

Figura 7. 16 - Principais feições microestruturais presentes nas amostras: a) Fraturas intra- e transgranular; b) Zoneamento presente em banda de deformação. RH=Rocha hospedeira; ZD=Zona de dano; NC=Núcleo da banda.
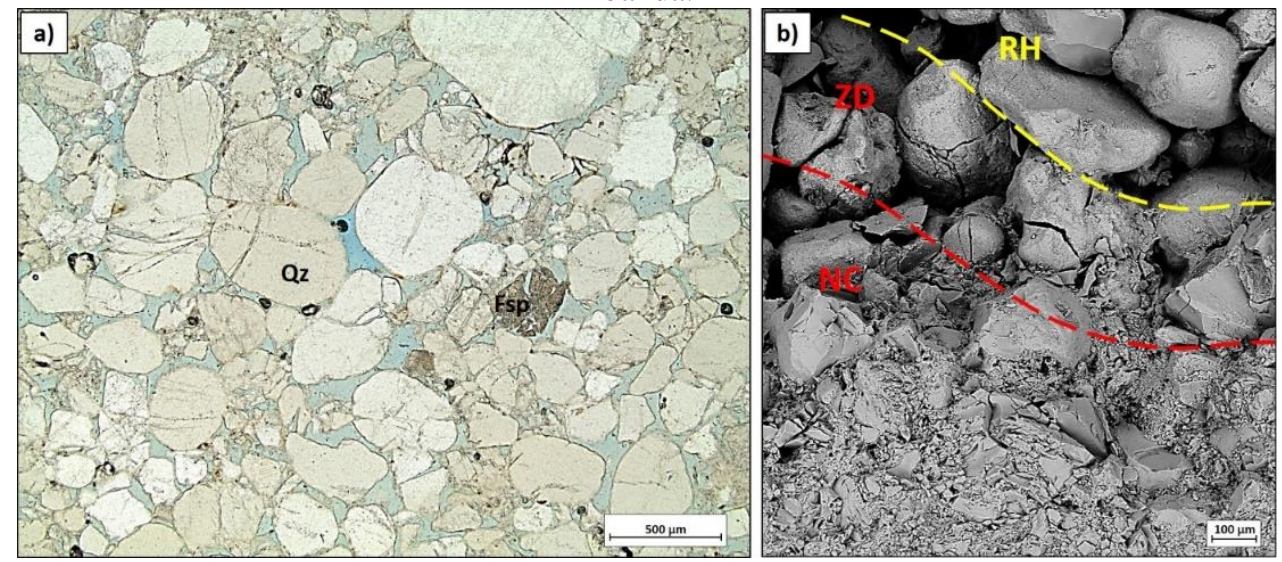

A amostra analisada por $\mu \mathrm{FRX}$, deste afloramento, foi a J3A cuja lâmina é totalmente constituída pela banda de deformação (figura 7.17). A distribuição do Si ressalta os poros (em preto) e a partir do conteúdo de $\mathrm{Ca}$, nota-se que este elemento está concentrado nos poros. Isso pode ser indicativo da geração de porosidade no interior da banda por dissolução de plagioclásio. Além disso, a concentração de Fe paralela à orientação da banda, também demarcar a direção do fluxo cataclástico.

Figura 7. 17 - Mapa de distribuição dos elementos químicos em amostra, da scanlinescanline 3, totalmente constituída por banda. a) Conteúdo de Si condizente com o arcabouço da rocha, evidenciando os poros, em preto; b) Maior concentração de Ca associada aos poros; c) Concentração de Fe paralela à direção do fluxo cataclástico.
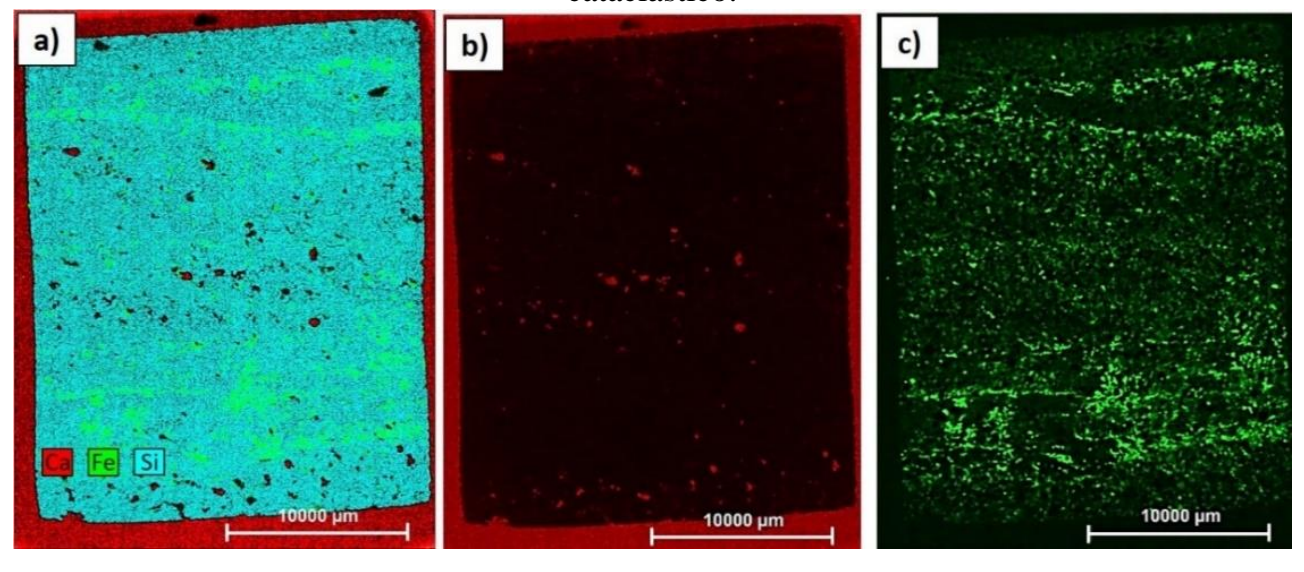
Nessas amostras também foram identificados poros primários (figura 7.18a), ampliados por dissolução de minerais (figura 7.18b) e/ou intenso fraturamento de grãos de quartzo, principalmente (figura 7.18c). Poros por dissolução total de feldspato também foram observado nas bandas de deformação. Os valores médios de raio obtidos para as amostras foram de 42,9 $\mu \mathrm{m}$ (MAS3D). Como a seção delgada da amostra MAS3A é totalmente constituída pela banda, não foi possível determinar o tamanho dos poros primários. Contudo, apesar de serem mais comuns os poros com raio de 1,6 $\mu \mathrm{m}$, também identificamos um tamanho médio de $96,1 \mu \mathrm{m}$ associado aos poros por dissolução total de feldspatos.

Figura 7. 18 - Fotomicrografias mostrando os tipos de poros: a) Primário parcialmente preservado, aumentado por dissolução; b) Em fraturas; c) Por dissolução.

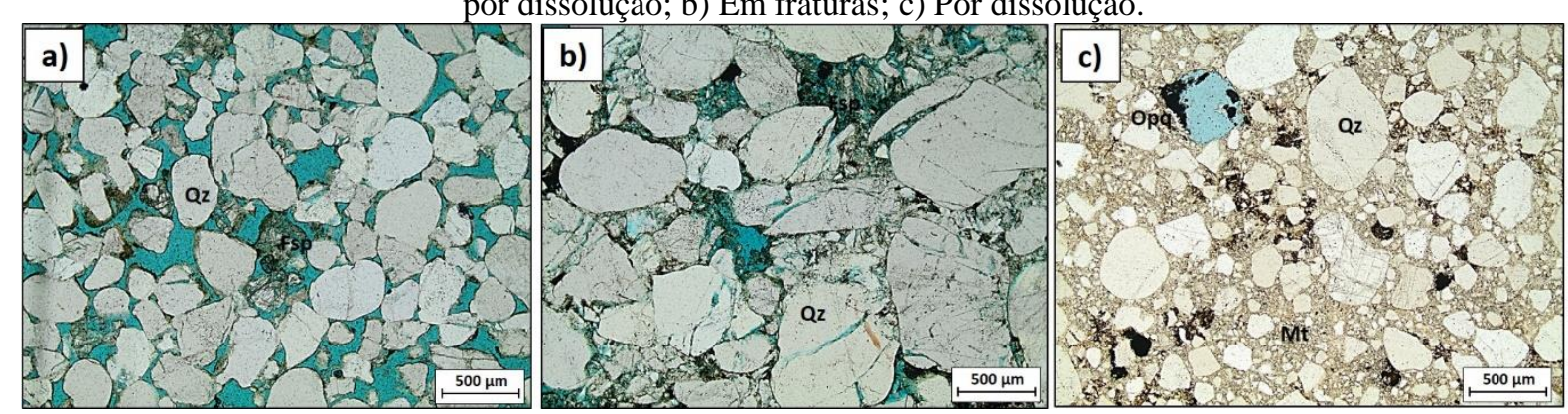

\subsection{Mineralogia magnética}

As amostras do Grupo Ilhas apresentam maior suscetibilidade magnética do que as do grupo Massacará, com valores entre $4,13 \times 10^{-6} \mathrm{e} 42,45 \times 10^{-6}$ na primeira unidade, e $1,90 \times 10^{-6} \mathrm{a}$ $10,22 \times 10^{-6}$ na segunda. Os loops de histerese de todas as amostras exibiram comportamentos para- e ferromagnéticos (figura 7.19). Foi realizada a correção do efeito paramagnético, com um campo magnético máximo de $700 \mathrm{mT}$ a fim de melhor observar a influência das partículas ferromagnéticas. Após a correção da fração paramagnética, pode-se observar o comportamento denominado "cintura de vespa", revelando uma mistura de minerais ferromagnéticos com coercividades contrastantes. Essa forma da curva se apresenta mais sutil em algumas amostras (ILH1A, MAS2B, MAS3B e MAS3B) do que em outras (ILH1C, ILH1D, ILH2A, ILH2C, ILH2E, MAS2A e MAS3A), como mostrado nas figuras 7.19A e 7.19B, respectivamente. 
Figura 7. 19 - Exemplos de curvas de histerese medidas (em cinza) e com a correção do efeito paramagnético (em preto).
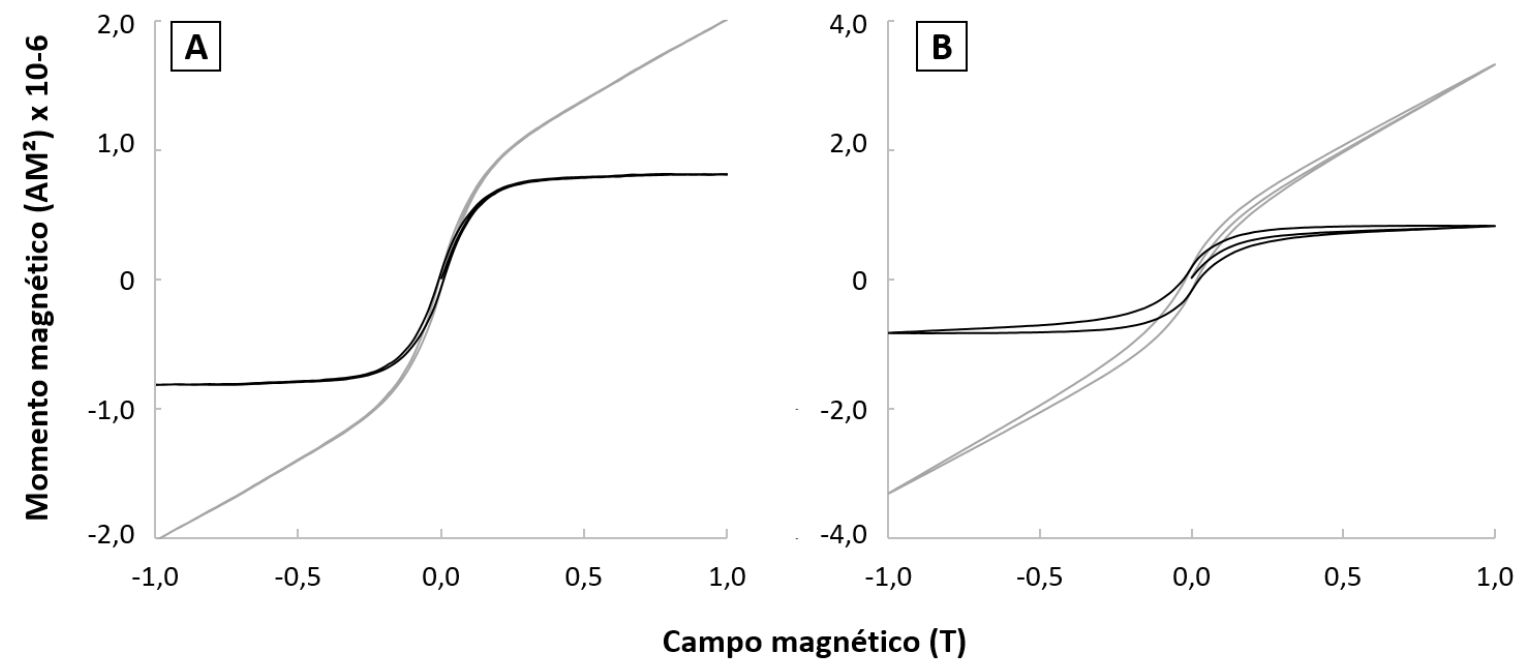

Após aquisição da magnetização remanente isotérmica (IRM, em inglês), o comportamento das curvas confirmou a mistura entre minerais de alta e de baixa coercividade em praticamente todas as amostras. No caso da amostra ILH2C, que alcançou o valor de saturação em campos próximos a 300 mT (figura 7.20), os dados indicam a predominância de minerais de mais baixa coercividade.

Figura 7. 20 - Curvas de aquisição IRM para as amostras dos grupos Ilhas e Massacará.

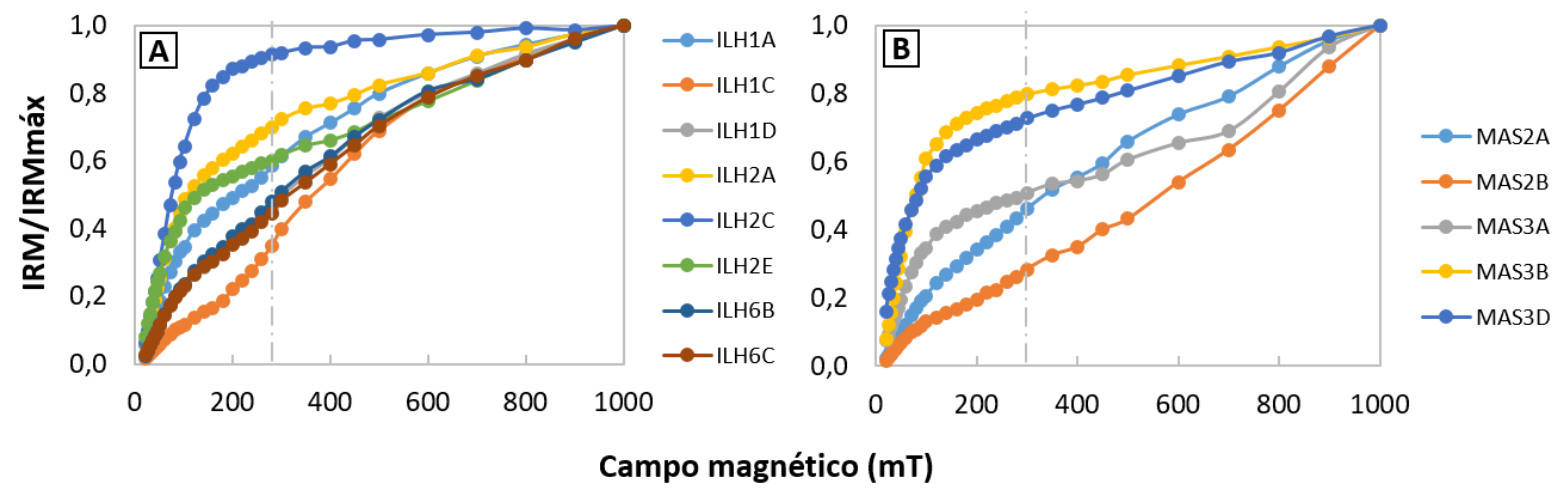

No espectro de coercividade, decomposto a partir das curvas $I R M$, foram identificadas as contribuições das fases magnéticas de diferentes coercividades (figura 7.21). Os valores do campo magnético (Bh) e do parâmetro de dispersão (DP) mostram o predomínio de magnetita e hematita nas amostras do Grupo Ilhas, sendo que em ILH6B também ocorre goethita. Nas amostras do Grupo Massacará os valores correspondem àqueles esperados para magnetita e goethita. 
Figura 7. 21 - Gráfico com as curvas de ajuste mostrando a contribuição de cada fase com diferentes coercividades em amostras representativas dos grupos Ilhas (A-B) e Massacará (C-D).

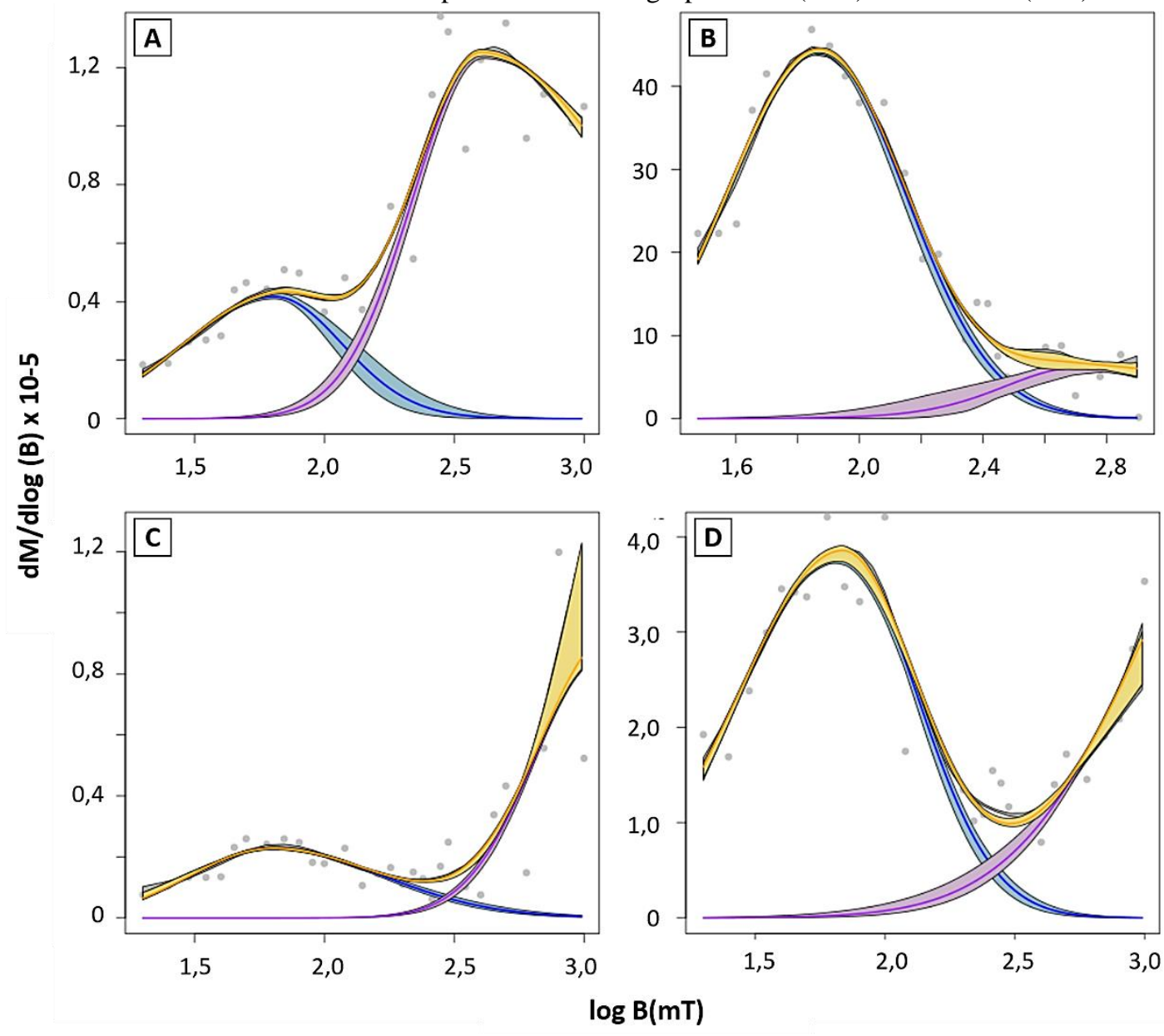

A contribuição da magnetita detrítica e magnetofósseis de baixa coercividade no conteúdo de minerais opacos das amostras varia de 12 a 90\% (Grupo Ilhas) e 14 a $75 \%$ (Grupo Massacará). Para a hematita, os valores são de 13 a $88 \%$ e 25 a $81 \%$, respectivamente. Nas amostras do Grupo Massacará há o predomínio da goethita como mineral de alta coercividade, com valores de 25 a 61\%, enquanto no Grupo Ilhas ocorre na proporção de 0,9 a 49 (tabela 7.1).

Tabela 7.1 - Fases minerais magnéticas obtidas a partir do espectro de coercividade.

\begin{tabular}{|c|c|c|c|c|c|c|c|c|c|}
\hline \multirow{2}{*}{ Amostras } & \multicolumn{9}{|c|}{ Fases magnéticas } \\
\hline & Bh & DP & OC $(\%)$ & Bh & DP & $\mathrm{OC}(\%)$ & Bh & DP & OC $(\%)$ \\
\hline ILH1A & $1,70 \pm 0,03$ & $0,32 \pm 0,02$ & 37 & $2,71 \pm 0,02$ & $0,36 \pm 0,01$ & 63 & - & - & - \\
\hline ILH1C & $1,71 \pm 0,06$ & $0,33 \pm 0,04$ & 12 & $2,76 \pm 0,01$ & $0,36 \pm 0,01$ & 88 & - & - & - \\
\hline ILH1D & $1,74 \pm 0,02$ & $0,31 \pm 0,02$ & 26 & $2,86 \pm 0,02$ & $0,44 \pm 0,02$ & 74 & - & - & - \\
\hline ILH2A & $1,76 \pm 0,02$ & $0,35 \pm 0,01$ & 61 & $2,49 \pm 0,04$ & $0,19 \pm 0,03$ & 13 & $3,06 \pm 0,06$ & $0,39 \pm 0,06$ & 26 \\
\hline ILH2C & $1,85 \pm 0,01$ & $0,29 \pm 0,00$ & 90 & $2,95 \pm 0,07$ & $0,42 \pm 0,07$ & 10 & - & - & - \\
\hline ILH2E & $1,63 \pm 0,02$ & $0,40 \pm 0,01$ & 51 & - & - & - & $3,14 \pm 0,05$ & $0,43 \pm 0,03$ & 49 \\
\hline ILH6B & $1,92 \pm 0,07$ & $0,40 \pm 0,05$ & 37 & $2,69 \pm 0,04$ & $0,29 \pm 0,02$ & 54 & $3,17 \pm 0,09$ & $0,20 \pm 0,03$ & 9 \\
\hline ILH6C & $1,81 \pm 0,03$ & $0,27 \pm 0,02$ & 28 & $2,77 \pm 0,04$ & $0,34 \pm 0,03$ & 72 & - & - & - \\
\hline MAS2A & $1,76 \pm 0,03$ & $0,30 \pm 0,02$ & 19 & $2,84 \pm 0,08$ & $0,43 \pm 0,04$ & 81 & - & - & - \\
\hline MAS2B & $1,72 \pm 0,05$ & $0,33 \pm 0,05$ & 14 & $2,50 \pm 0,04$ & $0,21 \pm 0,03$ & 25 & $3,06 \pm 0,03$ & $0,22 \pm 0,02$ & 61 \\
\hline
\end{tabular}




\begin{tabular}{llllllllll}
\hline MAS3A & $1,89 \pm 0,02$ & $0,37 \pm 0,01$ & 48 & - & - & - & $3,13 \pm 0,05$ & $0,29 \pm 0,03$ & 52 \\
\hline MAS3B & $1,75 \pm 0,02$ & $0,35 \pm 0,01$ & 75 & - & - & - & $3,24 \pm 0,17$ & $0,35 \pm 0,05$ & 25 \\
\hline MAS3D & $1,48 \pm 0,11$ & $0,52 \pm 0,07$ & 52 & - & - & - & $3,12 \pm 0,19$ & $0,44 \pm 0,06$ & 48 \\
\hline
\end{tabular}

\subsection{Petrofísica básica}

Estudos petrofísicos baseados na técnica de ressonância magnética nuclear (RMN) necessitam de correlação com outras técnicas como saturação por fluido, porosimetria a gás, descrição de lâminas petrográficas, dentre outros. Por esse motivo, os dados adquiridos (tabela 7.2) foram tratados estatisticamente e correlacionados para corroborar as interpretações baseadas nos dados de RMN.

Tabela 7.2 - Parâmetros petrofísicos para as amostras dos grupos Ilhas (Falha do Macaco) e Massacará (Falha de Caritá). BDs = Quantidade de bandas de deformação obtida por microtomografia de computadorizada de raios-X e microscopia óptica; $\phi=$ dados de porosidade; $\mathrm{k}=$ permeabilidade; $\mathrm{x}=$ suscetibilidade magnética; $<$ res. $=$ abaixo do limite de detecção do equipamento; ${ }^{1}$ Plugue paralelo à direção de mergulho da banda; ${ }^{2}$ Plugue perpendicular à direção de mergulho da banda.

\begin{tabular}{|c|c|c|c|c|c|c|c|c|}
\hline $\begin{array}{l}\text { Amostras } \\
\text { principais }\end{array}$ & $\begin{array}{l}\text { BDs } \\
(\%)\end{array}$ & $\begin{array}{c}\text { 申lâmina } \\
(\%)\end{array}$ & $\begin{array}{c}\Phi_{\text {água }} \\
(\%)\end{array}$ & $\begin{array}{c}\phi \mathrm{RMN} \\
(\%)\end{array}$ & $\begin{array}{c}\text { densidade } \\
(\%)\end{array}$ & $\begin{array}{c}\Phi_{\text {gás }} \\
(\%)\end{array}$ & $\begin{array}{c}\mathbf{k} \\
(\mathrm{mD})\end{array}$ & $\begin{array}{c}\mathrm{Km} \\
\left(10^{-6} \mathrm{SI}\right)\end{array}$ \\
\hline ILH1 $^{1}{ }^{1}$ & 100,0 & - & 11,77 & 11,28 & 13,96 & 14,18 & 97,05 & 4,13 \\
\hline ILH1A $^{2}$ & 100,0 & 8,3 & 12,12 & 12,24 & 12,45 & 12,39 & 1,92 & 4,13 \\
\hline ILH1C & - & 19 & 16,68 & 16,23 & 17,29 & 17 & 144,50 & 37,18 \\
\hline ILH1D & 11,1 & 18,5 & 19,35 & 19 & 20,68 & 20,63 & 291,65 & 26,48 \\
\hline ILH2A & - & 16,5 & 14,84 & 13,68 & 15,47 & 15,71 & 251,75 & 17,37 \\
\hline ILH2C & - & 17,5 & 16,04 & 15,52 & 16,60 & 16,76 & 32,88 & 23,84 \\
\hline ILH2E & - & 22,3 & 18,66 & 18,09 & 19,32 & 19,41 & 1,69 & 42,45 \\
\hline ILH6B & 2,6 & 24,3 & 26,77 & 26,35 & 26,89 & 27,07 & 530,37 & 16,89 \\
\hline ILH6C & 47,1 & 20,4 & 19,99 & 19,5 & 20,75 & 20,77 & 2,27 & 24,46 \\
\hline MAS2A & - & 14,3 & 17,07 & 16,28 & 18,11 & 18,16 & 116,80 & 7,07 \\
\hline MAS2B & - & 10,3 & 13,86 & 13,62 & 14,72 & 14,75 & 15,40 & 6,63 \\
\hline $\mathrm{MAS} \mathrm{A}^{1}$ & 100,0 & - & 7,49 & 7,08 & 7,52 & 7,38 & $<1 . d$ & 1,99 \\
\hline MAS3A ${ }^{2}$ & 100,0 & 5,3 & 6,44 & 5,57 & 7,49 & 7,51 & $<1 . d$ & 1,99 \\
\hline MAS3B & - & 14,5 & 11,86 & 11,67 & 13,58 & 13,71 & 1,90 & 1,90 \\
\hline MAS3D & 74,5 & 17,8 & 12,89 & 12,8 & 13,96 & 13,95 & 3,16 & 10,22 \\
\hline
\end{tabular}

A porosidade obtida por saturação de água e densidade mostraram uma boa correlação positiva $\left(\mathrm{R}^{2}=0,99\right)$ com os valores de porosidade a gás. Apesar da menor representatividade da lâmina delgada em relação aos plugues heterogêneos devido às bandas, a porosidade estimada 
por contagem modal também apresentou boa correlação positiva $\left(\mathrm{R}^{2}=0,86\right)$ (figura 7.22). Comparando com a porcentagem de bandas nos plugues (BDs), a porosidade obtida por todos os métodos apresentou boa correlação negativa $\left(\mathrm{R}^{2}=0,79\right.$ a 0,90$)$. Isso deixa claro a influência das bandas de deformação na redução de porosidade em ambos os afloramentos analisados

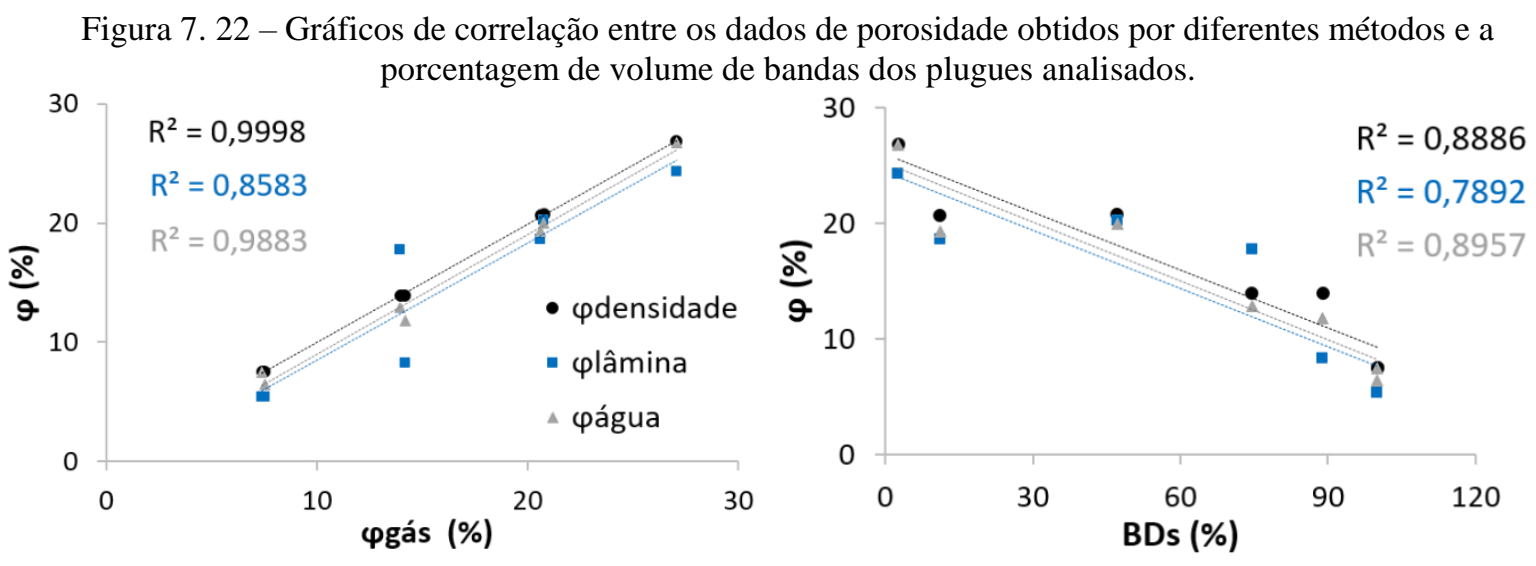

Os valores de permeabilidade apresentaram variação significativa de acordo com a quantidade de bandas, mas ainda assim apresentou boa correlação positiva com os valores de porosidade, e negativa com o volume de bandas (figura 7.23). Houve redução de até duas ordens de magnitude das amostras com menos bandas para amostras com mais bandas, principalmente quando a banda é perpendicular ou transversal ao comprimento do plugue, como em ILH1 $\mathrm{A}^{2}$, ILH2E, ILH6C e MAS3D. Em plugues com orientações diferentes da banda de deformação, a redução também foi de duas ordens de magnitude, como em ILH1A. Essa influência não está apenas relacionada à orientação da banda, mas também à sua espessura, como é o caso da amostra ILH2C. A presença de bandas transversais, porém de menor espessura em comparação com as demais citadas anteriormente, não impacta significativamente na redução de permeabilidade. A comparação dos dados de porosidade e permeabilidade a gás mostrou uma boa correlação positiva $\left(\mathrm{R}^{2}=0,81\right)$ para a maioria das amostras de ambos os afloramentos. Porém, as amostras da scanline 2 (Falha do Macaco) e a ILH6C (figura 7.23), indicam uma correlação negativa. Isso ocorre porque essas amostras em particular apresentam bandas transversais ao comprimento do cilindro, reduzindo significativamente a permeabilidade, ainda que os valores de porosidade sejam altos para o tipo de amostra analisado. 
Figura 7. 23 - Comparação entre os valores de porosidade e permeabilidade a gás, para ambos os afloramentos. Em preto, correlação entre todas as amostras de ambos os afloramentos, exceto às referentes à scanline ILH2C e amostra ILH6C (em azul).

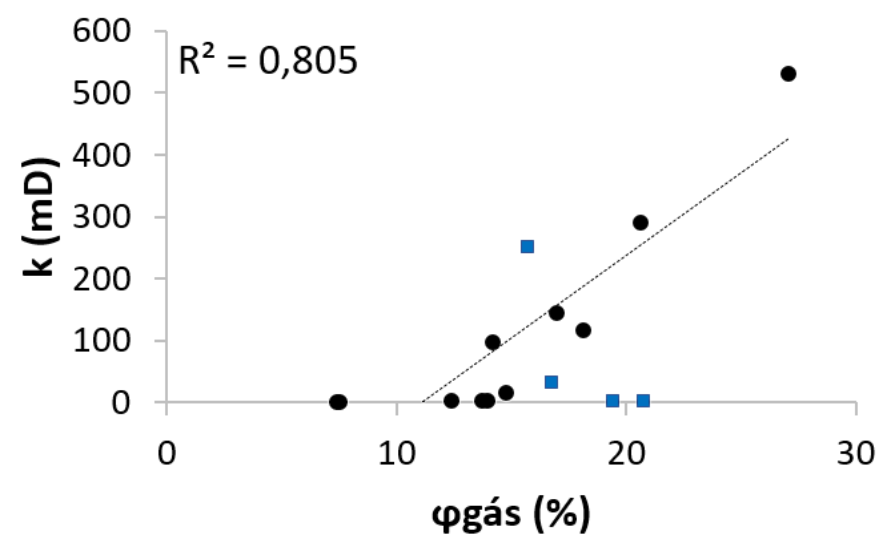

\subsection{Ressonância Magnética Nuclear}

A porosidade determinada por ressonância magnética nuclear (RMN) depende da total saturação da rocha pelo fluido contendo os núcleos de hidrogênio cujo sinal de precessão é medido. Então, os dados de porosidade por RMN foram primeiramente correlacionados com os dados obtidos por saturação de fluido (figura 7.24). Os dados apresentaram uma ótima correlação positiva, indicando que o sinal de RMN realmente representa a maior parte dos poros preenchidos pelo fluido e pouca variação de porosidade, ao longo do mesmo bloco, apesar das heterogeneidades impostas pelas bandas. Os valores de porosidade adquiridos por RMN apresentaram boa correlação positiva com os valores obtidos por porosidade a gás $(\mathrm{R}=0,99)$, densidade $(\mathrm{R}=0,98)$ e lâmina delgada $(\mathrm{R}=0,86)$. Comparado ao volume de bandas, houve uma boa correlação negativa $(\mathrm{R}=0,90)$, também indicando que quanto maior a proporção de bandas nos plugues, menor a porosidade.

Figura 7. 24 - Comparação entre os valores de porosidade obtidos por saturação de fluido e por RMN.

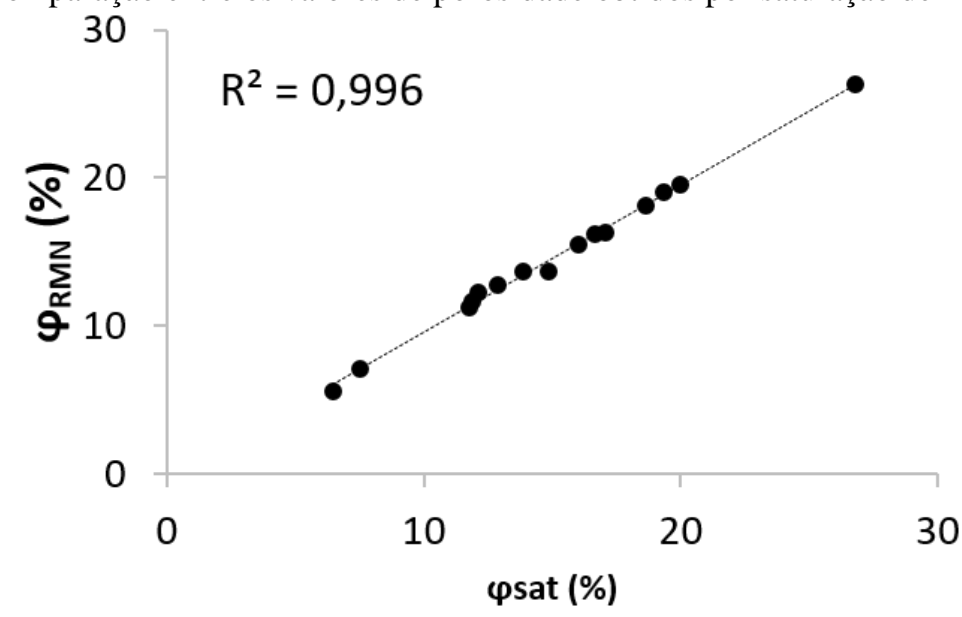


Os dados de tempos de relaxação transversal $\left(\mathrm{T}_{2}\right)$ obtidos com a sequência CPMG foram tratados com a aplicação da transformada inversa de Laplace, gerando uma distribuição de $\mathrm{T}_{2} \mathrm{a}$ partir da curva de decaimento exponencial do sinal. A área da curva corresponde à porosidade total, contudo foi necessária a aplicação de uma curva de ajuste log-normal para identificar a contribuição de cada pico dos tempos de relaxação para a intensidade do sinal. Esse tipo de dado apresenta um cut-off de $3 \mathrm{~ms}$, abaixo do qual o $\mathrm{T}_{2}$ é associado principalmente aos microporos de argilas, e de $33 \mathrm{~ms}$, acima do qual há fluido livre nos meso e macroporos das amostras.

Primeiramente, a variação na intensidade dos picos de $\mathrm{T}_{2}$ das amostras com menos bandas (ILH1D, ILH6B e MAS3D), relativamente, foi comparada com as amostras com mais bandas (ILH1 A ${ }^{1}$, ILH6C, MAS3A ${ }^{1}$ ) ao longo da mesma scanline. Então, foi observada uma diminuição da intensidade do pico mais longo de $\mathrm{T}_{2}(>75 \mathrm{~ms})$ e um aumento da intensidade, principalmente, dos picos menores e intermediários (de 3 a 50ms), conforme o aumento do volume de bandas (figura 7.25). Isso mostra um aumento na quantidade de poros com um menor tempo de relaxação nas amostras com mais bandas.

Figura 7. 25 - Distribuição dos tempos de relaxação transversal para as amostras cujo volume de bandas foi quantificado, nas scanlines ILH1 (A), ILH6 (B) e MAS3 (C).
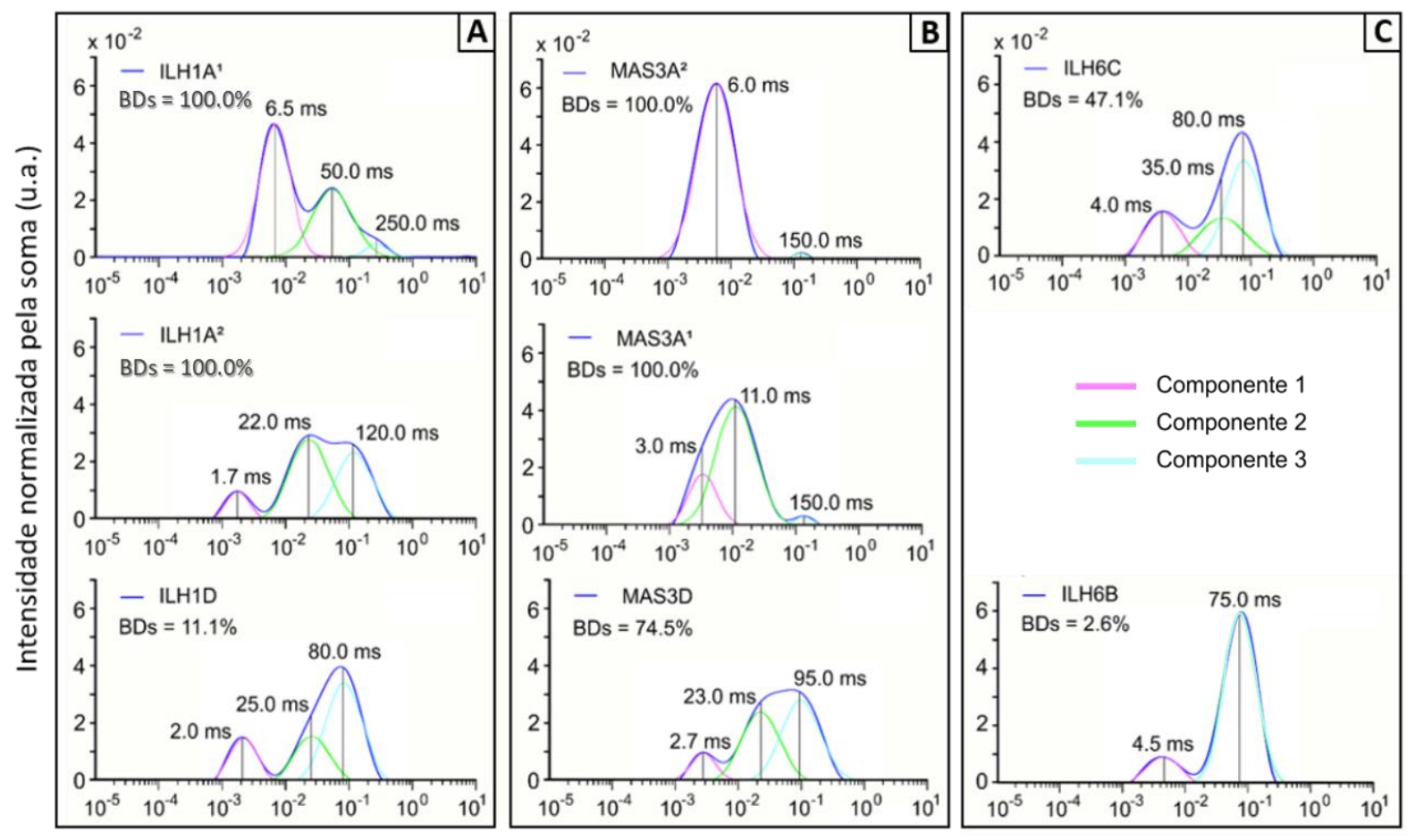

$$
\mathrm{T}_{2} \text { (s) }
$$


Para diferentes orientações do plugue em relação à banda, pode ser observada uma divisão de picos intermediários das amostras com banda perpendicular ao plugue para as com bandas paralelas. As amostras ILH1A ${ }^{1}$, ILH1 $^{2}$, MAS3A ${ }^{1}$ e MAS3A² também apresentam uma menor contribuição de $\mathrm{T}_{2}$ acima de 120 a $250 \mathrm{~ms}$. Analisando a variação de intensidade dos picos em relação ao volume de bandas para as amostras dos diferentes afloramentos, há uma distribuição de $\mathrm{T}_{2}$ muito semelhante para as amostras ILH1D e MAS3D. Ambas as amostras apresentam bandas transversais ao comprimento do plugue e tem volume de banda de 11,1 e 74,5, respectivamente. Pode ser observado claramente um aumento de intensidade de $\mathrm{T}_{2}$ intermediário (de $26.0 \%$ para $39,0 \%$ ) e uma diminuição na intensidade de $\mathrm{T}_{2}$ mais longo (de $54.0 \%$ para $49,0 \%$ ), como na tabela 7.3 .

Tabela 7.3 - Contribuição dos picos de intensidade do tempo de relaxação transversal.

\begin{tabular}{ccccccc}
\hline \multirow{2}{*}{ Amostras } & \multicolumn{2}{c}{ Pico 1 } & \multicolumn{2}{c}{ Pico 2 } & \multicolumn{2}{c}{ Pico 3 } \\
\cline { 2 - 6 } & T2 (s) & Área (\%) & T2 (s) & Área (\%) & T2 (s) & Área (\%) \\
\hline ILH1 A $^{1}$ & 0,007 & 57,0 & 0,050 & 39,0 & 0,250 & 4,0 \\
\hline ILH1A $^{2}$ & 0,002 & 12,0 & 0,022 & 50,0 & 0,120 & 38,0 \\
\hline ILH1D $^{*} 0,002$ & 20,0 & 0,025 & 26,0 & 0,080 & 54,0 \\
\hline ILH6B & 0,005 & 15,0 & - & 0,0 & 0,075 & 85,0 \\
\hline ILH6C & 0,004 & 23,0 & 0,035 & 27,0 & 0,080 & 50,0 \\
\hline MAS3A & 0,003 & 24,0 & 0,011 & 73,0 & 0,150 & 3,0 \\
\hline MAS3A & 0,006 & 98,0 & - & 0,0 & 0,150 & 2,0 \\
\hline MAS3D & 0,003 & 12,0 & 0,023 & 39,0 & 0,095 & 49,0 \\
\hline
\end{tabular}

Para verificar a dependência da intensidade do sinal de $\mathrm{T}_{2}$ com a quantidade de bandas, foi comparado o volume percentual de bandas com a área percentual de cada contribuição das componentes de $\mathrm{T}_{2}$ das amostras. Observou-se uma melhor correlação entre a soma dos picos 1 ( $\mathrm{T}_{2}$ mais curto) e 2 ( $\mathrm{T}_{2}$ intermediário) (figura 7.26), interpretados como estando associados principalmente às bandas. 
Figura 7. 26 - Correlação entre o volume percentual de bandas de deformação nos plugues e a área percentual das componentes de tempo de relaxação transversal.

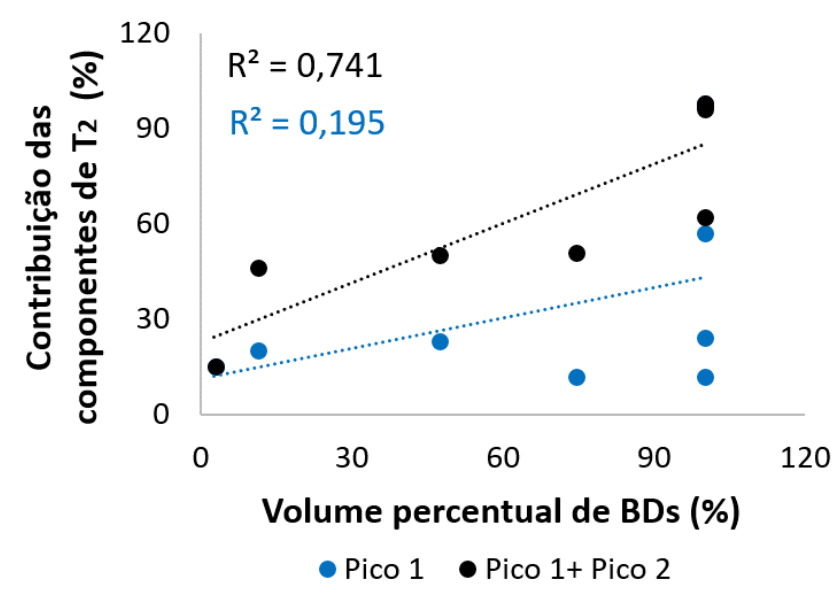

\subsection{Anisotropia de Susceptibilidade Magnética}

A partir dos blocos de rocha coletados para as análises petrofísicas, também foram extraídos os plugues de tamanho padrão (2,5cm de diâmetro x 2,0 a 2,2 cm de altura) para o estudo da anisotropia de susceptibilidade magnética (ASM). Contudo, nem todas as amostras geraram uma quantidade suficiente de cilindros que permitisse a aplicação das estatísticas de Jelinek (JELINEK, 1977).

Esta etapa do estudo foi dividida em duas partes: a primeira envolveu a identificação da foliação e/ou lineação magnética correspondente à orientação dos minerais magnéticos das amostras (plugues com dimensões padrão) e se há influência da orientação das bandas de deformação. Na segunda, foram selecionadas amostras correspondentes às bandas, porém com menores dimensões $(1,0 \mathrm{~cm}$ de diâmetro x 0,9 a $1,0 \mathrm{~cm}$ de altura), para impregnação com ferrofluido e verificação do alinhamento dos poros devido à deformação. O tamanho reduzido dos cilindros foi escolhido conforme a recomendação de Robion et al. (2014) para possibilitar uma impregnação mais eficiente em amostras pouco porosas e/ou permeáveis.

Do Grupo Ilhas, foram medidas as amostras ILH2C, ILH6B e ILH6C e a partir dos estereogramas, pode ser observada a semelhança de orientação com a foliação magnética, apesar dessas amostras apresentarem bandas com diferentes disposições espaciais ao longo dos respectivos plugues. Não foi possível estabelecer uma relação entre a orientação da foliação magnética e o plano da banda de deformação ou o plano de acamadamento da rocha (figura 7.27A). A estrutura presente na amostras ILH6C apresenta orientação N-S com mergulho de $72^{\circ}$ para leste, enquanto o plano de acamadamento tem orientação N-S porém com mergulho mais baixo $\left(40^{\circ}\right.$ a $\left.44^{\circ}\right)$. Nas amostras do grupo Massacará, a distribuição dos eixos principais 
se mostrou mais dispersa, não apresentando uma foliação magnética bem definida (figura 7.27B).

Figura 7. 27 - Comparação entre os eixos principais de anisotropia de susceptibilidade magnética e o padrão estrutural nas scanlines, nos afloramentos dos Grupo Ilhas (A) e Massacará (B), ao longo das quais as amostras foram coletadas. As linhas em preto, azul e vermelho em (B), correspondem às estruturas tipo Riedel $\mathrm{Y}, \mathrm{R}$ e R',

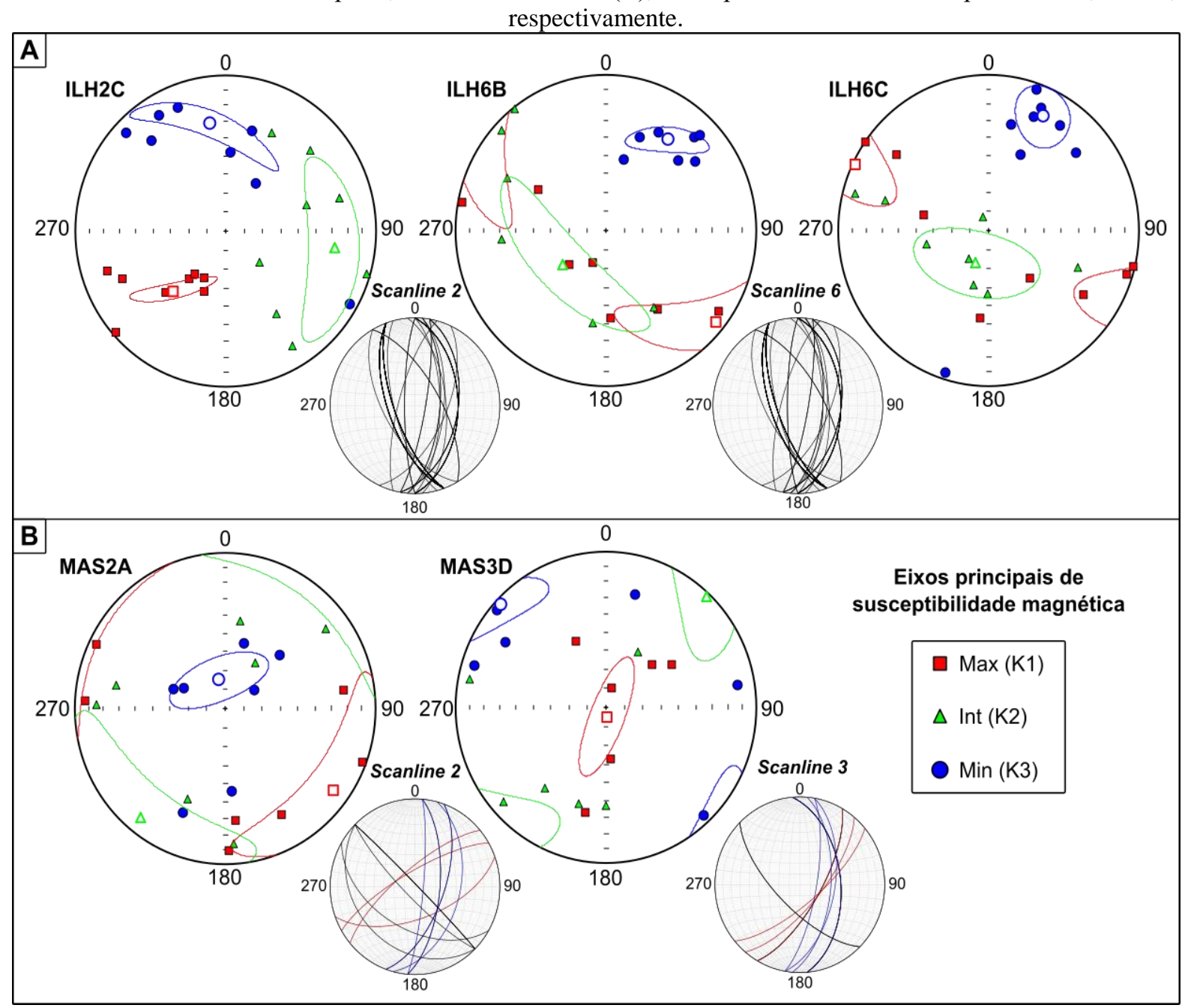

O parâmetro de forma $(\mathrm{T})$ indica uma trama com formato predominantemente oblato $(1>\mathrm{T}>0)$ para as amostras dos grupos Ilhas e Massacará. A relação entre o grau de anisotropia e a susceptibilidade magnética apresenta uma correlação negativa para todas as amostras, sendo mais expressiva no grupo Massacará, no qual as amostras apresentam menores valores de susceptibilidade magnética (figura 7.28). 
Figura 7. 28 - Gráficos mostrando a relação entre a) parâmetro de forma $(\mathrm{T})$ e grau de anisotropia $(\mathrm{Pj})$ e b) Variação do grau de anisotropia em função da susceptibilidade magnética $(\mathrm{Km})$, na amostras dos grupos Ilhas e
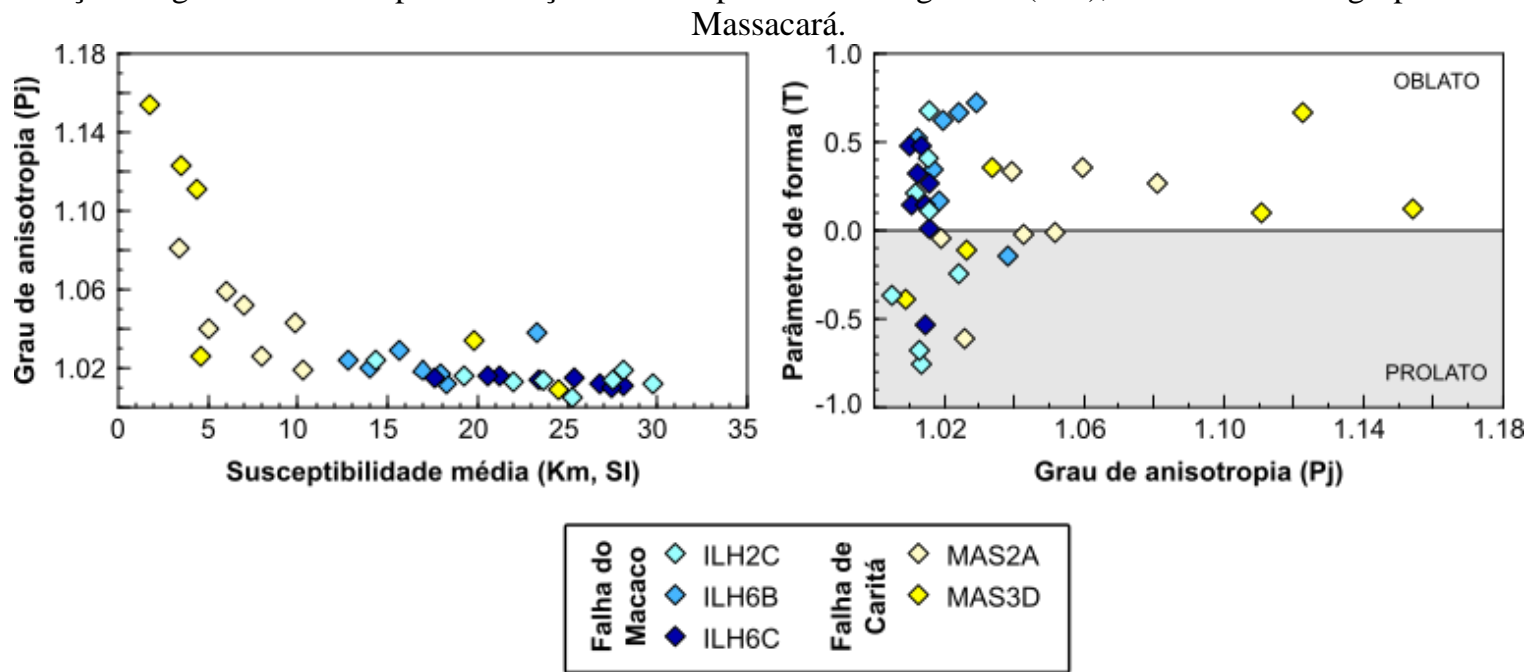

A baixa correlação entre as direções da foliação magnética e a orientação das bandas de deformação pode ser resultado da baixa susceptibilidade magnética das amostras. Esse parâmetro influencia significativamente os dados, resultando em erros maiores do que $20 \%$ para os eixos de anisotropia em diversos casos.

$\mathrm{Na}$ segunda etapa foi realizado o experimento com ferrofluido, no qual foram impregnadas as amostras correspondentes às bandas de deformação dos grupos Ilhas e Massacará. Essas amostras foram escolhidas devido a menor influência de prováveis estruturas primárias, de maneira que o ferrofluido pudesse refletir a estrutura porosa resultante do processo de deformação. Primeiramente, foi necessário garantir que as amostras tinham sido devidamente impregnadas. Para isso a porosidade por ferrofluido foi comparada com a porosidade por saturação de água. As amostras de ambos os afloramentos apresentaram boa correlação positiva entre os dados (figura 7.29).

Figura 7. 29 - Gráfico de correlação entre as medidas de porosidade em amostras saturadas com água e amostras impregnadas com ferrofluido, mostrando uma eficiente impregnação das amostras.

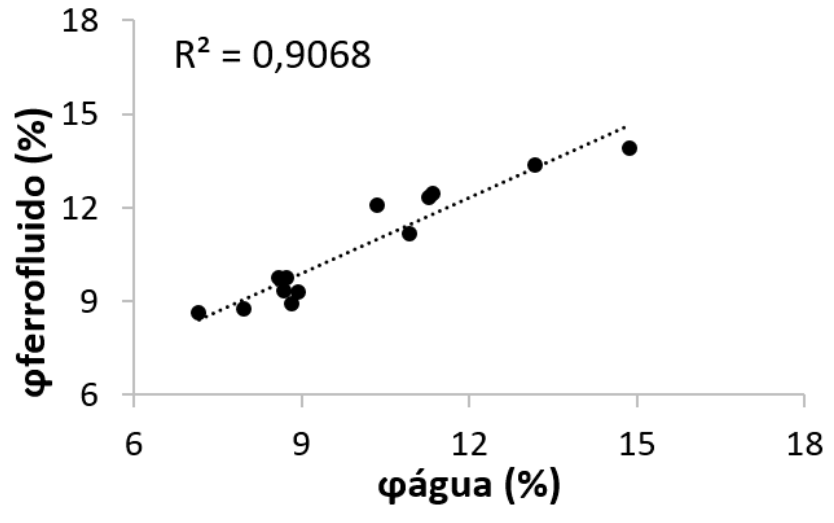


Na impregnação das amostras foi utilizado um ferrofluido contendo $1 \%$ de nanopartículas de magnetita superparamagnética. Esse valor é aplicado na literatura (e.g. ARONCHI, 2017; PARES et al., 2016; ROBION et al., 2014; PFLEIDERER \& HALL, 1990) para tamanhos de partícula em torno de $10 \mathrm{~nm}$, porém neste trabalho foram utilizadas partículas de 5,6 nm. Isso pode ter resultado em valores de susceptibilidade magnética da ordem de $10^{-4} \mathrm{SI}$, menores do que o ideal, pois se apresentam relativamente próximos à suscetibilidade das amostras. Outro parâmetro importante, medido antes da impregnação, foi o grau de anisotropia cujo valor ideal deve ser igual a 1 para que não haja influência nas medidas. Abaixo a tabela $7.4 \mathrm{com}$ os dados obtidos para ambas as amostras, antes e depois da impregnação com ferrofluido.

Tabela 7.4 - Parâmetros de anisotropia de susceptibilidade magnética para as amostras antes e após a impregnação com ferrofluido. L=lineação magnética; F=foliação magnética; $P j=$ grau de anisotropia; $\mathrm{T}=$ parâmetro de forma; $\mathrm{D}, \mathrm{I}=$ declinação e inclinação dos eixos de susceptibilidade magnética principais.

\begin{tabular}{|c|c|c|c|c|c|c|c|c|c|c|c|}
\hline \multirow{2}{*}{ Amostras } & \multicolumn{11}{|c|}{ Parâmetros pré-impregnação } \\
\hline & $\operatorname{Km}\left(10^{-6} \mathrm{SI}\right)$ & $\mathbf{L}$ & $\mathbf{F}$ & $\mathbf{P j}$ & $\mathbf{T}$ & Dmax & Imax & Dint & Iint & Dmin & Imin \\
\hline ILHA12 & $-6,51$ & 1,0189 & 1,006 & 1,0261 & $-0,5197$ & 223,2 & 40,6 & 15,2 & 45,8 & 120,5 & 14,3 \\
\hline ILHA13 & $-5,05$ & 1,0257 & 1,0085 & 1,0359 & $-0,4998$ & 353,4 & 83,7 & 215,1 & 4,7 & 124,7 & 4,2 \\
\hline ILHA14 & $-3,8$ & 1,0387 & 1,0236 & 1,0638 & $-0,2378$ & 188,6 & 35,5 & 315,5 & 40,1 & 74,4 & 29,9 \\
\hline ILHA15 & $-5,23$ & 1,0057 & 1,0123 & 1,0184 & 0,3682 & 162,2 & 43,3 & 28,1 & 36,4 & 278,1 & 24,8 \\
\hline ILHA103 & $-5,13$ & 1,0212 & 1,0181 & 1,0397 & $-0,0785$ & 354,6 & 24,5 & 193,8 & 64,2 & 88 & 7,5 \\
\hline MASA1 & $-9,11$ & 1,0193 & 1,0098 & 1,0298 & $-0,3265$ & 41,2 & 63,5 & 167 & 16,2 & 263,1 & 20,3 \\
\hline MASA2 & $-1,1$ & 1,0179 & 1,005 & 1,0242 & $-0,5601$ & 78,1 & 75,7 & 346,5 & 0,4 & 256,4 & 14,3 \\
\hline MASA107A & $-8,57$ & 1,0199 & 1,0059 & 1,0272 & $-0,538$ & 170,7 & 45,2 & 25,6 & 39,1 & 280,1 & 18,2 \\
\hline MASA107C & $-9,23$ & 1,0238 & 1,0144 & 1,0388 & $-0,2444$ & 35,7 & 63,6 & 182,1 & 22,5 & 277,7 & 13,2 \\
\hline MASA108 & $-8,6$ & 1,0107 & 1,0149 & 1,0259 & 0,1633 & 147,3 & 58,4 & 14,9 & 22,6 & 275,7 & 20,9 \\
\hline \multirow{2}{*}{ Amostras } & \multicolumn{11}{|c|}{ Parâmetros pós-impregnação } \\
\hline & $\operatorname{Km}\left(10^{-6} \mathrm{SI}\right)$ & $\mathbf{L}$ & $\mathbf{F}$ & $\mathbf{P j}$ & $\mathbf{T}$ & Dmax & Imax & Dint & Iint & Dmin & Imin \\
\hline ILHA12 & $-6,04$ & 1,0227 & 1,023 & 1,0462 & 0,0058 & 280,5 & 45 & 183,9 & 6,5 & 87,4 & 44,3 \\
\hline ILHA13 & $-2,22$ & 1,0827 & 1,0429 & 1,1313 & $-0,3082$ & 277 & 36,9 & 178,8 & 10,7 & 75,3 & 51 \\
\hline ILHA14 & $-3,78$ & 1,0787 & 1,0193 & 1,1055 & $-0,5968$ & 292,7 & 41,3 & 169,5 & 32 & 56,3 & 32,2 \\
\hline ILHA15 & $-2,16$ & 1,0643 & 1,0669 & 1,1355 & 0,0191 & 300,4 & 38,2 & 181,8 & 31,4 & 65,4 & 36,1 \\
\hline ILHA103 & $-2,11$ & 1,0887 & 1,0247 & 1,1217 & $-0,5535$ & 175,3 & 41,6 & 322,6 & 43,5 & 69,5 & 17 \\
\hline MASA1 & $-6,61$ & 1,0263 & 1,0216 & 1,0486 & $-0,0956$ & 61 & 65,9 & 174,2 & 10 & 268,2 & 21,7 \\
\hline MASA2 & $-7,02$ & 1,0207 & 1,0178 & 1,0389 & $-0,0744$ & 46,2 & 71,5 & 177,9 & 12,5 & 270,9 & 13,4 \\
\hline MASA107A & $-6,89$ & 1,0224 & 1,0086 & 1,0322 & $-0,4406$ & 132,6 & 73,5 & 18,8 & 6,8 & 287 & 15 \\
\hline MASA107C & $-6,9$ & 1,0239 & 1,0147 & 1,0393 & $-0,2351$ & 85,4 & 68,7 & 186,5 & 4,3 & 278,1 & 20,8 \\
\hline MASA108 & $-2,94$ & 1,0403 & 1,0288 & 1,0706 & $-0,1631$ & 123,6 & 50,2 & 10,2 & 18,3 & 267,4 & 33,9 \\
\hline
\end{tabular}

Como pode ser observado na figura 7.30, as amostras utilizadas no estudo de anisotropia de susceptibilidade magnética com ferrofluido já mostram a presença de uma foliação magnética de orientação N-S. Essa direção está associada à banda de deformação em cada amostra, uma vez que essas estruturas estão orientadas N-S com mergulho para oeste (ILH1A) e leste (MAS3A). Após a impregnação foi ressaltada a orientação média dos poros, indicada pelo Kmax, no mesmo sentido do mergulho. 
Figura 7. 30 - Estereogramas com a representação dos principais eixos de susceptibilidade magnética e suas elipses de confiança, para as amostras antes (A) e após (B) a impregnação com ferrofluido.

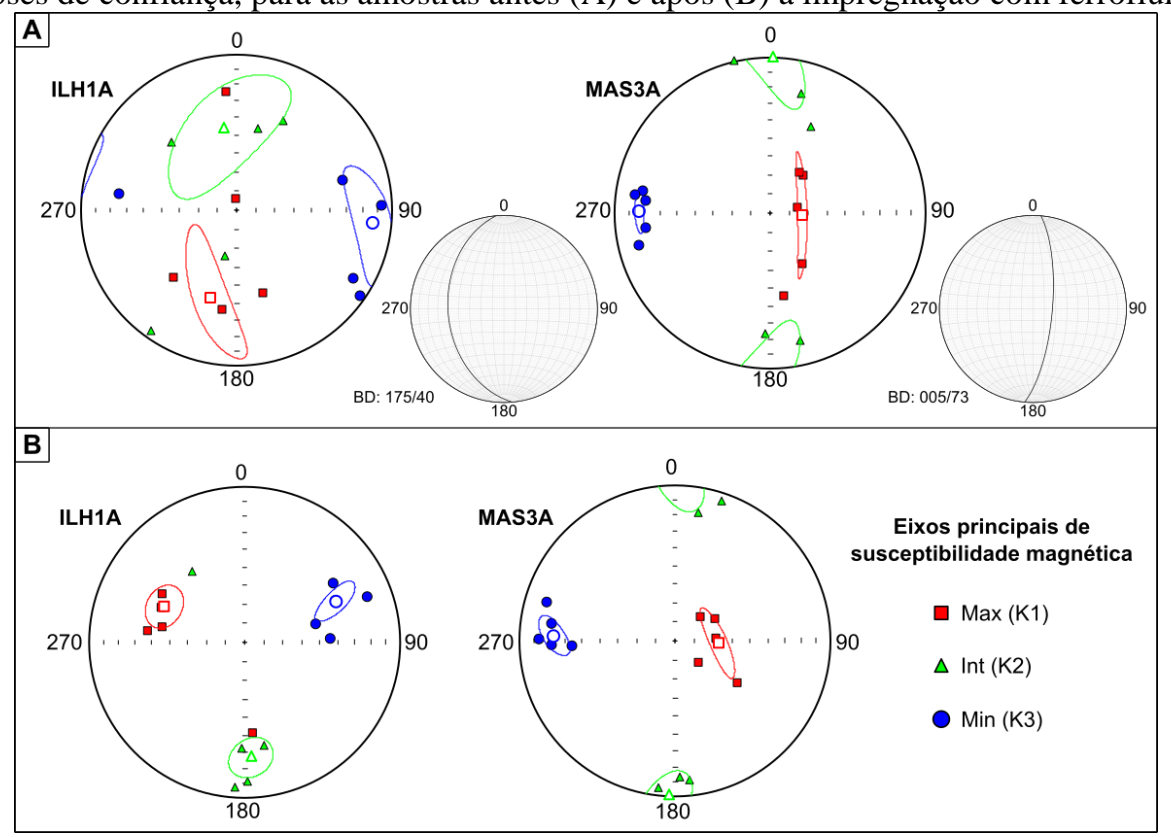

Após a impregnação das amostras, não houve mudança significativa no parâmetro de forma, que continuou predominante no formato prolato $(-0,597$ a 0,19$)$. Contudo, houve uma mudança significativa na relação entre o grau de anisotropia e a susceptibilidade magnética, que passou a ser positiva (figura 7.31).

Figura 7. 31 - Gráficos mostrando a relação entre o parâmetro de forma e o grau de anisotropia e deste último com a susceptibilidade magnética média, para as amostras antes (A) e depois (B) da impregnação com ferrofluido.

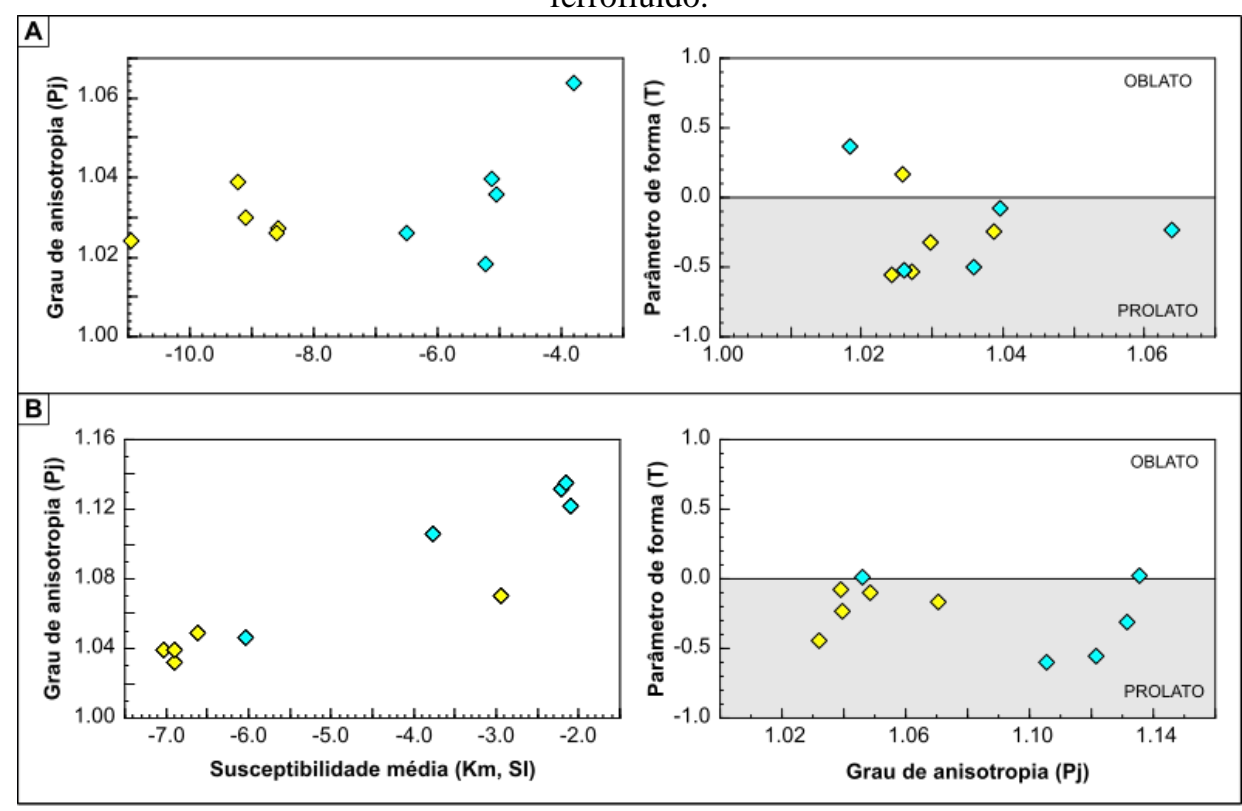




\section{DISCUSSÕES}

\subsection{Efeito das bandas de deformação na distribuição de tempos de relaxação transversal por Ressonância Magnética Nuclear}

Nas amostras, principalmente ILH1A ${ }^{1}$, ILH1A ${ }^{2}$, MAS3A $^{1}$ e MAS3A² é comum haver grãos de quartzo parcialmente preservados dentro das bandas, em comparação com os grãos de feldspato. Isso ocorre devido à maior resistência do quartzo, tendendo a se fragmentar por lascamento durante a deformação (LAUBACH, 2010). Porém, nos grãos de feldspato, além da menor resistência, existe a influência do processo de dissolução e da utilização de planos de clivagem durante o fraturamento. Isso faz com que alcancem um tamanho de partícula menor, dificultando a preservação desses minerais nas bandas, como foi observado neste trabalho.

A concentração e o alinhamento de minerais de argila e minerais opacos nas bandas, em comparação com a rocha hospedeira, podem ser explicados pela influência do fluxo cataclástico (por exemplo, LOMMATZSCH et al., 2015). O sobrecrescimento de minerais, que é insignificante na rocha hospedeira, é praticamente inexistente nas bandas. Isso ocorre devido ao lasqueamento das bordas dos grãos durante o fraturamento, eliminando a porção correspondente ao mineral secundário (LAUBACH, 2010).

Os arenitos do Grupo Ilhas apresentam maior quantidade de minerais opacos e argilominerais, principalmente na rocha hospedeira, ao contrário das amostras do Grupo Massacará. Isso explica a maior suscetibilidade magnética nessas amostras, exceto para ILH1A ${ }^{1}$ e ILH1A². Neste último caso, a baixa susceptibilidade magnética pode estar relacionada à percolação de fluidos durante a deformação e a consequente lixiviação de íons / minerais magnéticos que tenderiam a se concentrar naquela região durante a deformação. Maior susceptibilidade magnética, quantidade e tipos de minerais opacos nas amostras podem causar subestimação dos valores de porosidade (e.g. KEATING \& KNIGHT, 2007), no entanto, isso não foi identificado neste trabalho, bem como em Jácomo et al. (2020). No entanto, em ILH1A ${ }^{1}$, ILH1D e MAS3D ocorrem picos de $\mathrm{T}_{2}$ abaixo de $3 \mathrm{~ms}$, provavelmente associados a argilominerais que predominam como revestimento de grãos nessas amostras.

O tamanho dos poros também varia significativamente desde as rochas hospedeiras até as bandas de deformação, independentemente da textura primária. Conforme mostrado na figura $3 \mathrm{~A}$, nas bandas os poros podem atingir valores de raio menores que $0,5 \mu \mathrm{m}$. Na distribuição dos tempos de relaxação transversal $\left(\mathrm{T}_{2}\right)$, valores abaixo de 3 ms são atribuídos ao fluido presente tanto nos microporos quanto nos argilominerais (KENYON, 1997), enquanto acima de $33 \mathrm{~ms}$ correspondem aos poros com fluido livre. 
Os dados obtidos mostram que existe uma variação significativa na distribuição de $\mathrm{T}_{2} \mathrm{em}$ amostras com diferentes quantidades de bandas de deformação. A proporção relativa de picos entre 3 e $50 \mathrm{~ms}$ está diretamente relacionada ao aumento de poros menores devido ao fraturamento granular. Isto foi interpretado devido à maior influência da redução dos tamanhos dos poros devido à deformação da rocha quebradiça, em comparação com o teor de argila e porosidade associada ao crescimento de quartzo secundário (e.g. JÁCOMO et al., 2018).

Apesar da influência das bandas de deformação nas amostras, os dados de porosidade são compatíveis com trabalhos realizados anteriormente nos arenitos dos grupos Ilhas (e.g. RODRIGUES \& ALVES DA SILVA, 2018) e Massacará (por exemplo, FIGUEIREDO, 2017; ARONCHI, 2017). No entanto, Miranda (2004) e Medeiros et al. (2010) obtiveram maiores valores de permeabilidade para a rocha hospedeira, em comparação com este trabalho. Isso pode ser explicado pela escala de análise, mas também pelo fato de as medições não terem sido feitas em plugues sem bandas, neste trabalho. Para as bandas de deformação, os valores de permeabilidade são compatíveis com os trabalhos citados.

\subsection{Influência do desenvolvimento das bandas de deformação no alinhamento de minerais magnéticos e poros}

Em rochas sedimentares, a susceptibilidade magnética é influenciada principalmente por minerais paramagnéticos (TARLING \& HROUDA, 1993). As amostras estudadas neste trabalho são de arenitos de ambientes de sedimentação fluvio-deltaico (Grupo Ilhas) e fluvioeólico (Grupo Massacará), o primeiro com maior conteúdo de argila e óxidos de ferro como cobertura de grãos, além de minerais magnéticos detríticos orientados conforme a deposição. Durante o desenvolvimento de bandas de deformação, é comum a redução de porosidade, concentração e alinhamento desses minerais ao longo do plano da estrutura, como visto nas figuras 7.12 e 7.17, obtidas por microfluorescência de raios X. Neste trabalho foi investigado se a concentração dos minerais para- e ferromagnéticos das amostras por influência das bandas realmente pode refletir uma anisotropia de susceptibilidade magnética compatível com a orientação da estrutura. Nos plugues constituídos inteiramente pela banda de deformação, apesar da baixa susceptibilidade das amostras, a foliação magnética se mostrou compatível com a orientação da banda, para as amostras dos grupos Ilhas e Massacará. Entretanto, quando o volume de rocha hospedeira predomina em relação ao volume da banda nos plugues, não há correspondência direta entre a foliação magnética e a orientação da banda, como visto na figura 7.27. 
Bandas de deformação podem ter variação significativa da geometria e orientação, então, a estrutura medida em afloramento pode ser composta por estruturas menores, anastomosadas com orientação diferente do volume da banda principal, como identificado por Rodrigues \& Alves da Silva (2018). Por esse motivo, as amostras foram comparadas com a orientação das estruturas na scanline correspondente, porém sem resultados satisfatórios. Nas amostras ILHA6B e ILH6C, porém, a foliação magnética não correspondeu à orientação das bandas nem ao plano de deposição. Isso pode ser devido a menor susceptibilidade magnética média das amostras ou à influência dos minerais magnéticos orientados na bandas sobrepostos à influência dos orientados na rocha hospedeira.

Como as bandas de deformação podem ser muito heterogêneas ao longo da rocha, uma amostragem sistemática de plugues com menor diâmetro $(10 \mathrm{~mm})$ em blocos de rocha pode fornecer um maior controle da disposição espacial da banda. Isso possibilitará, uma melhor correlação entre a foliação magnética. A utilização imagens tridimensionais de microtomografia de raios-x em maior resolução também pode ser interessante para verificar heterogeneidades nas bandas no interior dos plugues.

Além da orientação dos minerais magnéticos associados às bandas de deformação, foi identificada também a orientação média dos poros associados a essas estruturas. Durante o desenvolvimento da deformação rúptil, pode ocorre a orientação de poros primários na direção do fluxo cataclástico. Ou ainda, minerais do arcabouço, como plagioclásios, podem ser totalmente dissolvidos durante a diagênese, posteriormente a sua orientação no interior da banda, como foi visto na figura 7.17.

Em amostras de arenitos sem a influência de bandas de deformação, a anisotropia de susceptibilidade magnética tende a refletir a orientação de minerais para-e/ou ferromagnéticos conforme o plano de deposição (foliação magnética) ou direção de paleocorrentes (lineação magnética) (e. g. ARONCHI, 2017; PARES et al., 2016; ROBION et al., 2014). Contudo, após a impregnação com ferrofluido, a trama magnética tende a refletir orientação média dos eixos maiores dos poros. Como neste trabalho foram analisadas apenas amostras totalmente constituídas por bandas, impregnadas com ferrofluido, os parâmetros magnéticos representam claramente um alinhamento de poros no sentido do mergulho dessas estruturas.

Apesar da impregnação com ferrofluido ter destacado a anisotropia de orientação dos poros, estudos adicionais com maior concentração ou tamanho de nanopartículas de magnetita superparamagnéticas são necessários, devido ao baixo contraste de susceptibilidade com as amostras. Também seria interessante comparar a estrutura porosa, impregnada com ferrofluido, em amostras com volume variável de bandas. 


\section{CONCLUSÕES}

As bandas de deformação foram identificadas nos picos intermediários de tempos de relaxação transversal $\left(\mathrm{T}_{2}\right)$, entre 3 e $50 \mathrm{~ms}$. A intensidade desses picos está relacionada principalmente ao volume das bandas, enquanto a largura ou proporção relativa depende da geometria e orientação. Estruturas mais homogêneas apresentaram apenas um pico mais estreito, enquanto estruturas com geometria anastomosada, contendo pods de rocha menos deformada em seu interior, foram associadas a dois picos ou a um pico mais largo. Nesse caso, a intensidade dos picos pode refletir até mesmo diferentes graus de fragmentação granular.

Devido à baixa susceptibilidade magnética das amostras e ao fato da distribuição de $\mathrm{T}_{2}$ ter sido realizada em baixo campo magnético, não houve indícios de subestimação significativa dos valores de porosidade, em relação a outras técnicas. Através da comparação das bandas de deformação em rochas hospedeiras com diferentes características texturais, principalmente o selecionamento, foi verificado que a modificação da estrutura porosa por processos deformacionais é determinante na variação de intensidade dos picos de $\mathrm{T}_{2}$ associados às bandas. Com isso, a ressonância magnética nuclear se mostrou uma ferramenta eficiente para auxiliar na identificação de bandas de deformação cataclásticas nos arenitos estudados neste trabalho. Contudo, a técnica permitiu apenas uma análise qualitativa do conteúdo de bandas nas amostras.

A partir dos dados de anisotropia de suscetibilidade magnética, não foi possível correlacionar diretamente a foliação magnética com a orientação das bandas de deformação nas amostras com predominância de rocha hospedeira. Ao contrário, em amostras totalmente constituídas por bandas a foliação magnética coincidiu com a orientação e mergulho da estrutura, provavelmente devido a menor influência dos minerais alinhados na rocha hospedeira pelos processos deformacionais. O Ferrofluido contendo nanopartículas de magnetita superparamagnética com tamanhos em torno de 5,6 nm, a uma concentração de $1 \%$, não aumentou significativamente a susceptibilidade magnética das amostras. Entretanto, os parâmetros de anisotropia para a estrutura porosa se mostraram coerentes com a orientação das bandas de deformação, indicando o alinhamento de poros no sentido de mergulho das estruturas, gerando elipsoide triaxial de susceptibilidade magnética.

Tanto para os estudos de distribuição de tempos de relaxação transversal quanto para os de anisotropia de susceptibilidade magnética, um maior controle da distribuição espacial das bandas, por meio de amostragens mais próximas, pode ser necessário. Isso permitirá correlacionar melhor a variação das propriedades petrofísicas com a orientação dessas estruturas. 


\section{REFERÊNCIAS}

ANTONELLINI, M. \& AYDIN, A. Effect of faulting on fluid flow in porous sandstones: geometry and spatial distribution. American Association of Petroleum Geologists Bulletin, v. 79, p. 642-671, 1995.

ANTONELLINI, M. \& MOLLEMA, P.N. Polygonal Deformation Bands. Journal of Structural Geology, 2015.

ANTONELLINI, M.; PETRACCHINI, L.; BILLI, A.; SCROCCA, D. First reported occurrence of deformation bands in a platform limestone, the Jurassic Calcare Massiccio Fm., northern Apennines, Italy. Tectonophysics, 2014.

ARAÚJO NETTO, J.M.; ALVES DA SILVA, F.C.; SÁ, E.F.J. Caracterização meso e microscópica de bandas de deformação em arenitos porosos: um exemplo nas tectonossequências Paleozoica, Pré- e Sin-rifte da Bacia do Araripe, Nordeste do Brasil. Geologia USP Série Científica, v. 12, n. 1, p. 83-98, abr. 2012.

ARONCHI, D. Caracterização da porosidade e sua orientação preferencial em arenitos do Grupo Serra Grande (Bacia do Parnaíba-CE) com aplicação de nanopartículas de magnetita. Dissertação de Mestrado, São Paulo: USP, 101 p., 2017.

AWDAL, A.; HEALY, D.; ALSOP, G. I. Geometrical analysis of deformation band lozenges and their scaling relationships to fault lenses. Journal of Structural Geology, 66, p. 11-23, 2014.

AYDIN, A. Small faults formed as deformation bands in sandstone. Pure and Applied Geophysics, v. 116, p. 913-930, 1978.

BALLAS, G.; FOSSEN, H.; SOLIVA, R. Factors controlling permeability of cataclastic deformation bands and faults in porous sandstone reservoirs. Journal of Structural Geology, 2015, doi: 10.1016/j.jsg.2015.03.013.

BALLAS, G.; SOLIVA, R.; BENEDICTO, A.; SIZUN, J. Control of tectonic setting and largescale faults on the basin-scale distribution of deformation bands in porous sandstone (Provence, France). Marine and Petroleum Geology, 55, p. 142-159, 2014.

BENSON, P. M.; MEREDITH, P. G.; PLATZMAN, E. S. Relating pore fabric geometry to acoustic and permeability anisotropy in Crab Orchard Sandstone: A laboratory study using magnetic ferrofluid. Geophysical Research Letters, v. 30, n. 19, 2003.

BIEDERMANN, A. R. Magnetic pore fabrics: the role of shape and distribution anisotropy in defining the magnetic anisotropy of ferrofluid-impregnated samples. American Geophysical Union, 2019.

BLOCH, F.; HANSEN, W. W. PACKARD, M. Phys. Rev. 69, 127, 1946.

BLOCH, F. Phys. Rev. 70, 460, 1946. 
BORRADAILE, G.J.; JACKSON, M. Anisotropy of magnetic susceptibility (AMS): magnetic petrofabrics of deformed rocks. London Geological Society, Special Publication, v. 238, p. 299-360, 2004.

BRANDES, C.; IGEL, J.; LOEWER, M.; TANNER, D. C.; LANG, J.; MULLER, K.; WINSEMANN, J. Visualization and analysis of shear-deformation bands in unconsolidated Pleistocene sand using ground-penetrating radar: Implications for paleoseismological studies. Sedimentary Geology, 367, p. 135-145, 2018.

BRANDES, C. \& TANNER, D. Three-dimensional geometry and fabric of shear deformationbands in unconsolidated Pleistocene sediments. Tectonophysics, 518-521, p. 84-92, 2012.

BROWSTEIN K.R., \& TARR C.E. Importance of classical diffusion in NMR studies of water in biological cells. Physical Review A, 19 (6), 2446-2453, 1979.

BUSCH, B.; HILGERS, C.; GRONEN, L.; ADELMANN, D. Cementation and structural diagenesis of fluvio-aeolian Rotliegend sandstones, northern England. Journal of the Geological Society, 2017, https://doi.org/10.1144/jgs2016-122.

BUTLER, R. F. Paleomagnetism: Magnetic domains to geologic terranes. Electronic edition, 24, 2004.

CAIXETA, J. M.; BUENO, G. V.; MAGNAVITA, L. P.; FEIJÓ, F. J. Bacias do Recôncavo, Tucano e Jatobá. Boletim de Geociências da PETROBRAS, v. 8, n. 1, p. 163-172, 1994.

CARR, H. Y. \& PURCELL, E. M. Effects of diffusion on free precession in nuclear magnetic resonance experiments: Physical Review, v. 94, p. 630-638, 1954.

CAVAILHES, T. \& ROTEVATN, A. Deformation bands in volcaniclastic rocks - Insights from the Shihtiping tuffs, Coastal Range of Taiwan. Journal of Structural Geology, 113, p. 155$175,2018$.

CHADIMA, M.; HROUDA, F.; JELÍNEK, V. Anisoft 5.1.-advanced treatment of magnetic anisotropy data. Geophys Res Abstracts 20, EGU-2018-15017, 2018.

COATES, G.R.; XIAO, L.; PRAMMER, M. NMR Logging-Principles and Applications. Gulf Publishing Company, Houston. Halliburton Energy Services Publication H02308, 1999.

COSTA, P.R.C.; SÁ, E.F.J.; SILVA, F.C. As Bandas de deformação na região de Jeremoabo (BA), Bacia de Tucano: implicações na compartimentação de reservatórios petrolíferos. $3^{\circ}$ Congresso Brasileiro de P\&D em Petróleo e Gás, 2005.

COSTA, I.P.; MILHOMEM, P.S.; BUENO, G.V.; SILVA, H.S.R.L.; KOSIN, M.D. Sub-bacias de Tucano Sul e Central. Boletim de Geociências da Petrobras, v. 15, n. 2, p. 433-443, maio/nov. 2007.

DESTRO, N.; ALKMIM, F. F.; MAGNAVITA, L. P.; SZATMARI, P. The Jeremoabo transpressional transfer fault, Recôncavo-Tucano Rift, NE Brazil. J. Struct. Geol., v. 25, n. 8, p. 1263-1279, 2003. 
D'EURYDICE, M. N. Desenvolvimento de metodologias para o estudo de meios porosos por ressonância magnética nuclear. Tese de Doutorado. São Carlos: USP, 174 p., 2011.

DUNLOP, D. J., \& OZDEMIR, O. Rock Magnetism, 573 pp., 1997.

DUNN, K. J.; BERGMAN, D.J.; LATORRACA, G.A. Nuclear Magnetic Resonance: Petrophysical and Logging Applications. Inglaterra: Elsevier Science, 2002.

EFFENBERGER, F. B.; CARBONARI, A. W.; ROSSI, L.M. The influence of 1,2-alkanediol on the crystallinity of magnetite nanoparticles. Journal of Magnetism and Magnetic Materials, v. 417, p. 49-55, 2016.

FERNANDES, J. S.; APPOLONI, C. R.; FERNANDES, C. P. Determinação de parâmetros microestruturais e reconstrução de imagens 3D de rochas reservatório por microtomografia de raios X. Revista Ciências Exatas e Naturais, v. 11, n. 1, p. 37-47, 2009.

FIGUEIREDO, H. G. Caracterização dos depósitos fluviais da Formação São Sebastião (Bacia do Tucano - BA) como análogo de reservatório. Dissertação de Mestrado - IGc-USP, 2017.

FERREIRA, T.S. \& ALVES DA SILVA, F.C. Bandas de deformação em arenitos porosos: estudo de casos em bacias do nordeste do Brasil. Boletim de Geociências da Petrobras, v. 18, n. 2, p. 207-231, mai/nov. 2010.

FOLK, R.L. Petrology of Sedimentary Rocks. Hemphill‘s Publ., Austin, Texas, 107 pp., 1974.

FOSSEN, H. Deformation bands formed during soft-sediment deformation: Observations from SE Utah. Marine and Petroleum Geology, 27, p. 215-222, 2010.

FOSSEN, H. \& BALE, A. Deformation bands and their influence on fluid flow. American Association of Petroleum Geologists Bulletin, v. 91, p. 1685-1700, 2007.

FOSSEN, H.; SCHULTZ, R.A.; SHIPTON, Z.K.; MAIR, K. Deformation bands in sandstones: a review. Journal of the Geological Society, v. 164, p. 755-769, 2007.

FOSSEN, H.; SOLIVA, R.; BALLAS, G.; TRZASKOS, B.; CAVALCANTE, C.; SCHULTZ, R. A review of deformation bands in reservoir sandstones: geometries, mechanisms and distribution. Geological Society London Special Publications, 459: 25p, 2017.

FOSSEN, H.; ZULUAGA, L.F.; BALLAS, G.; SOLIVA, R.; ROTEVATN, A. Contractional deformation of porous sandstone. Insights from the Aztec Sandstone, SE Nevada, USA. Journal of Structural Geology, 74, p. 172-184, 2015.

GOMES JR., C. P.; FOSSEN, H.; ALMEIDA, R. P.; SALMONI, B. Subseismic deformation in the Vaza-Barris Transfer Zone in the Cretaceous Recôncavo-Tucano-Jatobá rift system, NE Brazil. Journal of Structural Geology, 117, p. 81-95, 2018.

HROUDA, F. Physical principles of magnetic anisotropy course. In: Castle Meeting, Évora, Portugal. 2014. 
HROUDA, F. Magnetic Susceptibility, Anisotropy. Encyclopedia of Geomagnetism and Paleomagnetism. Springer. 546-560, 2007.

HROUDA, F.; HANAK, J.; TERZIJSKI, I. The magnetic and pore fabrics of extruded and pressed ceramic models. Geophys. J. Int., 142, p. 941-947, 2000.

JÁCOMO, M. H. Nuclear magnetic resonance characterization of sandstones with anomalous porosity. Tese de Doutorado. São Paulo: USP, 168 p., 2018.

JACOMO, M. H.; TRINDADE, R. I. F.; LUCAS-OLIVEIRA, E., LEITE, C. M. M.; MONTRAZI, E. T.; ANDREETA, M.; BONAGAMBA, T. J. Nuclear magnetic resonance and pore coupling in clay-coated sandstones with anomalous porosity preservation, Água Grande Formation, Recôncavo Basin, Brazil. Petrophysics, v. 59, n. 2, p. 136-152, 2018.

JACOMO, M. H.; TRINDADE, R. I. F.; FRENCH, M.; LUCAS-OLIVEIRA, E.; MONTRAZI, E. T.; BONAGAMBA, T. J. Nuclear magnetic resonance characterization of porositypreserving microcrystalline quartz coatings in Fontainebleau sandstones. AAPG Bulletin, v. 103, n. 9, p. 2117-2137, 2019.

JELINEK, V. The Statistical Theory of Measuring Anisotropy os Magnetic Susceptibility of Rocks and its application. Geofyzika Brno, 1977.

JELINEK, V. Characterization of the magnetic fabric of rocks. Tectonophysics, v.79, p. 63-67, 1981.

KAMINSKAITE, I.; FISHER, Q. J.; MICHIE, E. A. H. Microstructure and petrophysical properties of deformation bands in high porosity carbonates. International Journal of Rock Mechanics and Mining Sciences, 114, p. 153-163, 2019.

KEATING, K., \& KNIGHT, R. A laboratory study to determine the effect of iron oxides on proton NMR measurements: Geophysics, v. 72, no. 1, p. E27-E32, 2007.

KENYON, W. Petrophysical principles of applications of NMR logging, The Log Analyst, v.38, n.2, p 43, 1997.

KLEINBERG, R. L., KENYON, W. E., \& MITRA, P. P. Mechanism of NMR relaxation of fluids in rock. Journal of Magnetic Resonance, Series A, 108(2), 206-214, 1994.

KNUTSEN, H. H. Deformation bands in chalk: control on distribution and mechanism of formation. Dissertação de Mestrado. Bergen: UiB, 2016, 131 p. Disponível em: <http://bora. uib.no/handle/1956/917>. Acesso em: 04 jun. 2018.

KRUIVER, P. P., DEKKERS, M. J., \& HESLOP, D. Quantification of magnetic coercivity components by the analysis of acquisition curves of isothermal remanent magnetisation. Earth and Planetary Science Letters, 189(3-4), 269-276, 2001.

LAUBACH, S.E., EICHUBL, P., HILGERS, C., LANDER, R.H. Structural diagenesis. Journal of Structural Geology, v. 32, n. 12, p. 1866-1872, 2010. 
LIN, S.T. \& HUANG, W.J. Study of Deformation Bands in Ignimbrite in Shihtiping, Eastern Taiwan. AGU General Assembly, 2014.

LOMMATZSCH, M.; EXNER, U.; GIER, S.; GRASEMANN, B. Structural and chemical controls of deformation bands on fluid flow: Interplay between cataclasis and diagenetic alteration. AAPG Bulletin, v. 99, n. 4, p. 689-710, 2015.

LOWRIE, W. Fundamentals of geophysics. Cambridge university press, 2007.

MAGNAVITA, L. P.; DESTRO, N.; CARVALHO, M.S.S.; MILHOMEM, P.S.; SOUZALIMA, W. Bacias Sedimentares Brasileiras: Bacia de Tucano. Fundação Paleontológica Phoenix, n 52, abril 2003.

MAGNAVITA, L. P., DESTRO, N., FARANI, M. Curso de Campo - Geologia Estrutural, Bacias do Recôncavo-Tucano e Faixa Sergipana. Salvador: Universidade Petrobras, 2006.

MAGNAVITA, L. P. \& CUPERTINO, J. A. Concepção atual sobre as bacias do Tucano e Jatobá, nordeste do Brasil. Boletim de Geociências da Petrobras, v. 1, n. 2, p. 119-134, ago/dez. 1987.

MAXBAUER, D. P., FEINBERG, J. M., \& FOX, D. L. MAX UnMix: A web application for unmixing magnetic coercivity distributions. Computers \& Geosciences, 95, 140-145, 2016.

MEDEIROS, W. E.; NASCIMENTO, A. F.; ALVES DA SILVA, F. C.; DESTRO, N.; DEMÉTRIO, J. G. A. Evidence of hydraulic connectivity across deformation bands from field pumping tests: Two examples from Tucano Basin, NE Brazil. Journal of Structural Geology, 32, p. 1783-1791, 2010.

MEES, F.; SWENNEN, R.; GEET, M.V.; JACOBS, P. Applications of x-ray computed tomography in geosciences. London Geological Society, Special Publications, p. 1-6, 2003.

MEIBOOM, S., \& GILL D. Modified spin-echo method for measuring nuclear relaxation times. Rev. Sci. Instrum., v. 29, p. 668-691, 1958.

MIRANDA, H. C. B. Interpretação conjunta de dados de GPR e medidas de permeabilidade sobre um análogo de reservatório siliciclástico falhado na Bacia de Tucano, NE do Brasil, Dissertação de Mestrado, Natal:UFRN, 127 p, 2004.

NÉDÉLEC, A., \& BOUCHEZ, J. L. Granites: petrology, structure, geological setting, and metallogeny. Oxford University Press, 352p. 2015.

OLIVEIRA, E. L. Difusão de spins nucleares em meios porosos - uma abordagem computacional da RMN. Dissertação de Mestrado. São Carlos: USP, 143 p.,2015.

PARÉS, J. M.; MIGUENS, L.; SAIZ, L. Characterizing pore fabric in sandstones with magnetic anisotropy methods: Initial results Journal of Petroleum Science and Engineering, 143, p. 113$120,2016$.

PFLEIDERER, S. \& HALLS, H.C. Magnetic susceptibility anisotropy of rocks saturated with ferrofluid, a new method to study pore fabric, Phys. Earth planet. Inter., 65, 158-164, 1990. 
PHILIT, E.; SOlIVA, R.; CASTILlA, R.; BALLAS, G.; TAILEFER, A. Clusters of cataclastic deformation bands in porous sandstones. Journal of Structural Geology, 114, p. 235$250,2018$.

PHILIT, S.; SOLIVA, R.; LABAUME, P.; GOUT, C.; WIBBERLEY, C. Relations between shallow cataclastic faulting and cementation in porous sandstones: First insight from a groundwater environmental context. Journal of Structural Geology, 81, p. 89-105, 2015.

PONTES, C. C. C.; NOGUEIRA, F. C. C.; BEZERRA, F. H. R.; BALSAMO, F.; MIRANDA, T. S.; NICCHIO, M. A.; SOUZA, J. A. B.; CARVALHO, B. R. B. M. Petrophysical properties of deformation bands in high porous sandstones across fault zones in the Rio do Peixe Basin, Brazil. Journal of Structural Geology, 119, p. 61-80, 2019.

PURCELL, E. M.; Torrey, H. C.; Pound, R. V. Phys. Rev. 69, 37, 1945.

ROBERTSON, D. J., \& FRANCE, D. E. Discrimination of remanence-carrying minerals in mixtures, using isothermal remanent magnetisation acquisition curves. Physics of the Earth and Planetary interiors, 82(3-4), 223-234, 1994.

ROBION, P; DAVID, C.; DAUTRIAT, J.; COLOMBIER, J.; ZINSMEISTER, L.; COLLIN, $P$. Pore fabric geometry inferred from magnetic and acoustic anisotropies in rocks with various mineralogy, permeability and porosity. Tectonophysics, 2014.

RODRIGUES, R.S. Análise meso e microscópica de bandas de deformação em arenitos porosos: aplicação na Bacia de Tucano-BA, NE do Brazil. Dissertação de Mestrado. Natal: UFRN, 135 p., 2018.

RODRIGUES, R. S. \& ALVES DA SILVA, F. C. Deformation bands and associated structures in the Tucano Basin, NE Brazil: A multiscale analysis. Marine and Petroleum Geology, 96, p. 202-213, 2018.

RODRIGUES, M. C. N. L.; TRZASKOS, B.; LOPES, A. P. Influence of deformation bands on sandstone porosity: A case study using three-dimensional microtomography. Journal of Structural Geology, 72, p. 96-110, 2015.

ROTEVATN, A.; THORSHEIM, E.; BASTESEN, E.; FOSSMARK, H.S.S.; TORABI, A.; HEIDI, S.S.; SÆLEN, G. Sequential growth of deformation bands in carbonate grainstones in the hangingwall of an active growth fault: Implications for deformation mechanisms in different tectonic regimes. Journal of Structural Geology, 90, p. 27-47, 2016.

SAIDIAN, M. \& PRASAD, M. Effect of mineralogy on nuclear magnetic resonance surface relaxivity: A case study of Middle Bakken and Three Forks formations. Fuel, 161 p. 197-206, 2015.

SCHÖN, J.H. Physical properties of rocks: Fundamentals and principles of petrophysics. Elsevier, 2015.

SILVA, R. O. Utilização da RMN no estudo de rochas-reservatório siliciclásticas. Tese de Doutorado. São Carlos: USP, 209 p., 2014. 
SOLIVA, R.; FOSSEN, H.; GREGORY, B.; PHILIT, S. Tectonic regime controls clustering of deformation bands in porous sandstone. Geology, v. 44, n. 6, 2016.

SONG, Y. Q. Using internal magnetic fields to obtain pore size distributions of porous media. Concepts in Magnetic Resonance Part A: An Educational Journal, 18(2), 97-110, 2003.

SONG, Y. Recent Progress of Nuclear Magnetic Resonance Applications in Sandstones and Carbonate Rocks. Vadose Zone Journal, v. 9, p. 828-834, 2010.

SOUZA, A. A. Estudos de propriedades petrofísicas de rochas sedimentares por Ressonância Magnética Nuclear. Tese de Doutorado. São Carlos: USP, 236 p., 2012.

TARLING, D. H. \& HROUDA, F. H. The magnetic anisotropy of rocks. Chapman \& Hall, 1993.

TAUXE, L. Essentials of paleomagnetism. Univ of California Press, 2008.

TAUXE, L., MULlENDER, T. A. T., \& PICK, T. Potbellies, wasp-waists, and superparamagnetism in magnetic hysteresis. Journal of Geophysical Research: Solid Earth, v. 101(B1), p. 571-583, 1996.

TEWKSBURY, B.; WILLIAMSON, E.K.; KATTENHORN, S.A.; BARNES, J.E. Fragile glass: deformation band formation in unconsolidated hyalotuff, Valahnúkar, Iceland. Conference: 2009 GSA Annual Meeting, Volume: GSA Abstracts with Programs 41, paper 173-16, 2009. Disponível em: <https://www.researchgate.net/publication/270686080_Fragile _glass_deformation_band_formation_in_unconsolidated_hyalotuff_Valahnukar_Iceland $>$. Acesso em: 04 jun. 2018.

TINDALL, S. E. Simple calculations of fluid flow across jointed cataclastic deformation bands. Marine and Petroleum Geology, 57, p. 152-159, 2014.

TORABI, A. \& ALIKARAMI, R. Heterogeneity within deformation bands in sandstone reservoirs. ARMA Conference Paper, 2012.

VASCONCELOS, D.V.F. Falha de transferência de Caritá: o significado tectônico no Rifte do Recôncavo-Tucano-Jatobá, NE Brasil. Dissertação de Mestrado. Ouro Preto: UFOP, 82 p., 2003.

VIANA, C. F.; GAMA JUNIOR, E. G.; SIMÕES, I. A.; MOURA, J. A.; FONSECA, J. R.; ALVES, R. J. Revisão estratigráfica da Bacia do Recôncavo/Tucano. Boletim Técnico da Petrobras, v. 14, n. 3-4, p. 157-192, 1971.

WENNBERG, O.P.; CASINI, G.; JAHANPANAH, A.; LAPPONI, F.; INESON, J.; WALL, B.G.; GILLESPIE, P. Deformation bands in chalk, examples from the Shetland Group of the Oseberg Field, North Sea, Norway. Journal of Structural Geology, 56, p. 103-117, 2013.

WILSON, J.E.; GOODWIN, L.B.; LEWIS, C.J. Deformation bands in nonwelded ignimbrites: Petrophysical controls on fault-zone deformation and evidence of preferential fluid flow. Geology, v. 31, n. 10, p. 837-840, 2003. 


\section{APÊNDICE A - DADOS ESTRUTURAIS DAS SCANLINES DO}

AFLORAMENTO DA FALHA DO MACACO

\begin{tabular}{|c|c|c|c|c|c|c|c|}
\hline Linha & $\begin{array}{c}\text { Comprimento } \\
(\mathbf{m})\end{array}$ & Intervalo & Geometria & $\begin{array}{c}\text { Espessura } \\
(\mathrm{cm})\end{array}$ & $\begin{array}{c}\text { Orientação } \\
\text { da banda }\end{array}$ & $\begin{array}{c}\text { Direção do } \\
\text { mergulho }\end{array}$ & Cinemática \\
\hline 1 & 10,00 & \multirow{9}{*}{0 a $1 \mathrm{~m}$} & Banda individual retilínea & 0,10 & $000-180$ & - & - \\
\hline 1 & 10,00 & & Agrupamento de bandas anastomosado & 0,30 & $025-205$ & - & - \\
\hline 1 & 10,00 & & Agrupamento de bandas anastomosado & 0,20 & $164-344$ & $076 / 84$ & - \\
\hline 1 & 10,00 & & Agrupamento de bandas anastomosado & 1,00 & $175-355$ & $085 / 56$ & - \\
\hline 1 & 10,00 & & Banda individual retilínea & 0,20 & $170-350$ & - & - \\
\hline 1 & 10,00 & & Banda individual retilínea & 0,20 & $160-340$ & - & - \\
\hline 1 & 10,00 & & Banda individual retilínea & 0,30 & $015-195$ & - & - \\
\hline 1 & 10,00 & & Banda individual anastomosada & 0,10 & $150-330$ & - & - \\
\hline 1 & 10,00 & & Banda individual anastomosada & 0,10 & $160-340$ & - & - \\
\hline 1 & 10,00 & \multirow{26}{*}{1 a $2 \mathrm{~m}$} & Banda individual anastomosada & 0,30 & $150-330$ & - & - \\
\hline 1 & 10,00 & & Banda individual anastomosada & 0,20 & $160-340$ & $250 / 52$ & - \\
\hline 1 & 10,00 & & Banda individual anastomosada & 0,20 & $170-350$ & - & - \\
\hline 1 & 10,00 & & Banda individual anastomosada & 0,20 & $170-350$ & - & - \\
\hline 1 & 10,00 & & Banda individual anastomosada & 0,20 & $170-350$ & - & - \\
\hline 1 & 10,00 & & Banda individual anastomosada & 0,20 & $170-350$ & - & - \\
\hline 1 & 10,00 & & Banda individual anastomosada & 0,20 & $170-350$ & - & - \\
\hline 1 & 10,00 & & Banda individual anastomosada & 0,20 & $170-350$ & - & - \\
\hline 1 & 10,00 & & Banda individual anastomosada & 0,20 & $170-350$ & - & - \\
\hline 1 & 10,00 & & Banda individual anastomosada & 0,20 & $170-350$ & - & - \\
\hline 1 & 10,00 & & Banda individual anastomosada & 0,50 & $030-210$ & - & - \\
\hline 1 & 10,00 & & Banda individual anastomosada & 0,30 & $010-190$ & $280 / 60$ & - \\
\hline 1 & 10,00 & & Banda individual anastomosada & 0,10 & $000-180$ & - & - \\
\hline 1 & 10,00 & & Banda individual anastomosada & 0,10 & $000-180$ & - & - \\
\hline 1 & 10,00 & & Banda individual anastomosada & 0,10 & $000-180$ & - & - \\
\hline 1 & 10,00 & & Banda individual anastomosada & 0,10 & $000-180$ & - & - \\
\hline 1 & 10,00 & & Banda individual anastomosada & 0,10 & $000-180$ & - & - \\
\hline 1 & 10,00 & & Banda individual anastomosada & 0,10 & $000-180$ & - & - \\
\hline 1 & 10,00 & & Agrupamento de bandas anastomosado & 0,70 & $175-355$ & $085 / 84$ & - \\
\hline 1 & 10,00 & & Banda individual anastomosada & 0,10 & $010-190$ & - & - \\
\hline 1 & 10,00 & & Banda individual anastomosada & 0,10 & 010-190 & - & - \\
\hline 1 & 10,00 & & Banda individual anastomosada & 0,10 & $005-185$ & - & - \\
\hline 1 & 10,00 & & Banda individual anastomosada & 0,10 & $175-355$ & - & - \\
\hline 1 & 10,00 & & Banda individual anastomosada & 0,10 & $175-355$ & - & - \\
\hline 1 & 10,00 & & Banda individual anastomosada & 0,10 & $175-355$ & - & - \\
\hline 1 & 10,00 & & Agrupamento de bandas anastomosado & 0,80 & $005-185$ & $275 / 56$ & - \\
\hline 1 & 10,00 & \multirow{10}{*}{2 a $3 \mathrm{~m}$} & Banda individual retilínea & 0,30 & $170-350$ & $080 / 74$ & - \\
\hline 1 & 10,00 & & Agrupamento de bandas anastomosado & 0,80 & $150-330$ & - & - \\
\hline 1 & 10,00 & & Banda individual retilínea & 0,10 & $025-205$ & $115 / 60$ & - \\
\hline 1 & 10,00 & & Banda individual anastomosada & 0,10 & $140-320$ & - & - \\
\hline 1 & 10,00 & & Banda individual retilínea & 0,10 & $175-355$ & - & - \\
\hline 1 & 10,00 & & Agrupamento de bandas anastomosado & 0,50 & 010-190 & - & - \\
\hline 1 & 10,00 & & Banda individual anastomosada & 0,10 & $165-345$ & - & - \\
\hline 1 & 10,00 & & Banda individual anastomosada & 0,10 & $165-345$ & - & - \\
\hline 1 & 10,00 & & Banda individual anastomosada & 0,10 & $165-345$ & $075 / 46$ & - \\
\hline 1 & 10,00 & & Banda individual anastomosada & 0,10 & $165-345$ & $075 / 46$ & - \\
\hline 1 & 10,00 & \multirow{4}{*}{3 a $4 \mathrm{~m}$} & Banda individual anastomosada & 0,20 & $175-355$ & $085 / 82$ & - \\
\hline 1 & 10,00 & & Banda individual anastomosada & 0,20 & $175-355$ & $085 / 82$ & - \\
\hline 1 & 10,00 & & Banda individual anastomosada & 0,20 & $160-340$ & - & - \\
\hline 1 & 10,00 & & Banda individual anastomosada & 0,20 & $000-180$ & - & - \\
\hline 1 & 10,00 & \multirow{4}{*}{4 a $5 \mathrm{~m}$} & Banda individual anastomosada & 0,10 & $010-190$ & - & - \\
\hline 1 & 10,00 & & Banda individual anastomosada & 0,10 & $010-190$ & - & - \\
\hline 1 & 10,00 & & Banda individual anastomosada & 0,10 & $010-190$ & - & - \\
\hline 1 & 10,00 & & Agrupamento de bandas anastomosado & 0,50 & $020-200$ & - & - \\
\hline
\end{tabular}




\begin{tabular}{|c|c|c|c|c|c|c|c|}
\hline 1 & 10,00 & & Agrupamento de bandas anastomosado & 2,00 & $020-200$ & $290 / 70$ & - \\
\hline 1 & 10,00 & & Agrupamento de bandas anastomosado & 2,00 & 005-185 & - & - \\
\hline 1 & 10,00 & & Banda individual anastomosada & 0,10 & 010-190 & - & - \\
\hline 1 & 10,00 & & Banda individual anastomosada & 0,10 & $010-190$ & - & - \\
\hline 1 & 10,00 & & Banda individual anastomosada & 0,10 & $010-190$ & - & - \\
\hline 1 & 10,00 & & Agrupamento de bandas anastomosado & 3,00 & $000-180$ & - & - \\
\hline 1 & 10,00 & & Agrupamento de bandas anastomosado & 3,00 & $000-180$ & - & - \\
\hline 1 & 10,00 & \multirow{7}{*}{5 a $6 \mathrm{~m}$} & Banda individual anastomosada & 0,30 & $160-340$ & - & - \\
\hline 1 & 10,00 & & Banda individual anastomosada & 0,30 & $160-340$ & - & - \\
\hline 1 & 10,00 & & Agrupamento de bandas anastomosado & 1,50 & $155-335$ & - & - \\
\hline 1 & 10,00 & & Agrupamento de bandas anastomosado & 0,80 & $010-190$ & - & - \\
\hline 1 & 10,00 & & Agrupamento de bandas anastomosado & 0,80 & $010-190$ & - & - \\
\hline 1 & 10,00 & & Banda individual retilínea & 0,10 & $170-350$ & $260 / 40$ & - \\
\hline 1 & 10,00 & & Agrupamento de bandas anastomosado & 0,20 & $175-355$ & $265 / 46$ & - \\
\hline 1 & 10,00 & \multirow{9}{*}{6 a $7 \mathrm{~m}$} & Banda individual anastomosada & 0,10 & $020-200$ & - & - \\
\hline 1 & 10,00 & & Banda individual anastomosada & 0,10 & $155-335$ & - & - \\
\hline 1 & 10,00 & & Agrupamento de bandas anastomosado & 0,50 & $005-185$ & $275 / 45$ & - \\
\hline 1 & 10,00 & & Banda individual anastomosada & 0,50 & $155-335$ & - & - \\
\hline 1 & 10,00 & & Agrupamento de bandas anastomosado & 0,70 & $005-185$ & $275 / 66$ & - \\
\hline 1 & 10,00 & & Banda individual anastomosada & 0,20 & $010-190$ & - & - \\
\hline 1 & 10,00 & & Banda individual anastomosada & 0,20 & $010-190$ & - & - \\
\hline 1 & 10,00 & & Banda individual anastomosada & 0,20 & $010-190$ & - & - \\
\hline 1 & 10,00 & & Banda individual anastomosada & 0,30 & $000-180$ & - & - \\
\hline 1 & 10,00 & \multirow{13}{*}{7 a 8 m } & Banda individual anastomosada & 0,20 & $160-340$ & - & - \\
\hline 1 & 10,00 & & Banda individual anastomosada & 0,50 & $010-190$ & - & - \\
\hline 1 & 10,00 & & Agrupamento de bandas anastomosado & 1,50 & $000-180$ & $090 / 46$ & - \\
\hline 1 & 10,00 & & Banda individual anastomosada & 0,20 & $175-355$ & $265 / 46$ & - \\
\hline 1 & 10,00 & & Banda individual anastomosada & 0,20 & $175-355$ & $265 / 46$ & - \\
\hline 1 & 10,00 & & Banda individual anastomosada & 0,20 & $175-355$ & $265 / 46$ & - \\
\hline 1 & 10,00 & & Banda individual anastomosada & 0,20 & $175-355$ & $265 / 46$ & - \\
\hline 1 & 10,00 & & Banda individual anastomosada & 0,20 & $175-355$ & $265 / 46$ & - \\
\hline 1 & 10,00 & & Banda individual anastomosada & 0,20 & $175-355$ & $265 / 46$ & - \\
\hline 1 & 10,00 & & Banda individual anastomosada & 0,20 & $175-355$ & $265 / 72$ & - \\
\hline 1 & 10,00 & & Banda individual anastomosada & 0,20 & $175-355$ & $265 / 72$ & - \\
\hline 1 & 10,00 & & Banda individual anastomosada & 0,20 & $175-355$ & $265 / 72$ & - \\
\hline 1 & 10,00 & & Agrupamento de bandas anastomosado & 0,50 & $165-345$ & $255 / 40$ & - \\
\hline 1 & 10,00 & 8 a $9 \mathrm{~m}$ & \multicolumn{5}{|c|}{ Intervalo coberto } \\
\hline 1 & 10,00 & \multirow{11}{*}{9 a $10 \mathrm{~m}$} & Agrupamento de bandas anastomosado & 0,70 & $175-355$ & $085 / 60$ & - \\
\hline 1 & 10,00 & & Agrupamento de bandas anastomosado & 0,70 & $175-355$ & $085 / 60$ & - \\
\hline 1 & 10,00 & & Banda individual anastomosada & $0,3-0,5$ & $170-350$ & - & - \\
\hline 1 & 10,00 & & Banda individual anastomosada & $0,3-0,5$ & $170-350$ & - & - \\
\hline 1 & 10,00 & & Banda individual anastomosada & $0,3-0,5$ & $170-350$ & - & - \\
\hline 1 & 10,00 & & Banda individual anastomosada & $0,3-0,5$ & $170-350$ & - & - \\
\hline 1 & 10,00 & & Banda individual anastomosada & $0,3-0,5$ & $170-350$ & - & - \\
\hline 1 & 10,00 & & Banda individual anastomosada & $0,3-0,5$ & $170-350$ & - & - \\
\hline 1 & 10,00 & & Agrupamento de bandas anastomosado & 0,30 & $160-340$ & - & - \\
\hline 1 & 10,00 & & Agrupamento de bandas anastomosado & 0,30 & $160-340$ & - & - \\
\hline 1 & 10,00 & & Banda individual anastomosada & 0,30 & $010-190$ & - & - \\
\hline 2 & 7,00 & \multirow{11}{*}{0 a $1 \mathrm{~m}$} & Banda individual anastomosada & 0,10 & $160-340$ & $250 / 64$ & - \\
\hline 2 & 7,00 & & Banda individual anastomosada & 0,10 & $160-340$ & $250 / 64$ & - \\
\hline 2 & 7,00 & & Banda individual anastomosada & 0,10 & $160-340$ & $250 / 64$ & - \\
\hline 2 & 7,00 & & Banda individual anastomosada & 0,10 & $160-340$ & $250 / 64$ & - \\
\hline 2 & 7,00 & & Banda individual anastomosada & 0,10 & $160-340$ & $250 / 64$ & - \\
\hline 2 & 7,00 & & Banda individual anastomosada & 0,10 & $160-340$ & $250 / 64$ & - \\
\hline 2 & 7,00 & & Banda individual anastomosada & 0,10 & $160-340$ & $250 / 64$ & - \\
\hline 2 & 7,00 & & Banda individual anastomosada & 0,10 & $160-340$ & $250 / 64$ & - \\
\hline 2 & 7,00 & & Banda individual anastomosada & 0,10 & $160-340$ & $250 / 64$ & - \\
\hline 2 & 7,00 & & Banda individual anastomosada & 0,10 & $160-340$ & $250 / 64$ & - \\
\hline 2 & 7,00 & & Banda individual anastomosada & 0,10 & $160-340$ & $250 / 64$ & - \\
\hline
\end{tabular}




\begin{tabular}{|c|c|c|c|c|c|c|c|}
\hline 2 & 7,00 & & Banda individual anastomosada & 0,10 & $160-340$ & $250 / 64$ & - \\
\hline 2 & 7,00 & & Banda individual anastomosada & 0,10 & $160-340$ & $250 / 64$ & - \\
\hline 2 & 7,00 & & Banda individual anastomosada & 0,10 & $160-340$ & $250 / 64$ & - \\
\hline 2 & 7,00 & & Banda individual anastomosada & 0,10 & $160-340$ & $250 / 64$ & - \\
\hline 2 & 7,00 & & Banda individual anastomosada & 0,10 & $160-340$ & $250 / 64$ & - \\
\hline 2 & 7,00 & & Banda individual anastomosada & 0,10 & $160-340$ & $250 / 64$ & - \\
\hline 2 & 7,00 & & Banda individual anastomosada & 0,10 & $160-340$ & $250 / 64$ & - \\
\hline 2 & 7,00 & & Banda individual anastomosada & 0,10 & $160-340$ & $250 / 64$ & - \\
\hline 2 & 7,00 & & Banda individual anastomosada & 0,10 & $160-340$ & $250 / 64$ & - \\
\hline 2 & 7,00 & & Banda individual anastomosada & 0,10 & $160-340$ & $250 / 64$ & - \\
\hline 2 & 7,00 & & Banda individual anastomosada & 0,10 & $160-340$ & $250 / 64$ & - \\
\hline 2 & 7,00 & & Banda individual anastomosada & 0,10 & $160-340$ & $250 / 64$ & - \\
\hline 2 & 7,00 & & Banda individual anastomosada & 0,10 & $160-340$ & $250 / 64$ & - \\
\hline 2 & 7,00 & & Banda individual anastomosada & 0,10 & $000-180$ & $090 / 48$ & - \\
\hline 2 & 7,00 & & Banda individual anastomosada & 0,10 & $000-180$ & $090 / 48$ & - \\
\hline 2 & 7,00 & & Banda individual anastomosada & 0,10 & $000-180$ & $090 / 48$ & - \\
\hline 2 & 7,00 & & Banda individual anastomosada & 0,10 & $000-180$ & $090 / 48$ & - \\
\hline 2 & 7,00 & & Banda individual anastomosada & 0,10 & $000-180$ & $090 / 48$ & - \\
\hline 2 & 7,00 & & Banda individual anastomosada & 0,10 & $000-180$ & $090 / 48$ & - \\
\hline 2 & 7,00 & & Banda individual anastomosada & 0,10 & $000-180$ & $090 / 48$ & - \\
\hline 2 & 7,00 & & Banda individual anastomosada & 0,10 & $000-180$ & $090 / 48$ & - \\
\hline 2 & 7,00 & & Banda individual anastomosada & 0,10 & $000-180$ & $090 / 48$ & - \\
\hline 2 & 7,00 & & Banda individual anastomosada & 0,10 & $000-180$ & $090 / 48$ & - \\
\hline 2 & 7,00 & \multirow{35}{*}{1 a $2 \mathrm{~m}$} & Banda individual anastomosada & 0,20 & $160-340$ & - & - \\
\hline 2 & 7,00 & & Banda individual anastomosada & 0,10 & $160-340$ & $250 / 70$ & - \\
\hline 2 & 7,00 & & Banda individual anastomosada & 0,10 & $160-340$ & $250 / 70$ & - \\
\hline 2 & 7,00 & & Banda individual anastomosada & 0,10 & $160-340$ & $250 / 70$ & - \\
\hline 2 & 7,00 & & Banda individual anastomosada & 0,10 & $160-340$ & $250 / 70$ & - \\
\hline 2 & 7,00 & & Banda individual anastomosada & 0,10 & $160-340$ & $250 / 70$ & - \\
\hline 2 & 7,00 & & Banda individual anastomosada & 0,10 & $160-340$ & $250 / 70$ & - \\
\hline 2 & 7,00 & & Banda individual anastomosada & 0,10 & $160-340$ & $250 / 70$ & - \\
\hline 2 & 7,00 & & Banda individual anastomosada & 0,10 & $160-340$ & $250 / 70$ & - \\
\hline 2 & 7,00 & & Banda individual anastomosada & 0,10 & $160-340$ & $250 / 70$ & - \\
\hline 2 & 7,00 & & Banda individual anastomosada & 0,10 & $160-340$ & $250 / 70$ & - \\
\hline 2 & 7,00 & & Banda individual anastomosada & 0,10 & $160-340$ & $250 / 70$ & - \\
\hline 2 & 7,00 & & Banda individual anastomosada & 0,10 & $160-340$ & $250 / 70$ & - \\
\hline 2 & 7,00 & & Banda individual anastomosada & 0,10 & $160-340$ & $250 / 70$ & - \\
\hline 2 & 7,00 & & Banda individual anastomosada & 0,10 & $160-340$ & $250 / 70$ & - \\
\hline 2 & 7,00 & & Banda individual anastomosada & 0,10 & $160-340$ & $250 / 70$ & - \\
\hline 2 & 7,00 & & Banda individual anastomosada & 0,10 & $160-340$ & $250 / 70$ & - \\
\hline 2 & 7,00 & & Banda individual anastomosada & 0,10 & $160-340$ & $250 / 70$ & - \\
\hline 2 & 7,00 & & Banda individual anastomosada & 0,10 & $160-340$ & $250 / 70$ & - \\
\hline 2 & 7,00 & & Banda individual anastomosada & 0,10 & $160-340$ & $250 / 70$ & - \\
\hline 2 & 7,00 & & Banda individual anastomosada & 0,10 & $160-340$ & $250 / 70$ & - \\
\hline 2 & 7,00 & & Banda individual anastomosada & 0,10 & $160-340$ & $250 / 70$ & - \\
\hline 2 & 7,00 & & Banda individual anastomosada & 0,10 & $160-340$ & $250 / 70$ & - \\
\hline 2 & 7,00 & & Banda individual anastomosada & 0,10 & $160-340$ & $250 / 70$ & - \\
\hline 2 & 7,00 & & Banda individual anastomosada & 0,10 & $160-340$ & $250 / 70$ & - \\
\hline 2 & 7,00 & & Banda individual anastomosada & 0,10 & $160-340$ & $250 / 70$ & - \\
\hline 2 & 7,00 & & Banda individual anastomosada & 0,10 & $160-340$ & $250 / 70$ & - \\
\hline 2 & 7,00 & & Banda individual anastomosada & 0,10 & $160-340$ & $250 / 70$ & - \\
\hline 2 & 7,00 & & Banda individual anastomosada & 0,10 & $160-340$ & $250 / 70$ & - \\
\hline 2 & 7,00 & & Banda individual anastomosada & 0,10 & $160-340$ & $250 / 70$ & - \\
\hline 2 & 7,00 & & Banda individual anastomosada & 0,10 & $160-340$ & $250 / 70$ & - \\
\hline 2 & 7,00 & & Banda individual anastomosada & 0,10 & $010-190$ & $100 / 48$ & - \\
\hline 2 & 7,00 & & Banda individual anastomosada & 0,10 & $010-190$ & $100 / 48$ & - \\
\hline 2 & 7,00 & & Banda individual anastomosada & 0,10 & $010-190$ & $100 / 48$ & - \\
\hline 2 & 7,00 & & Banda individual anastomosada & 0,10 & $010-190$ & $100 / 48$ & - \\
\hline 2 & 7,00 & & Banda individual anastomosada & 0,10 & $000-180$ & $270 / 80$ & - \\
\hline
\end{tabular}




\begin{tabular}{|c|c|c|c|c|c|c|c|}
\hline 2 & 7,00 & \multirow[t]{24}{*}{2 a $3 \mathrm{~m}$} & Banda individual anastomosada & 0,10 & $000-180$ & $270 / 80$ & - \\
\hline 2 & 7,00 & & Banda individual anastomosada & 0,10 & $140-320$ & - & - \\
\hline 2 & 7,00 & & Banda individual anastomosada & 0,10 & $170-350$ & - & - \\
\hline 2 & 7,00 & & Banda individual anastomosada & 0,10 & 010-190 & - & - \\
\hline 2 & 7,00 & & Agrupamento de bandas anastomosado & 0,50 & 010-190 & $100 / 80$ & - \\
\hline 2 & 7,00 & & Agrupamento de bandas anastomosado & 0,50 & 010-190 & $100 / 80$ & - \\
\hline 2 & 7,00 & & Banda individual anastomosada & 0,10 & $150-330$ & - & - \\
\hline 2 & 7,00 & & Banda individual anastomosada & 0,10 & $150-330$ & - & - \\
\hline 2 & 7,00 & & Banda individual anastomosada & 0,10 & $150-330$ & - & - \\
\hline 2 & 7,00 & & Banda individual anastomosada & 0,10 & $150-330$ & - & - \\
\hline 2 & 7,00 & & Banda individual anastomosada & 0,10 & $150-330$ & - & - \\
\hline 2 & 7,00 & & Agrupamento de bandas anastomosado & 1,00 & $150-330$ & $240 / 60$ & - \\
\hline 2 & 7,00 & & Banda individual anastomosada & 0,10 & $175-355$ & $085 / 60$ & - \\
\hline 2 & 7,00 & & Banda individual anastomosada & 0,10 & $160-340$ & - & - \\
\hline 2 & 7,00 & & Banda individual anastomosada & 0,30 & $000-180$ & - & - \\
\hline 2 & 7,00 & & Banda individual anastomosada & 0,10 & $170-350$ & - & - \\
\hline 2 & 7,00 & & Banda individual anastomosada & 0,10 & $170-350$ & - & - \\
\hline 2 & 7,00 & & Banda individual anastomosada & 0,10 & $170-350$ & - & - \\
\hline 2 & 7,00 & & Banda individual anastomosada & 0,10 & $170-350$ & - & - \\
\hline 2 & 7,00 & & Agrupamento de bandas anastomosado & 0,30 & $165-345$ & $255 / 70$ & - \\
\hline 2 & 7,00 & & Banda individual anastomosada & 0,10 & $170-350$ & - & - \\
\hline 2 & 7,00 & & Banda individual anastomosada & 0,10 & $170-350$ & - & - \\
\hline 2 & 7,00 & & Banda individual anastomosada & 0,10 & $170-350$ & - & - \\
\hline 2 & 7,00 & & Banda individual anastomosada & 0,10 & $000-180$ & - & - \\
\hline 2 & 7,00 & \multirow{35}{*}{3 a 4 m } & Banda individual anastomosada & 0,10 & $000-180$ & - & - \\
\hline 2 & 7,00 & & Banda individual anastomosada & 0,10 & $000-180$ & - & - \\
\hline 2 & 7,00 & & Banda individual anastomosada & 0,10 & $000-180$ & - & - \\
\hline 2 & 7,00 & & Banda individual anastomosada & 0,10 & $000-180$ & - & - \\
\hline 2 & 7,00 & & Banda individual anastomosada & 0,10 & $000-180$ & - & - \\
\hline 2 & 7,00 & & Banda individual anastomosada & 0,10 & $000-180$ & - & - \\
\hline 2 & 7,00 & & Banda individual anastomosada & 0,10 & $000-180$ & - & - \\
\hline 2 & 7,00 & & Banda individual anastomosada & 0,10 & $000-180$ & - & - \\
\hline 2 & 7,00 & & Banda individual anastomosada & 0,10 & $170-350$ & - & - \\
\hline 2 & 7,00 & & Banda individual anastomosada & 0,10 & $170-350$ & - & - \\
\hline 2 & 7,00 & & Banda individual anastomosada & 0,10 & $170-350$ & - & - \\
\hline 2 & 7,00 & & Banda individual anastomosada & 0,10 & $170-350$ & - & - \\
\hline 2 & 7,00 & & Banda individual anastomosada & 0,10 & $170-350$ & - & - \\
\hline 2 & 7,00 & & Banda individual anastomosada & 0,10 & $170-350$ & - & - \\
\hline 2 & 7,00 & & Banda individual anastomosada & 0,10 & $170-350$ & - & - \\
\hline 2 & 7,00 & & Banda individual anastomosada & 0,10 & $170-350$ & - & - \\
\hline 2 & 7,00 & & Banda individual anastomosada & 0,10 & $170-350$ & - & - \\
\hline \multirow[t]{2}{*}{2} & 7,00 & & Banda individual anastomosada & 0,10 & $170-350$ & - & - \\
\hline & & & Banda individual anastomosada & 0,10 & $170-350$ & - & - \\
\hline 2 & 7,00 & & Banda individual anastomosada & 0,10 & 005-185 & $095 / 62$ & - \\
\hline 2 & 7,00 & & Banda individual anastomosada & 0,10 & $160-340$ & - & - \\
\hline 2 & 7,00 & & Banda individual anastomosada & 0,10 & $160-340$ & - & - \\
\hline 2 & 7,00 & & Banda individual anastomosada & 0,10 & 010-190 & - & - \\
\hline 2 & 7,00 & & Banda individual anastomosada & 0,10 & 010-190 & - & - \\
\hline 2 & 7,00 & & Banda individual anastomosada & 0,10 & 010-190 & - & - \\
\hline 2 & 7,00 & & Banda individual anastomosada & 0,20 & 005-185 & $095 / 60$ & - \\
\hline 2 & 7,00 & & Banda individual anastomosada & 0,20 & $005-185$ & $095 / 60$ & - \\
\hline 2 & 7,00 & & Banda individual anastomosada & 0,20 & 025-205 & $115 / 60$ & - \\
\hline 2 & 7,00 & & Agrupamento de bandas anastomosado & 0,50 & $000-180$ & $090 / 66$ & - \\
\hline 2 & 7,00 & & Banda individual anastomosada & 0,10 & $110-290$ & - & - \\
\hline 2 & 7,00 & & Banda individual anastomosada & 0,10 & $150-330$ & $060 / 66$ & - \\
\hline 2 & 7,00 & & Banda individual anastomosada & 0,10 & $150-330$ & $060 / 66$ & - \\
\hline 2 & 7,00 & & Banda individual anastomosada & 0,10 & $170-350$ & - & Dextral \\
\hline 2 & 7,00 & & Banda individual anastomosada & 0,10 & $170-350$ & - & Dextral \\
\hline 2 & 7,00 & & Banda individual anastomosada & 0,10 & $170-350$ & - & Dextral \\
\hline
\end{tabular}




\begin{tabular}{|c|c|c|c|c|c|c|c|}
\hline 2 & 7,00 & & Banda individual anastomosada & 0,10 & $000-180$ & - & - \\
\hline 2 & 7,00 & & Banda individual anastomosada & 0,10 & $000-180$ & - & - \\
\hline 2 & 7,00 & & Agrupamento de bandas anastomosado & 6,00 & $170-350$ & - & - \\
\hline 2 & 7,00 & & Banda individual anastomosada & 0,10 & $030-210$ & - & - \\
\hline 2 & 7,00 & & Banda individual anastomosada & 0,10 & $030-210$ & - & - \\
\hline 2 & 7,00 & & Banda individual anastomosada & 0,10 & $160-340$ & - & - \\
\hline 2 & 7,00 & & Banda individual anastomosada & 0,10 & $160-340$ & - & - \\
\hline 2 & 7,00 & & Banda individual anastomosada & 0,10 & $160-340$ & - & - \\
\hline 2 & 7,00 & & Banda individual anastomosada & 0,10 & $160-340$ & - & - \\
\hline 2 & 7,00 & & Banda individual anastomosada & 0,10 & $160-340$ & - & - \\
\hline 2 & 7,00 & & Banda individual anastomosada & 0,10 & $160-340$ & - & - \\
\hline 2 & 7,00 & & Banda individual anastomosada & 0,10 & $160-340$ & - & - \\
\hline 2 & 7,00 & & Banda individual anastomosada & 0,10 & $160-340$ & - & - \\
\hline 2 & 7,00 & & Banda individual anastomosada & 0,10 & $150-330$ & - & - \\
\hline 2 & 7,00 & \multirow{26}{*}{5 a $6 \mathrm{~m}$} & Banda individual anastomosada & 0,10 & $000-180$ & - & - \\
\hline 2 & 7,00 & & Banda individual anastomosada & 0,10 & $000-180$ & - & - \\
\hline 2 & 7,00 & & Banda individual anastomosada & 0,10 & $000-180$ & - & - \\
\hline 2 & 7,00 & & Banda individual anastomosada & 0,10 & $010-190$ & - & - \\
\hline 2 & 7,00 & & Banda individual anastomosada & 0,10 & $010-190$ & - & - \\
\hline 2 & 7,00 & & Banda individual anastomosada & 0,10 & $010-190$ & - & - \\
\hline 2 & 7,00 & & Banda individual anastomosada & 0,10 & $010-190$ & - & - \\
\hline 2 & 7,00 & & Banda individual anastomosada & 0,10 & $010-190$ & - & - \\
\hline 2 & 7,00 & & Banda individual anastomosada & 0,10 & $010-190$ & - & - \\
\hline 2 & 7,00 & & Banda individual anastomosada & 0,10 & $010-190$ & - & - \\
\hline 2 & 7,00 & & Banda individual anastomosada & 0,10 & $010-190$ & - & - \\
\hline 2 & 7,00 & & Banda individual anastomosada & 0,10 & $160-340$ & - & - \\
\hline 2 & 7,00 & & Banda individual anastomosada & 0,10 & $020-200$ & - & - \\
\hline 2 & 7,00 & & Banda individual anastomosada & 0,10 & $020-200$ & - & - \\
\hline 2 & 7,00 & & Banda individual anastomosada & 0,10 & $020-200$ & - & - \\
\hline 2 & 7,00 & & Banda individual anastomosada & 0,10 & $020-200$ & - & - \\
\hline 2 & 7,00 & & Banda individual anastomosada & 0,10 & $020-200$ & - & - \\
\hline 2 & 7,00 & & Banda individual anastomosada & 0,10 & $020-200$ & - & - \\
\hline 2 & 7,00 & & Banda individual anastomosada & 0,10 & 015-195 & - & - \\
\hline 2 & 7,00 & & Banda individual anastomosada & 0,10 & $000-180$ & - & Dextral \\
\hline 2 & 7,00 & & Agrupamento de bandas anastomosado & 0,30 & $015-195$ & $285 / 74$ & - \\
\hline 2 & 7,00 & & Banda individual anastomosada & 0,10 & $170-350$ & - & - \\
\hline 2 & 7,00 & & Agrupamento de bandas anastomosado & 3,00 & $030-210$ & - & - \\
\hline 2 & 7,00 & & Agrupamento de bandas anastomosado & 1,00 & $040-220$ & - & - \\
\hline 2 & 7,00 & & Banda individual anastomosada & 0,20 & $030-210$ & - & - \\
\hline 2 & 7,00 & & Banda individual anastomosada & 0,20 & $000-180$ & - & - \\
\hline 2 & 7,00 & \multirow{6}{*}{6 a $7 \mathrm{~m}$} & Banda individual anastomosada & 0,10 & $000-180$ & - & - \\
\hline 2 & 7,00 & & Banda individual anastomosada & 0,10 & $000-180$ & - & - \\
\hline 2 & 7,00 & & Banda individual anastomosada & 0,10 & $000-180$ & - & - \\
\hline 2 & 7,00 & & Banda individual anastomosada & 0,20 & $030-210$ & - & - \\
\hline 2 & 7,00 & & Banda individual anastomosada & 0,10 & $020-200$ & - & - \\
\hline 2 & 7,00 & & Banda individual anastomosada & 0,10 & $020-200$ & - & - \\
\hline 3 & 11,00 & \multirow{8}{*}{0 a $1 \mathrm{~m}$} & Banda individual retilínea & 0,20 & $040-220$ & - & - \\
\hline 3 & 11,00 & & Banda individual retilínea & 0,20 & $170-350$ & - & - \\
\hline 3 & 11,00 & & Banda individual retilínea & 0,50 & $000-180$ & - & - \\
\hline 3 & 11,00 & & Banda individual anastomosada & 0,50 & $040-220$ & - & - \\
\hline 3 & 11,00 & & Banda individual anastomosada & 0,20 & $160-340$ & - & - \\
\hline 3 & 11,00 & & Banda individual anastomosada & 0,10 & $170-350$ & - & - \\
\hline 3 & 11,00 & & Banda individual anastomosada & 0,10 & $170-350$ & - & - \\
\hline 3 & 11,00 & & Banda individual retilínea & 0,10 & $000-180$ & - & - \\
\hline 3 & 11,00 & \multirow{5}{*}{1 a $2 \mathrm{~m}$} & Banda individual anastomosada & 0,20 & $000-180$ & - & - \\
\hline 3 & 11,00 & & Banda individual anastomosada & 0,20 & $000-180$ & - & - \\
\hline 3 & 11,00 & & Banda individual anastomosada & 0,20 & $140-320$ & - & - \\
\hline 3 & 11,00 & & Banda individual anastomosada & 0,20 & $010-190$ & - & - \\
\hline 3 & 11,00 & & Banda individual anastomosada & 0,20 & 010-190 & - & - \\
\hline
\end{tabular}




\begin{tabular}{|c|c|c|c|c|c|c|c|}
\hline 3 & 11,00 & & Banda individual anastomosada & 0,10 & $150-330$ & - & - \\
\hline 3 & 11,00 & & Banda individual anastomosada & 0,10 & $150-330$ & - & - \\
\hline 3 & 11,00 & & Banda individual anastomosada & 0,10 & $150-330$ & - & - \\
\hline 3 & 11,00 & & Banda individual anastomosada & 0,20 & $150-330$ & - & - \\
\hline 3 & 11,00 & & Agrupamento de bandas anastomosado & 0,30 & $020-200$ & - & - \\
\hline 3 & 11,00 & & Banda individual anastomosada & 0,10 & $020-200$ & - & - \\
\hline 3 & 11,00 & & Banda individual retilínea & 0,10 & 010-190 & - & - \\
\hline 3 & 11,00 & 2 a $3 \mathrm{~m}$ & Banda individual retilínea & 0,10 & 010-190 & - & - \\
\hline 3 & 11,00 & & Banda individual anastomosada & 0,10 & $020-200$ & - & - \\
\hline 3 & 11,00 & 3 a $4 \mathrm{~m}$ & Banda individual anastomosada & 0,10 & $050-230$ & - & - \\
\hline 3 & 11,00 & & Agrupamento de bandas anastomosado & 0,70 & $170-350$ & - & - \\
\hline 3 & 11,00 & 4 a $5 \mathrm{~m}$ & Agrupamento de bandas anastomosado & 0,30 & $150-330$ & - & - \\
\hline 3 & 11,00 & 5 a $6 \mathrm{~m}$ & \multicolumn{5}{|c|}{ Intervalo coberto } \\
\hline 3 & 11,00 & $6.7 \mathrm{~m}$ & Banda individual anastomosada & 0,30 & $150-330$ & - & - \\
\hline 3 & 11,00 & o a $/ \mathrm{m}$ & Banda individual anastomosada & 0,30 & $170-350$ & - & - \\
\hline 3 & 11,00 & $7 \mathrm{a} 8 \mathrm{~m}$ & \multicolumn{5}{|c|}{ Intervalo coberto } \\
\hline 3 & 11,00 & $8 \mathrm{a} 9 \mathrm{~m}$ & \multicolumn{5}{|c|}{ Intervalo sem bandas } \\
\hline 3 & 11,00 & 9 a $10 \mathrm{~m}$ & Agrupamento de bandas anastomosado & 0,60 & $160-340$ & - & - \\
\hline 3 & 11,00 & 10 a $11 \mathrm{~m}$ & \multicolumn{5}{|c|}{ Intervalo sem bandas } \\
\hline 4 & 4,00 & \multirow{12}{*}{0 a $1 \mathrm{~m}$} & Agrupamento de bandas anastomosado & 0,50 & $170-350$ & - & - \\
\hline 4 & 4,00 & & Banda individual anastomosada & 0,10 & $170-350$ & - & - \\
\hline 4 & 4,00 & & Banda individual anastomosada & 0,10 & $170-350$ & - & - \\
\hline 4 & 4,00 & & Banda individual anastomosada & 0,10 & $150-330$ & - & - \\
\hline 4 & 4,00 & & Banda individual anastomosada & 0,10 & $150-330$ & - & - \\
\hline 4 & 4,00 & & Banda individual anastomosada & 0,10 & $150-330$ & - & - \\
\hline 4 & 4,00 & & Banda individual anastomosada & 0,10 & $150-330$ & - & - \\
\hline 4 & 4,00 & & Banda individual anastomosada & 0,10 & $010-190$ & - & - \\
\hline 4 & 4,00 & & Banda individual anastomosada & 0,10 & 010-190 & - & - \\
\hline 4 & 4,00 & & Banda individual anastomosada & 0,30 & 010-190 & - & - \\
\hline 4 & 4,00 & & Banda individual anastomosada & 0,30 & 010-190 & - & - \\
\hline 4 & 4,00 & & Banda individual anastomosada & 0,30 & $010-190$ & - & - \\
\hline 4 & 4,00 & \multirow{9}{*}{1 a $2 \mathrm{~m}$} & Agrupamento de bandas anastomosado & 0,30 & $170-350$ & - & - \\
\hline 4 & 4,00 & & Agrupamento de bandas anastomosado & 1,00 & $160-340$ & $070 / 78$ & - \\
\hline 4 & 4,00 & & Agrupamento de bandas anastomosado & 0,20 & $150-330$ & - & - \\
\hline 4 & 4,00 & & Agrupamento de bandas anastomosado & 0,20 & $150-330$ & - & - \\
\hline 4 & 4,00 & & Agrupamento de bandas anastomosado & 0,20 & $010-190$ & - & - \\
\hline 4 & 4,00 & & Agrupamento de bandas anastomosado & 0,20 & $010-190$ & - & - \\
\hline 4 & 4,00 & & Agrupamento de bandas anastomosado & 0,20 & $170-350$ & - & - \\
\hline 4 & 4,00 & & Banda individual anastomosada & 0,10 & $000-180$ & - & - \\
\hline 4 & 4,00 & & Banda individual anastomosada & 0,10 & $170-350$ & - & - \\
\hline 4 & 4,00 & \multirow{5}{*}{2 a $3 \mathrm{~m}$} & Banda individual anastomosada & 0,10 & $000-180$ & - & - \\
\hline 4 & 4,00 & & Banda individual anastomosada & 0,20 & $150-330$ & - & - \\
\hline 4 & 4,00 & & Agrupamento de bandas anastomosado & 0,30 & $160-340$ & - & - \\
\hline 4 & 4,00 & & Banda individual anastomosada & 0,10 & $150-330$ & - & - \\
\hline 4 & 4,00 & & Banda individual anastomosada & 0,10 & $150-330$ & - & - \\
\hline 4 & 4,00 & \multirow{2}{*}{3 a $4 \mathrm{~m}$} & Banda individual anastomosada & 0,20 & $175-355$ & - & - \\
\hline 4 & 4,00 & & Agrupamento de bandas anastomosado & 0,30 & $150-330$ & - & - \\
\hline 5 & 4,00 & \multirow{8}{*}{0 a $1 \mathrm{~m}$} & Banda individual anastomosada & 0,30 & $155-335$ & $245 / 70$ & - \\
\hline 5 & 4,00 & & Banda individual anastomosada & 0,20 & $020-200$ & - & - \\
\hline 5 & 4,00 & & Banda individual anastomosada & 0,40 & $170-350$ & $260 / 40$ & - \\
\hline 5 & 4,00 & & Banda individual anastomosada & 0,30 & $165-345$ & - & - \\
\hline 5 & 4,00 & & Banda individual anastomosada & 0,30 & $170-350$ & - & - \\
\hline 5 & 4,00 & & Banda individual anastomosada & 0,30 & $170-350$ & - & - \\
\hline 5 & 4,00 & & Banda individual anastomosada & 0,10 & $150-330$ & - & - \\
\hline 5 & 4,00 & & Banda individual anastomosada & 0,10 & $170-350$ & - & - \\
\hline 5 & 4,00 & \multirow{4}{*}{1 a $2 \mathrm{~m}$} & Agrupamento de bandas anastomosado & 0,50 & $140-320$ & - & - \\
\hline 5 & 4,00 & & Banda individual retilínea & 0,10 & $080-260$ & - & - \\
\hline 5 & 4,00 & & Agrupamento de bandas anastomosado & 0,50 & $150-330$ & - & - \\
\hline 5 & 4,00 & & Agrupamento de bandas anastomosado & 0,50 & $150-330$ & - & - \\
\hline
\end{tabular}




\begin{tabular}{|c|c|c|c|c|c|c|c|}
\hline 5 & 4,00 & & Banda individual anastomosada & 0,20 & $160-340$ & - & - \\
\hline 5 & 4,00 & & Agrupamento de bandas anastomosado & 0,50 & $020-200$ & - & - \\
\hline 5 & 4,00 & & Banda individual anastomosada & 0,20 & $160-340$ & - & - \\
\hline 5 & 4,00 & & Banda individual anastomosada & 0,20 & $160-340$ & - & - \\
\hline 5 & 4,00 & & Banda individual anastomosada & 0,20 & $160-340$ & - & - \\
\hline 5 & 4,00 & & Banda individual anastomosada & 0,20 & $160-340$ & - & - \\
\hline 5 & 4,00 & & Banda individual anastomosada & 0,20 & $160-340$ & - & - \\
\hline 5 & 4,00 & & Agrupamento de bandas anastomosado & 0,50 & $170-350$ & - & - \\
\hline 5 & 4,00 & & Agrupamento de bandas anastomosado & 0,50 & $170-350$ & - & - \\
\hline 5 & 4,00 & & Agrupamento de bandas anastomosado & 0,50 & $170-350$ & - & - \\
\hline 5 & 4,00 & & Banda individual anastomosada & 0,20 & $000-180$ & - & - \\
\hline 5 & 4,00 & & Banda individual anastomosada & 0,20 & $160-340$ & - & - \\
\hline 5 & 4,00 & & Banda individual anastomosada & 0,20 & $160-340$ & - & - \\
\hline 5 & 4,00 & \multirow{10}{*}{2 a $3 \mathrm{~m}$} & Agrupamento de bandas anastomosado & 0,30 & $000-180$ & - & - \\
\hline 5 & 4,00 & & Banda individual anastomosada & 0,20 & $160-340$ & - & - \\
\hline 5 & 4,00 & & Banda individual anastomosada & 0,20 & $150-330$ & - & - \\
\hline 5 & 4,00 & & Banda individual anastomosada & 0,20 & $150-330$ & - & - \\
\hline 5 & 4,00 & & Banda individual anastomosada & 0,20 & $170-350$ & - & - \\
\hline 5 & 4,00 & & Banda individual anastomosada & 0,20 & $170-350$ & - & - \\
\hline 5 & 4,00 & & Agrupamento de bandas anastomosado & 1,50 & $155-335$ & $065 / 84$ & - \\
\hline 5 & 4,00 & & Banda individual anastomosada & 0,20 & $160-340$ & - & - \\
\hline 5 & 4,00 & & Banda individual anastomosada & 0,20 & $030-210$ & - & - \\
\hline 5 & 4,00 & & Agrupamento de bandas anastomosado & 1,50 & $140-320$ & $230 / 86$ & - \\
\hline 5 & 4,00 & \multirow{12}{*}{3 a $4 \mathrm{~m}$} & Banda individual anastomosada & 0,50 & $145-325$ & $055 / 70$ & - \\
\hline 5 & 4,00 & & Agrupamento de bandas anastomosado & 0,40 & $170-350$ & $080 / 70$ & - \\
\hline 5 & 4,00 & & Banda individual anastomosada & 0,30 & $125-305$ & - & - \\
\hline 5 & 4,00 & & Banda individual anastomosada & 0,10 & $155-335$ & - & - \\
\hline 5 & 4,00 & & Banda individual anastomosada & 0,30 & $150-330$ & - & - \\
\hline 5 & 4,00 & & Banda individual anastomosada & 0,10 & $130-310$ & - & - \\
\hline 5 & 4,00 & & Banda individual anastomosada & 0,10 & $160-340$ & - & - \\
\hline 5 & 4,00 & & Banda individual anastomosada & 0,10 & $160-340$ & - & - \\
\hline 5 & 4,00 & & Banda individual anastomosada & 0,10 & $160-340$ & - & - \\
\hline 5 & 4,00 & & Banda individual anastomosada & 0,10 & $160-340$ & - & - \\
\hline 5 & 4,00 & & Banda individual anastomosada & 0,10 & 010-190 & - & - \\
\hline 5 & 4,00 & & Agrupamento de bandas anastomosado & 0,50 & $150-330$ & - & - \\
\hline 6 & 4,00 & \multirow{3}{*}{0 a $1 \mathrm{~m}$} & Agrupamento de bandas anastomosado & 0,30 & $040-220$ & - & - \\
\hline 6 & 4,00 & & Agrupamento de bandas anastomosado & 0,50 & $010-190$ & $100 / 66$ & - \\
\hline 6 & 4,00 & & Banda individual anastomosada & 0,30 & $020-200$ & - & - \\
\hline 6 & 4,00 & \multirow{4}{*}{1 a $2 \mathrm{~m}$} & Banda individual anastomosada & 0,10 & $000-180$ & - & - \\
\hline 6 & 4,00 & & Banda individual anastomosada & 0,10 & 005-185 & - & - \\
\hline 6 & 4,00 & & Banda individual anastomosada & 0,20 & $170-350$ & - & - \\
\hline 6 & 4,00 & & Agrupamento de bandas anastomosado & 1,00 & 015-195 & $105 / 70$ & - \\
\hline 6 & 4,00 & \multirow{12}{*}{2 a $3 \mathrm{~m}$} & Agrupamento de bandas anastomosado & 0,30 & 005-185 & $095 / 64$ & - \\
\hline 6 & 4,00 & & Agrupamento de bandas anastomosado & 0,30 & $010-190$ & $100 / 64$ & - \\
\hline 6 & 4,00 & & Agrupamento de bandas anastomosado & 0,30 & $010-190$ & - & - \\
\hline 6 & 4,00 & & Agrupamento de bandas anastomosado & 0,30 & $010-190$ & - & - \\
\hline 6 & 4,00 & & Agrupamento de bandas anastomosado & 0,30 & $010-190$ & - & - \\
\hline 6 & 4,00 & & Agrupamento de bandas anastomosado & 0,30 & $010-190$ & - & - \\
\hline 6 & 4,00 & & Agrupamento de bandas anastomosado & 0,30 & $010-190$ & - & - \\
\hline 6 & 4,00 & & Agrupamento de bandas anastomosado & 0,30 & 010-190 & - & - \\
\hline 6 & 4,00 & & Agrupamento de bandas anastomosado & 0,30 & $010-190$ & - & - \\
\hline 6 & 4,00 & & Agrupamento de bandas anastomosado & 0,30 & $010-190$ & - & - \\
\hline 6 & 4,00 & & Agrupamento de bandas anastomosado & 0,30 & $055-235$ & - & - \\
\hline 6 & 4,00 & & Agrupamento de bandas anastomosado & 0,30 & $055-235$ & - & - \\
\hline 6 & 4,00 & \multirow{5}{*}{3 a $4 \mathrm{~m}$} & Agrupamento de bandas anastomosado & 0,50 & 015-195 & $105 / 62$ & - \\
\hline 6 & 4,00 & & Agrupamento de bandas anastomosado & 0,50 & $015-195$ & $105 / 62$ & - \\
\hline 6 & 4,00 & & Agrupamento de bandas anastomosado & 0,30 & $020-200$ & - & - \\
\hline 6 & 4,00 & & Agrupamento de bandas anastomosado & 0,30 & $175-355$ & - & - \\
\hline 6 & 4,00 & & Agrupamento de bandas anastomosado & 0,30 & $175-355$ & - & - \\
\hline
\end{tabular}




\begin{tabular}{|c|c|c|c|c|c|c|c|}
\hline 7 & 2,00 & \multirow{5}{*}{0 a $1 \mathrm{~m}$} & Banda individual anastomosada & 0,20 & $000-180$ & $090 / 78$ & - \\
\hline 7 & 2,00 & & Agrupamento de bandas anastomosado & 0,30 & $000-180$ & - & - \\
\hline 7 & 2,00 & & Banda individual anastomosada & 0,40 & $020-200$ & - & - \\
\hline 7 & 2,00 & & Banda individual anastomosada & 0,40 & $000-180$ & - & - \\
\hline 7 & 2,00 & & Banda individual anastomosada & 0,40 & $130-310$ & $040 / 70$ & - \\
\hline 7 & 2,00 & \multirow{11}{*}{1 a $2 \mathrm{~m}$} & Agrupamento de bandas anastomosado & 1,00 & $020-200$ & $110 / 80$ & - \\
\hline 7 & 2,00 & & Banda individual anastomosada & 0,20 & $040-220$ & - & - \\
\hline 7 & 2,00 & & Agrupamento de bandas anastomosado & 0,20 & $025-205$ & - & - \\
\hline 7 & 2,00 & & Agrupamento de bandas anastomosado & 1,00 & $110-290$ & - & Dextral \\
\hline 7 & 2,00 & & Agrupamento de bandas anastomosado & 1,00 & $110-290$ & - & Dextral \\
\hline 7 & 2,00 & & Banda individual anastomosada & 0,10 & $175-355$ & - & - \\
\hline 7 & 2,00 & & Banda individual anastomosada & 0,20 & $060-240$ & - & - \\
\hline 7 & 2,00 & & Banda individual anastomosada & 0,20 & $050-230$ & - & - \\
\hline 7 & 2,00 & & Agrupamento de bandas anastomosado & 0,30 & $000-180$ & $090 / 70$ & - \\
\hline 7 & 2,00 & & Agrupamento de bandas anastomosado & 0,30 & $000-180$ & $090 / 70$ & - \\
\hline 7 & 2,00 & & Banda individual anastomosada & 0,20 & $150-330$ & - & - \\
\hline 8 & 2,00 & \multirow{7}{*}{0 a $1 \mathrm{~m}$} & Banda individual anastomosada & 0,30 & $140-320$ & - & - \\
\hline 8 & 2,00 & & Agrupamento de bandas anastomosado & 0,30 & 015-195 & $105 / 70$ & - \\
\hline 8 & 2,00 & & Agrupamento de bandas anastomosado & 0,30 & 015-195 & $105 / 70$ & - \\
\hline 8 & 2,00 & & Banda individual anastomosada & 0,30 & $130-310$ & $040 / 70$ & - \\
\hline 8 & 2,00 & & Banda individual anastomosada & 0,30 & $170-350$ & $080 / 82$ & - \\
\hline 8 & 2,00 & & Banda individual anastomosada & 0,30 & $170-350$ & $080 / 82$ & - \\
\hline 8 & 2,00 & & Banda individual anastomosada & 0,30 & $120-300$ & $030 / 74$ & - \\
\hline 8 & 2,00 & \multirow{14}{*}{1 a $2 \mathrm{~m}$} & Agrupamento de bandas anastomosado & 0,50 & $165-345$ & $075 / 76$ & - \\
\hline 8 & 2,00 & & Agrupamento de bandas anastomosado & 0,50 & $165-345$ & $075 / 76$ & - \\
\hline 8 & 2,00 & & Banda individual anastomosada & 0,20 & $165-345$ & - & - \\
\hline 8 & 2,00 & & Banda individual anastomosada & 0,20 & $165-345$ & - & - \\
\hline 8 & 2,00 & & Banda individual anastomosada & 0,20 & $165-345$ & - & - \\
\hline 8 & 2,00 & & Banda individual anastomosada & 0,20 & $165-345$ & - & - \\
\hline 8 & 2,00 & & Banda individual anastomosada & 0,10 & $140-320$ & - & - \\
\hline 8 & 2,00 & & Banda individual anastomosada & 0,10 & $140-320$ & - & - \\
\hline 8 & 2,00 & & Agrupamento de bandas anastomosado & 1,00 & 040-220 & - & - \\
\hline 8 & 2,00 & & Banda individual anastomosada & 0,20 & $160-340$ & $070 / 70$ & - \\
\hline 8 & 2,00 & & Banda individual anastomosada & 0,20 & $160-340$ & $070 / 70$ & - \\
\hline 8 & 2,00 & & Banda individual anastomosada & 0,20 & $160-340$ & $070 / 70$ & - \\
\hline 8 & 2,00 & & Banda individual anastomosada & 0,20 & $160-340$ & $070 / 70$ & - \\
\hline 8 & 2,00 & & Banda individual anastomosada & 0,20 & $160-340$ & $070 / 70$ & - \\
\hline
\end{tabular}




\section{APÊNDICE B - DADOS ESTRUTURAIS DAS SCANLINES DO}

\section{AFLORAMENTO DA FALHA DE CARITÁ}

\begin{tabular}{|c|c|c|c|c|c|c|c|}
\hline Linha & $\begin{array}{c}\text { Comprimento } \\
(\mathbf{m})\end{array}$ & Intervalo & Geometria & $\begin{array}{l}\text { Espessura } \\
(\mathrm{cm})\end{array}$ & Orientação & $\begin{array}{c}\text { Direção do } \\
\text { mergulho }\end{array}$ & Cinemática \\
\hline 1 & 31,0 & \multirow{6}{*}{0 a $1 \mathrm{~m}$} & Agrupamento de bandas anastomosado & $\begin{array}{c}\text { Afm 0,2 a } \\
0,5 / \mathrm{Ac} 1,5 / 7,0\end{array}$ & $050-230$ & $140 / 68$ & - \\
\hline 1 & 31,0 & & Agrupamento de bandas anastomosado & $\begin{array}{c}\text { Afm } 0,2 \mathrm{a} \\
0,5 / \mathrm{Ac} 1,5 / 7,0\end{array}$ & $050-230$ & $140 / 68$ & - \\
\hline 1 & 31,0 & & Agrupamento de bandas anastomosado & $\begin{array}{c}\text { Afm } 0,2 \mathrm{a} \\
0,5 / \mathrm{Ac} 1,5 / 7,0\end{array}$ & $050-230$ & $140 / 68$ & - \\
\hline 1 & 31,0 & & Banda individual retilínea & 0,1 & $050-230$ & - & - \\
\hline 1 & 31,0 & & Agrupamento de bandas anastomosado & 1,0 a 4,0 & $040-220$ & $310 / 78$ & - \\
\hline 1 & 31,0 & & Agrupamento de bandas anastomosado & 1,0 a 4,0 & $035-215$ & $305 / 80$ & - \\
\hline 1 & 31,0 & \multirow{3}{*}{1 a $2 \mathrm{~m}$} & Agrupamento de bandas anastomosado & 0,5 a 3,0 & $010-190$ & $100 / 60$ & - \\
\hline 1 & 31,0 & & Banda individual retilínea & 0,1 & $035-215$ & & - \\
\hline 1 & 31,0 & & Banda individual retilínea & 0,1 & $050-230$ & & Sinistral \\
\hline 1 & 31,0 & 2 a $3 \mathrm{~m}$ & & Intervalo coberto & & & \\
\hline 1 & 31,0 & \multirow{3}{*}{3 a $4 \mathrm{~m}$} & Banda individual retilínea & 0,1 a 1,0 & $050-230$ & $140 / 66$ & - \\
\hline 1 & 31,0 & & Banda individual retilínea & 0,1 a 1,0 & $050-230$ & $140 / 66$ & - \\
\hline 1 & 31,0 & & Banda individual retilínea & 0,1 a 1,0 & $050-230$ & $140 / 66$ & - \\
\hline 1 & 31,0 & 4 a $5 \mathrm{~m}$ & Agrupamento de bandas anastomosado & 3,0 a 10,0 & $075-255$ & $165 / 80$ & - \\
\hline 1 & 31,0 & \multirow{4}{*}{5 a $6 \mathrm{~m}$} & Banda individual retilínea & 0,1 & 010-190 & - & - \\
\hline 1 & 31,0 & & Agrupamento de bandas anastomosado & 0,7 a 4,0 & $070-250$ & $160 / 60$ & - \\
\hline 1 & 31,0 & & Agrupamento de bandas anastomosado & 0,5 a 3,0 & $025-205$ & - & - \\
\hline 1 & 31,0 & & Agrupamento de bandas anastomosado & 0,1 a 2,5 & $080-260$ & - & - \\
\hline 1 & 31,0 & \multirow{4}{*}{6 a $7 \mathrm{~m}$} & Agrupamento de bandas anastomosado & 1,5 a 2,0 & $055-235$ & $145 / 66$ & - \\
\hline 1 & 31,0 & & Agrupamento de bandas anastomosado & 1,5 a 2,0 & $055-235$ & $145 / 66$ & - \\
\hline 1 & 31,0 & & Banda individual retilínea & 0,1 & $020-200$ & - & - \\
\hline 1 & 31,0 & & Agrupamento de bandas anastomosado & 8,0 & $050-230$ & $140 / 70$ & - \\
\hline 1 & 31,0 & \multirow{6}{*}{7 a $8 \mathrm{~m}$} & Agrupamento de bandas anastomosado & 7,0 & 010-190 & $110 / 50$ & - \\
\hline 1 & 31,0 & & Agrupamento de bandas anastomosado & 0,5 & $050-230$ & $140 / 70$ & Sinistral \\
\hline 1 & 31,0 & & Banda individual retilínea & 0,1 & $050-230$ & - & - \\
\hline 1 & 31,0 & & Banda individual retilínea & 0,1 & $060-240$ & - & - \\
\hline 1 & 31,0 & & Agrupamento de bandas anastomosado & 2,0 & $060-240$ & $150 / 66$ & - \\
\hline 1 & 31,0 & & Banda individual retilínea & 0,1 & $030-210$ & - & - \\
\hline 1 & 31,0 & 8 a $9 \mathrm{~m}$ & Agrupamento de bandas anastomosado & 2,0 & $035-215$ & $125 / 68$ & - \\
\hline 1 & 31,0 & \multirow{2}{*}{9 a $10 \mathrm{~m}$} & Agrupamento de bandas anastomosado & 0,5 & 010-190 & - & Dextral \\
\hline 1 & 31,0 & & Agrupamento de bandas anastomosado & 0,1 & $005-185$ & 095/70 & Dextral \\
\hline 1 & 31,0 & $10 \mathrm{a} 11 \mathrm{~m}$ & Agrupamento de bandas anastomosado & 0,2 & $040-220$ & - & - \\
\hline 1 & 31,0 & \multirow{3}{*}{11 a $12 \mathrm{~m}$} & Banda individual retilínea & 0,1 & $000-180$ & - & - \\
\hline 1 & 31,0 & & Banda individual retilínea & 0,1 & $020-200$ & - & Dextral \\
\hline 1 & 31,0 & & Agrupamento de bandas anastomosado & 0,5 a 2,5 & $045-225$ & $135 / 60$ & Sinistral \\
\hline 1 & 31,0 & \multirow{2}{*}{12 a $13 \mathrm{~m}$} & Agrupamento de bandas anastomosado & 3,0 & 010-190 & $110 / 40$ & - \\
\hline 1 & 31,0 & & Agrupamento de bandas anastomosado & 0,1 a 1,0 & $000-180$ & - & - \\
\hline 1 & 31,0 & 13 a $15 \mathrm{~m}$ & & Intervalo coberto & & & \\
\hline 1 & 31,0 & \multirow{4}{*}{15 a $16 \mathrm{~m}$} & Agrupamento de bandas anastomosado & 2,0 & $175-355$ & $085 / 54$ & - \\
\hline 1 & 31,0 & & Banda individual retilínea & 0,2 & $175-355$ & $085 / 68$ & Dextral \\
\hline 1 & 31,0 & & Agrupamento de bandas anastomosado & 0,3 & $075-255$ & - & - \\
\hline 1 & 31,0 & & Banda individual retilínea & 0,2 & $060-240$ & - & - \\
\hline 1 & 31,0 & \multirow{3}{*}{16 a $17 \mathrm{~m}$} & Agrupamento de bandas anastomosado & 17,0 & $045-225$ & $135 / 58$ & - \\
\hline 1 & 31,0 & & Agrupamento de bandas anastomosado & 0,3 a 0,5 & $158-338$ & $068 / 84$ & - \\
\hline 1 & 31,0 & & Agrupamento de bandas anastomosado & 0,2 & $000-180$ & - & - \\
\hline 1 & 31,0 & \multirow{5}{*}{17 a $18 \mathrm{~m}$} & Agrupamento de bandas anastomosado & 7,0 & $175-355$ & $085 / 58$ & - \\
\hline 1 & 31,0 & & Agrupamento de bandas anastomosado & 0,3 a 1,0 & $030-210$ & $120 / 70$ & Sinistral \\
\hline 1 & 31,0 & & Agrupamento de bandas anastomosado & 0,1 a 1,0 & $030-210$ & $120 / 82$ & - \\
\hline 1 & 31,0 & & Agrupamento de bandas anastomosado & 0,1 a 1,0 & $030-210$ & $120 / 82$ & - \\
\hline 1 & 31,0 & & Agrupamento de bandas anastomosado & 0,1 a 1,0 & $030-210$ & $120 / 82$ & - \\
\hline 1 & 31,0 & 18 a $19 \mathrm{~m}$ & Agrupamento de bandas anastomosado & 0,2 & $170-350$ & 080/76 & - \\
\hline
\end{tabular}




\begin{tabular}{|c|c|c|c|c|c|c|c|}
\hline 1 & 31,0 & & Agrupamento de bandas anastomosado & 3,0 a 5,0 & $040-220$ & $130 / 78$ & - \\
\hline 1 & 31,0 & & Agrupamento de bandas anastomosado & 0,5 & $170-350$ & $080 / 66$ & - \\
\hline 1 & 31,0 & & Agrupamento de bandas anastomosado & 4,0 a 5,5 & $040-220$ & $130 / 72$ & - \\
\hline 1 & 31,0 & & Banda individual retilínea & 0,5 & $130-310$ & - & - \\
\hline 1 & 31,0 & \multirow{9}{*}{19 a $20 \mathrm{~m}$} & Agrupamento de bandas anastomosado & 3,0 & $175-355$ & $085 / 56$ & - \\
\hline 1 & 31,0 & & Agrupamento de bandas anastomosado & 2,0 & $165-345$ & $075 / 60$ & - \\
\hline 1 & 31,0 & & Banda individual retilínea & 0,1 & $135-315$ & - & - \\
\hline 1 & 31,0 & & Agrupamento de bandas anastomosado & 6,0 & 005-185 & $095 / 50$ & - \\
\hline 1 & 31,0 & & Agrupamento de bandas anastomosado & 6,0 & $005-185$ & $095 / 50$ & - \\
\hline 1 & 31,0 & & Agrupamento de bandas anastomosado & 6,0 & 005-185 & $095 / 50$ & - \\
\hline 1 & 31,0 & & Agrupamento de bandas anastomosado & 3,0 & $040-220$ & $130 / 48$ & Sinistral \\
\hline 1 & 31,0 & & Agrupamento de bandas anastomosado & 3,0 & $040-220$ & $130 / 48$ & Sinistral \\
\hline 1 & 31,0 & & Agrupamento de bandas anastomosado & 3,0 & $040-220$ & $130 / 48$ & Sinistral \\
\hline 1 & 31,0 & \multirow{5}{*}{20 a $21 \mathrm{~m}$} & Agrupamento de bandas anastomosado & 8,0 & $005-185$ & $095 / 50$ & - \\
\hline 1 & 31,0 & & Agrupamento de bandas anastomosado & 0,5 & $170-350$ & $080 / 64$ & - \\
\hline 1 & 31,0 & & Banda individual retilínea & 0,3 & $170-350$ & $080 / 80$ & - \\
\hline 1 & 31,0 & & Agrupamento de bandas anastomosado & 1,0 & $040-220$ & $130 / 62$ & - \\
\hline 1 & 31,0 & & Agrupamento de bandas anastomosado & 1,0 & $040-220$ & $130 / 62$ & - \\
\hline 1 & 31,0 & 21 a $23 \mathrm{~m}$ & & Intervalo coberto & & & \\
\hline 1 & 31,0 & \multirow{4}{*}{23 a $24 \mathrm{~m}$} & Agrupamento de bandas anastomosado & 22,0 & $050-230$ & - & - \\
\hline 1 & 31,0 & & Agrupamento de bandas anastomosado & 3,0 & $020-200$ & - & - \\
\hline 1 & 31,0 & & Agrupamento de bandas anastomosado & 2,5 & $030-210$ & $120 / 40$ & - \\
\hline 1 & 31,0 & & Agrupamento de bandas anastomosado & 11,0 & $040-220$ & $130 / 80$ & - \\
\hline 1 & 31,0 & \multirow{2}{*}{24 a $25 \mathrm{~m}$} & Banda individual retilínea & 0,5 & $020-200$ & - & - \\
\hline 1 & 31,0 & & Agrupamento de bandas anastomosado & 3,5 & $170-350$ & $080 / 72$ & - \\
\hline 1 & 31,0 & \multirow{2}{*}{25 a $26 \mathrm{~m}$} & Banda individual retilínea & 0,5 & $175-355$ & $085 / 70$ & Dextral \\
\hline 1 & 31,0 & & Agrupamento de bandas anastomosado & 0,5 & $035-215$ & $125 / 64$ & - \\
\hline 1 & 31,0 & \multirow{4}{*}{26 a $27 \mathrm{~m}$} & Agrupamento de bandas anastomosado & 2,0 & $010-190$ & $110 / 40$ & - \\
\hline 1 & 31,0 & & Banda individual retilínea & 0,5 & $045-225$ & - & - \\
\hline 1 & 31,0 & & Agrupamento de bandas anastomosado & 1,0 & $175-355$ & - & Dextral \\
\hline 1 & 31,0 & & Agrupamento de bandas anastomosado & 4,5 & $035-215$ & $125 / 72$ & - \\
\hline 1 & 31,0 & \multirow{4}{*}{27 a $28 \mathrm{~m}$} & Agrupamento de bandas anastomosado & 1,0 & $170-350$ & $080 / 72$ & Dextral \\
\hline 1 & 31,0 & & Agrupamento de bandas anastomosado & 4,0 & $000-180$ & - & - \\
\hline 1 & 31,0 & & Agrupamento de bandas anastomosado & 1,0 & $035-215$ & $125 / 66$ & - \\
\hline 1 & 31,0 & & Agrupamento de bandas anastomosado & 1,0 & $035-215$ & $125 / 66$ & - \\
\hline 1 & 31,0 & \multirow{2}{*}{28 a $29 \mathrm{~m}$} & Agrupamento de bandas anastomosado & 0,5 & $050-230$ & - & - \\
\hline 1 & 31,0 & & Agrupamento de bandas anastomosado & 1,5 & $000-180$ & - & - \\
\hline 1 & 31,0 & 29 a $30 \mathrm{~m}$ & & Intervalo coberto & & & \\
\hline 1 & 31,0 & \multirow{5}{*}{30 a $31 \mathrm{~m}$} & Agrupamento de bandas anastomosado & 6,0 & $175-355$ & $085 / 58$ & - \\
\hline 1 & 31,0 & & Agrupamento de bandas anastomosado & 1,0 & $045-225$ & $135 / 58$ & - \\
\hline 1 & 31,0 & & Agrupamento de bandas anastomosado & 1,0 & $045-225$ & $135 / 58$ & - \\
\hline 1 & 31,0 & & Agrupamento de bandas anastomosado & 1,0 & $045-225$ & $135 / 58$ & - \\
\hline 1 & 31,0 & & Agrupamento de bandas anastomosado & 2,0 & $040-220$ & $130 / 50$ & - \\
\hline 2 & 8,00 & \multirow{16}{*}{0 a $1 \mathrm{~m}$} & Banda individual anastomosada & 0,5 & $070-250$ & $160 / 60$ & Sinistral \\
\hline 2 & 8,00 & & Banda individual anastomosada & 0,2 & $030-210$ & - & - \\
\hline 2 & 8,00 & & Banda individual anastomosada & 0,2 & $050-230$ & - & Sinistral \\
\hline 2 & 8,00 & & Agrupamento de bandas retilíneo & 0,5 & $135-315$ & $045 / 88$ & Dextral \\
\hline 2 & 8,00 & & Agrupamento de bandas retilíneo & 3,0 & $135-315$ & $045 / 88$ & Dextral \\
\hline 2 & 8,00 & & Banda individual retilínea & 0,1 & $130-310$ & - & - \\
\hline 2 & 8,00 & & Banda individual retilínea & 0,1 & 015-195 & - & - \\
\hline 2 & 8,00 & & Banda individual retilínea & 0,1 & $140-320$ & - & - \\
\hline 2 & 8,00 & & Agrupamento de bandas retilíneo & 1,0 & $060-240$ & $330 / 76$ & Sinistral \\
\hline 2 & 8,00 & & Banda individual anastomosada & 0,3 & $130-310$ & - & - \\
\hline 2 & 8,00 & & Banda individual anastomosada & 0,1 & $130-310$ & - & - \\
\hline 2 & 8,00 & & Banda individual anastomosada & 0,1 & $130-310$ & - & - \\
\hline 2 & 8,00 & & Agrupamento de bandas retilíneo & 1,0 & $135-315$ & $045 / 88$ & - \\
\hline 2 & 8,00 & & Agrupamento de bandas retilíneo & 0,5 & $065-245$ & - & Sinistral \\
\hline 2 & 8,00 & & Banda individual anastomosada & 0,3 & $120-300$ & - & - \\
\hline 2 & 8,00 & & Banda individual anastomosada & 0,3 & $120-300$ & - & - \\
\hline
\end{tabular}




\begin{tabular}{|c|c|c|c|c|c|c|c|}
\hline 2 & 8,00 & & Banda individual anastomosada & 0,3 & $120-300$ & - & - \\
\hline 2 & 8,00 & \multirow{16}{*}{1 a $2 \mathrm{~m}$} & Agrupamento de bandas curvilíneo & 1,5 & $005-185$ & $095 / 82$ & Dextral \\
\hline 2 & 8,00 & & Banda individual retilínea & 0,3 & $060-240$ & - & Sinistral \\
\hline 2 & 8,00 & & Banda individual anastomosada & 0,3 & $120-300$ & - & - \\
\hline 2 & 8,00 & & Agrupamento de bandas retilíneo & 1,5 & $050-230$ & - & - \\
\hline 2 & 8,00 & & Agrupamento de bandas retilíneo & 1,5 & $050-230$ & - & - \\
\hline 2 & 8,00 & & Agrupamento de bandas anastomosado & 0,5 & $140-320$ & - & - \\
\hline 2 & 8,00 & & Banda individual anastomosada & 0,2 & $065-245$ & - & - \\
\hline 2 & 8,00 & & Banda individual anastomosada & 0,2 & $065-245$ & - & - \\
\hline 2 & 8,00 & & Banda individual anastomosada & 0,3 & $170-350$ & - & - \\
\hline 2 & 8,00 & & Agrupamento de bandas anastomosado & 0,5 & $020-200$ & - & Dextral \\
\hline 2 & 8,00 & & Banda individual retilínea & 0,2 & $020-200$ & - & - \\
\hline 2 & 8,00 & & Banda individual retilínea & 0,2 & $020-200$ & - & - \\
\hline 2 & 8,00 & & Agrupamento de bandas retilíneo & 0,5 & $140-320$ & - & - \\
\hline 2 & 8,00 & & Agrupamento de bandas retilíneo & 1,0 & $070-250$ & - & - \\
\hline 2 & 8,00 & & Agrupamento de bandas anastomosado & 0,3 & $120-300$ & $210 / 50$ & - \\
\hline 2 & 8,00 & & Agrupamento de bandas retilíneo & 0,5 & $030-210$ & - & Dextral \\
\hline 2 & 8,00 & \multirow{42}{*}{2 a $3 \mathrm{~m}$} & Agrupamento de bandas anastomosado & 0,5 & $030-210$ & - & - \\
\hline 2 & 8,00 & & Agrupamento de bandas anastomosado & 0,5 & $030-210$ & - & - \\
\hline 2 & 8,00 & & Banda individual retilínea & 0,1 & $135-315$ & - & - \\
\hline 2 & 8,00 & & Banda individual retilínea & 0,1 & $135-315$ & - & - \\
\hline 2 & 8,00 & & Banda individual retilínea & 0,1 & $135-315$ & - & - \\
\hline 2 & 8,00 & & Banda individual retilínea & 0,1 & $135-315$ & - & - \\
\hline 2 & 8,00 & & Banda individual retilínea & 0,1 & 135-315 & - & - \\
\hline 2 & 8,00 & & Agrupamento de bandas retilíneo & 0,7 & $130-310$ & - & - \\
\hline 2 & 8,00 & & Agrupamento de bandas retilíneo & 0,7 & $130-310$ & - & - \\
\hline 2 & 8,00 & & Banda individual anastomosada & 0,1 & $080-260$ & - & - \\
\hline 2 & 8,00 & & Agrupamento de bandas retilíneo & 2,0 & $050-230$ & $320 / 74$ & Sinistral \\
\hline 2 & 8,00 & & Agrupamento de bandas retilíneo & 1,0 & $130-310$ & - & Dextral \\
\hline 2 & 8,00 & & Banda individual retilínea & 0,3 & $055-235$ & - & Sinistral \\
\hline 2 & 8,00 & & Banda individual retilínea & 0,3 & $055-235$ & - & Sinistral \\
\hline 2 & 8,00 & & Banda individual anastomosada & 0,1 & $080-260$ & - & Sinistral \\
\hline 2 & 8,00 & & Banda individual anastomosada & 0,1 & $080-260$ & - & Sinistral \\
\hline 2 & 8,00 & & Banda individual anastomosada & 0,1 & $080-260$ & - & Sinistral \\
\hline 2 & 8,00 & & Agrupamento de bandas anastomosado & 0,5 & $045-225$ & - & Sinistral \\
\hline 2 & 8,00 & & Banda individual retilínea & 0,1 & $065-245$ & - & Sinistral \\
\hline 2 & 8,00 & & Banda individual retilínea & 0,1 & $065-245$ & - & Sinistral \\
\hline 2 & 8,00 & & Banda individual retilínea & 0,1 & $065-245$ & - & Sinistral \\
\hline 2 & 8,00 & & Banda individual retilínea & 0,3 & $135-315$ & - & - \\
\hline 2 & 8,00 & & Banda individual retilínea & 0,3 & $135-315$ & - & - \\
\hline 2 & 8,00 & & Banda individual retilínea & 0,3 & $135-315$ & - & - \\
\hline 2 & 8,00 & & Banda individual retilínea & 0,3 & $135-315$ & - & - \\
\hline 2 & 8,00 & & Agrupamento de bandas retilíneo & 4,0 & 015-195 & $105 / 46$ & - \\
\hline 2 & 8,00 & & Banda individual retilínea & 0,1 & $010-190$ & - & - \\
\hline 2 & 8,00 & & Banda individual retilínea & 0,1 & 010-190 & - & - \\
\hline 2 & 8,00 & & Banda individual retilínea & 0,2 & $060-240$ & - & Sinistral \\
\hline 2 & 8,00 & & Agrupamento de bandas retilíneo & 0,4 & $130-310$ & - & \\
\hline 2 & 8,00 & & Banda individual retilínea & 0,3 & $000-180$ & - & Dextral \\
\hline 2 & 8,00 & & Banda individual retilínea & 0,3 & $135-315$ & - & - \\
\hline 2 & 8,00 & & Banda individual retilínea & 0,1 & $070-250$ & - & - \\
\hline 2 & 8,00 & & Banda individual retilínea & 0,1 & $070-250$ & - & - \\
\hline 2 & 8,00 & & Banda individual retilínea & 0,1 & $070-250$ & - & - \\
\hline 2 & 8,00 & & Banda individual retilínea & 0,1 & $070-250$ & - & - \\
\hline 2 & 8,00 & & Banda individual retilínea & 0,1 & $070-250$ & - & - \\
\hline 2 & 8,00 & & Banda individual retilínea & 0,1 & $070-250$ & - & - \\
\hline 2 & 8,00 & & Agrupamento de bandas retilíneo & 2,0 & $175-355$ & - & - \\
\hline 2 & 8,00 & & Banda individual retilínea & 0,1 & 010-190 & - & Dextral \\
\hline 2 & 8,00 & & Banda individual retilínea & 0,1 & 010-190 & - & Dextral \\
\hline 2 & 8,00 & & Banda individual retilínea & 0,1 & 010-190 & - & Dextral \\
\hline
\end{tabular}




\begin{tabular}{|c|c|c|c|c|c|c|c|}
\hline 2 & 8,00 & & Agrupamento de bandas retilíneo & 0,3 & $060-240$ & - & Sinistral \\
\hline 2 & 8,00 & & Agrupamento de bandas retilíneo & 0,3 & $060-240$ & - & Sinistral \\
\hline 2 & 8,00 & & Agrupamento de bandas retilíneo & 0,3 & $060-240$ & - & Sinistral \\
\hline 2 & 8,00 & & Agrupamento de bandas retilíneo & 0,3 & $060-240$ & - & Sinistral \\
\hline 2 & 8,00 & & Agrupamento de bandas retilíneo & 0,4 & $130-310$ & - & - \\
\hline 2 & 8,00 & & Agrupamento de bandas retilíneo & 0,4 & $130-310$ & - & - \\
\hline 2 & 8,00 & \multirow{20}{*}{4 a $5 \mathrm{~m}$} & Agrupamento de bandas retilíneo & 0,4 & $130-310$ & - & - \\
\hline 2 & 8,00 & & Agrupamento de bandas retilíneo & 0,3 & $060-240$ & - & Sinistral \\
\hline 2 & 8,00 & & Agrupamento de bandas retilíneo & 0,3 & $060-240$ & - & Sinistral \\
\hline 2 & 8,00 & & Agrupamento de bandas retilíneo & 0,3 & $060-240$ & - & Sinistral \\
\hline 2 & 8,00 & & Agrupamento de bandas retilíneo & 1,0 & $135-315$ & $225 / 30$ & - \\
\hline 2 & 8,00 & & Agrupamento de bandas retilíneo & 0,7 & $005-185$ & $095 / 66$ & - \\
\hline 2 & 8,00 & & Agrupamento de bandas retilíneo & 0,7 & 005-185 & $095 / 66$ & - \\
\hline 2 & 8,00 & & Banda individual retilínea & 0,3 & $040-220$ & - & - \\
\hline 2 & 8,00 & & Banda individual retilínea & 0,3 & 125-305 & - & - \\
\hline 2 & 8,00 & & Banda individual retilínea & 0,3 & $125-305$ & - & - \\
\hline 2 & 8,00 & & Banda individual retilínea & 0,3 & $125-305$ & - & - \\
\hline 2 & 8,00 & & Banda individual retilínea & 0,2 & $060-240$ & - & Sinistral \\
\hline 2 & 8,00 & & Banda individual retilínea & 0,2 & $060-240$ & - & Sinistral \\
\hline 2 & 8,00 & & Banda individual retilínea & 0,2 & $060-240$ & - & Sinistral \\
\hline 2 & 8,00 & & Banda individual retilínea & 0,1 & $010-190$ & - & - \\
\hline 2 & 8,00 & & Banda individual retilínea & 0,1 & 010-190 & - & - \\
\hline 2 & 8,00 & & Agrupamento de bandas retilíneo & 2,0 & $135-315$ & $225 / 80$ & - \\
\hline 2 & 8,00 & & Banda individual retilínea & 0,2 & $000-180$ & - & Dextral \\
\hline 2 & 8,00 & & Banda individual retilínea & 0,2 & $140-320$ & - & - \\
\hline 2 & 8,00 & & Banda individual retilínea & 0,2 & $060-240$ & - & Sinistral \\
\hline 2 & 8,00 & \multirow{29}{*}{5 a $6 \mathrm{~m}$} & Banda individual retilínea & 0,3 & $060-240$ & - & - \\
\hline 2 & 8,00 & & Banda individual retilínea & 0,3 & $060-240$ & - & - \\
\hline 2 & 8,00 & & Banda individual retilínea & 0,3 & $060-240$ & - & - \\
\hline 2 & 8,00 & & Banda individual retilínea & 0,3 & $060-240$ & - & - \\
\hline 2 & 8,00 & & Banda individual retilínea & 0,2 & $140-320$ & - & - \\
\hline 2 & 8,00 & & Banda individual retilínea & 0,2 & $140-320$ & - & - \\
\hline 2 & 8,00 & & Banda individual retilínea & 0,2 & $140-320$ & - & - \\
\hline 2 & 8,00 & & Banda individual retilínea & 0,3 & $020-200$ & $110 / 62$ & Dextral \\
\hline 2 & 8,00 & & Banda individual retilínea & 0,3 & $020-200$ & $110 / 62$ & Dextral \\
\hline 2 & 8,00 & & Banda individual retilínea & 0,2 & $140-320$ & - & - \\
\hline 2 & 8,00 & & Banda individual retilínea & 0,2 & $140-320$ & - & - \\
\hline 2 & 8,00 & & Banda individual retilínea & 0,2 & $140-320$ & - & - \\
\hline 2 & 8,00 & & Banda individual retilínea & 0,2 & $040-220$ & - & - \\
\hline 2 & 8,00 & & Banda individual retilínea & 0,5 & $080-260$ & - & Sinistral \\
\hline 2 & 8,00 & & Banda individual retilínea & 0,1 & $010-190$ & - & \\
\hline 2 & 8,00 & & Agrupamento de bandas retilíneo & 0,4 & $050-230$ & - & Sinistral \\
\hline 2 & 8,00 & & Agrupamento de bandas retilíneo & 0,3 & $000-180$ & - & Dextral \\
\hline 2 & 8,00 & & Banda individual retilínea & 0,1 & $050-230$ & - & - \\
\hline 2 & 8,00 & & Banda individual retilínea & 0,1 & $050-230$ & - & - \\
\hline 2 & 8,00 & & Banda individual retilínea & 0,1 & $050-230$ & - & - \\
\hline 2 & 8,00 & & Banda individual retilínea & 0,1 & $050-230$ & - & - \\
\hline 2 & 8,00 & & Banda individual retilínea & 0,2 & $160-340$ & - & - \\
\hline 2 & 8,00 & & Banda individual retilínea & 0,3 & $010-190$ & - & - \\
\hline 2 & 8,00 & & Banda individual retilínea & 0,1 & $030-210$ & - & - \\
\hline 2 & 8,00 & & Banda individual retilínea & 0,1 & $030-210$ & - & - \\
\hline 2 & 8,00 & & Banda individual retilínea & 0,1 & $070-250$ & - & - \\
\hline 2 & 8,00 & & Banda individual retilínea & 0,1 & $070-250$ & - & - \\
\hline 2 & 8,00 & & Banda individual retilínea & 0,1 & $070-250$ & - & - \\
\hline 2 & 8,00 & & Banda individual retilínea & 0,2 & 010-190 & - & - \\
\hline 2 & 8,00 & \multirow{4}{*}{6 a $7 \mathrm{~m}$} & Banda individual retilínea & 0,2 & 010-190 & - & Dextral \\
\hline 2 & 8,00 & & Agrupamento de bandas retilíneo & 0,6 & $060-240$ & - & Sinistral \\
\hline 2 & 8,00 & & Agrupamento de bandas retilíneo & 0,6 & $060-240$ & - & Sinistral \\
\hline 2 & 8,00 & & Agrupamento de bandas retilíneo & 0,6 & $060-240$ & - & Sinistral \\
\hline
\end{tabular}




\begin{tabular}{|c|c|c|c|c|c|c|c|}
\hline 2 & 8,00 & & Banda individual retilínea & 0,1 & $085-265$ & - & Sinistral \\
\hline 2 & 8,00 & & Banda individual retilínea & 0,5 & $140-320$ & - & - \\
\hline 2 & 8,00 & & Banda individual retilínea & 0,5 & $140-320$ & - & - \\
\hline 2 & 8,00 & & Banda individual retilínea & 0,5 & $140-320$ & - & - \\
\hline 2 & 8,00 & & Banda individual retilínea & 0,5 & $140-320$ & - & - \\
\hline 2 & 8,00 & & Banda individual retilínea & 0,5 & $140-320$ & - & - \\
\hline 2 & 8,00 & & Agrupamento de bandas retilíneo & 0,7 & $020-200$ & - & - \\
\hline 2 & 8,00 & & Agrupamento de bandas retilíneo & 1,0 & $040-220$ & - & - \\
\hline 2 & 8,00 & & Agrupamento de bandas retilíneo & 1,0 & $002-182$ & - & - \\
\hline 2 & 8,00 & & Agrupamento de bandas retilíneo & 1,5 & $140-320$ & - & - \\
\hline 2 & 8,00 & & Banda individual retilínea & 0,1 & $005-185$ & - & - \\
\hline 2 & 8,00 & & Banda individual retilínea & 0,1 & $005-185$ & - & - \\
\hline 2 & 8,00 & & Banda individual retilínea & 0,1 & $005-185$ & - & - \\
\hline 2 & 8,00 & & Banda individual retilínea & 0,3 & $070-250$ & - & - \\
\hline 2 & 8,00 & & Banda individual retilínea & 0,3 & $070-250$ & - & - \\
\hline 2 & 8,00 & & Banda individual retilínea & 0,2 & $160-340$ & - & - \\
\hline 2 & 8,00 & \multirow{15}{*}{7 a $8 \mathrm{~m}$} & Banda individual retilínea & 0,1 & $060-240$ & - & Sinistral \\
\hline 2 & 8,00 & & Banda individual retilínea & 0,1 & $060-240$ & - & Sinistral \\
\hline 2 & 8,00 & & Banda individual retilínea & 0,1 & $060-240$ & - & Sinistral \\
\hline 2 & 8,00 & & Banda individual retilínea & 0,1 & $060-240$ & - & Sinistral \\
\hline 2 & 8,00 & & Banda individual retilínea & 0,1 & $060-240$ & - & Sinistral \\
\hline 2 & 8,00 & & Banda individual retilínea & 0,1 & $150-330$ & - & - \\
\hline 2 & 8,00 & & Agrupamento de bandas retilíneo & 1,0 & $000-180$ & - & - \\
\hline 2 & 8,00 & & Banda individual retilínea & 0,3 & $110-290$ & - & - \\
\hline 2 & 8,00 & & Banda individual retilínea & 0,2 & $130-310$ & - & - \\
\hline 2 & 8,00 & & Banda individual retilínea & 0,2 & $130-310$ & - & - \\
\hline 2 & 8,00 & & Banda individual retilínea & 0,2 & $130-310$ & - & - \\
\hline 2 & 8,00 & & Banda individual retilínea & 0,2 & $130-310$ & - & - \\
\hline 2 & 8,00 & & Banda individual retilínea & 0,2 & $130-310$ & - & - \\
\hline 2 & 8,00 & & Agrupamento de bandas retilíneo & 0,1 & $060-240$ & - & Sinistral \\
\hline 2 & 8,00 & & Agrupamento de bandas retilíneo & 0,1 & $060-240$ & - & Sinistral \\
\hline 3 & 10,00 & \multirow{17}{*}{0 a $1 \mathrm{~m}$} & Banda individual retilínea & 0,1 & $040-220$ & - & Sinistral \\
\hline 3 & 10,00 & & Banda individual retilínea & 0,3 & $130-310$ & - & - \\
\hline 3 & 10,00 & & Banda individual retilínea & 0,3 & $130-310$ & - & - \\
\hline 3 & 10,00 & & Banda individual retilínea & 0,3 & $130-310$ & - & - \\
\hline 3 & 10,00 & & Agrupamento de bandas retilíneo & 2,0 & $010-190$ & - & Dextral \\
\hline 3 & 10,00 & & Agrupamento de bandas retilíneo & 0,3 & $130-310$ & - & - \\
\hline 3 & 10,00 & & Agrupamento de bandas retilíneo & 0,3 & $130-310$ & - & - \\
\hline 3 & 10,00 & & Agrupamento de bandas retilíneo & 0,3 & $130-310$ & - & - \\
\hline 3 & 10,00 & & Agrupamento de bandas retilíneo & 0,3 & $130-310$ & - & - \\
\hline 3 & 10,00 & & Agrupamento de bandas retilíneo & 0,3 & $130-310$ & - & - \\
\hline 3 & 10,00 & & Agrupamento de bandas retilíneo & 0,3 & $130-310$ & - & - \\
\hline 3 & 10,00 & & Agrupamento de bandas retilíneo & 0,3 & $130-310$ & - & - \\
\hline 3 & 10,00 & & Agrupamento de bandas retilíneo & 0,3 & $130-310$ & - & - \\
\hline 3 & 10,00 & & Agrupamento de bandas retilíneo & 0,3 & $130-310$ & - & - \\
\hline 3 & 10,00 & & Agrupamento de bandas retilíneo & 0,3 & $130-310$ & - & - \\
\hline 3 & 10,00 & & Agrupamento de bandas retilíneo & 0,3 & $130-310$ & - & - \\
\hline 3 & 10,00 & & Agrupamento de bandas retilíneo & 1,0 & $050-230$ & - & - \\
\hline 3 & 10,00 & \multirow{11}{*}{1 a $2 \mathrm{~m}$} & Agrupamento de bandas retilíneo & 0,3 & $050-230$ & - & - \\
\hline 3 & 10,00 & & Agrupamento de bandas retilíneo & 0,3 & $050-230$ & - & - \\
\hline 3 & 10,00 & & Agrupamento de bandas retilíneo & 0,3 & $000-180$ & - & Dextral \\
\hline 3 & 10,00 & & Banda individual retilínea & 0,2 & $130-310$ & - & - \\
\hline 3 & 10,00 & & Banda individual retilínea & 0,2 & $130-310$ & - & - \\
\hline 3 & 10,00 & & Banda individual retilínea & 0,2 & $130-310$ & - & - \\
\hline 3 & 10,00 & & Banda individual retilínea & 0,2 & $130-310$ & - & - \\
\hline 3 & 10,00 & & Banda individual retilínea & 0,2 & $130-310$ & - & - \\
\hline 3 & 10,00 & & Banda individual retilínea & 0,2 & $130-310$ & - & - \\
\hline 3 & 10,00 & & Banda individual retilínea & 0,2 & $130-310$ & - & - \\
\hline 3 & 10,00 & & Banda individual retilínea & 0,2 & $130-310$ & - & - \\
\hline
\end{tabular}




\begin{tabular}{|c|c|c|c|c|c|c|c|}
\hline 3 & 10,00 & & Banda individual retilínea & 0,2 & $130-310$ & - & - \\
\hline 3 & 10,00 & & Banda individual retilínea & 0,2 & $130-310$ & - & - \\
\hline 3 & 10,00 & & Banda individual retilínea & 0,2 & $130-310$ & - & - \\
\hline 3 & 10,00 & & Banda individual retilínea & 0,2 & $130-310$ & - & - \\
\hline 3 & 10,00 & & Banda individual retilínea & 0,2 & $130-310$ & - & - \\
\hline 3 & 10,00 & & Banda individual retilínea & 0,5 & $060-240$ & - & Sinistral \\
\hline 3 & 10,00 & & Banda individual retilínea & 0,5 & $060-240$ & - & Sinistral \\
\hline 3 & 10,00 & & Banda individual retilínea & 0,5 & $060-240$ & - & Sinistral \\
\hline 3 & 10,00 & \multirow{20}{*}{2 a $3 \mathrm{~m}$} & Banda individual retilínea & 0,2 & $130-310$ & - & - \\
\hline 3 & 10,00 & & Banda individual retilínea & 0,2 & $130-310$ & - & - \\
\hline 3 & 10,00 & & Banda individual retilínea & 0,2 & $130-310$ & - & - \\
\hline 3 & 10,00 & & Banda individual retilínea & 0,2 & $045-225$ & - & Sinistral \\
\hline 3 & 10,00 & & Banda individual retilínea & 0,3 & 015-195 & - & - \\
\hline 3 & 10,00 & & Agrupamento de bandas retilíneo & 2,5 & $000-180$ & - & - \\
\hline 3 & 10,00 & & Banda individual retilínea & 0,2 & $040-220$ & - & Sinistral \\
\hline 3 & 10,00 & & Agrupamento de bandas retilíneo & 0,5 & $040-220$ & - & Sinistral \\
\hline 3 & 10,00 & & Agrupamento de bandas retilíneo & 1,0 & $135-315$ & - & - \\
\hline 3 & 10,00 & & Agrupamento de bandas retilíneo & 1,0 & $135-315$ & - & - \\
\hline 3 & 10,00 & & Banda individual retilínea & 0,2 & $135-315$ & - & - \\
\hline 3 & 10,00 & & Banda individual retilínea & 0,2 & $135-315$ & - & - \\
\hline 3 & 10,00 & & Banda individual retilínea & 0,2 & $135-315$ & - & - \\
\hline 3 & 10,00 & & Banda individual retilínea & 0,2 & $135-315$ & - & - \\
\hline 3 & 10,00 & & Banda individual retilínea & 0,2 & $135-315$ & - & - \\
\hline 3 & 10,00 & & Banda individual retilínea & 0,2 & $135-315$ & - & - \\
\hline 3 & 10,00 & & Banda individual retilínea & 0,2 & $135-315$ & - & - \\
\hline 3 & 10,00 & & Banda individual retilínea & 0,2 & $135-315$ & - & - \\
\hline 3 & 10,00 & & Banda individual retilínea & 0,2 & $135-315$ & - & - \\
\hline 3 & 10,00 & & Banda individual retilínea & 0,2 & $135-315$ & - & - \\
\hline 3 & 10,00 & \multirow{23}{*}{3 a $4 \mathrm{~m}$} & Banda individual retilínea & 0,2 & $135-315$ & - & - \\
\hline 3 & 10,00 & & Banda individual retilínea & 0,2 & $135-315$ & - & - \\
\hline 3 & 10,00 & & Banda individual retilínea & 0,2 & $135-315$ & - & - \\
\hline 3 & 10,00 & & Agrupamento de bandas anastomosado & 2,5 & $135-315$ & - & - \\
\hline 3 & 10,00 & & Agrupamento de bandas anastomosado & 2,5 & $135-315$ & - & - \\
\hline 3 & 10,00 & & Agrupamento de bandas anastomosado & 2,5 & $135-315$ & - & - \\
\hline 3 & 10,00 & & Agrupamento de bandas anastomosado & 2,5 & $135-315$ & - & - \\
\hline 3 & 10,00 & & Agrupamento de bandas anastomosado & 2,5 & $135-315$ & - & - \\
\hline 3 & 10,00 & & Agrupamento de bandas anastomosado & 2,5 & $135-315$ & - & - \\
\hline 3 & 10,00 & & Agrupamento de bandas anastomosado & 2,5 & $135-315$ & - & - \\
\hline 3 & 10,00 & & Agrupamento de bandas anastomosado & 2,5 & $135-315$ & - & - \\
\hline 3 & 10,00 & & Agrupamento de bandas anastomosado & 2,5 & $135-315$ & - & - \\
\hline 3 & 10,00 & & Agrupamento de bandas anastomosado & 2,5 & $135-315$ & - & - \\
\hline 3 & 10,00 & & Agrupamento de bandas anastomosado & 2,5 & $135-315$ & - & - \\
\hline 3 & 10,00 & & Agrupamento de bandas anastomosado & 2,5 & $135-315$ & - & - \\
\hline 3 & 10,00 & & Agrupamento de bandas anastomosado & 2,5 & $135-315$ & - & - \\
\hline 3 & 10,00 & & Agrupamento de bandas anastomosado & 2,5 & $135-315$ & - & - \\
\hline 3 & 10,00 & & Agrupamento de bandas anastomosado & 2,5 & $135-315$ & - & - \\
\hline 3 & 10,00 & & Agrupamento de bandas retilíneo & 0,7 & $030-210$ & - & - \\
\hline 3 & 10,00 & & Agrupamento de bandas retilíneo & 1,0 & $030-210$ & $120 / 70$ & - \\
\hline 3 & 10,00 & & Agrupamento de bandas retilíneo & 1,0 & $030-210$ & $120 / 70$ & - \\
\hline 3 & 10,00 & & Agrupamento de bandas retilíneo & 1,0 & $030-210$ & $120 / 70$ & - \\
\hline 3 & 10,00 & & Agrupamento de bandas retilíneo & 1,0 & $010-190$ & $100 / 74$ & - \\
\hline 3 & 10,00 & \multirow{5}{*}{4 a $5 \mathrm{~m}$} & Agrupamento de bandas retilíneo & 3,0 & $005-185$ & $095 / 60$ & Dextral \\
\hline 3 & 10,00 & & Agrupamento de bandas retilíneo & 1,0 & $010-190$ & $100 / 56$ & - \\
\hline 3 & 10,00 & & Banda individual retilínea & 0,2 & $010-190$ & - & Dextral \\
\hline 3 & 10,00 & & Banda individual retilínea & 0,2 & 010-190 & - & Dextral \\
\hline 3 & 10,00 & & Agrupamento de bandas retilíneo & 7,0 & $050-230$ & $140 / 72$ & - \\
\hline 3 & 10,00 & \multirow{3}{*}{5 a $6 \mathrm{~m}$} & Banda individual retilínea & 0,5 & $030-210$ & - & - \\
\hline 3 & 10,00 & & Banda individual retilínea & 0,3 & $175-355$ & $085 / 50$ & Dextral \\
\hline 3 & 10,00 & & Banda individual retilínea & 0,3 & $175-355$ & $085 / 50$ & Dextral \\
\hline
\end{tabular}




\begin{tabular}{|c|c|c|c|c|c|c|c|}
\hline 3 & 10,00 & & Banda individual retilínea & 0,3 & $175-355$ & $085 / 50$ & Dextral \\
\hline 3 & 10,00 & & Banda individual retilínea & 0,3 & $175-355$ & $085 / 50$ & Dextral \\
\hline 3 & 10,00 & & Banda individual retilínea & 0,2 & $040-220$ & - & Sinistral \\
\hline 3 & 10,00 & & Banda individual retilínea & 0,2 & $040-220$ & - & Sinistral \\
\hline 3 & 10,00 & & Banda individual retilínea & 0,2 & $040-220$ & - & Sinistral \\
\hline 3 & 10,00 & & Agrupamento de bandas retilíneo & 2,0 & $135-315$ & $225 / 68$ & - \\
\hline 3 & 10,00 & & Agrupamento de bandas retilíneo & 0,5 & $135-315$ & $225 / 68$ & - \\
\hline 3 & 10,00 & & Banda individual retilínea & 0,2 & $000-180$ & - & Dextral \\
\hline 3 & 10,00 & \multirow{8}{*}{6 a $7 \mathrm{~m}$} & Banda individual retilínea & 0,2 & $000-180$ & - & - \\
\hline 3 & 10,00 & & Banda individual retilínea & 0,2 & 000-180 & - & - \\
\hline 3 & 10,00 & & Banda individual retilínea & 0,2 & $000-180$ & - & - \\
\hline 3 & 10,00 & & Banda individual retilínea & 0,2 & $000-180$ & - & - \\
\hline 3 & 10,00 & & Banda individual retilínea & 0,2 & $000-180$ & - & - \\
\hline 3 & 10,00 & & Banda individual retilínea & 0,2 & 000-180 & - & - \\
\hline 3 & 10,00 & & Agrupamento de bandas retilíneo & 1,0 & $040-220$ & $130 / 70$ & - \\
\hline 3 & 10,00 & & Agrupamento de bandas retilíneo & 0,7 & 000-180 & - & - \\
\hline 3 & 10,00 & \multirow{6}{*}{7 a 8 m } & Banda individual retilínea & 0,2 & $050-230$ & - & Sinistral \\
\hline 3 & 10,00 & & Banda individual retilínea & 0,2 & $000-180$ & - & - \\
\hline 3 & 10,00 & & Banda individual retilínea & 0,2 & $000-180$ & - & - \\
\hline 3 & 10,00 & & Banda individual retilínea & 0,2 & $135-315$ & - & - \\
\hline 3 & 10,00 & & Banda individual retilínea & 0,2 & $135-315$ & - & - \\
\hline 3 & 10,00 & & Agrupamento de bandas retilíneo & 2,5 & $040-220$ & - & - \\
\hline 3 & 10,00 & \multirow{6}{*}{8 a 9 m } & Agrupamento de bandas retilíneo & 2,0 & $000-180$ & - & - \\
\hline 3 & 10,00 & & Agrupamento de bandas retilíneo & 1,0 & $050-230$ & - & - \\
\hline 3 & 10,00 & & Agrupamento de bandas retilíneo & 1,0 & $050-230$ & - & - \\
\hline 3 & 10,00 & & Agrupamento de bandas retilíneo & 1,0 & $050-230$ & - & - \\
\hline 3 & 10,00 & & Banda individual retilínea & 0,7 & 010-190 & - & - \\
\hline 3 & 10,00 & & Banda individual retilínea & 0,5 & $060-240$ & - & Sinistral \\
\hline 3 & 10,00 & \multirow{13}{*}{9 a $10 \mathrm{~m}$} & Banda individual retilínea & 0,1 & 015-195 & - & Dextral \\
\hline 3 & 10,00 & & Banda individual retilínea & 0,1 & 015-195 & - & Dextral \\
\hline 3 & 10,00 & & Agrupamento de bandas retilíneo & 1,0 & $130-310$ & - & - \\
\hline 3 & 10,00 & & Banda individual retilínea & 0,2 & $045-225$ & - & - \\
\hline 3 & 10,00 & & Banda individual anastomosada & 0,3 & $155-335$ & - & - \\
\hline 3 & 10,00 & & Banda individual retilínea & 0,3 & $042-222$ & - & - \\
\hline 3 & 10,00 & & Banda individual retilínea & 0,3 & $042-222$ & - & - \\
\hline 3 & 10,00 & & Banda individual retilínea & 0,3 & $042-222$ & - & - \\
\hline 3 & 10,00 & & Banda individual retilínea & 0,3 & $160-340$ & - & - \\
\hline 3 & 10,00 & & Banda individual retilínea & 0,3 & $120-300$ & - & - \\
\hline 3 & 10,00 & & Banda individual retilínea & 0,1 & $150-330$ & - & - \\
\hline 3 & 10,00 & & Agrupamento de bandas retilíneo & 0,5 & $042-222$ & - & - \\
\hline 3 & 10,00 & & Agrupamento de bandas retilíneo & 6,5 & $130-310$ & - & - \\
\hline 4 & 8,00 & \multirow{17}{*}{0 a $1 \mathrm{~m}$} & Agrupamento de bandas retilíneo & 1,0 & $040-220$ & - & - \\
\hline 4 & 8,00 & & Banda individual retilínea & 0,3 & $130-310$ & - & - \\
\hline 4 & 8,00 & & Banda individual retilínea & 0,3 & $130-310$ & - & - \\
\hline 4 & 8,00 & & Banda individual retilínea & 0,3 & $130-310$ & - & - \\
\hline 4 & 8,00 & & Banda individual retilínea & 0,3 & $130-310$ & - & - \\
\hline 4 & 8,00 & & Banda individual retilínea & 0,2 & $165-345$ & $075 / 34$ & - \\
\hline 4 & 8,00 & & Banda individual retilínea & 0,2 & 020-200 & - & Dextral \\
\hline 4 & 8,00 & & Banda individual retilínea & 0,1 & $115-295$ & - & - \\
\hline 4 & 8,00 & & Banda individual retilínea & 0,1 & $115-295$ & - & - \\
\hline 4 & 8,00 & & Banda individual retilínea & 0,1 & $115-295$ & - & - \\
\hline 4 & 8,00 & & Banda individual retilínea & 0,1 & $045-225$ & - & - \\
\hline 4 & 8,00 & & Banda individual retilínea & 0,3 & $160-340$ & - & - \\
\hline 4 & 8,00 & & Banda individual retilínea & 0,3 & $160-340$ & - & - \\
\hline 4 & 8,00 & & Agrupamento de bandas retilíneo & 0,6 & $135-315$ & $045 / 74$ & - \\
\hline 4 & 8,00 & & Agrupamento de bandas retilíneo & 0,6 & $135-315$ & $045 / 74$ & - \\
\hline 4 & 8,00 & & Banda individual anastomosada & 0,3 & 015-195 & $105 / 42$ & Dextral \\
\hline 4 & 8,00 & & Banda individual anastomosada & 0,3 & 015-195 & $105 / 42$ & Dextral \\
\hline 4 & 8,00 & $1 \mathrm{a} 2 \mathrm{~m}$ & Banda individual retilínea & 0,5 & $120-300$ & - & - \\
\hline
\end{tabular}




\begin{tabular}{|c|c|c|c|c|c|c|c|}
\hline 4 & 8,00 & & Banda individual retilínea & 0,3 & 015-195 & - & Dextral \\
\hline 4 & 8,00 & & Banda individual retilínea & 0,5 & $155-335$ & - & Dextral \\
\hline 4 & 8,00 & & Banda individual retilínea & 0,5 & $040-220$ & - & - \\
\hline 4 & 8,00 & & Banda individual anastomosada & 0,3 & $130-310$ & - & - \\
\hline 4 & 8,00 & & Banda individual retilínea & 0,3 & $155-335$ & - & - \\
\hline 4 & 8,00 & & Banda individual retilínea & 0,3 & $155-335$ & - & - \\
\hline 4 & 8,00 & & Banda individual retilínea & 0,2 & $040-220$ & - & Sinistral \\
\hline 4 & 8,00 & & Banda individual retilínea & 0,2 & $040-220$ & - & Sinistral \\
\hline 4 & 8,00 & & Banda individual retilínea & 0,2 & $040-220$ & - & Sinistral \\
\hline 4 & 8,00 & & Banda individual retilínea & 0,2 & $040-220$ & - & Sinistral \\
\hline 4 & 8,00 & & Banda individual retilínea & 0,5 & $160-340$ & - & Dextral \\
\hline 4 & 8,00 & \multirow{29}{*}{2 a $3 \mathrm{~m}$} & Agrupamento de bandas retilíneo & 0,7 & $140-320$ & - & - \\
\hline 4 & 8,00 & & Banda individual retilínea & 0,3 & $040-220$ & - & - \\
\hline 4 & 8,00 & & Banda individual retilínea & 0,3 & $040-220$ & - & - \\
\hline 4 & 8,00 & & Banda individual retilínea & 0,3 & $040-220$ & - & - \\
\hline 4 & 8,00 & & Banda individual retilínea & 0,5 & $155-335$ & - & Dextral \\
\hline 4 & 8,00 & & Banda individual retilínea & 0,5 & $155-335$ & - & Dextral \\
\hline 4 & 8,00 & & Banda individual retilínea & 0,5 & $155-335$ & - & Dextral \\
\hline 4 & 8,00 & & Banda individual retilínea & 0,5 & $155-335$ & - & Dextral \\
\hline 4 & 8,00 & & Banda individual retilínea & 0,5 & 155-335 & - & Dextral \\
\hline 4 & 8,00 & & Banda individual retilínea & 0,5 & $155-335$ & - & Dextral \\
\hline 4 & 8,00 & & Banda individual retilínea & 0,5 & $155-335$ & - & Dextral \\
\hline 4 & 8,00 & & Banda individual retilínea & 0,5 & $155-335$ & - & Dextral \\
\hline 4 & 8,00 & & Banda individual retilínea & 0,3 & $100-280$ & - & - \\
\hline 4 & 8,00 & & Agrupamento de bandas retilíneo & 1,0 & $060-240$ & - & - \\
\hline 4 & 8,00 & & Banda individual retilínea & 0,3 & $040-220$ & - & Sinistral \\
\hline 4 & 8,00 & & Banda individual retilínea & 0,3 & $040-220$ & - & Sinistral \\
\hline 4 & 8,00 & & Banda individual retilínea & 1,0 & $040-220$ & - & Sinistral \\
\hline 4 & 8,00 & & Banda individual anastomosada & 0,2 & $105-285$ & - & - \\
\hline 4 & 8,00 & & Banda individual anastomosada & 0,2 & $120-300$ & - & - \\
\hline 4 & 8,00 & & Banda individual anastomosada & 0,2 & $120-300$ & - & - \\
\hline 4 & 8,00 & & Banda individual retilínea & 0,5 & $160-340$ & - & Dextral \\
\hline 4 & 8,00 & & Banda individual retilínea & 0,2 & $140-320$ & - & - \\
\hline 4 & 8,00 & & Banda individual retilínea & 0,2 & $140-320$ & - & - \\
\hline 4 & 8,00 & & Banda individual retilínea & 0,2 & $140-320$ & - & - \\
\hline 4 & 8,00 & & Banda individual retilínea & 0,2 & $140-320$ & - & - \\
\hline 4 & 8,00 & & Banda individual retilínea & 0,2 & $140-320$ & - & - \\
\hline 4 & 8,00 & & Banda individual retilínea & 0,3 & $165-345$ & - & - \\
\hline 4 & 8,00 & & Banda individual retilínea & 0,2 & $020-200$ & - & - \\
\hline 4 & 8,00 & & Banda individual retilínea & 0,2 & $020-200$ & - & - \\
\hline 4 & 8,00 & \multirow{14}{*}{3 a $4 \mathrm{~m}$} & Banda individual retilínea & 0,2 & $020-200$ & - & - \\
\hline 4 & 8,00 & & Banda individual retilínea & 0,2 & $140-320$ & - & - \\
\hline 4 & 8,00 & & Banda individual retilínea & 0,2 & $140-320$ & - & - \\
\hline 4 & 8,00 & & Banda individual retilínea & 0,2 & $140-320$ & - & - \\
\hline 4 & 8,00 & & Banda individual retilínea & 0,2 & $140-320$ & - & - \\
\hline 4 & 8,00 & & Banda individual retilínea & 0,3 & $030-210$ & - & - \\
\hline 4 & 8,00 & & Agrupamento de bandas retilíneo & 1,2 & $150-330$ & $060 / 54$ & Dextral \\
\hline 4 & 8,00 & & Banda individual retilínea & 0,3 & $150-330$ & $060 / 54$ & Dextral \\
\hline 4 & 8,00 & & Banda individual retilínea & 0,3 & $150-330$ & $060 / 54$ & Dextral \\
\hline 4 & 8,00 & & Agrupamento de bandas retilíneo & 1,0 & $170-350$ & - & - \\
\hline 4 & 8,00 & & Banda individual retilínea & 0,3 & $170-350$ & - & - \\
\hline 4 & 8,00 & & Banda individual retilínea & 0,3 & $170-350$ & - & - \\
\hline 4 & 8,00 & & Banda individual retilínea & 0,3 & $040-220$ & - & Sinistral \\
\hline 4 & 8,00 & & Banda individual retilínea & 0,3 & $170-350$ & - & Dextral \\
\hline 4 & 8,00 & \multirow{5}{*}{4 a $5 \mathrm{~m}$} & Banda individual retilínea & 0,3 & $170-350$ & - & Dextral \\
\hline 4 & 8,00 & & Banda individual retilínea & 0,3 & $170-350$ & - & Dextral \\
\hline 4 & 8,00 & & Banda individual retilínea & 0,3 & $170-350$ & - & Dextral \\
\hline 4 & 8,00 & & Banda individual retilínea & 0,3 & $170-350$ & - & Dextral \\
\hline 4 & 8,00 & & Banda individual retilínea & 0,3 & $170-350$ & - & Dextral \\
\hline
\end{tabular}




\begin{tabular}{|c|c|c|c|c|c|c|c|}
\hline 4 & 8,00 & & Agrupamento de bandas anastomosado & 0,8 & $100-280$ & - & - \\
\hline 4 & 8,00 & & Banda individual retilínea & 0,5 & $130-310$ & - & - \\
\hline 4 & 8,00 & & Banda individual retilínea & 0,5 & $130-310$ & - & - \\
\hline 4 & 8,00 & & Banda individual retilínea & 0,5 & $130-310$ & - & - \\
\hline 4 & 8,00 & & Banda individual retilínea & 0,5 & $130-310$ & - & - \\
\hline 4 & 8,00 & & Banda individual retilínea & 0,5 & $130-310$ & - & - \\
\hline 4 & 8,00 & & Banda individual retilínea & 0,5 & $130-310$ & - & - \\
\hline 4 & 8,00 & & Banda individual retilínea & 0,5 & $130-310$ & - & - \\
\hline 4 & 8,00 & & Banda individual retilínea & 0,5 & $130-310$ & - & - \\
\hline 4 & 8,00 & & Banda individual retilínea & 0,5 & $065-245$ & - & Sinistral \\
\hline 4 & 8,00 & & Agrupamento de bandas anastomosado & 0,6 & $170-350$ & - & - \\
\hline 4 & 8,00 & & Agrupamento de bandas anastomosado & 0,6 & $170-350$ & - & - \\
\hline 4 & 8,00 & \multirow{18}{*}{5 a $6 \mathrm{~m}$} & Banda individual retilínea & 0,3 & $070-250$ & - & - \\
\hline 4 & 8,00 & & Banda individual retilínea & 0,2 & $130-310$ & - & - \\
\hline 4 & 8,00 & & Banda individual retilínea & 0,2 & $130-310$ & - & - \\
\hline 4 & 8,00 & & Banda individual retilínea & 0,2 & $130-310$ & - & - \\
\hline 4 & 8,00 & & Banda individual retilínea & 0,2 & $130-310$ & - & - \\
\hline 4 & 8,00 & & Banda individual retilínea & 0,2 & $130-310$ & - & - \\
\hline 4 & 8,00 & & Banda individual retilínea & 0,2 & $130-310$ & - & - \\
\hline 4 & 8,00 & & Banda individual retilínea & 0,2 & $130-310$ & - & - \\
\hline 4 & 8,00 & & Banda individual retilínea & 0,2 & $130-310$ & - & - \\
\hline 4 & 8,00 & & Banda individual retilínea & 0,2 & $130-310$ & - & - \\
\hline 4 & 8,00 & & Banda individual retilínea & 0,2 & $130-310$ & - & - \\
\hline 4 & 8,00 & & Banda individual retilínea & 0,2 & $130-310$ & - & - \\
\hline 4 & 8,00 & & Banda individual retilínea & 0,2 & $040-220$ & - & Sinistral \\
\hline 4 & 8,00 & & Banda individual retilínea & 0,2 & $040-220$ & - & Sinistral \\
\hline 4 & 8,00 & & Banda individual retilínea & 0,2 & $040-220$ & - & Sinistral \\
\hline 4 & 8,00 & & Agrupamento de bandas retilíneo & 1,0 & $005-185$ & - & - \\
\hline 4 & 8,00 & & Agrupamento de bandas retilíneo & 1,0 & $030-210$ & - & - \\
\hline 4 & 8,00 & & Banda individual retilínea & 0,5 & 000-180 & - & - \\
\hline 4 & 8,00 & \multirow{11}{*}{6 a $7 \mathrm{~m}$} & Banda individual retilínea & 0,3 & $040-220$ & - & - \\
\hline 4 & 8,00 & & Banda individual retilínea & 0,3 & $040-220$ & - & - \\
\hline 4 & 8,00 & & Agrupamento de bandas retilíneo & 2,5 & $170-350$ & - & - \\
\hline 4 & 8,00 & & Banda individual retilínea & 0,5 & $170-350$ & - & - \\
\hline 4 & 8,00 & & Banda individual retilínea & 0,7 & 005-185 & - & Dextral \\
\hline 4 & 8,00 & & Banda individual retilínea & 0,2 & $120-300$ & - & - \\
\hline 4 & 8,00 & & Banda individual retilínea & 0,2 & $120-300$ & - & - \\
\hline 4 & 8,00 & & Banda individual retilínea & 0,2 & $120-300$ & - & - \\
\hline 4 & 8,00 & & Banda individual retilínea & 0,2 & $120-300$ & - & - \\
\hline 4 & 8,00 & & Agrupamento de bandas retilíneo & 3,5 & $045-225$ & - & - \\
\hline 4 & 8,00 & & Banda individual retilínea & 0,3 & $160-340$ & - & - \\
\hline 4 & 8,00 & \multirow{18}{*}{7 a $8 \mathrm{~m}$} & Banda individual retilínea & 0,3 & 015-195 & - & - \\
\hline 4 & 8,00 & & Banda individual retilínea & 0,3 & 005-185 & - & Dextral \\
\hline 4 & 8,00 & & Banda individual retilínea & 0,3 & $160-340$ & - & - \\
\hline 4 & 8,00 & & Banda individual retilínea & 0,3 & $130-310$ & - & - \\
\hline 4 & 8,00 & & Banda individual retilínea & 0,3 & $130-310$ & - & - \\
\hline 4 & 8,00 & & Banda individual retilínea & 0,3 & $130-310$ & - & - \\
\hline 4 & 8,00 & & Banda individual retilínea & 0,3 & 010-190 & - & Dextral \\
\hline 4 & 8,00 & & Agrupamento de bandas retilíneo & 3,5 & 005-185 & - & \\
\hline 4 & 8,00 & & Banda individual retilínea & 0,6 & 005-185 & - & Dextral \\
\hline 4 & 8,00 & & Banda individual retilínea & 0,6 & 005-185 & - & Dextral \\
\hline 4 & 8,00 & & Banda individual retilínea & 0,6 & $005-185$ & - & Dextral \\
\hline 4 & 8,00 & & Banda individual retilínea & 0,3 & $040-220$ & - & \\
\hline 4 & 8,00 & & Banda individual retilínea & 0,3 & $060-240$ & - & Sinistral \\
\hline 4 & 8,00 & & Banda individual retilínea & 0,3 & $140-320$ & - & - \\
\hline 4 & 8,00 & & Banda individual retilínea & 0,3 & $140-320$ & - & - \\
\hline 5 & 5,00 & & Agrupamento de bandas retilíneo & 1,0 & $060-240$ & $330 / 88$ & - \\
\hline 5 & 5,00 & & Agrupamento de bandas retilíneo & 1,0 & $060-240$ & $330 / 88$ & - \\
\hline 5 & 5,00 & & Agrupamento de bandas retilíneo & 1,0 & $060-240$ & $330 / 88$ & - \\
\hline
\end{tabular}




\begin{tabular}{|c|c|c|c|c|c|c|c|}
\hline 5 & 5,00 & \multirow{29}{*}{0 a $1 \mathrm{~m}$} & Agrupamento de bandas retilíneo & 1,0 & $060-240$ & $330 / 88$ & - \\
\hline 5 & 5,00 & & Agrupamento de bandas retilíneo & 1,0 & $060-240$ & $330 / 88$ & - \\
\hline 5 & 5,00 & & Agrupamento de bandas retilíneo & 1,0 & $060-240$ & $330 / 88$ & - \\
\hline 5 & 5,00 & & Agrupamento de bandas retilíneo & 1,0 & $060-240$ & $330 / 88$ & - \\
\hline 5 & 5,00 & & Banda individual retilínea & 0,1 & $150-330$ & - & - \\
\hline 5 & 5,00 & & Banda individual retilínea & 1,0 & $90-270$ & - & - \\
\hline 5 & 5,00 & & Banda individual retilínea & 0,3 & $000-180$ & - & Dextral \\
\hline 5 & 5,00 & & Banda individual retilínea & 0,3 & $000-180$ & - & Dextral \\
\hline 5 & 5,00 & & Banda individual retilínea & 0,3 & $000-180$ & - & Dextral \\
\hline 5 & 5,00 & & Banda individual retilínea & 0,3 & $000-180$ & - & Dextral \\
\hline 5 & 5,00 & & Banda individual retilínea & 0,3 & $010-190$ & - & - \\
\hline 5 & 5,00 & & Banda individual retilínea & 0,3 & $010-190$ & - & - \\
\hline 5 & 5,00 & & Banda individual retilínea & 0,3 & $010-190$ & - & - \\
\hline 5 & 5,00 & & Banda individual retilínea & 0,3 & $010-190$ & - & - \\
\hline 5 & 5,00 & & Banda individual retilínea & 0,3 & $010-190$ & - & - \\
\hline 5 & 5,00 & & Banda individual retilínea & 0,3 & $010-190$ & - & - \\
\hline 5 & 5,00 & & Banda individual retilínea & 0,3 & $010-190$ & - & - \\
\hline 5 & 5,00 & & Banda individual retilínea & 0,3 & $010-190$ & - & - \\
\hline 5 & 5,00 & & Agrupamento de bandas retilíneo & 0,5 & $155-335$ & - & - \\
\hline 5 & 5,00 & & Banda individual retilínea & 0,3 & $110-290$ & - & - \\
\hline 5 & 5,00 & & Banda individual retilínea & 0,3 & $000-180$ & - & - \\
\hline 5 & 5,00 & & Banda individual retilínea & 0,3 & $000-180$ & - & - \\
\hline 5 & 5,00 & & Banda individual retilínea & 0,3 & $150-330$ & - & - \\
\hline 5 & 5,00 & & Banda individual retilínea & 0,3 & $150-330$ & - & - \\
\hline 5 & 5,00 & & Banda individual retilínea & 0,3 & $150-330$ & - & - \\
\hline 5 & 5,00 & & Banda individual retilínea & 0,3 & $150-330$ & - & - \\
\hline 5 & 5,00 & & Agrupamento de bandas retilíneo & 0,5 & $050-230$ & - & - \\
\hline 5 & 5,00 & & Agrupamento de bandas retilíneo & 0,3 & $160-340$ & - & - \\
\hline 5 & 5,00 & & Banda individual retilínea & 0,3 & $010-190$ & - & - \\
\hline 5 & 5,00 & \multirow{30}{*}{1 a $2 \mathrm{~m}$} & Banda individual retilínea & 0,3 & $150-330$ & - & - \\
\hline 5 & 5,00 & & Banda individual retilínea & 0,3 & $100-280$ & - & - \\
\hline 5 & 5,00 & & Banda individual retilínea & 0,3 & $050-230$ & - & Sinistral \\
\hline 5 & 5,00 & & Banda individual retilínea & 0,3 & $050-230$ & - & Sinistral \\
\hline 5 & 5,00 & & Banda individual retilínea & 0,3 & $050-230$ & - & Sinistral \\
\hline 5 & 5,00 & & Agrupamento de bandas retilíneo & 0,6 & 030-210 & - & - \\
\hline 5 & 5,00 & & Agrupamento de bandas anastomosado & 1,2 & $050-230$ & - & - \\
\hline 5 & 5,00 & & Banda individual anastomosada & 0,3 & $140-320$ & - & - \\
\hline 5 & 5,00 & & Banda individual retilínea & 0,3 & $050-230$ & - & Sinistral \\
\hline 5 & 5,00 & & Banda individual retilínea & 0,3 & $160-340$ & - & - \\
\hline 5 & 5,00 & & Agrupamento de bandas retilíneo & 0,3 & $155-335$ & - & - \\
\hline 5 & 5,00 & & Agrupamento de bandas retilíneo & 0,3 & $155-335$ & - & - \\
\hline 5 & 5,00 & & Agrupamento de bandas retilíneo & 0,3 & $155-335$ & - & - \\
\hline 5 & 5,00 & & Agrupamento de bandas retilíneo & 0,3 & $155-335$ & - & - \\
\hline 5 & 5,00 & & Agrupamento de bandas retilíneo & 0,3 & $155-335$ & - & - \\
\hline 5 & 5,00 & & Agrupamento de bandas retilíneo & 0,6 & $050-230$ & - & - \\
\hline 5 & 5,00 & & Banda individual retilínea & 0,5 & $170-350$ & - & - \\
\hline 5 & 5,00 & & Banda individual retilínea & 0,2 & $100-280$ & - & - \\
\hline 5 & 5,00 & & Banda individual retilínea & 0,2 & $120-300$ & - & - \\
\hline 5 & 5,00 & & Banda individual retilínea & 0,5 & $000-180$ & - & - \\
\hline 5 & 5,00 & & Banda individual retilínea & 0,5 & $160-340$ & - & - \\
\hline 5 & 5,00 & & Banda individual retilínea & 0,5 & $160-340$ & - & - \\
\hline 5 & 5,00 & & Banda individual retilínea & 0,5 & $160-340$ & - & - \\
\hline 5 & 5,00 & & Banda individual retilínea & 0,5 & $020-200$ & - & - \\
\hline 5 & 5,00 & & Banda individual retilínea & 0,3 & $160-340$ & - & - \\
\hline 5 & 5,00 & & Banda individual retilínea & 0,5 & $125-305$ & - & - \\
\hline 5 & 5,00 & & Banda individual retilínea & 0,5 & $130-310$ & - & - \\
\hline 5 & 5,00 & & Banda individual retilínea & 0,5 & $130-310$ & - & - \\
\hline 5 & 5,00 & & Banda individual retilínea & 0,5 & $130-310$ & - & - \\
\hline 5 & 5,00 & & Banda individual retilínea & 0,5 & $130-310$ & - & - \\
\hline
\end{tabular}




\begin{tabular}{|c|c|c|c|c|c|c|c|}
\hline 5 & 5,00 & & Agrupamento de bandas retilíneo & 1,0 & $165-345$ & - & - \\
\hline 5 & 5,00 & & Banda individual retilínea & 0,3 & $170-350$ & - & - \\
\hline 5 & 5,00 & & Banda individual retilínea & 0,3 & $170-350$ & - & - \\
\hline 5 & 5,00 & & Banda individual retilínea & 0,3 & 035-215 & - & - \\
\hline 5 & 5,00 & & Banda individual retilínea & 0,3 & 035-215 & - & - \\
\hline 5 & 5,00 & & Banda individual retilínea & 0,1 & 010-190 & - & Dextral \\
\hline 5 & 5,00 & & Banda individual retilínea & 0,1 & 010-190 & - & Dextral \\
\hline 5 & 5,00 & & Banda individual retilínea & 0,3 & $115-295$ & - & - \\
\hline 5 & 5,00 & & Agrupamento de bandas anastomosado & 1,0 & 005-185 & $095 / 78$ & - \\
\hline 5 & 5,00 & & Agrupamento de bandas anastomosado & 1,0 & 005-185 & $095 / 78$ & - \\
\hline 5 & 5,00 & & Banda individual retilínea & 0,3 & $165-345$ & - & - \\
\hline 5 & 5,00 & & Banda individual retilínea & 0,3 & $175-355$ & - & - \\
\hline 5 & 5,00 & & Banda individual retilínea & 0,3 & $120-300$ & - & - \\
\hline 5 & 5,00 & & Banda individual retilínea & 0,2 & $140-320$ & - & - \\
\hline 5 & 5,00 & & Banda individual retilínea & 0,2 & $140-320$ & - & - \\
\hline 5 & 5,00 & & Banda individual retilínea & 0,2 & $140-320$ & - & - \\
\hline 5 & 5,00 & \multirow{2}{*}{3 a $4 \mathrm{~m}$} & Banda individual retilínea & 0,2 & $140-320$ & - & - \\
\hline 5 & 5,00 & & Banda individual retilínea & 0,2 & $140-320$ & - & - \\
\hline 5 & 5,00 & \multirow{9}{*}{4 a $5 \mathrm{~m}$} & Banda individual retilínea & 0,3 & $140-320$ & - & - \\
\hline 5 & 5,00 & & Banda individual retilínea & 0,3 & $140-320$ & - & - \\
\hline 5 & 5,00 & & Banda individual retilínea & 0,3 & $140-320$ & - & - \\
\hline 5 & 5,00 & & Banda individual retilínea & 0,3 & $140-320$ & - & - \\
\hline 5 & 5,00 & & Banda individual retilínea & 0,3 & $000-180$ & - & Dextral \\
\hline 5 & 5,00 & & Banda individual retilínea & 0,3 & $030-210$ & - & - \\
\hline 5 & 5,00 & & Agrupamento de bandas retilíneo & 4,0 & $000-180$ & - & - \\
\hline 5 & 5,00 & & Agrupamento de bandas anastomosado & 2,0 & $000-180$ & - & - \\
\hline 5 & 5,00 & & Banda individual retilínea & 0,5 & $000-180$ & - & - \\
\hline
\end{tabular}




\section{APÊNDICE C - DADOS DE AMOSTRAGEM}

\begin{tabular}{|c|c|c|c|c|c|}
\hline Afloramento & Amostra & $\begin{array}{c}\text { Orientação da } \\
\text { superfície do bloco* }\end{array}$ & $\begin{array}{c}\text { Orientação da } \\
\text { estrutura* }\end{array}$ & $\begin{array}{c}\text { Espessura da } \\
\text { banda }(\mathrm{cm})\end{array}$ & Geometria \\
\hline F. de Caritá & MAS2A & $315 / 03$ & - & - & $\begin{array}{l}\text { Bandas individuais e agrupamento de } \\
\text { bandas retilíneos }\end{array}$ \\
\hline F. de Caritá & MAS2B & $235 / 45$ & $235 / 45$ & 9,0 & Agrupamento de bandas anastomosado \\
\hline F. de Caritá & MAS3A & $005 / 73$ & $005 / 73$ & 5,0 & Banda individual retilínea \\
\hline F. de Caritá & MAS3B & $160 / 85$ & - & - & Agrupamento de bandas anastomosado \\
\hline F. de Caritá & MAS3D & $246 / 87$ & - & - & Agrupamento de bandas anastomosado \\
\hline F. do Macaco & ILH1A & $175 / 40$ & $175 / 40$ & 10,0 & Agrupamento de bandas anastomosado \\
\hline F. do Macaco & ILH1C & $015 / 17$ & - & - & - \\
\hline F. do Macaco & ILH1D & $030 / 27$ & - & - & Bandas individuais retilíneas \\
\hline F. do Macaco & ILH2A & $255 / 64$ & - & - & $\begin{array}{l}\text { Bandas individuais e agrupamento de } \\
\text { bandas retilíneos }\end{array}$ \\
\hline F. do Macaco & ILH2C & $032 / 48$ & - & - & Bandas individuais retilíneas \\
\hline F. do Macaco & ILH2E & $017 / 34$ & - & - & Bandas individuais retilíneas \\
\hline F. do Macaco & ILH6B & $345 / 78$ & - & - & Bandas individuais retilíneas \\
\hline F. do Macaco & ILH6C & $328 / 62$ & $005 / 72$ & 3,0 & Agrupamento de bandas anastomosado \\
\hline
\end{tabular}

* Orientações obtidas utilizando a regra da mão direita. 